UCRL-CR-133488

SC-B340088

\title{
FAA Debris Mitigation Phase I Impact Test Report
}

\author{
Richard Couch
}

November 15, 1998

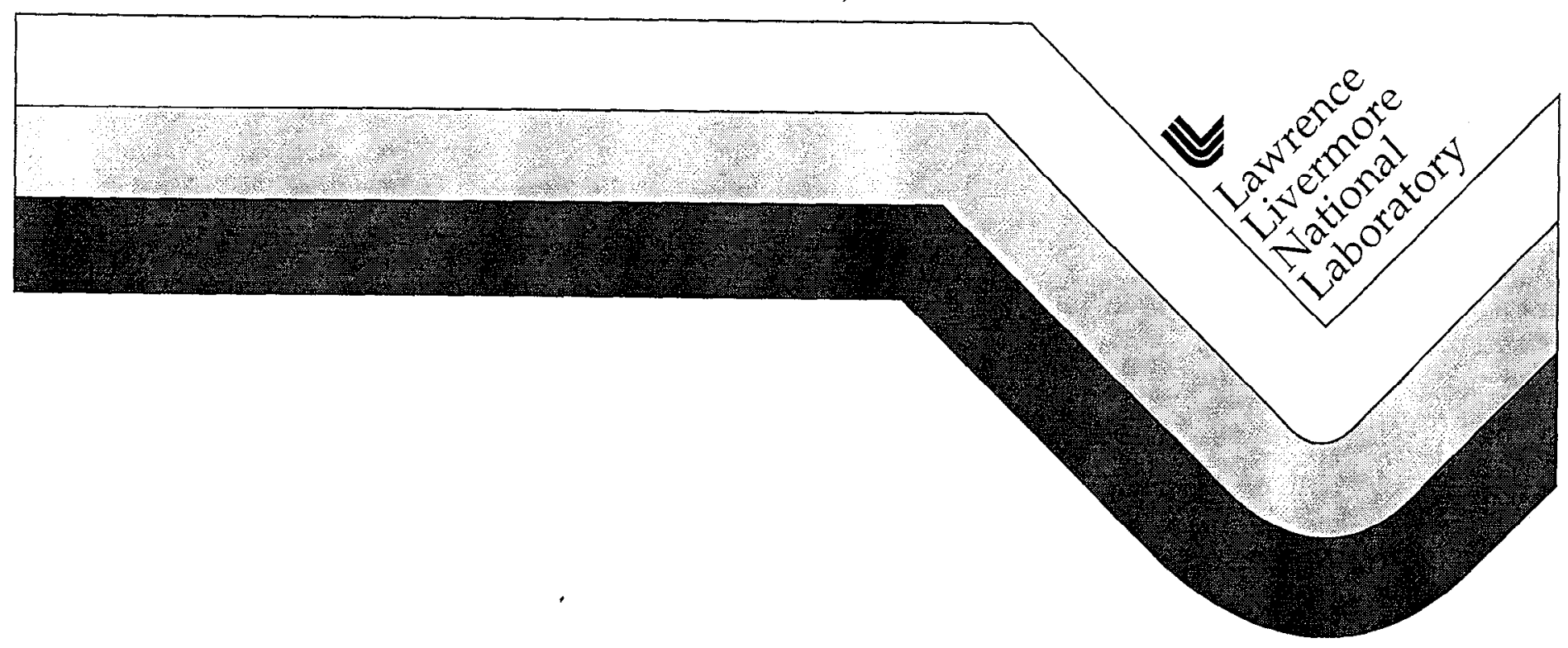




\section{DISCLAIMER}

This document was prepared as an account of work sponsored by an agency of the United States Government. Neither the United States Government nor the University of California nor any of their employees, makes any warranty, express or implied, or assumes any legal liability or responsibility for the accuracy, completeness, or usefulness of any information, apparatus, product, or process disclosed, or represents that its use would not infringe privately owned rights. Reference herein to any specific commercial product, process, or service by trade name, trademark, manufacturer, or otherwise, does not necessarily constitute or imply its endorsement, recommendation, or favoring by the United States Government or the University of California. The views and opinions of authors expressed herein do not necessarily state or reflect those of the United States Government or the University of California, and shall not be used for advertising or product endorsement purposes.

This report has been reproduced directly from the best available copy.

Available to DOE and DOE contractors from the Office of Scientific and Technical Information P.O. Box 62, Oak Ridge, TN 37831

Prices available from (615) 576-8401, FTS 626-8401

Available to the public from the National Technical Information Service

U.S. Department of Commerce 5285 Port Royal Rd., Springfield, VA 22161

Work performed under the auspices of the U.S. Department of Energy by Lawrence Livermore National Laboratory under Contract W-7405-ENG-48. 


$$
\text { UCRL-CR-133488 }
$$

\section{FAA DEBRIS MITIGATION \\ PHASE 1 \\ IMPACT TEST REPORT}

Approved By:

Andy Cobb, Manager

Structures 
TABLE OF CONTENTS

Page

1. INTRODUCTION 1

2. BACKGROUND 2

3. TEST PLAN

4. TEST PROCEDURE

5. DATA ACQUISITION 5

6. TEST RESULTS 6

7. ANALYSIS 10

8. CONCLUSIONS 12

9. LESSONS LEARNED 12

APPENDIXES

I. COMPLETE TEST PROCEDURE AND TEST MATRIX (5 pages)

II. DRAWINGS OF TEST RIG COMPONENTS AND SPECIMENS (12 pages)

III. PICTURES OF FOUR SPECIMENS BEFORE TESTING (2 pages)

IV. PICTURES OF FOUR SPECIMENS ON TEST RIG BEFORE TEST (4 pages)

V. PICTURES OF SPECIMENS SHOWING SIGNIFICANT DEFORMATION AFTER TEST WHILE STILL ON TEST RIG (11 pages)

VI. PICTURES OF ALL SPECIMENS AFTER TEST (FREE STANDING) (15 pages)

VII. SKETCHES OF ALL SPECIMENS AFTER TEST WTTH TEST NOTES (16 pages)

VIII. RAW LOAD-CELL DATA (11 pages)

IX. STRAIN GAGE VS. TIME PLOTS AND MAXIMUM STRAIN PLOTS (9 pages)

$X$. DEFLECTION VS. TIME PLOTS AND MAXIMUM DEFLECTION PLOTS (9 pages)

XI. LOAD VS. TIME PLOTS AND MAXIMUM LOAD PLOTS (9 pages)

XII. MISCELLANEOUS PLOTS ( 1 page)

\section{ATTACHMENTS}

1. COMPONENT DESIGN DOCUMENT (29 pages) 


\section{LIST OF FIGURES}

Figure

$\underline{\text { Page }}$

II-1. Containment Test Specimen: Thick Cross Section II-1

II-2. Containment Test Specimen: Thin Cross Section II-2

II-3. Containment Test Specimen: Strain Gage Placement II-3

II-4. Containment Test Fixture Base II-5

II-5. Containment Test Fixture: Support Housing : II-6

II-6. Containment Test Fixture Assembly $\quad$ II-7

II-7. Containment Test Fixture: Inner Support Insert II-8

II-8. Containment Test Fixture: Outer Support Insert II-9

II-9. Containment Test Fixture: Specimen Lock Cap II-10

II-10. Containment Test Fixture, Specimen Cap Insert II-11

II-11. Containment Test Fixture: TUP $\quad$ II-12

III-1. Thick Titanium 6-4 Sample III-1

III-2. Thin Titanium 6-4 Sample III-1

III-3. Thick Aluminum 2024 Sample $\quad$ III-2

III-4. Thin Aluminum 2024 Sample III-2

IV-1. Thick Titanium 6-4 Sample Test Setup - Before Test No. 3 IV-1

IV-2. Thin Titanium 6-4 Sample Test Setup - Before Test No. 13 IV-2

IV-3. Thick Aluminum 2024 Sample Test Setup - Before Test No. $9 \quad$ IV-3

IV-4. Thin Aluminum 2024 Sample Test Setup - Before Test No. $16 \quad$ IV-4

V-1. PAP001237-2 S/N 2: Thick Titanium 6-4 Sample After Test Run No. 2, Drop Height 3.25 Inches

V-2. PAP001237-2 S/N 1: Thick Titanium 6-4 Sample After Test Run No. 3, Drop Height 15.75 Inches

V-3. PAP001237-1 S/N 4: Thick Aluminum 2024 Sample After Test Run No. 5, Drop Height 0.50 Inch

V-4. PAP001238-2 S/N 2: Thin Titanium 6-4 Sample After Test Run No. 6, Drop Height 0.25 Inch

V-5. PAP001238-1 S/N 1: Thin Aluminum 2024 Sample After Test Run No. 7, Drop Height 0.25 Inch

V-6. PAP001238-2 S/N 1: Thin Titanium 6-4 Sample After Test Run No. 8, Drop Height, 0.25 Inch

V-7. PAP001237-1 S/N 3: Thick Aluminum 2024 Sample After Test Run No. 9, Drop Height 1.00 Inch

V-8. PAP001237-2 S/N 3: Thick Titanium 6-4 Sample After Test Run No. 10, Drop Height 12.00 Inches

V-9. PAP001237-1 S/N 2: Thick Aluminum 2024 Sample After Test Run No. 11, Drop Height 5.00 Inches

V-10. PAP001237-2 S/N 4: Thick Titanium 6-4 Sample After Test Run No. 12, Drop Height 8.00 Inches 


\section{LIST OF FIGURES (Cont)}

Figure

Page

V-11. PAP001238-2 S/N 4: Thin Titanium 6-4 Sample After Test Run No. 13, Drop Height 1.00 Inch V-9

V-12. PAP001238-1 S/N 2: Thin Aluminum 2024 Sample After Test Run No. 14, Drop Height, 0.50 Inch

V-13. PAP001238-2 S/N 3: Thin Titanium 6-4 Sample After Test Run No. 15, Drop Height 3.00 Inches

V-14. PAP001238-1 S/N 3: Thin Aluminum 2024 Sample After Test Run No. 16, Drop Height 2.00 Inches

VI-1. PAP001237-2 S/N 2: Thick Titanium 6-4 Sample After Test Run No. 2, Drop Height 3.25 Inches

VI-2. PAP001237-2 S/N 1: Thick Titanium 6-4 Sample After Test Run No. 3, Drop Height 15.75 Inches

VI-3. PAP001237-1 S/N 1: Thick Aluminum 2024 Sample After Test Run No. 4, Drop Height 0.25 Inch

VI-4. PAP001237-1 S/N 4: Thick Aluminum 2024 Sample After Test Run No. 5, Drop Height 0.50 Inch

VI-5. PAP001238-2 S/N 2: Thin Titanium 6-4 Sample After Test Run No. 6, Drop Height 0.25 Inch

VI-6. PAP001238-1 S/N 1: Thin Aluminum 2024 Sample After Test Run No. 7, Drop Height 0.25 Inch

VI-7. PAP001238-2 S/N 1: Thin Titanium 6-4 Sample After Test Run No. 8, Drop Height 0.25 Inch

VI-8. PAP001237-1 S/N 3: Thick Aluminum 2024 Sample After Test Run No. 9 , Drop Height 1.00 Inch

VI-9. PAP001237-2 S/N 3: Thick Titanium 6-4 Sample After Test Run No. 10, Drop Height 12.00 Inches

VI-10. PAP001237-1 S/N 2: Thick Aluminum 2024 Sample After Test Run No. 11, Drop Height 5.00 Inches

VI-11. PAP001237-2 S/N 4: Thick Titanium 6-4 Sample After Test Run No. 12, Drop Height 8.00 Inches

VI-12. PAP001238-2 S/N 4: Thin Titanium 6-4 Sample After Test Run No. 13, Drop Height 1.00 Inch

VI-13. PAP001238-1. S/N 2: Thin Aluminum 2024 Sample After Test Run No. 14, Drop Height 0.50 Inches

VI-14. PAP001238-2 S/N 3: Thin Titanium 6-4 Sample After Test Run No. 15, Drop Height 3.00 Inches

VI-15. PAP001238-1 S/N 3: Thin Aluminum 2024 Sample After Test Run No. 16, Drop Height 2.00 Inches 


\section{LIST OF FIGURES (Cont)}

Figure

Page

VII-1. PAP001237-2 S/N 1: Titanium 6-4 Sample After Runs No. 1 and 1A, Drop Height 0.25 Inch

VII-1

VII-2. PAP001237-2 S/N 2: Titanium 6-4 Sample After Run No. 2, Drop Height 3.25 Inches

VII-2

VII-3. PAP001237-2 S/N 1: Titanium 6-4 Sample After Run No. 3, Drop Height 15.75 Inches

VII-3

VII-4. PAP001237-1 S/N 1: Aluminum 2024 Sample After Test Run No. 4, Drop Height 0.25 Inches

VII-4

VII-5. PAP001237-1 S/N 4: Aluminum 2024 Sample After Test Run No. 5, Drop Height 0.50 Inch

VII-5

VII-6. PAP001238-2 S/N 2: Titanium 6-4 Sample After Test Run No. 6, Drop Height 0.25 Inch

VII-6

VII-7. PAP001238-1 S/N 1: Aluminum 2024 Sample After Test Run No. 7, Drop Height 0.25 Inch

VII-7

VII-8. PAP001238-2 S/N 1: Titanium 6-4 Sample After Test Run No. 8, Drop Height 0.25 Inch

VII-9. PAP001237-1 S/N 3: Aluminum 2024 Sample After Test Run No. 9, Drop Height 1.00 Inch

VII-10. PAP001237-2 S/N 3: Titanium 6-4 Sample After Run No. 10, Drop Height 12.00 Inches

VII-11. PAP001237-1 S/N 2: Aluminum 2024 Sample After Test Run No. 11, Drop Height 5.00 Inches

VII-12. PAP001237-2 S/N 4: Titanium 6-4 Sample After Test Run No. 12, Drop Height 8.00 Inches

VII-8

VII-9

VII-10

VII-11

VII-12

VII-13. PAP001238-2 S/N 4: Titanium 6-4 Sample After Test Run No. 13, Drop Height 1.00 Inch

VII-13

VII-14. PAP001238-1 S/N 2: Aluminum 2024 Sample After Test Run No. 14, Drop Height 0.50 Inch

VII-14

VII-15. PAP001238-2 S/N 3: Titanium 6-4 Sample After Test Run No. 15, Drop Height 3.00 Inches

VII-15

VII-16. PAP001238-1 S/N 3: Aluminum 2024 Sample After Test Run No. 16, Drop Height 2.00 Inches

VII-16

VII-1. Load vs. Time, Test No. 1

VIII-1

VIII-2. Load vs. Time, Test No. 2

VIII-2

VIII-3. Load vs. Time, Test No. 3

VIII-3

VIII-4. Load vs. Time, Test No. 4

VIII-4

VIII-5. Load vs. Time, Test No. 5

VIII-5

VIII-6. Load vs. Time, Test No. 9

VIII-6

VIII-7. Load vs. Time, Test No. 10 


\section{LIST OF FIGURES (Cont)}

Figure

Page

VIII-8. Load vs. Time, Test No. 11

VIII-8

VIII-9. Load vs. Time, Test No. 12

VIII-9

VIII-10. Load vs. Time, Test No. 13

VIII-10

VIII-11. Load vs. Time, Test No. 14

IX-1. Strain Gage vs. Time, Test No. 2, Thick Titanium Sample, 3.25-Inch Drop

VIII-11

IX-1

IX-2. Strain Gage vs. Time, Test No. 3, Thick Titanium Sample, 15.75-Inch Drop

IX-1

IX-3. Strain Gage vs. Time, Test No. 4, Thick Aluminum Sample, 0.25-Inch Drop

IX-2

[X-4. Strain Gage vs. Time, Test No. 5, Thick Aluminum Sample, 0.50-Inch Drop

IX-2

IX-5. Strain Gage vs. Time, Test No. 6, Thin Titanium Sample, 0.25-Inch Drop

IX-3

IX-6. Strain Gage vs. Time, Test No. 7, Thin Aluminum Sample, 0.25-Inch Drop

IX-7. Strain Gage vs. Time, Test No. 8, Thin Titanium Sample, 0.25-Inch Drop

IX-3

IX-8. Strain Gage vs. Time, Test No. 9, Thick Aluminum Sample, 1.00-Inch Drop

IX-4

IX-4

IX-9. Strain Gage vs. Time, Test No. 10, Thick Titanium Sample, 12.00-Inch Drop

IX-5

IX-10. Strain Gage vs. Time, Test No. 11, Thick Aluminum Sample, 5.00-Inch Drop

IX-5

IX-11. Strain Gage vs. Time, Test No. 12, Thick Titanium Sample, 8.00-Inch Drop

IX-6

IX-12. Strain Gage vs. Time, Test No. 13, Thin Titanium Sample, 1.00-Inch Drop

IX-6

IX-13. Strain Gage vs. Time, Test No. 14, Thin Aluminum Sample, 0.50-Inch Drop

IX-7

IX-14. Strain Gage vs. Time, Test No. 15, Thin Titanium Sample, 3.00-Inch Drop

IX:-7

IX-15. Strain Gage vs. Time, Test No. 16, Thin Aluminum Sample, 2.00-Inch Drop

IX-8

IX-16. Maximum Strain vs. Drop Height

IX-17. Maximum Strain vs. Drop Height, Small Drop Height Detail

IX-9

X-1. Deflection vs. Time, Test No. 1, Thick Titanium Sample, 0.25-Inch Drop

X-2. Deflection vs. Time, Test No. 2, Thick Titanium Sample, 3.25-Inch Drop

X-3. Deflection vs. Time, Test No. 3, Thick Titanium Sample, 15.75-Inch Drop

X-4. Deflection vs. Time, Test No. 4, Thick Aluminum Sample, 0.25-Inch Drop

X-5. Deflection vs. Time, Test No. 5, Thick Aluminum Sample, 0.50-Inch Drop

X-6. Deflection vs. Time, Test No. 6, Thin Titanium Sample, 0.25-Inch Drop

X-7. Deflection vs. Time, Test No. 7, Thin Aluminum Sample, 0.25-Inch Drop

X-8. Deflection vs. Time, Test No. 8, Thin Titanium Sample, 0.25-Inch Drop

X-9. Deflection vs. Time, Test No. 9, Thick Aluminum Sample, 1.00-Inch Drop

DX-9

$\mathrm{X}-1$

$\mathrm{X}-1$

$X-2$

$X-2$

$X-3$

$\mathrm{X}-3$

$X-4$

$X-4$

$X-5$

X-10. Deflection vs. Time, Test No. 10, Thick Titanium Sample, 12.00-Inch Drop

$X-5$

X-11. Deflection vs. Time, Test No. 11, Thick Aluminum Sample, 5.00-Inch Drop

$X-6$

$\mathrm{X}$-12. Deflection vs: Time, Test No. 12, Thick Titanium Sample, 8.00-Inch Drop

$X-6$

$\mathrm{X}$-13. Deflection vs. Time, Test No. 12, Thin Titanium Sample, 1.00-Inch Drop

$X-7$

X-14. Deflection vs. Time, Test No. 14, Thin Aluminum Sample, 0.50-Inch Drop

$\mathrm{X}-7$

X-15. Deflection vs. Time, Test No. 15, Thin Titanium Sample, 3.00-Inch Drop

X-16. Maximum Deflection Plots

$X-8$

$X-9$

X-17. Maximum Deflection Plots, Small Drop Height Detail

$X-9$

XI-1. Load vs. Time, Test No. 1, Thick Titanium Sample, 0.25-Inch Drop

XI-1 


\section{LIST OF FIGURES (Cont)}

Figure

Page

XI-2. Load vs. Time, Test No. 1, Thick Titanium Sample, 3.25-Inch Drop XI-1

XI-3. Load vs. Time, Test No. 3, Thick Titanium Sample, 15.75-Inch Drop XI-2

XI-4. Load vs. Time, Test No. 4, Thick Aluminum Sample, 0.25-Inch Drop XI-2

XI-5. Load vs. Time, Test No. 5, Thick Aluminum Sample, 0.50-Inch Drop XI-3

XI-6. Load vs. Time, Test No. 6, Thin Titanium Sample, 0.25-Inch Drop XI-3

XI-7. Load vs. Time, Test No. 7, Thin Aluminum Sample, 0.25-Inch Drop XI-4

XI-8. Load vs. Time, Test No. 8, Thin Titanium Sample, 0.25-Inch Drop XI-4

XI-9. Load vs. Time, Test No. 9, Thick Aluminum Sample, 1.00-Inch Drop XI-5

XI-10. Load vs. Time, Test No. 10, Thick Titanium Sample, 12.00-Inch Drop XI-5

XI-11. Load vs. Time, Test No. 11, Thick Aluminum Sample, 5.00-Inch Drop XI-6

XI-12. Load vs. Time, Test No. 12, Thick Titanium Sample, 8.00-Inch Drop XI-6

XI-13. Load vs. Time, Test No. 13, Thin Titanium Sample, 1.00-Inch Drop XI-7

XI-14. Load vs. Time, Test No. 14, Thin Aluminum Sample, 0.50-Inch Drop XI-7

XI-15. Load vs. Time, Test No. 15, Thin Titanium Sample, 3.00-Inch Drop XI-8

XI-16. Load vs. Time, Test No. 16, Thin Aluminum Sample, 2.00-Inch Drop XI-8

XI-17. Maximum Load Plots XI-9

XI-18. Maximum Load Plots, Small Drop Height Detail XI-9

XII-1. Peak Time Regression Plot XII-1

XII-2. Maximum Energy Plots XI-1.

\section{LIST OF TABLES}

Table

Page

1. Summary of Tests for PAP001237-2 Specimens (Thick Titanium) 13

2. Summary of Tests for PAPO01238-2 Specimens (Thin Titanium) 13

3. Summary of Tests for PAP001237-1 Specimens (Thick Aluminum) 13

4. Summary of Tests for PAP001238-1 Specimens (Thin Aluminum) 13

I-1. Test Drop Heights (inches) per Configuration I-1

I-2. Test Hardware Parts List I-2

I-3. Test Coupon Summary I-3

II-1. Assembly List: Containment Test Fixture II-4 


\section{FAA DEBRIS MITIGATION \\ PHASE 1 \\ IMPACT TEST REPORT}

\section{INTRODUCTION}

This document, prepared by AlliedSignal Engines, Phoenix, Arizona, provides the results of the Phase I Impact Test on curved-beam specimens, performed as part of the Federal Aviation Administration (FAA) Debris Mitigation Study. This study is a joint effort of AlliedSignal Engines (AE), Lawrence Livermore National Laboratory (LLNL), The Boeing Company, and Pratt \& Whitney (P\&W). AE performed the Phase I Impact Test portion of the study under subcontract to LLNL, Department of Energy (DOE) Contract No. W-7405-ENG-48.

The goal of the study is the accurate prediction of the effect of uncontained engine debris on aircraft structures. This will provide airframe engineers the information required to design for damage mitigation and improved safety. The basis for predictive simulation tools lies in the experimental data, which motivates the initial development and application of codes that can adequately describe past experiments. This in turn validates the predictive capability of the codes to simulate future experiments.

The LL-DYNA3D software code was developed by the Lawrence Livermore National Laboratory as a tool for simulating dynamic non-linear events such as impact. AE is responsible for correlation and calibration of LL-DYNA3D. Events were modeled from AE experience, which includes dynamics and failure modes similar to those found in engine/airframe-debris interaction. The selected events were a turbofan blade-out scenario and the impact testing of curved beam specimens. The former is an actual event, the latter a controlled test. An impact test employed by $\mathrm{AE}$ for material characterization was adopted for use in this program. Fifteen curved-beam samples were tested to obtain data needed for proper calibration of LL-DYNA3D. The materials tested were Aluminum 2024 and Titanium 6-4. 


\section{BACKGROUND}

In mid-1996, an unsolicited proposal, "Development of Methodologies for Evaluating Containment and Mitigation of Uncontained Engine Debris," was submitted to the FAA as a joint effort by AE, Boeing, LLNL, and P\&W. The proposal was in response to needs expressed at the second FAA-sponsored workshop on "Uncontained Engine Debris Characterization, Modeling and Mitigation," held January 21 and 22, 1996. The proposed efforts consisted of two phases. Phase 1 consisted of a comprehensive program of material impact testing and characterization, plus development of the LL-DYNA3D computer code. The testing and development was aimed at delivering a methodology to the aerospace industry for prediction of damaged fan containment and debris mitigation in hardwall systems and solid blades. The proposed Phase 2 would extend Phase 1 into other systems, such as softwall, Kevlar wrap, composites, or composite fan blades.

The Phase 1 investigations have been completed. A test similar to the current one described in this report was performed in late 1997 (under other funding, detailed in AE Internal Document No. 13-CDD-STRU0199-0027). In that test, a total of six samples were impact tested under similar conditions: two were Aluminum 6061-T6 specimens and four were Inconel 718 specimens. All six had a thick cross section $(0.20$ inch $)$ and dimensions equal to the thick samples used in the current test, except for the arc diameter. The previous test used an 8.25-inch diameter, while the current test used samples with an 8.00 -inch diameter. Thin cross-section samples $(0.040 \mathrm{inch})$ were not used in the 1997 test. The goal of the test was to impact the specimens at a velocity of 5 meters/second ( 16.4 feet/second). This was achieved with a drop height of approximately 4 feet (1.2 meters) and an impact head loading of between 1000 and 1200 $\mathrm{lb}(454$ and $545 \mathrm{~kg}$ ). The tests resulted in tensile failure times of just under 2 milliseconds. After comparing the test results with LS-DYNA model predictions, it was concluded that both the failure times and strain predictions agreed well with the measured test results. 


\section{TEST PLAN}

The Impact Specimen Test Plan and Procedure is included in Appendix I. Fifteen specimens were tested. Specimens were 120-degree arc segments on an 8.0-inch diameter, one inch wide, eight with a thick cross-section $(0.20$ inch) and seven with a thin cross section $(0.040$-inch). The thick cross section was chosen to represent airframe structural members, while the thin cross section would represent fuselage skin. These are divided into eight specimens of Titanium 6-4 and seven of Aluminum 2024. The titanium samples are evenly divided (four thick samples, four thin samples), while the aluminum samples consist of four thick samples and three thin samples. Drawings of the specimens are included in Appendix II. All specimens were hit by a controlled drop-hammer impactor from different heights, as explained in the Test Procedure section. Testing was performed at GRC International, Goleta, California, in April 1998. 


\section{TEST PROCEDURE}

The 15 curved-beam specimens were tested via a controlled drop-hammer impactor. The impactor is a wedge-shaped piece made of high-strength steel. The impactor ends in a 0.25 -inch radius. The flank angle on the nose is $\mathbf{3 5}$ degrees. The specimens were held in place by a test fixture supplied by AE. Drawings of the impactor, test fixture, and specimens are shown in Appendix II. The drop-hammer weight for all 15 tests was $500 \mathrm{lb}$.

The general setup procedure for all samples regardless of material or configuration was the same. A picture was taken of the sample before it was loaded in the test fixture (Appendix III). The locking plates were removed by turning the four tightening bolts on each side of the support housing. All strain gage wire leads were connected to the amplifier machine. The sample was carefully loaded into one side of the support housing, then snapped into place by gently pushing down on it. The strain gage wire leads were checked to make sure that they were not being subject to any unnecessary force. The locking plates were put in place and tightened by turning the four tightening bolts on each side. The impact head was lowered to the desired drop height. A picture of the test setup was taken at this time (Appendix IV). The strain gages were electronically checked and balanced by one technician, while the other prepared the load cell to record all the impact data. Once this was done, all cameras were prepared for recording. The camera operator gave the signal, all computers were readied for recording, and the load was dropped. All computers and cameras were checked to verify whether data was successfully recorded. The impact head was raised and a picture was taken of the test setup after the test (Appendix V). After all data was verified, the locking plates were loosened and the specimen was removed from the test fixture. The specimen and test fixture were visually inspected for damage. The wire leads were cut from the specimen. The specimen was photographed by itself after the test to document the damage (Appendix VI). The specimen was sketched on a 1-to-1 scale and notes were made describing the damage to the specimen and measurement data collected (Appendix VII). The specimen was carefully surrounded with bubble wrap and prepared for shipment back to AlliedSignal. This procedure was repeated for every test.

Drop heights varied for each configuration. The drop heights for the thick titanium specimens varied from 0.25 to 15.75 inches. For the thick aluminum specimens, drop heights were anywhere from 0.25 to 5.00 inches. The thin titanium specimens were tested from 0.25 to 3.00 inches, while the thin aluminum specimens were tested from 0.25 to 2.00 inches. Drop heights were chosen to bracket the energy needed to make a given configuration fail.

The complete test plan, including full step-by-step procedures and drop height for each individual sample, is included as Appendix I. 


\section{DATA ACQUISITION}

Several data acquisition methods were used during the experiment. They included highspeed film, high-speed video, strain gages attached to the specimens, and a load cell connected to the impact head. The strain gages provided strain data and also showed the peak time.

The system was not calibrated correctly to obtain the loads, with the result that some load information was missing. The load cell was difficult to calibrate and trigger. A solid impact was required to activate the load cell, and most of the thin specimens were soft enough that they did not activate it. Therefore, load-cell data for thin specimens is not complete and a full analysis could not be made. It was, however, the most useful and thorough data collection system. The load cell provided impact energy, impact velocity, maximum load, peak time and peak deflection. Load-cell data was used to complete the missing load data from the strain gage readings.

The high-speed film was used to measure the maximum deflection in the parts. The highspeed video was used first only as a reference to view the response of the specimens to the impacts. Afterwards, a high-speed video analysis was made to obtain the deflection and velocity of three points on each setup (a point on the impact head, bottom dead center hash mark on the specimen, and 15-degree hash mark on the specimen). Because the camera was not positioned normal to the motion, most of this data was not used for the analysis, but was used for reference only. Where possible, only load-cell and strain-gage data were used. It was necessary to use film analysis data to provide some missing data points and to cross-check data.

Printouts from the load cell are shown in Appendix VIII. Strain vs. Time plots are included in Appendix IX and Deflection vs. Time plots in Appendix X. Load vs. Time plots are shown in Appendix XI and Peak Time Regression Curve and Energy plots in Appendix XII.

Raw data from the high-speed video analysis, high-speed film displacement data and raw strain gage data are not included in this report, but can be obtained by contacting the Structures Department at AE in Phoenix, AZ. 


\section{TEST RESULTS}

Test No. 1: PAP001237-2, Serial Number 1, Titanium 6-4 (thick configuration), 0.25-inch drop

The test produced no permanent deformation on the specimen. This test had to be run twice because the load cell stopped recording after $7.8 \mathrm{~ms}$ and the high-speed video was late triggering. After the first run, a visual inspection of the specimen was made and no permanent damage was observed, so it was decided to nun the test again. Due to the fact that it was the first test, the gain on the strain gage signal conditioner could not be predicted accurately enough to record good strain gage data on either run. The peak time recorded was $10.35 \mathrm{~ms}$, with a peak load of $3716 \mathrm{lb}$. and a peak deflection of 0.12 inch. Because the specimen was not plastically deformed, it was decided to reuse it for a further test (No. 3).

\section{Test No. 2: PAP001237-2, Serial Number 2, Titanium 6-4 (thick configuration),} 3.25-inch drop

The specimen showed plastic deformation as a result of the test. The maximum deflection recorded during the test was 0.315 inch at the peak time of $10.00 \mathrm{~ms}$. Strain gage No. 1 did not function properly. The raw strain gage data for gages No. 2 and No. 3 did not fit the general pattern observed in the other tests (gage No. 3 showed higher strains than gage No. 2), so they were reversed for consistency. The highest recorded strain was 0.02255 . The maximum load recorded was $10789 \mathrm{lb}$.

Test No. 3: PAP001237-2, Serial Number 1, Titanium 6-4 (thick configuration), 15.75-inch drop

This test used the undamaged specimen from Test No. 1. The goal of this test was to achieve a clear failure, which was achieved. Maximum strain recorded before failure was 0.02252. Failure time was $2.97 \mathrm{~ms}$. Maximum load recorded was $11916 \mathrm{lb}$. Heavy necking was observed on the outer diameter of the specimen around the break area. The maximum deflection noted at the peak time was 0.317 inch.

Test No. 4: PAP001237-1, Serial Number 1, Aluminum 2024 (thick configuration), 0.25-inch drop

This aluminum specimen showed a small degree of plastic deformation. The maximum deflection noted was 0.174 inch at the peak time. Strain gage No. 1 did not record any data, and the highest strain recorded at any point was 0.0105 , at gage No. 2 . The maximum load recorded was $2368 \mathrm{lb}$. The peak force, deflection and strain point occurred at $16.0 \mathrm{~ms}$. Slight necking was observed on the outer diameter of the specimen directly under the impact area. 
Test No. 5: PAP001237-1, Serial Number 4, Aluminum 2024 (thick configuration), 0.50 -inch drop

This aluminum specimen showed a larger degree of deformation than the previous test. The maximum deflection noted was 0.23 inch at the peak time. The maximum strain recorded was at strain gage No. 2, and it was 0.01732 . The maximum load was $3014 \mathrm{lb}$. The peak strain and load occurred at $15.5 \mathrm{~ms}$. There was necking evident on the outer diameter of the part under the impact point and visible material stretching.

Test No. 6: PAP001238-2, Serial Number 2, Titanium 6-4 (thin configuration), 0.25 -inch drop

This was the first thin cross section sample that was tested. The impact head was changed before the test to a more sensitive one, anticipating a softer impact. Strain gages No. 2 and No. 5 did not balance properly prior to the test, so no data is available for them. The load cell was not triggered by the impact, and the part did not break. There was considerable stretching in the part, both elastic and plastic. The maximum deflection noted was 0.231 inch. The maximum strain recorded by the strain gages was 0.00622 , by strain gage No. 1 . The peak load was $3051 \mathrm{lb}$. The time for the peak values was $22.15 \mathrm{~ms}$.

Test No. 7: PAP001238-1, Serial Number 1, Aluminum 2024 (thin configuration), 0.25 -inch drop

This was the second thin cross section sample tested, and once again the impact did not trigger the load cell despite several adjustments that were made. Strain gage No. 7 did not balance properly prior to the test and strain gage No. 1 did not record any data. The part showed great flexibility and absorbed most of the impact, to the point where extra bounces of the impact head on the part were minimal. The maximum deflection noted was 0.355 inch. The maximum strain recorded was 0.00908 at gage No. 2. Maximum load was $2132 \mathrm{lb}$. The time of maximum load and strain was around $27.5 \mathrm{~ms}$. Surface cracking of the outer oxide layer was visible on the outer diameter of the impact area.

Test No. 8: PAP001238-2, Serial Number 1, Titanium 6-4 (thin configuration), 0.25-inch drop

This is a repeat of test No. 6, with the same configuration. Once again, the part deformed plastically. The load cell did not trigger at impact and did not record data. Strain gages No. 3 and No. 4 did not balance properly prior to the test and did not record data. The maximum deflection noted was 0.202 inch. Strain gage No. 2 recorded the highest strain, which was 0.00583 at approximately $21.7 \mathrm{~ms}$. The highest load recorded was $2932 \mathrm{lb}$. at the same point in time.

Test No. 9: PAP001237-1, Serial Number 3, Aluminum 2024 (thick configuration), 1.00-inch drop

The test was expected to test the endurance of the aluminum sample. The sample showed significant plastic deformation after the test, with considerable necking on the outer diameter of 
the specimen under the impact area, and there are clear signs of material stretching. The maximum deflection noted was 0.300 inch. The highest strain recorded was 0.02563 , at strain gage No. 2. The highest load recorded was $4047 \mathrm{lb}$. The peak point for load and strain is centered at approximately $16.5 \mathrm{~ms}$.

Test No. 10: PAP001237-2, Serial Number 3, Titanium 6-4 (thick configuration), 12.00-inch drop

This test produced a clean break with little velocity slowdown of the impact head. The part shows heavy necking around the impact area and material adhesion along the necked sides of the right side segment. Maximum deflection at the break was approximately 0.343 inch. The maximum strain recorded before breakage was 0.02661 , by strain gage No. 2 . The highest load recorded was $12517 \mathrm{lb}$. The point of maximum strain and load was $3.90 \mathrm{~ms}$.

Test No. 11: PAP001237-1, Serial Number 2, Aluminum 2024 (thick configuration), 5.00-inch drop

This was the last thick aluminum sample run. The drop height was adjusted in order to produce a clear failure. Strain gage No. 2 did not record any data, and gages No. 4 and No. 5 had to be rewired before the test. The specimen did break, but the high-speed video shows that it absorbed most of the impact before breaking. Necking and heavy material stretching are evident around the break area. The maximum deflection noted was $0.359 \mathrm{inch}$. The highest strain recorded was 0.03015 by strain gage No. 1 . The highest load recorded was $4738 \mathrm{lb}$. at approximately $5.88 \mathrm{~ms}$.

\section{Test No. 12: PAP001237-2, Serial Number 4, Titanium 6-4 (thick configuration), 8.00-inch drop}

This test produced a clean break similar to most of the other thick titanium specimens run. The specimen showed the same necking and material adhesion pattern as the previous two titanium samples that were broken. The maximum deflection noted was 0.333 inch. The strain gage data shows that the maximum strain before failure was 0.02349 . The maximum load recorded was $12105 \mathrm{lb}$. The point of maximum load and strain was approximately $4.96 \mathrm{~ms}$.

Test No. 13: PAP001238-2, Serial Number 4, Titanium 6-4 (thin configuration), 1.00-inch drop

This test resulted in the titanium specimen deforming a maximum of 0.398 inch. The specimen did not break or show cracks after the impact. There was some discoloration on the inside diameter of the impact area, as well as deformation in the thick areas of the sample. The maximum strain was recorded by gage No. 2 , and it was 0.01116 . The maximum load recorded was $6024 \mathrm{lb}$. The point of maximum load and strain was $16.5 \mathrm{~ms}$. 


\section{AlliedSignal \\ A E OS PACE}

Test No. 14: PAP001238-1, Serial Number 2, Aluminum 2024 (thin configuration), 0.50 -inch drop

The aluminum specimen reached a 0.441 -inch maximum deflection and did not break. Cracks were observed under the impact area but they were only present on the surface finish, which flaked off. The highest strain was 0.01088 , recorded by strain gage No. 2 . The highest load recorded was $2433 \mathrm{lb}$. The point of maximum strain and load occurred at approximately $26.9 \mathrm{~ms}$.

Test No. 15: PAP001238-2, Serial Number 3, Titanium 6-4 (thin configuration), 3.00-inch drop

This was the last thin titanium specimen run. A clean break was desirable in this run and it was achieved. The part broke just to the right of bottom dead center. The thicker parts of the specimen showed no plastic deformation. The high-speed video showed that the specimen absorbed a good portion of the impact before breaking. The maximum deflection noted was 0.457 inch. The maximum strain recorded by the strain gages before failure was 0.01247 , by strain gage No. 2. The maximum load recorded was $2363 \mathrm{lb}$. The point of maximum strain and load was approximately $11.10 \mathrm{~ms}$.

Test No. 16: PAP001238-1, Serial Number 3, Aluminum 2024 (thin configuration), 2.00-inch drop

This was the last specimen tested. A clean break of a thin aluminum specimen was desired and achieved. The impact was directly on bottom dead center but the part broke just right of bottom dead center, much like the previous thin titanium sample. The thicker areas of the specimen showed little plastic deformation. The maximum deflection noted was 0.643 inch. High-speed film deflection analysis was not available for this test, so the deflection was obtained from the high-speed video analysis. The maximum strain recorded by the strain gages was 0.0143 , and the maximum load was $1013 \mathrm{lb}$. Both occurred at approximately $14.25 \mathrm{~ms}$. 


\section{ANALYSIS}

There were several stages of data analysis. The strain gage results were available first. Peak strains and times were obtained from this data. Peak load data was included with the strain gage data. Some of the load data was incomplete as a result of miscalibration. Peak deflection data was obtained from the high-speed film analysis performed by GRC. The load-cell printouts (Appendix VIII) provided a wealth of valuable information to cross-check all the other data. These printouts were used to verify the peak loads and fill in missing load information, verify peak deflection, verify peak time, and to obtain impact velocity and maximum energy. Most of the data agreed favorably among the different data collection methods used. The only differences, although very slight, were in the peak times. Plots were used to decide on reasonable peak times for the discrepant ones.

The strain gage results were analyzed first. The raw data from GRC was put in a spreadsheet program and plots of strain versus time were made. These plots show the maximum strain in each specimen, as well as the peak time of deflection. Time corrections had to be made in order to place the starting time at zero seconds. In some cases, certain strain gages did not work, as noted in the previous section. In general, strain gages No. 1 and No. 2 showed tension and gages No. 4 through No. 7 showed compression. Gage No. 3 showed tension in the thick specimens and wavered between tension and compression in the thin specimens depending on the time point. This behavior was observed in the high-speed video. The specimens that stretched showed a bellshaped data pattern with clear peaks. The specimens that broke showed an upward sloping pattern followed by an abrupt break. The peak strain was consistently recorded by strain gage No. 2. In general, the thin titanium samples withstood the least amount of strain before failure, followed by thin aluminum, thick titanium, and thick aluminum. Raw strain plots and maximum strain plots can be found in Appendix DX.

Deflection data was obtained from the high-speed film analysis by GRC. This data follows a similar pattern to strain data. Specimens that deflected show a bell curve distribution, while broken specimens show an increasing linear pattern that ends abruptly. The smallest deflections before failure were observed in the thick titanium samples, with a plateau just over 0.30 inch. The next lowest deflections were observed in the thick aluminum samples, at about 0.35 inch. One thin titanium sample deflected about 0.46 inch before failure, and one thin aluminum sample broke after a deflection of just over $0.6 \mathrm{inch}$. The deflection plots for all samples and associated peak deflection plots can be found in Appendix X.

Peak loads, impact velocity, and maximum absorbed energy by the specimen were recorded by the load cell. Impact velocity shows a parabolic pattern and can be calculated by the formula $\sqrt{ }(2 g h)$, where $h$ is the drop height and $g$ is the acceleration due to gravity. The peak loads and maximum energy absorbed show the same pattern as peak strain and deflection, so plots showing maximum load vs. drop height were created for each configuration. Thick titanium samples withstood the highest loads, followed by thin titanium, thick aluminum, and thin aluminum. Maximum energy vs. drop height plots could only be created for the thick configurations because load-cell data was not available for most of the thin samples. A Peak Time vs. Drop Height plot 
was constructed using all available data points. Enough points in a pattern were available to perform a regression analysis on the data with satisfactory results. The resulting peak time regression curve and maximum energy plots can be found in Appendix XII. The maximum load plots can be found in Appendix XI.

Due to the limited number of data points available, the maximum strain, maximum load, maximum deflection and maximum energy plots are only intended to provide estimates at each drop height. An attempt was made to best-fit a line or curve to the data. The best-fit curves, according to statistical analyses, did not show a realistic data pattern in most cases. When trying to fit quadratic or higher order equations to the data, the curves would show peaks that were too high. Since not enough data points were available to perform a thorough regression analysis with acceptable results, the original data points are shown connected by lines in order to give the reader a chance to interpolate and estimate values at any drop height. These plots can be used to interpolate only within the drop heights tested for each configuration. Extrapolation should not be attempted. 


\section{CONCLUSIONS}

AlliedSignal Engines performed the Phase I Impact Test portion of the FAA Debris Mitigation Study as outlined under the subcontract with LLNL for the DOE Prime Contract No. W-7405-ENG-48. Fifteen curved-beam samples of Aluminum 2024 and Titanium 6-4 were tested to obtain the data needed for proper calibration of the LL-DYNA3D computer simulation.

The impact testing provided data to compare the means to predict the materials' response to selected drop heights. Based on the data analysis of specimen deformation after testing, the maximum strain, maximum load, maximum deflection, and maximum energy plots will provide accurate data for computer simulation to predict the effect of debris on airframe materials. The LL-DYNA3D simulations and comparisons to these test data are reported in AE internal Document No. 13-CDD-STRU0199-0055 (See Attachment 1).

\section{LESSONS LEARNED}

The bonding of the strain gages to the samples was excellent. There were no strain gage detachments during any of the 16 test runs. The wiring, however, came apart in some cases, limiting the data that was recorded. The wire leads should be bundled around the area where they exit the fixture, so that they are not pressured by the locking plates when the specimens are tightened down.

In some cases, strain gages were not functional when checked by the technicians before the tests. Although they were inspected by the installing vendor before shipping and certified to be good, the high rate of non-functional strain gages at test time is cause for concern. The act of balancing the strain gages before the tests was time consuming, due to the non-functional ones.

The test facility was not ready for the first day of testing. There were concerns with the ability of the impact to trigger the load cell on the low-height drops. A number of test runs were made; however, the first two tests were used to calibrate the later ones. It turned out to be almost impossible to get the load cell to trigger on thin specimen runs. Some of the equipment malfunctioned between a set of tests, and a time-consuming equipment substitution had to be made. Having all equipment checked for proper functioning before the day of the test would save time. The load cell was the most useful data collection system used during the test. It is important to have it functioning properly for every test in future experiments. 
Table 1. Summary of Tests for PAP001237-2 Specimens (Thick Titanium)

\begin{tabular}{|c|c|c|c|c|c|c|c|c|c|c|c|}
\hline Part & S/N & Material & Config. & $\begin{array}{c}\text { Drop } \\
\text { Height }\end{array}$ & Result & $\begin{array}{c}\text { Peak } \\
\text { Time }\end{array}$ & $\begin{array}{c}\text { Peak } \\
\text { Strain }\end{array}$ & $\begin{array}{c}\text { Peak } \\
\text { Load }\end{array}$ & $\begin{array}{c}\text { Peak } \\
\text { Defl. }\end{array}$ & $\begin{array}{c}\text { Imp. } \\
\text { Vel. }\end{array}$ & E max \\
\hline PAP001237-2 & 1 & Ti 6-4 & Thick & $\mathbf{0 . 2 5}$ & Nothing & 10.35 & n/a & 3716 & 0.120 & 1.16 & 18.92 \\
\hline PAP001237-2 & 2 & Ti 6-4 & Thick & 3.25 & Stretched & 10.00 & 0.02255 & 10789 & 0.315 & 4.18 & 157.48 \\
\hline PAP001237-2 & 4 & Ti 6-4 & Thick & 8.00 & Broke & 4.96 & 0.02349 & 12105 & 0.333 & 6.55 & 192.92 \\
\hline PAP001237-2 & 3 & Ti 6-4 & Thick & 12.00 & Broke & 3.90 & 0.02661 & 12517 & 0.343 & 8.07 & 196.98 \\
\hline PAP001237-2 & 1 & Ti 6-4 & Thick & 15.75 & Broke & 2.97 & 0.02252 & 11916 & 0.317 & 9.18 & 165.12 \\
\hline
\end{tabular}

Table 2. Summary of Tests for PAP001238-2 Specimens (Thin Titanium)

\begin{tabular}{|c|c|c|c|c|c|c|c|c|c|c|c|}
\hline Part & S/N & Material & Config & $\begin{array}{c}\text { Prop } \\
\text { Height }\end{array}$ & Result & $\begin{array}{c}\text { Peak } \\
\text { Time }\end{array}$ & $\begin{array}{c}\text { Peak } \\
\text { Strain }\end{array}$ & $\begin{array}{c}\text { Peak } \\
\text { Load }\end{array}$ & $\begin{array}{c}\text { Peak } \\
\text { Defl. }\end{array}$ & $\begin{array}{c}\text { Imp. } \\
\text { Vel. }\end{array}$ & E max \\
\hline PAP001238-2 & 2 & Ti 6-4 & Thin & 0.25 & Stretched & 22.15 & 0.00622 & 3051 & 0.231 & 1.16 & $\mathrm{n} / \mathrm{a}$ \\
\hline PAP001238-2 & 1 & Ti 6-4 & Thin & 0.25 & Stretched & 21.70 & 0.00583 & 2932 & 0.202 & 1.16 & $\mathrm{n} / \mathrm{a}$ \\
\hline PAP001238-2 & 4 & Ti 6-4 & Thin & 1.00 & Stretched & 16.50 & 0.01116 & 6024 & 0.398 & 2.32 & 61.8 \\
\hline PAP001238-2 & 3 & Ti 6-4 & Thin & 3.00 & Broke & 11.10 & 0.01247 & 2363 & 0.457 & 4.01 & $\mathrm{n} / \mathrm{a}$ \\
\hline
\end{tabular}

Table 3. Summary of Tests for PAP001237-1 Specimens (Thick Aluminum)

\begin{tabular}{|c|c|c|c|c|c|c|c|c|c|c|c|}
\hline Part & S/N & Material & Config & $\begin{array}{c}\text { Drop } \\
\text { Height }\end{array}$ & Result & $\begin{array}{c}\text { Peak } \\
\text { Time }\end{array}$ & $\begin{array}{c}\text { Peak } \\
\text { Strain }\end{array}$ & $\begin{array}{c}\text { Peak } \\
\text { Load }\end{array}$ & $\begin{array}{c}\text { Peak } \\
\text { Defl. }\end{array}$ & $\begin{array}{c}\text { Imp. } \\
\text { Vel. }\end{array}$ & E max \\
\hline PAP001237-1 & 1 & Al 2024 & Thick & 0.25 & Stretched & 16.00 & 0.01050 & 2368 & 0.174 & 1.16 & 21.17 \\
\hline PAP001237-1 & 4 & Al 2024 & Thick & 0.50 & Stretched & 15.50 & 0.01732 & 3014 & 0.230 & 1.64 & 34.59 \\
\hline PAP001237-1 & 3 & Al 2024 & Thick & 1.00 & Stretched & 16.50 & 0.02563 & 4047 & 0.300 & 2.32 & 60.73 \\
\hline PAP001237-1 & 2 & Al 2024 & Thick & 5.00 & Broke & 5.88 & 0.03015 & 4738 & 0.359 & 5.18 & 80.27 \\
\hline
\end{tabular}

Table 4. Summary of Tests for PAP001238-1 Specimens (Thin Aluminum)

\begin{tabular}{|c|c|c|c|c|c|c|c|c|c|c|c|}
\hline Part & S/N & Material & Config & $\begin{array}{c}\text { Drop } \\
\text { Height }\end{array}$ & Result & $\begin{array}{c}\text { Peak } \\
\text { Time }\end{array}$ & $\begin{array}{c}\text { Peak } \\
\text { Strain }\end{array}$ & $\begin{array}{c}\text { Peak } \\
\text { Load }\end{array}$ & $\begin{array}{c}\text { Peak } \\
\text { Defl. }\end{array}$ & $\begin{array}{c}\text { Imp. } \\
\text { Vel. }\end{array}$ & E max \\
\hline PAP001238-1 & 1 & Al 2024 & Thin & 0.25 & Stretched & 27.50 & 0.00908 & 2132 & 0.355 & 1.16 & n/a \\
\hline PAP001238-1 & 2 & Al 2024 & Thin & 0.50 & Stretched & 26.90 & 0.01088 & 2433 & 0.441 & 1.64 & 42.94 \\
\hline PAP001238-1 & 3 & Al 2024 & Thin & 2.00 & Broke & 14.25 & 0.01430 & 1013 & 0.643 & 3.28 & n/a \\
\hline
\end{tabular}

\begin{tabular}{|l|l|}
\hline \multicolumn{1}{|c|}{ Measurement } & \multicolumn{1}{|c|}{ Units } \\
\hline Drop Height & inches \\
\hline Peak Time & milliseconds \\
\hline Peak Load & lb. \\
\hline Peak Defl. Time & seconds \\
\hline Peak Deflection & inches \\
\hline Impact Velocity & feet/second \\
\hline Maximum Energy & ft-lb \\
\hline
\end{tabular}




\section{APPENDIX I}

FAA DEBRIS MITIGATION PROGRAM GRC IMPACT SPECIMEN TEST PLAN AND PROCEDURE

(5 pages) 


\section{APPENDIX I \\ FAA DEBRIS MITIGATION PROGRAM \\ GRC IMPACT SPECIMEN TEST PLAN AND PROCEDURE}

\section{PURPOSE}

This test is designed to examine the behavior of aircraft structure materials under impact loading. Execution of this test will be performed by GRC, using test coupons, fixturing, and impactors provided by AlliedSignal Engines (AE). GRC will record and report relevant test data, such as strain gage response, and high-speed film imaging. GRC will also provide displacement versus time information by postprocessing the high-speed film. AE will provide an on-site test monitor.

\section{DESCRIPTION}

Aluminum and titanium curved-beam coupons will be tested via a controlled drop-hammer impactor. The drop weight shall be $500 \mathrm{lbs}$. The drop heights will vary for each test (see Table I-1). The open positions in this test matrix will be determined based upon the results of the defined tests. Complete the testing in this sequence:
(1) Configuration $\mathrm{A}$
(2) Configuration $\mathrm{C}$
(3) Configuration $\mathrm{B}$
(4) Configuration D

Table I-1. Test Drop Heights (inches) per Configuration

\begin{tabular}{|c|c|c|c|c|}
\hline $\begin{array}{c}\text { Test } \\
\text { Number }\end{array}$ & $\begin{array}{c}\text { Configuration A } \\
\text { Ti 6-4, thick section } \\
\text { PAP001237-2 }\end{array}$ & $\begin{array}{c}\text { Configuration B } \\
\text { Ti 6-4, thin section } \\
\text { PAP001238-2 }\end{array}$ & $\begin{array}{c}\text { Configuration C } \\
\text { Al 2024, thick section } \\
\text { PAP001237-1 }\end{array}$ & $\begin{array}{c}\text { Configuration D } \\
\text { Al 2024, thin section } \\
\text { PAP001238-1 }\end{array}$ \\
\hline 1 & $\mathrm{dA} 1=3.25$ & $\mathrm{~dB} 1=0.25$ & $\mathrm{dC1}=0.25$ & $\mathrm{dD} 1=0.25$ \\
\hline 2 & $\mathrm{dA} 2=15.75$ & $\mathrm{~dB} 2=0.25$ & $\mathrm{dC2}=0.50$ & $\mathrm{dD} 2=0.50$ \\
\hline 3 & $\mathrm{dA} 3=0.25$ & $\mathrm{~dB} 3=1.00$ & $\mathrm{dC} 3=1.00$ & $\mathrm{dD} 3=2.00$ \\
\hline 4 & $\mathrm{dA} 4=12.00$ & $\mathrm{~dB} 4=3.00$ & $\mathrm{dC} 4=5.00$ & - \\
\hline 5 & $\mathrm{dA} 5=8.00$ & - & - & - \\
\hline
\end{tabular}

The impact specimens are 120-degree arc segments, on an 8.0 inch diameter, and one inch wide. Two thicknesses will be tested: 0.200 inches, and 0.040 inches. See drawings PAP001237 and PAP001238, respectively. The ends are machined into "dogbone" shaped knobs for support. 
The impactor is a wedge shaped piece ending in a 0.25 inch radius. The flank angle on the nose is 35 degrees. See drawing GED-646. Supporting hardware includes the remaining items listed in Table I-2, and displayed in the referenced drawings. Table I-3 describes the impact specimens to be tested.

The baseplate provides the foundation for the test fixturing, and as the interface to the test machine installation pad. The supports are bolted to the baseplate. The channels in the top of each support cradle the insert blocks that shoulder the clamping ends of the test specimen. The lock cap secures the specimen in place, in conjunction with the cap insert. These two parts provide a resisting load to the bending moments carried at the specimen ends, as well as the rebound forces generated when the specimen fails under the impactor. The insert is a softer steel than the other supporting structure. It can yield to absorb energy from the specimen end. This piece was intended to be sacrificial in order to avoid excessive loads on the cap bolts.

Table I-2: Test Hardware Parts List.

\begin{tabular}{|l|l|c|}
\hline Ged Drawing No. & \multicolumn{1}{|c|}{ Description } & Quantity \\
\hline 638 & Baseplate & 1 \\
\hline 639 & Support & 2 \\
\hline 640 & - & - \\
\hline 641 & Assembly & - \\
\hline 642 & Inner support insert & 2 \\
\hline 643 & Outer support insert & 2 \\
\hline 644 & Specimen lock cap & 2 \\
\hline 645 & Specimen cap insert & 2 \\
\hline 646 & Impactor, blunt-nose & 1 \\
\hline $3 / 4 "-10$ by $2-1 / 2$ & Bolts - baseplate to support & 8 \\
\hline $3 / 4 "-10$ by $2-1 / 2$ & Bolts - cap insert to support & 4 \\
\hline $5 / 8 "-18$ by 1 & Bolts - cap insert “jack screws" & 4 \\
\hline
\end{tabular}

Table I-3: Test Coupon Summary

\begin{tabular}{|l|c|c|}
\hline \multicolumn{1}{|c|}{ Material } & $\begin{array}{c}\text { Quantity, Thick } \\
\text { (PAP001237) }\end{array}$ & $\begin{array}{c}\text { Quantity, Thin } \\
\text { (PAP001238) }\end{array}$ \\
\hline Al 2024-T351 & 4 & 3 \\
\hline Ti 6-4 & 4 & 4 \\
\hline
\end{tabular}




\section{ASSEMBLY}

Refer to drawing 641 for the assembly schematic.

(1) Attach the supports (item 639) to the baseplate (item 638) with eight 3/4"-10 Allen-head bolts.

(2) Set the outer support inserts in the channel on top of the support. These should be centered across the length of the channel, and set back against the support channel wall, radius facing up and out.

(3) Place the specimen (item 637) on the outer inserts, centered in the radius notch. Note that because of dimensional stackup, the specimen will not fit exactly flush at each end. Ensure that the hashmarks on the specimen side will face the high-speed camera.

(4) Slip the inner support insert (item 642) under the specimen end and into the support channel. The notch radius should align with the specimen end shoulder radius. Center and align all parts within each support channel.

(5) Hook the specimen lock cap (item 644) over the tang on the support, then place the specimen cap insert (item 645) between the specimen end and the lock cap. Be sure that the insert does not interfere with the bolt holes in the lock cap.

(6) Thread in two 3/4"-10 bolts through the bottom row of lock plate holes, into the support. Hand-tighten the bolts enough to secure the assembly.

(7) Repeat the lock plate assembly on the other support. Note: because of the stackup, additional force will be needed to push the lock cap and insert down to seat the specimen end.

(8) Double-check that the specimen, support inserts, the lock cap, and lock insert are all centered and aligned relative to the supports.

(9) Tighten all $3 / 4$ " bolts.

(10) Thread the $5 / 8$ "- 18 bolts into the lock cap and tighten. Retighten all bolts as needed to secure the assembly.

The fixture assembly will be installed in the test rig and aligned such that the impactor strikes the specimen at bottom dead center. The impactor nose surface should strike the specimen surface flush to avoid imparting a torsional moment on the specimen. The impactor should remain square to the specimen as viewed top down along the line of travel, and as viewed from the side. In other words, the impactor should be perpendicular to the specimen surface in all three viewing planes. 


\section{INSTRUMENTATION AND DATA ACQUISITION}

The specimens will be strain-gaged according to drawing 637SG. Gage leads should be restrained and led away from the specimen to the recording instrument. The leads should not interfere with the camera view. Leads should have enough restraint to avoid large motion in response to the impact.

There will be three independent data acquisition systems. The load-energy system is triggered by a detector unique to that system. The 8 channel strain gage DA system can be triggered from the load signal in parallel (with pre trigger samples). The load on this system may also be recorded to assure synchronicity with the strain gages. The instrumentation should be triggered just before impact, if possible. Ideally, the same triggering signal will start the gage recording and the highspeed camera. Record the strain gage data for a period of 10 milliseconds. Record the load versus time output from the drop-weight impactor head.

The photography will be done with high-speed film and later transferred to video for digital displacement analysis. The camera is triggered by simply pushing a button prior to dropping the impactor. An LED and simple contact switch may be connected between the striker and specimen to provide a visual timing cue for incipient load. Subsequent visual analysis can then be determined by timing. Aim the high-speed camera field of view established so that the specimen's entire range of motion will be captured (see ASSEMBLY instructions).

\section{POST-TEST DOCUMENTATION}

The following information will be documented and provided for each specimen test:

(1) Impact load versus time, preferably stored in a suitable electronic format.

(2) Strain gage data, preferably stored in a suitable electronic format.

(3) High-speed film on VHS video.

(4) Specimen displacement versus time, preferably stored in a suitable electronic format.

(5) Velocity of impactor.

(6) Still photos of the rig and specimen before fixture disassembly.

(7) Still photos of the specimen after fixture disassembly.

(8) Still photos of the fixture hardware (only if fixture damage is seen).

(9) Overlay trace of the specimen on the 1:1 scale specimen drawing (copies attached). This will provide a means of measuring permanent set, etc. 


\section{TEST PROCEDURE}

The following will serve as a test checklist.

\section{Pre-Test:}

(1) Check installation of the specimen in the fixture - hashmarks facing camera

(2) Check orientation of impactor relative to the specimen

(3) Check strain gage lead routing and hookups

(4) Check recording devices

(5) Check triggering mechanism

(6) Check high-speed camera

(7) Check impactor drop-hammer settings

\section{Post-Test:}

(1) Verify triggering of strain gages and camera

(2) Verify test parameters (impactor speed, etc.)

(3) Download and store all recorded data, as required

(4) Take photos of specimen and fixture while assembled

(5) Remove specimen from fixture

(6) Check impactor head for damage - document if necessary and replace

(7) Check all fixture pieces for damage - document if necessary and replace

(8) Take photos of specimen after removal from fixture

(9) Trace specimen pieces on pre-test specimen outline chart (see attachments)

\section{WRAP-UP}

After all testing is completed, disassemble all fixtures and ship back to AlliedSignal. Test coupons may be hand-carried back by test monitor. Use the following address:

Bob Kennelly

\section{AlliedSignal Engines}

111 S 34th St

Phoenix, AZ 85034

The test report should include all post-test documentation listed above. Also include any "lessons learned" or other observations relative to this test. These will be used for planning, defining, and improving future specimen tests. 


\section{$\triangle$ AlliedSignal}

A EROSPACE

\section{APPENDIX II \\ DRAWINGS OF TEST RIG COMPONENTS AND SPECIMENS}

(12 pages) 


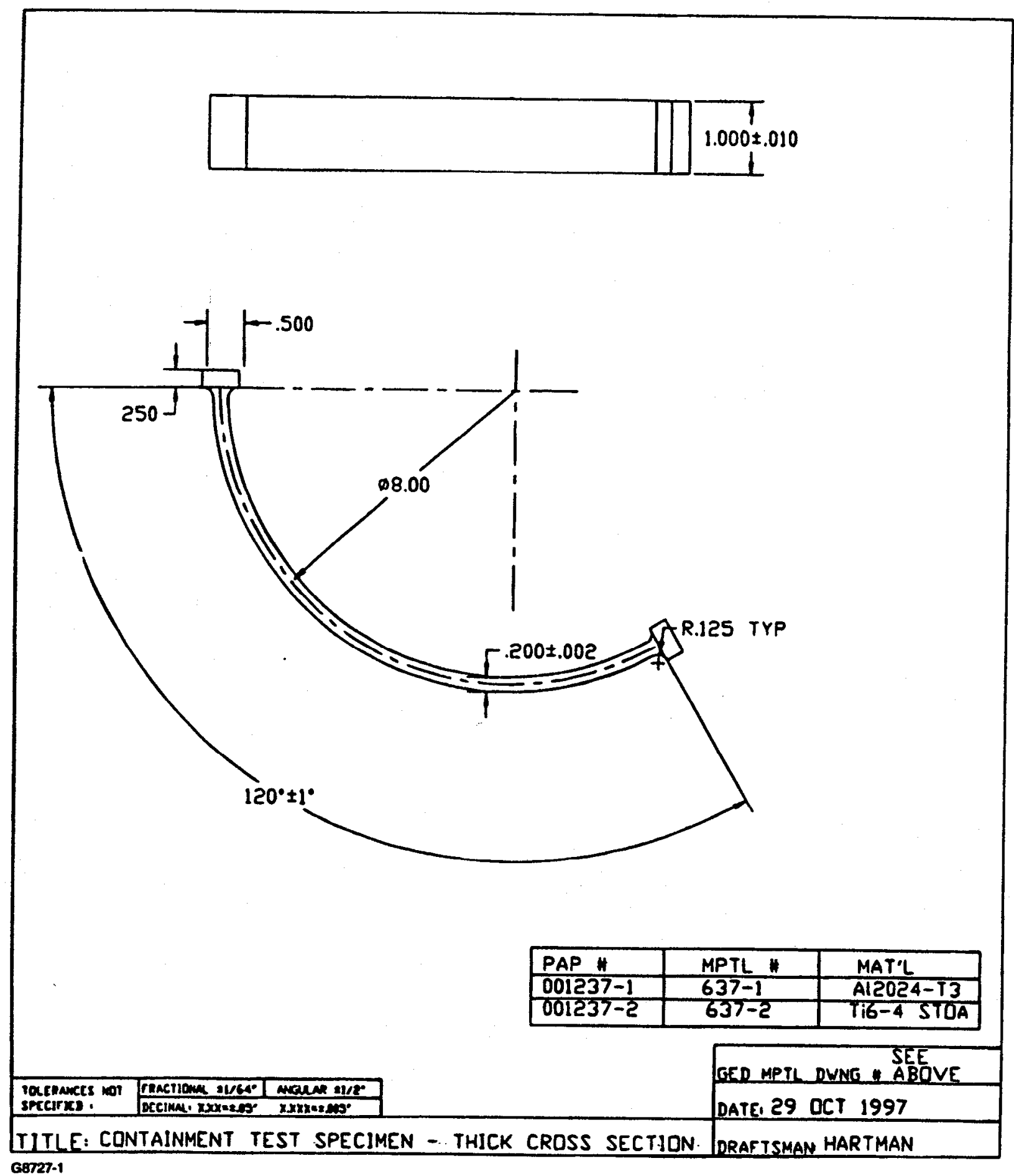

Figure II-1. Containment Test Specimen: Thick Cross Section. 


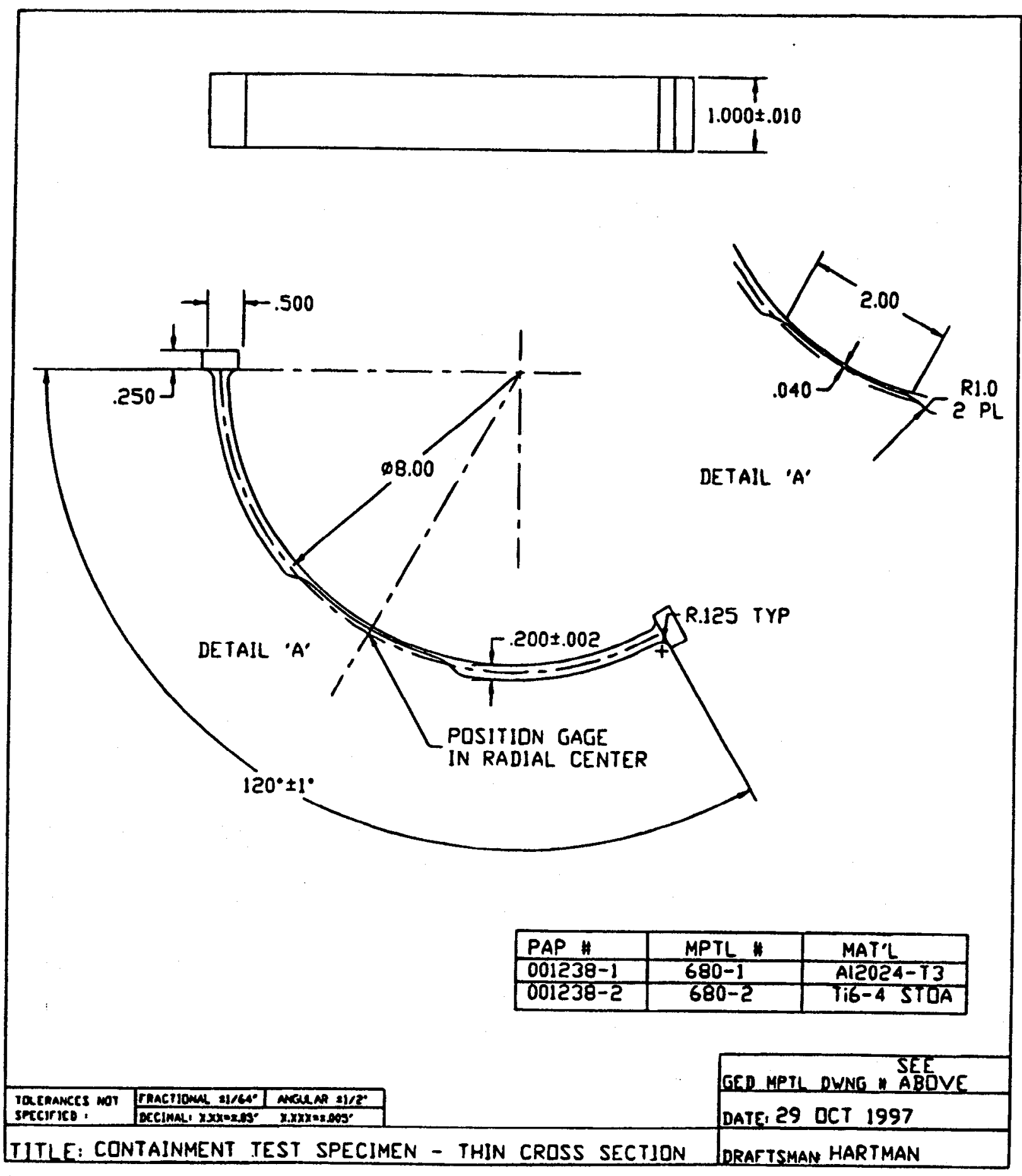

Figure II-2. Containment Test Specimen: Thin Cross Section. 


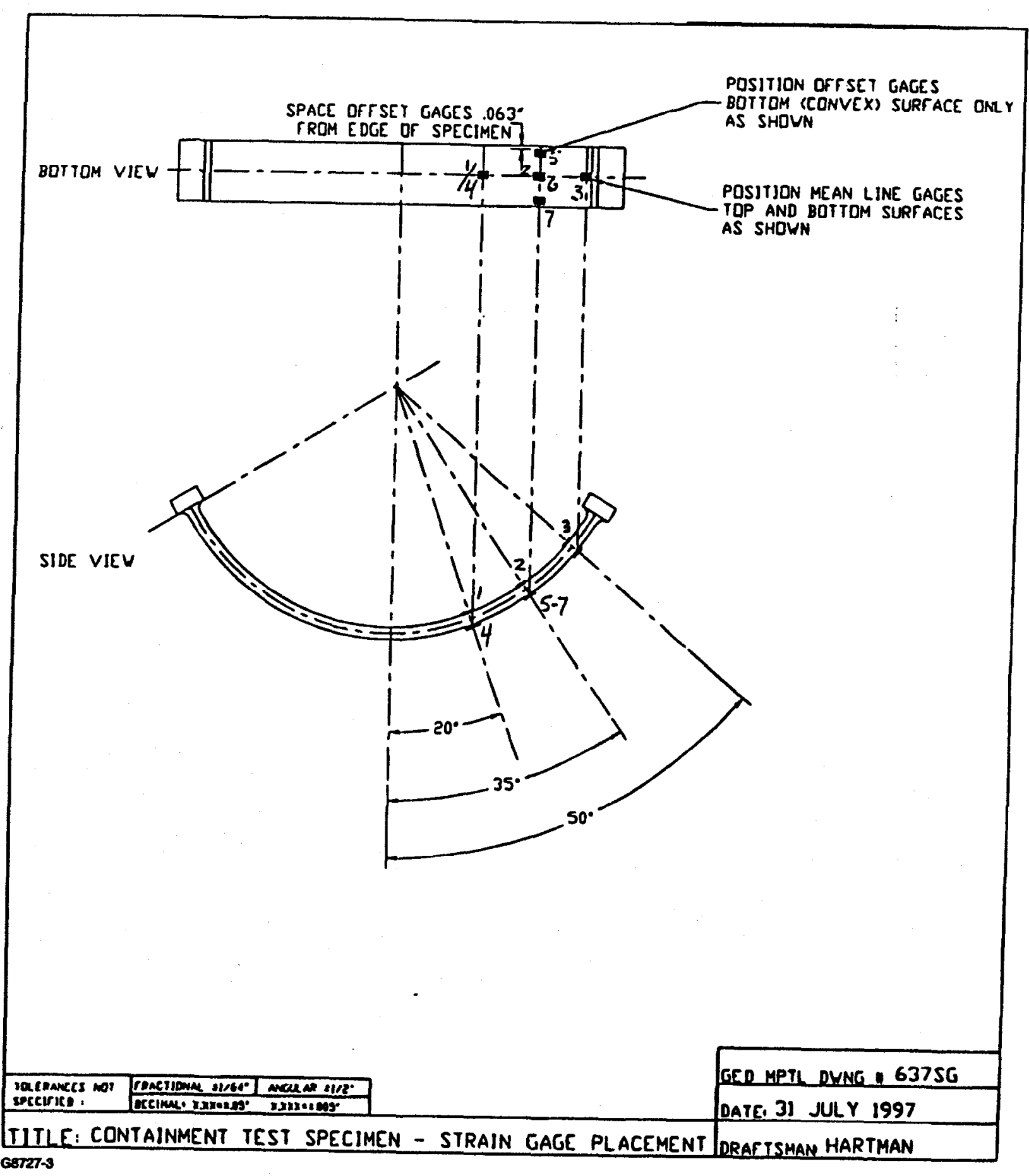

Figure II-3. Containment Test Specimen: Strain Gage Placement. 
Table II-1. Assembly List: Containment Test Fixture

\begin{tabular}{|c|c|c|c|c|c|}
\hline $\begin{array}{c}\text { Drawing } \\
\text { No. }\end{array}$ & Description & Basic Stock Size & Material & $\begin{array}{c}\text { Heat } \\
\text { Treatment }\end{array}$ & $\begin{array}{c}\text { Quantity } \\
\text { for Assembly }\end{array}$ \\
\hline 637 & Specimen & N/A & As Supplied & None & 1 \\
\hline 638 & Baseplate & $163 / 4 \times 71 / 2 \times 2$ & 4340 & Note $A$ & 1 \\
\hline 639 & Support & $5 \times 91 / 2 \times 71 / 2$ each & 4340 & Note $A$ & 2 \\
\hline 640 & No longer used & N/A & - & N/A & - \\
\hline 641 & Assembly & $\mathrm{N} / \mathrm{A}$ & - & N/A & - \\
\hline 642 & Inner Support Insert & $1 \times 11 / 25$ each & $\mathrm{C} 250$ & Note C & 2 \\
\hline 643 & Outer Support Insert & $1 \times 1 \times 5$ each & C250 & Note C & 2 \\
\hline 644 & Specimen Lock Cap & $5 \times 51 / 2 \times 13 / 4$ & 4340 & Note A & 2 \\
\hline 645 & Specimen Cap Insert & $5 \times 13 / 4 \times 1 / 4$ & 4340 & Note B & 2 \\
\hline 646 & tup & $4 \times 4 \times 11 / 2$ & $\mathrm{C} 250$ & Note C & 1 \\
\hline Note A: & \multicolumn{5}{|c|}{$\begin{array}{l}\text { 4340.Heat Treatment for High Strength (approximately } 46 \mathrm{HRC} \text { ) } \\
\text { Anneal at } 1550 \mathrm{~F} 1 \mathrm{hr} \text {, Furnace Cool } \\
\text { Harden at } 1550 \mathrm{~F} 15 \mathrm{~min} / \mathrm{in}, \mathrm{H} 2 \mathrm{O} \text { Cool } \\
\text { Temper at } 800 \mathrm{~F}, 1 \mathrm{hr} \text {, Air Cool }\end{array}$} \\
\hline Note B: & \multicolumn{5}{|c|}{$\begin{array}{l}4340 \text { Heat Treatment for High Ductility (approximately } 24 \mathrm{HRC} \text { ) } \\
\text { Anneal at } 1550 \mathrm{~F} 1 \mathrm{hr} \text {, Furnace Cool } \\
\text { Harden at } 1550 \mathrm{~F} 15 \mathrm{~min} / \mathrm{in}, \mathrm{H} 2 \mathrm{O} \text { Cool } \\
\text { Temper at } 130 \mathrm{~F}, 1 \mathrm{hr} \text {, Air Cool }\end{array}$} \\
\hline Note C: & \multicolumn{5}{|c|}{$\begin{array}{l}\text { C250 Standard Heat Treatment (HRC } 48 \text { to 54) } \\
\text { Solution at } 1750 \mathrm{~F} 1 \mathrm{hr} \text {, Air Cool to below 200F } \\
\text { Re-Solution at } 1450 \mathrm{~F}, 1 \mathrm{hr} / \mathrm{in} \text {, Air Cool to RT } \\
\text { Age at } 850 \mathrm{~F}, 1 \mathrm{hr} \text {, Air Cool to RT }\end{array}$} \\
\hline
\end{tabular}




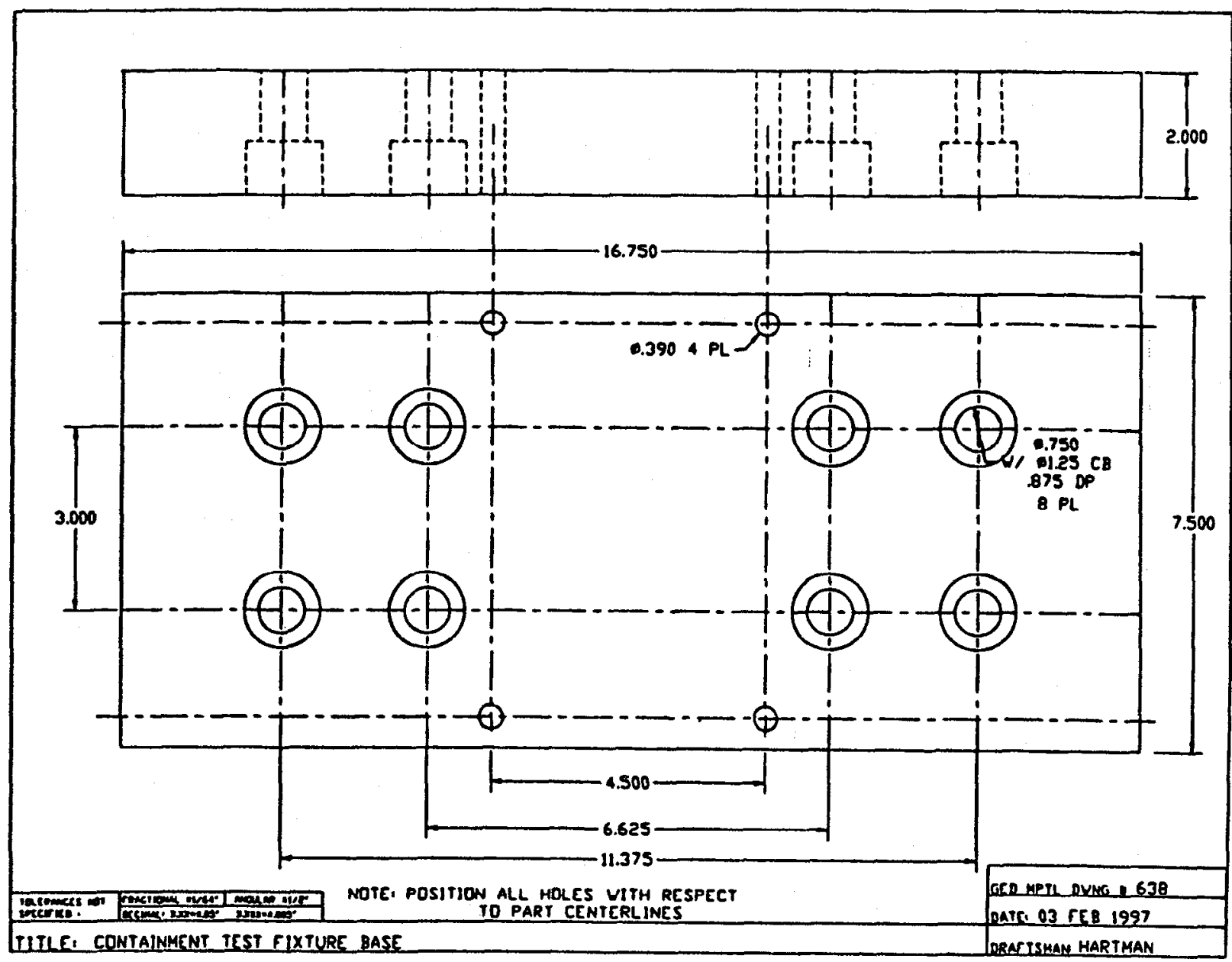

Figure II-4. Containment Test Fixture Base. 


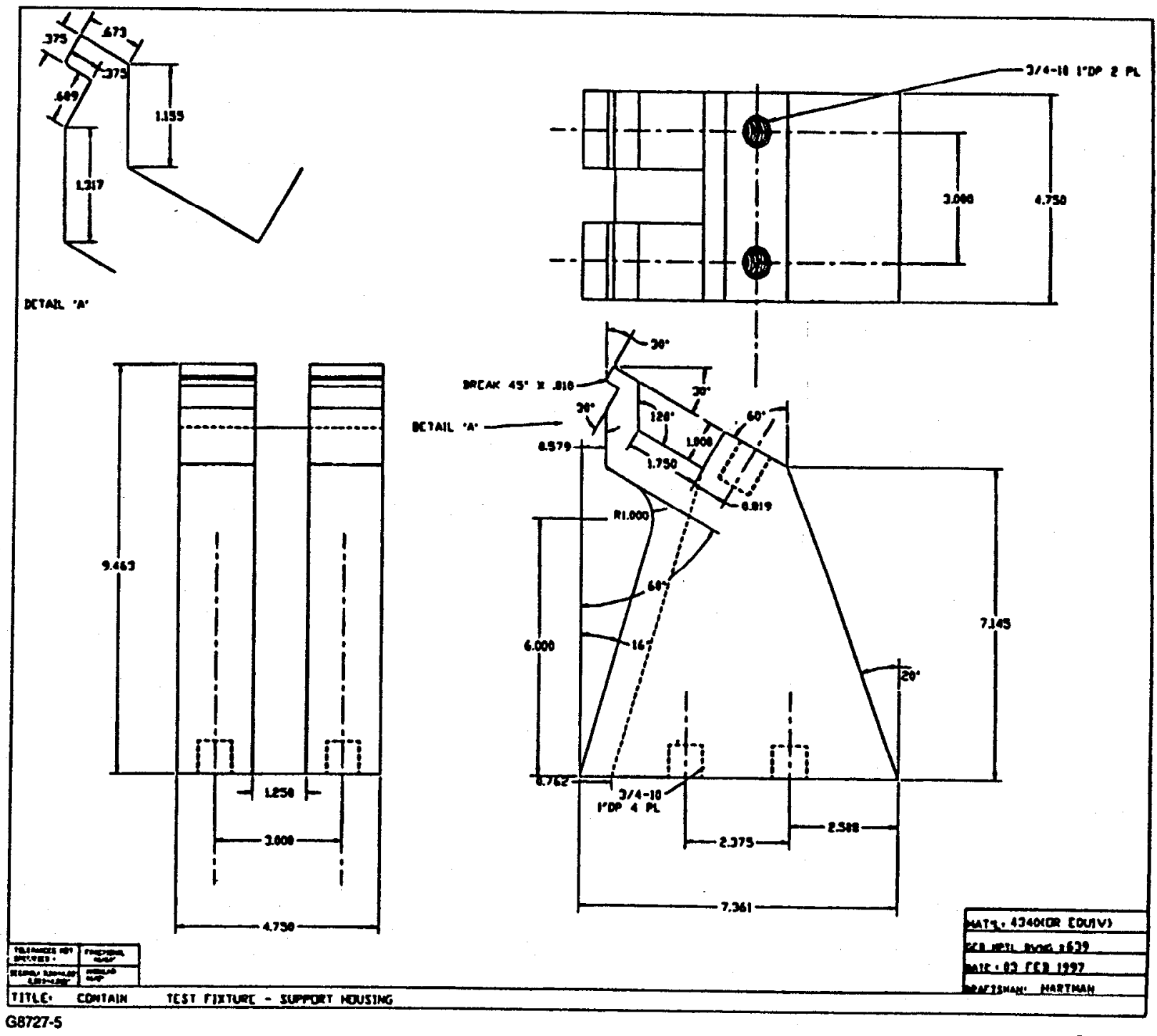

Figure II-5. Containment Test Fixture: Support Housing. 


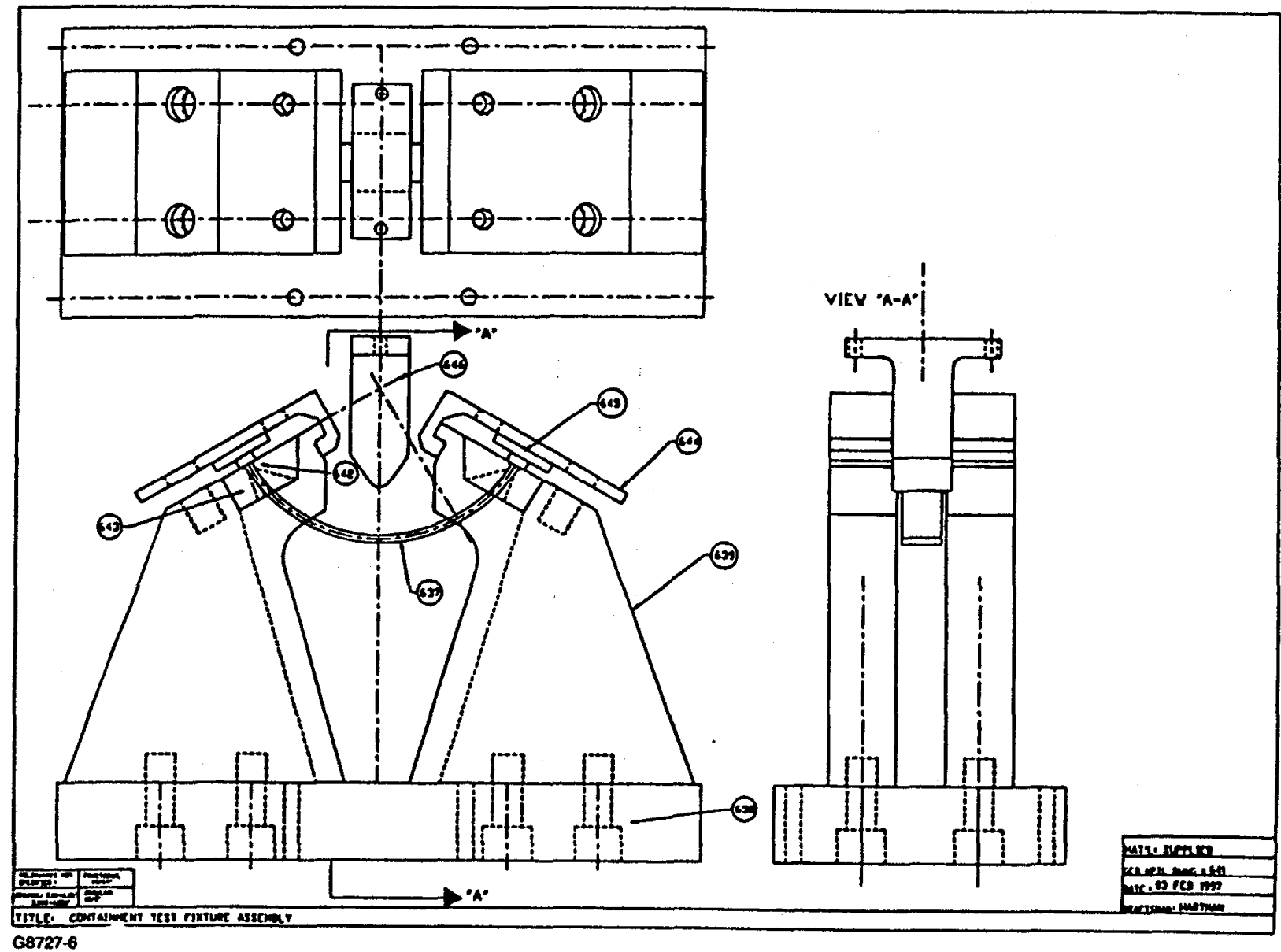

Figure II-6. Containment Test Fixture Assembly. 

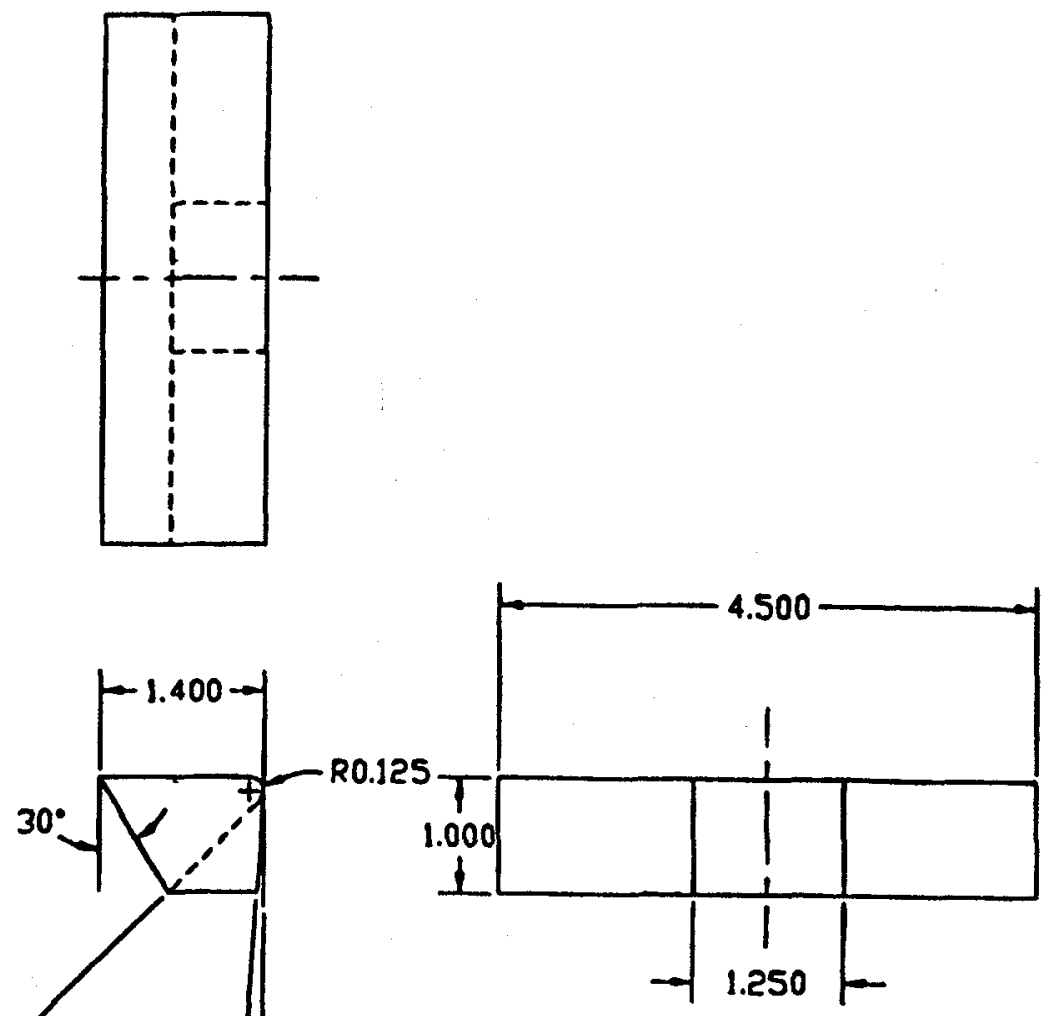

$3.7-10$

$45^{\circ}$

$\rightarrow$

MAT'L. MARAGING STEEL

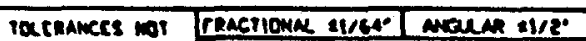

GED MPTL DYMG 642

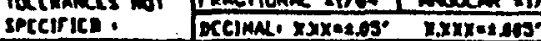

DATEI 25 JAN 1997

TITLE: CONTAINMENT TEST FIXTURE - INNER SUPPDRT INSERT IDRAFTSMAN HARTMAN 68727.7

Figure II-7. Containment Test Fixture: Inner Support Insert. 

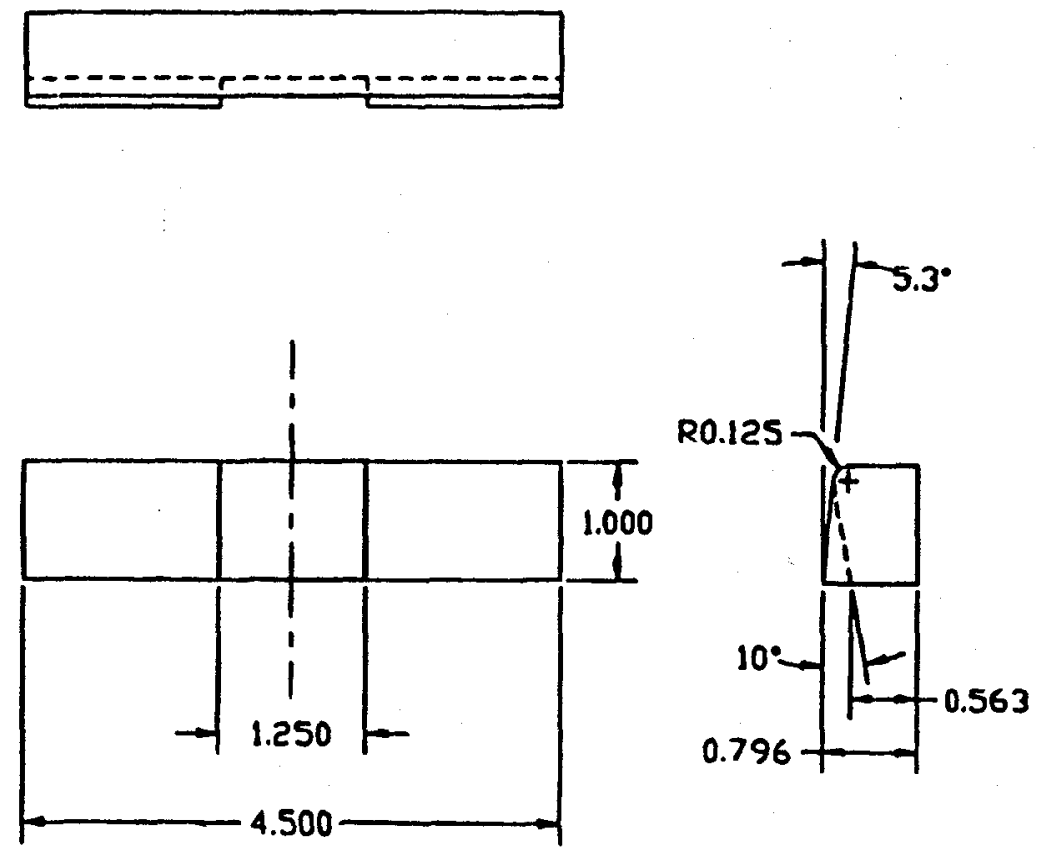

MAT'L. MARAGING STEEL

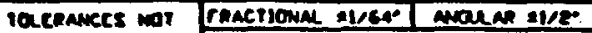

GED MPTL DWNG 1643

secarres

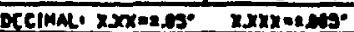

DATE.25 JAN 1997

ITITLE, CONTAINMENT TEST FIXTURE - DUTER SUPPORT INSERT/DRAFTSMAN HARTMAN

Figure II-8. Containment Test Fixture: Outer Support Insert. 


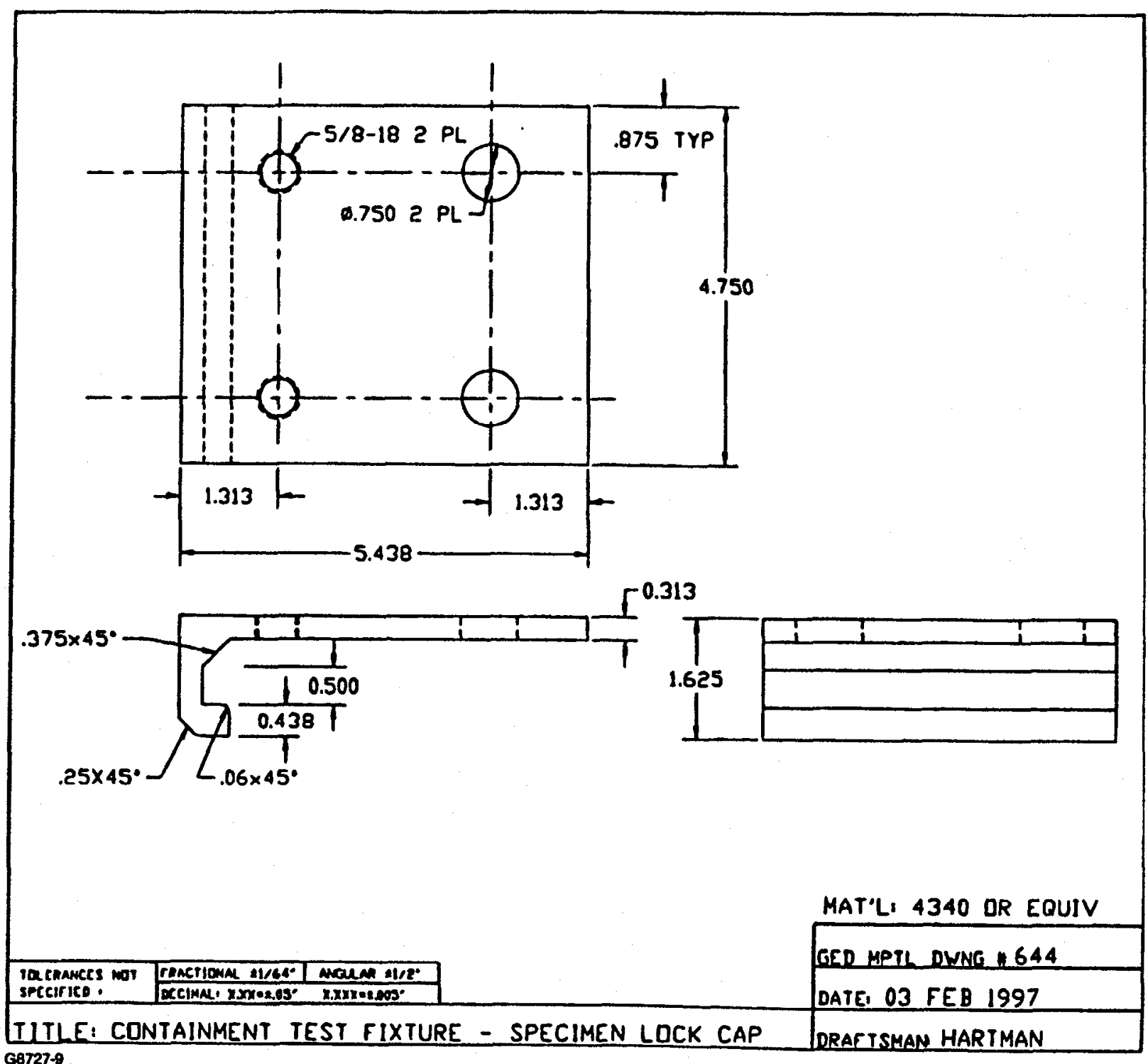

Figure II-9. Containment Test Fixture: Specimen Lock Cap. 

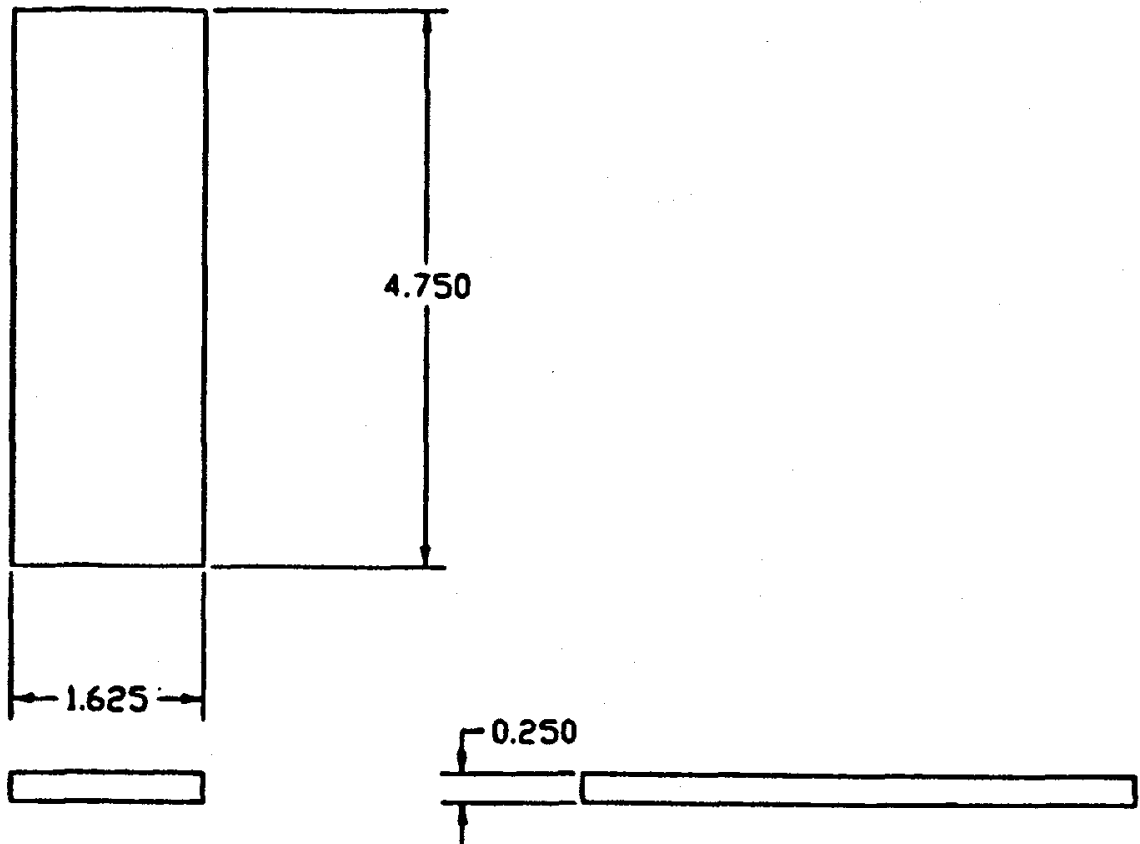

MAT'LI 4340 DR EQUIV

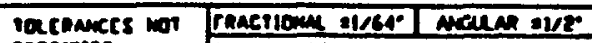

GED MPTL DWNG 645

secerics.

TITLE, CDNTAINMENT TEST FIXTURE - SPECIMEN CAP INSERT IDRAFTSMAN HARTMAN 68727-10

Figure II-10. Containment Test Fixture, Specimen Cap Insert. 

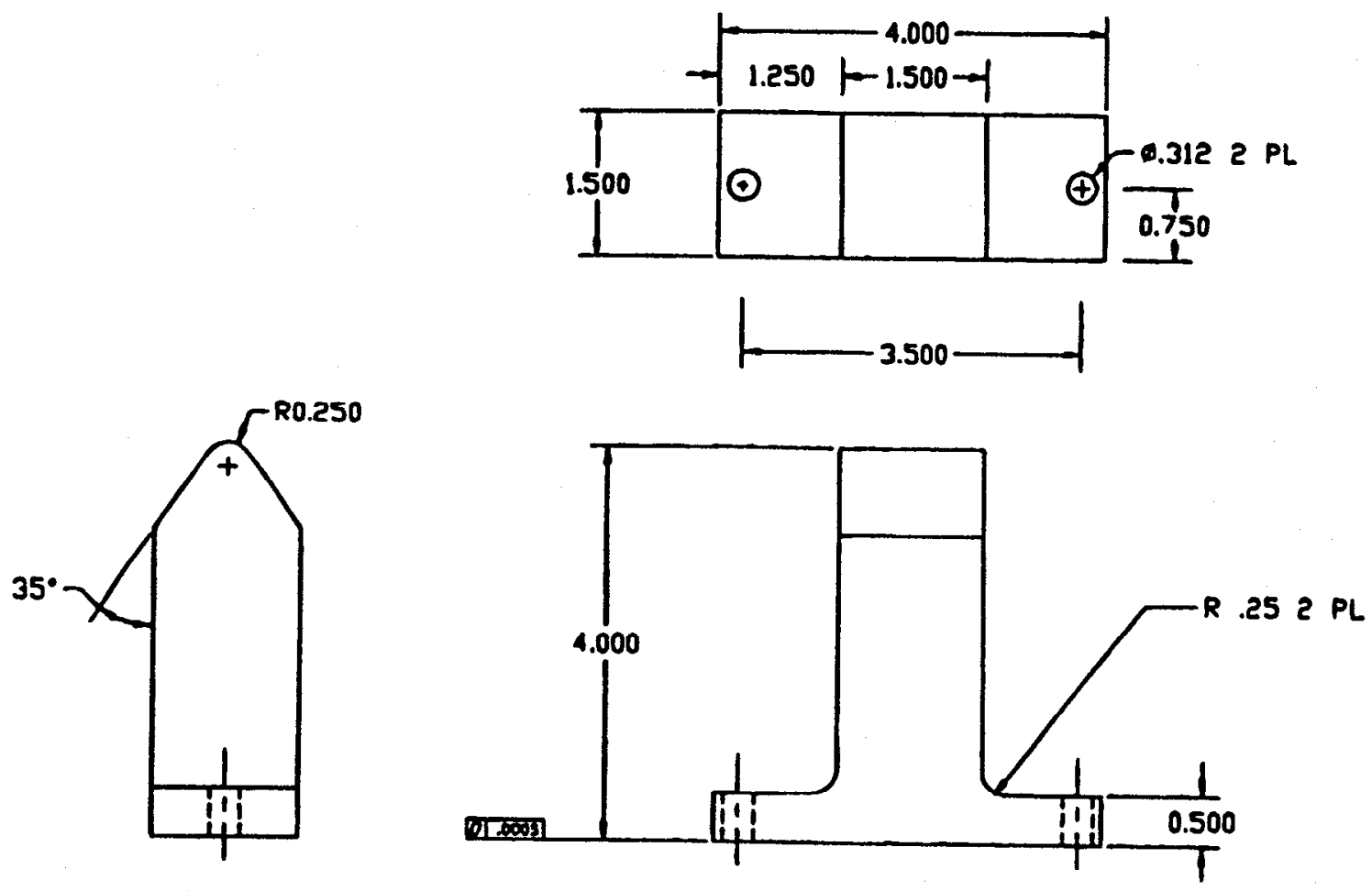

Figure II-11. Containment Test Fixture: TUP. 
APPENDIX III

PHOTOGRAPHS OF FOUR SPECIMENS

BEFORE TESTING

(2 pages)

III-i 


\section{Allied Signal}

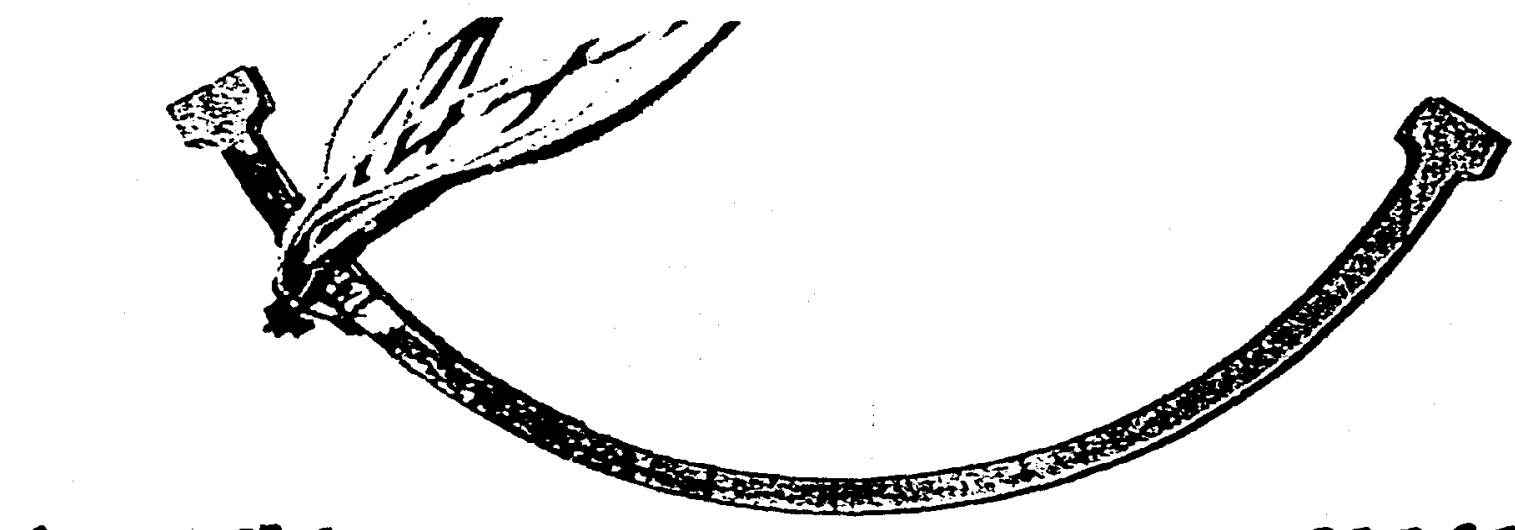

PAPOO1237-2

$S / N 1$

Ti $6-4$

4-21-98

BEFORE

Figure III-1. Thick Titanium 6-4 Sample.

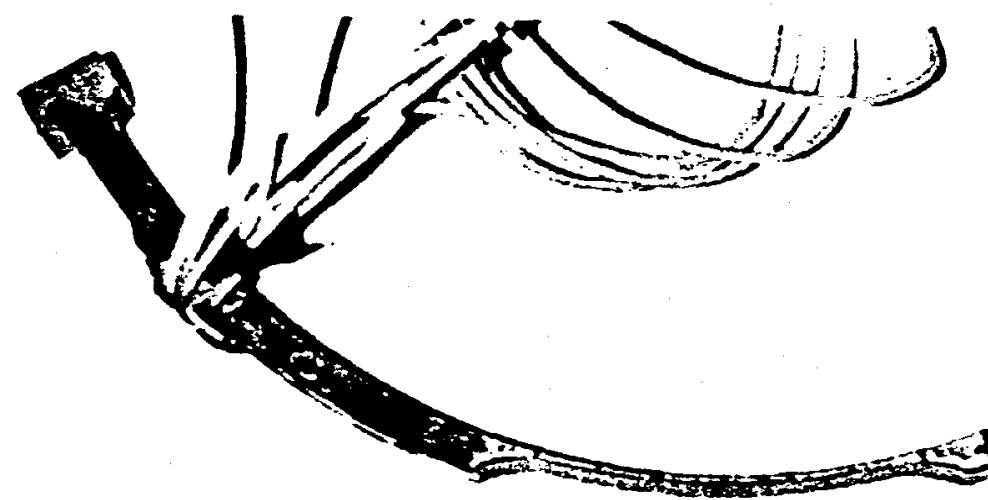

BEFORE

$$
\begin{aligned}
& \text { APODIO38-2 } \\
& \text { SIN 1 } \\
& T i 6-4 \\
& 4-22-9 P
\end{aligned}
$$

Figure III-2. Thin Titanium 6-4 Sample. 
AlliedSignal

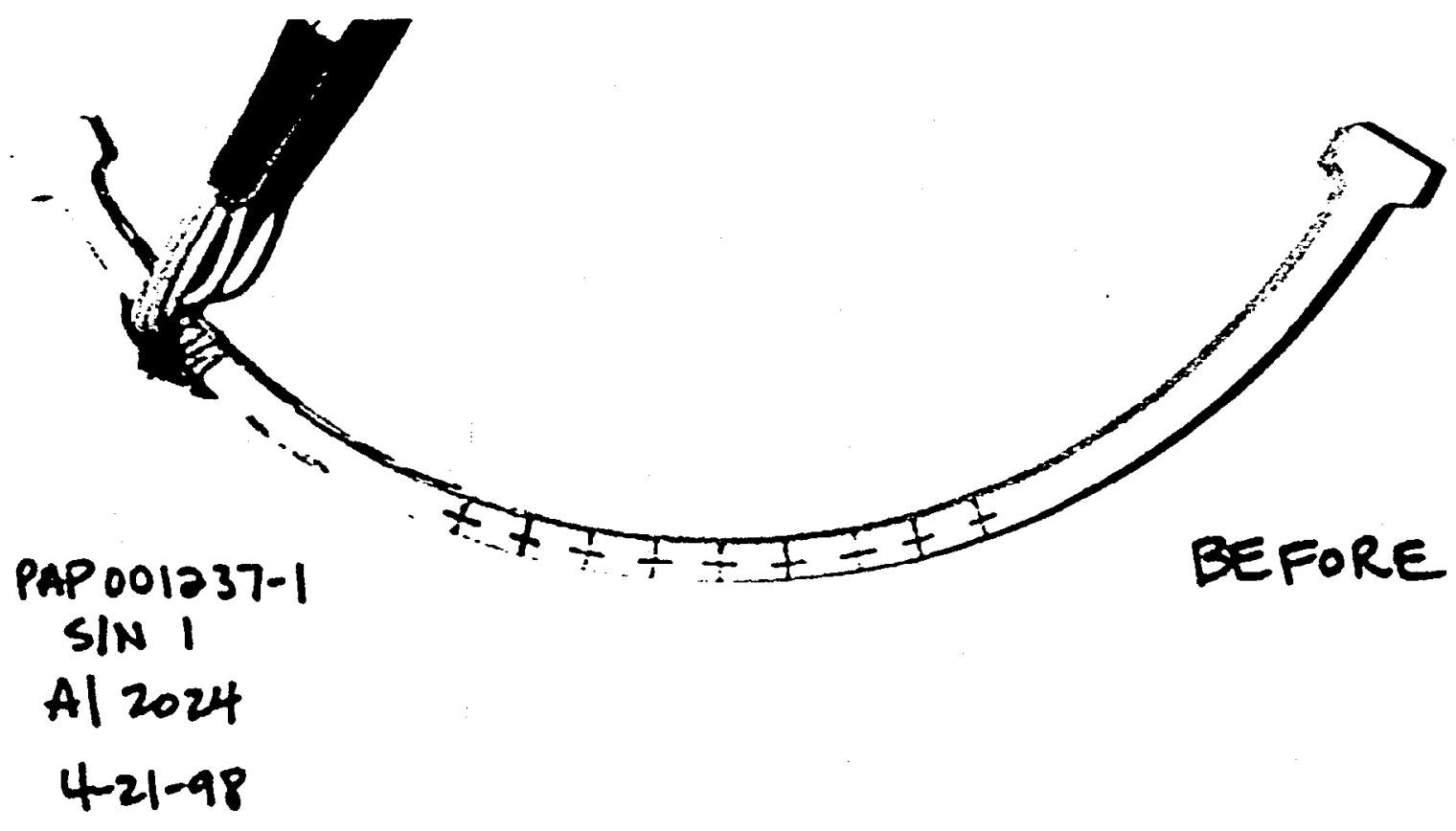

Figure III-3. Thick Aluminum 2024 Sample.

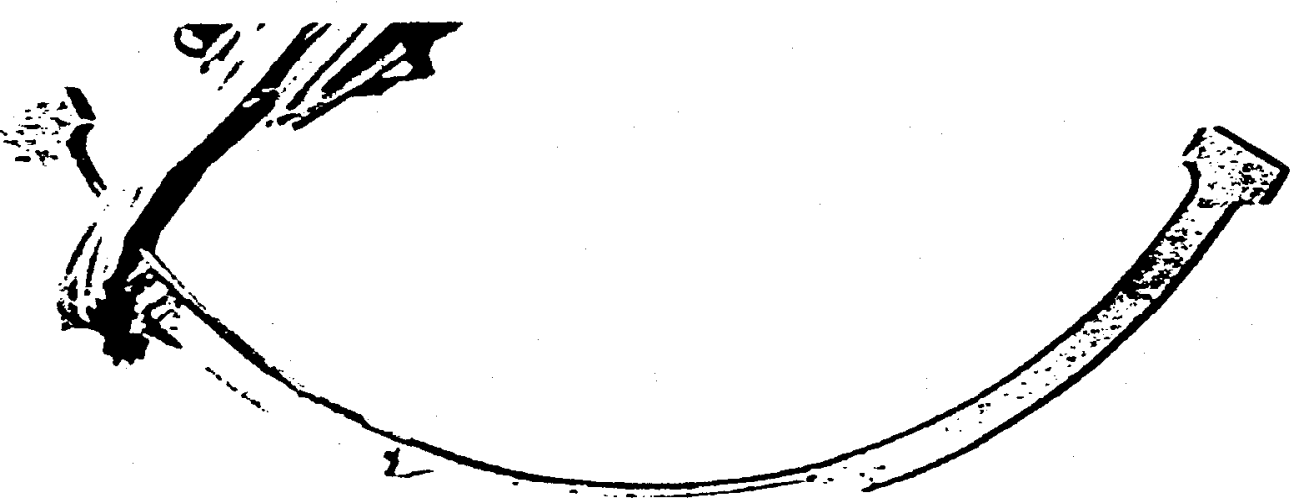

BEFORE

$$
\begin{aligned}
& \text { PAP DON 23i-1 } \\
& \text { SiN } 1 \\
& A 12024 \\
& 4=22-98
\end{aligned}
$$

Figure III-4. Thin Aluminum 2024 Sample.

$$
\text { 21-10392 }
$$

III-2 
AlliedSignal

\begin{abstract}
APPENDIX IV
PICTURES OF FOUR SPECIMENS ON TEST RIG

BEFORE TEST

(4 pages)
\end{abstract}




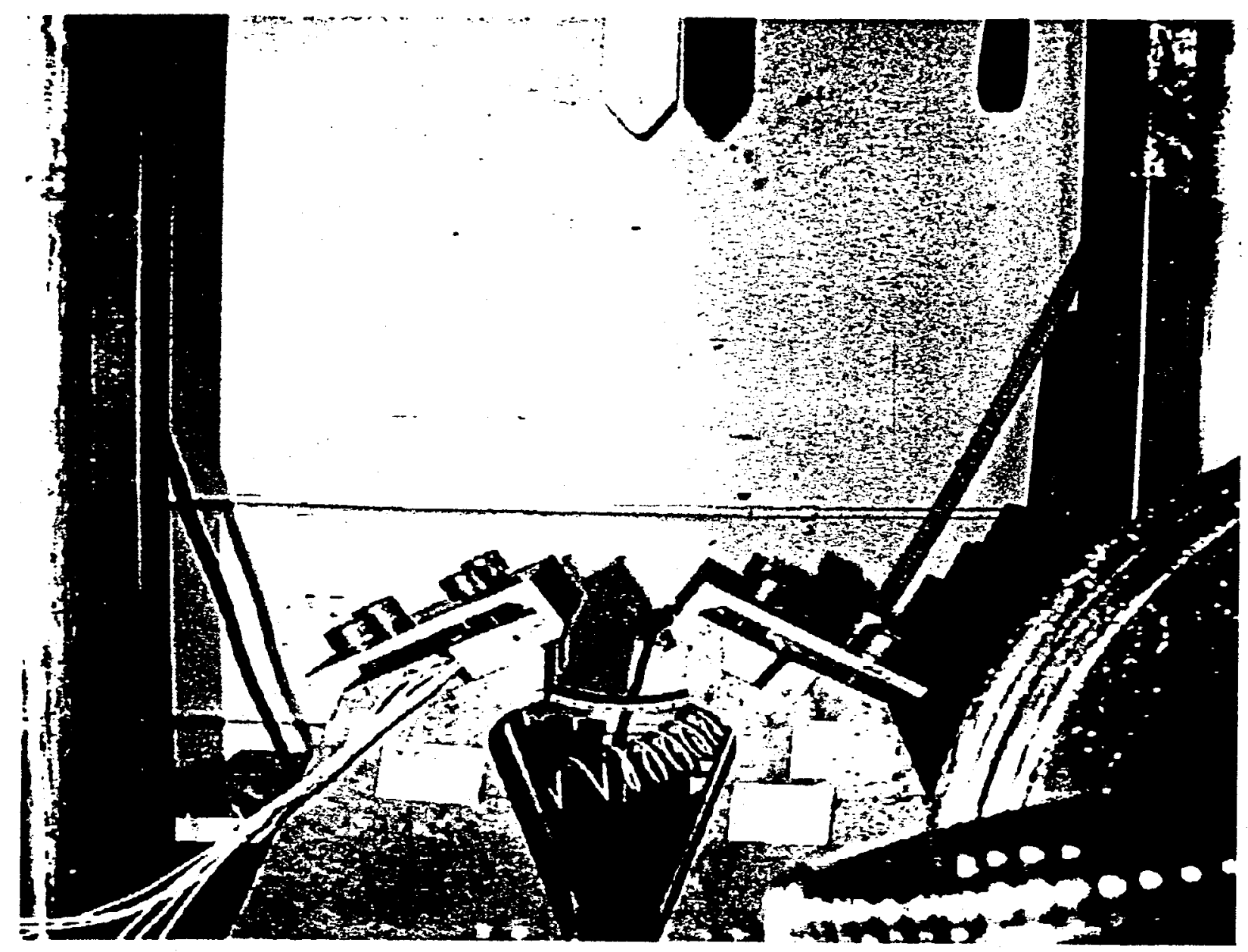

Figure IV-1. Thick Titanium 6-4 Sample Test Setup - Before Test No. 3. 


\section{AlliedSignal}

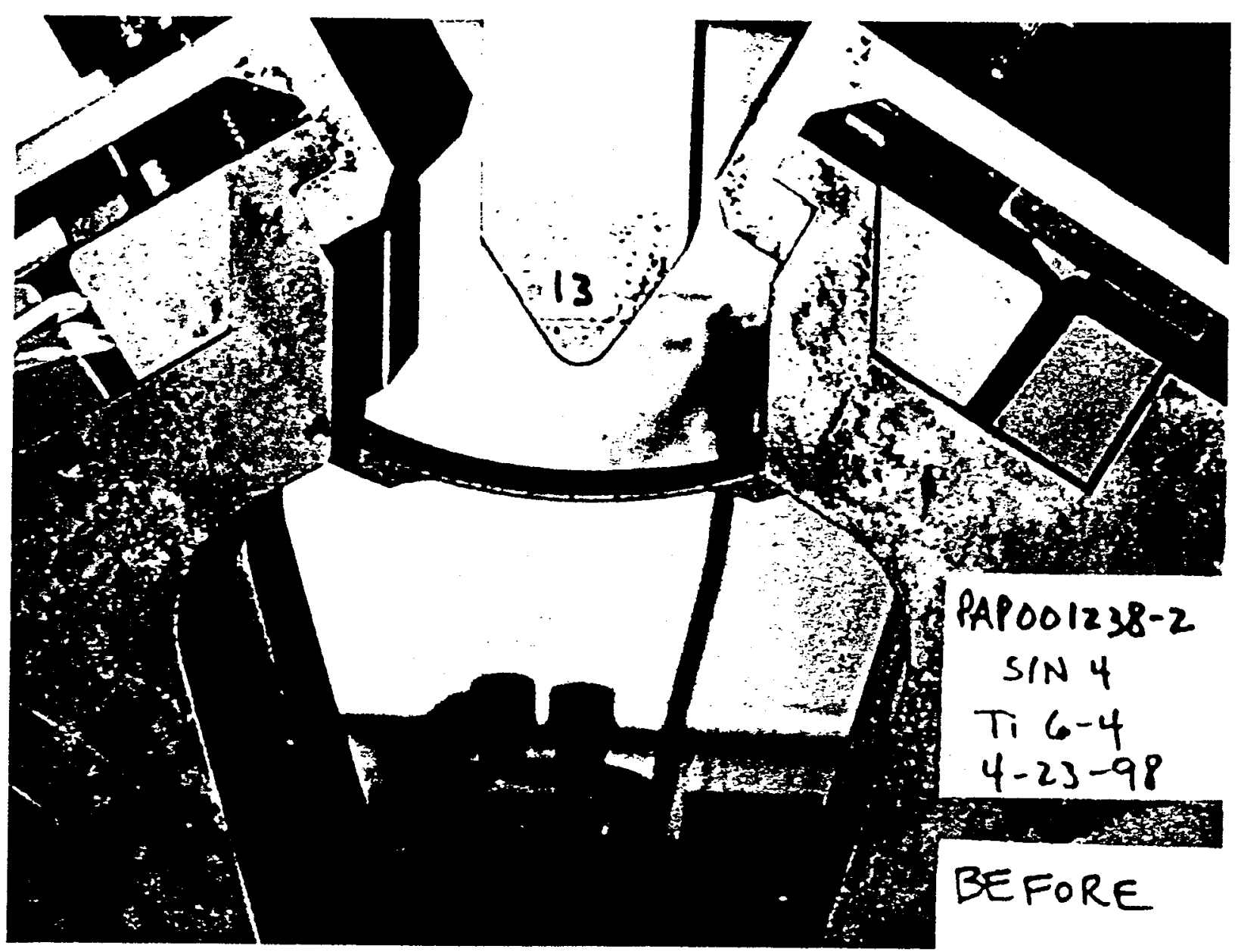

Figure IV-2. Thin Titanium 6-4 Sample Test Setup - Before Test No. 13. 


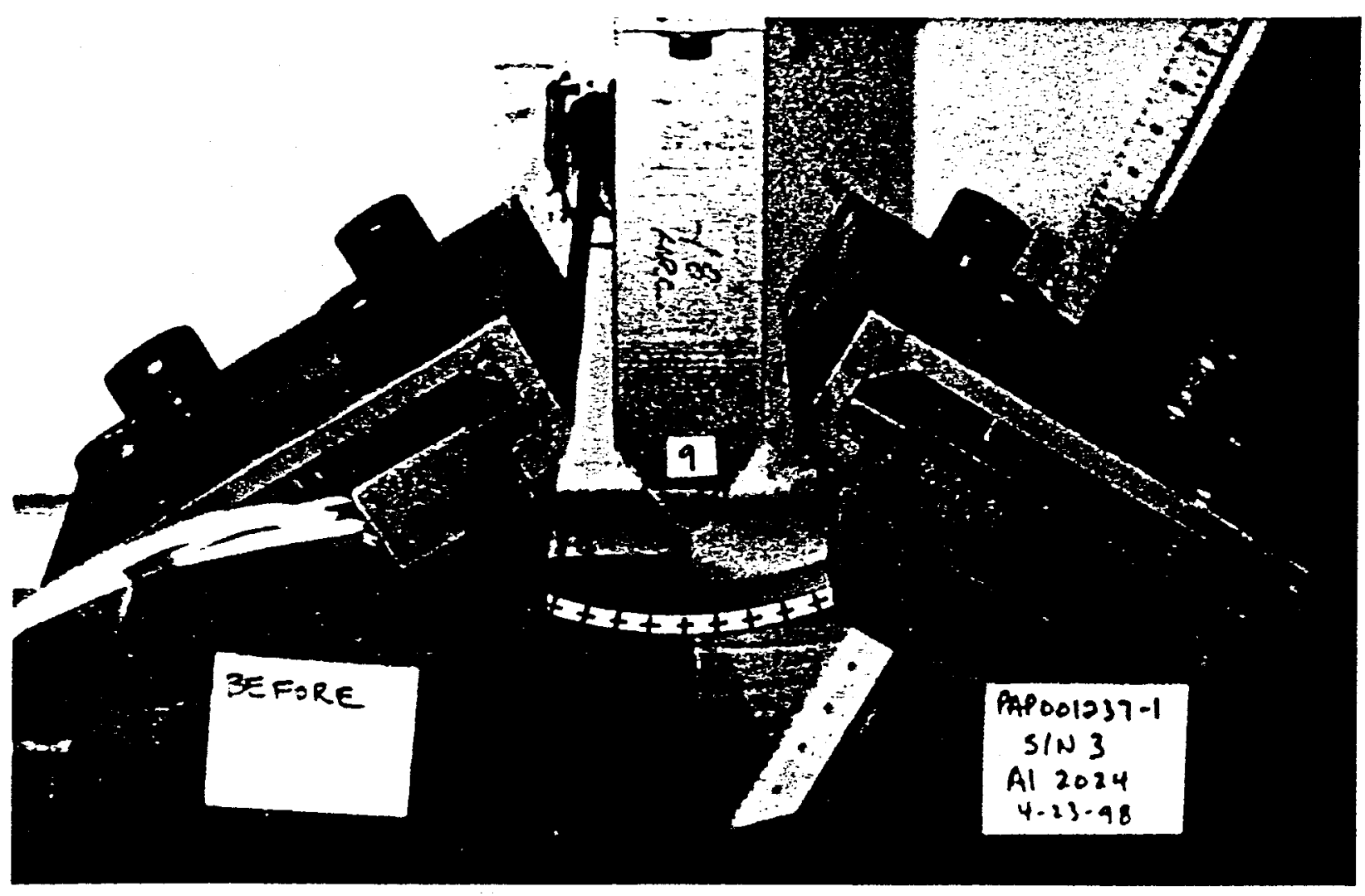

Figure IV-3. Thick Aluminum 2024 Sample Test Setup - Before Test No. 9. 


\section{AlliedSignal}

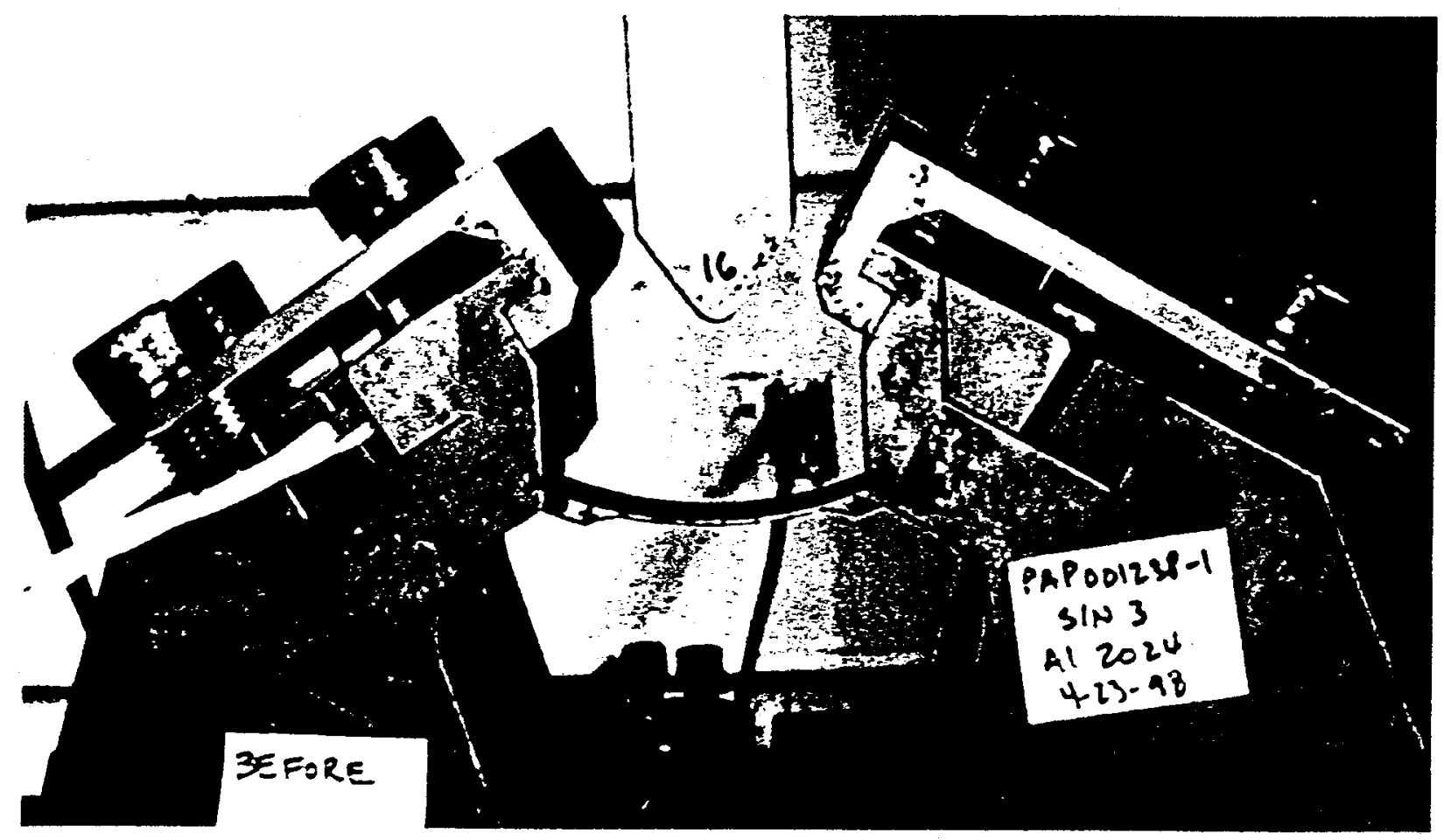

Figure IV-4. Thin Aluminum 2024 Sample Test Setup - Before Test No. 16. 


\section{AlliedSignal}

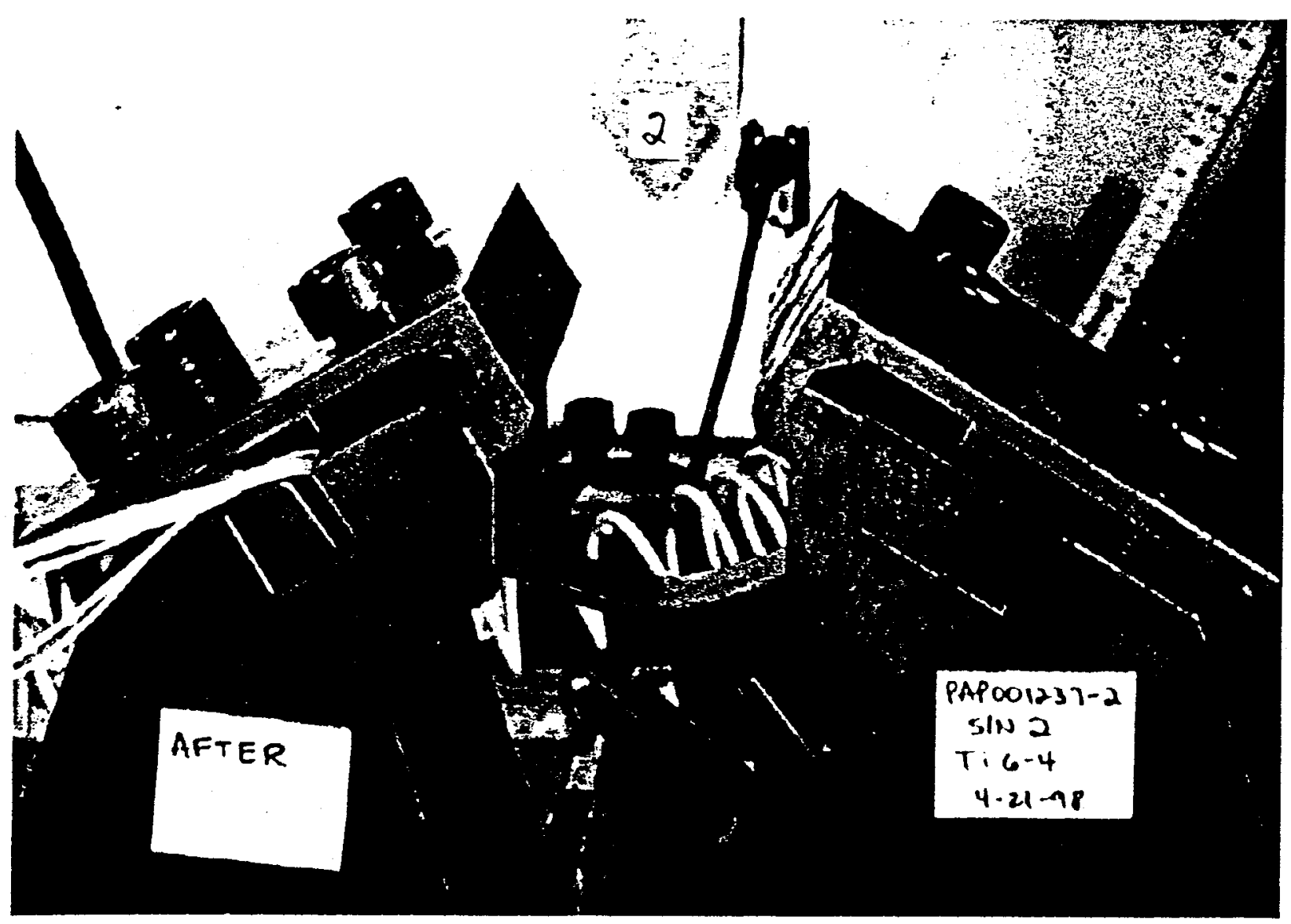

Figure V-1. PAP001237-2 S/N 2: Thick Titanium 6-4 Sample After Test Run No. 2, Drop Height 3.25 Inches. 


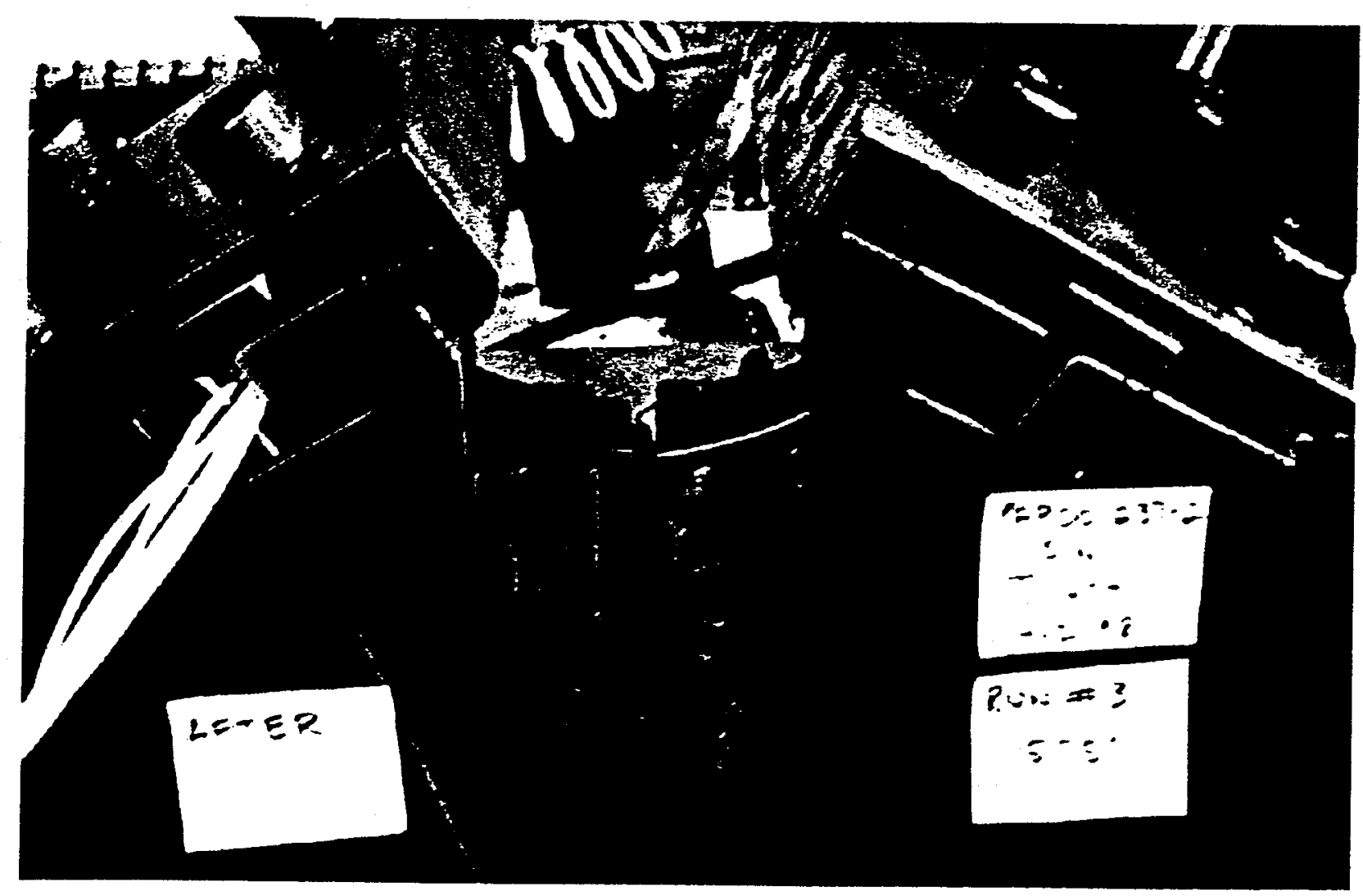

Figure V-2. PAP001237-2 S/N 1: Thick Titanium 6-4 Sample After Test Run No. 3, Drop Height 15.75 Inches. 


\section{AlliedSignal}

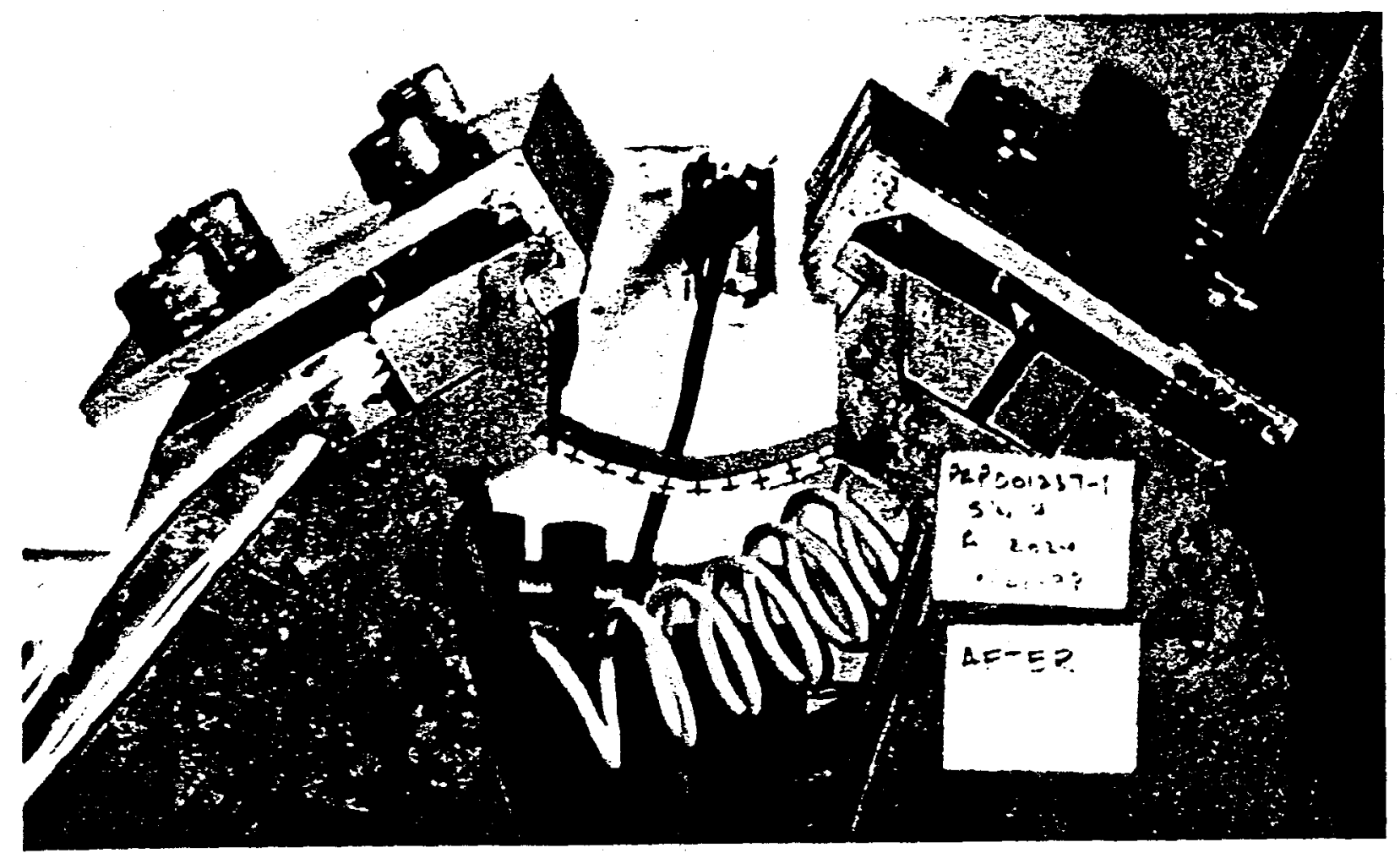

Figure V-3. PAP001237-1 S/N 4: Thick Aluminum 2024 Sample After Test Run No. 5, Drop Height 0.50 Inch. 


\section{$\Delta$ NliedSignal

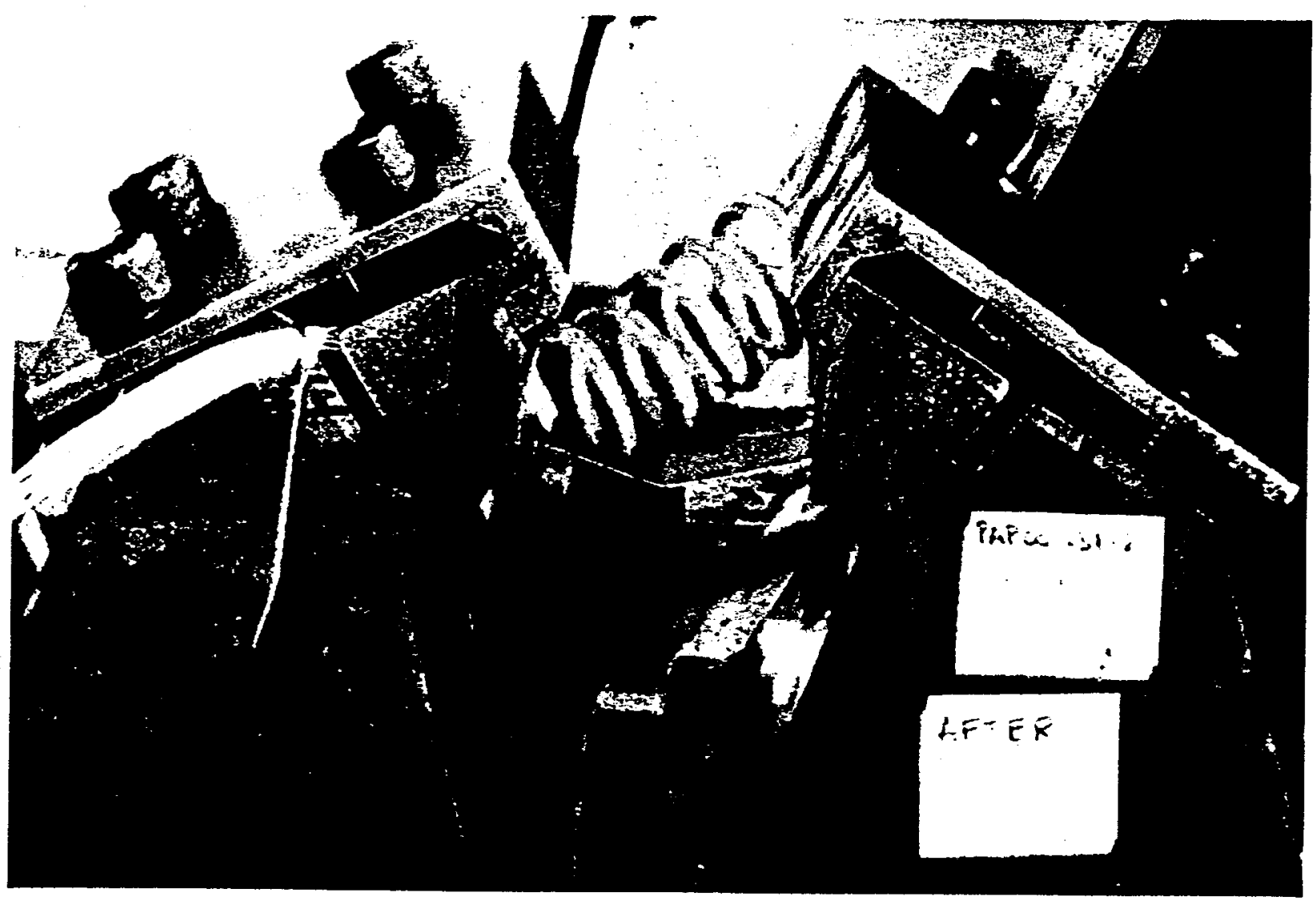

Figure V-4. PAP001238-2 S/N 2: Thin Titanium 6-4 Sample After Test Run No. 6, Drop Height 0.25 Inch. 


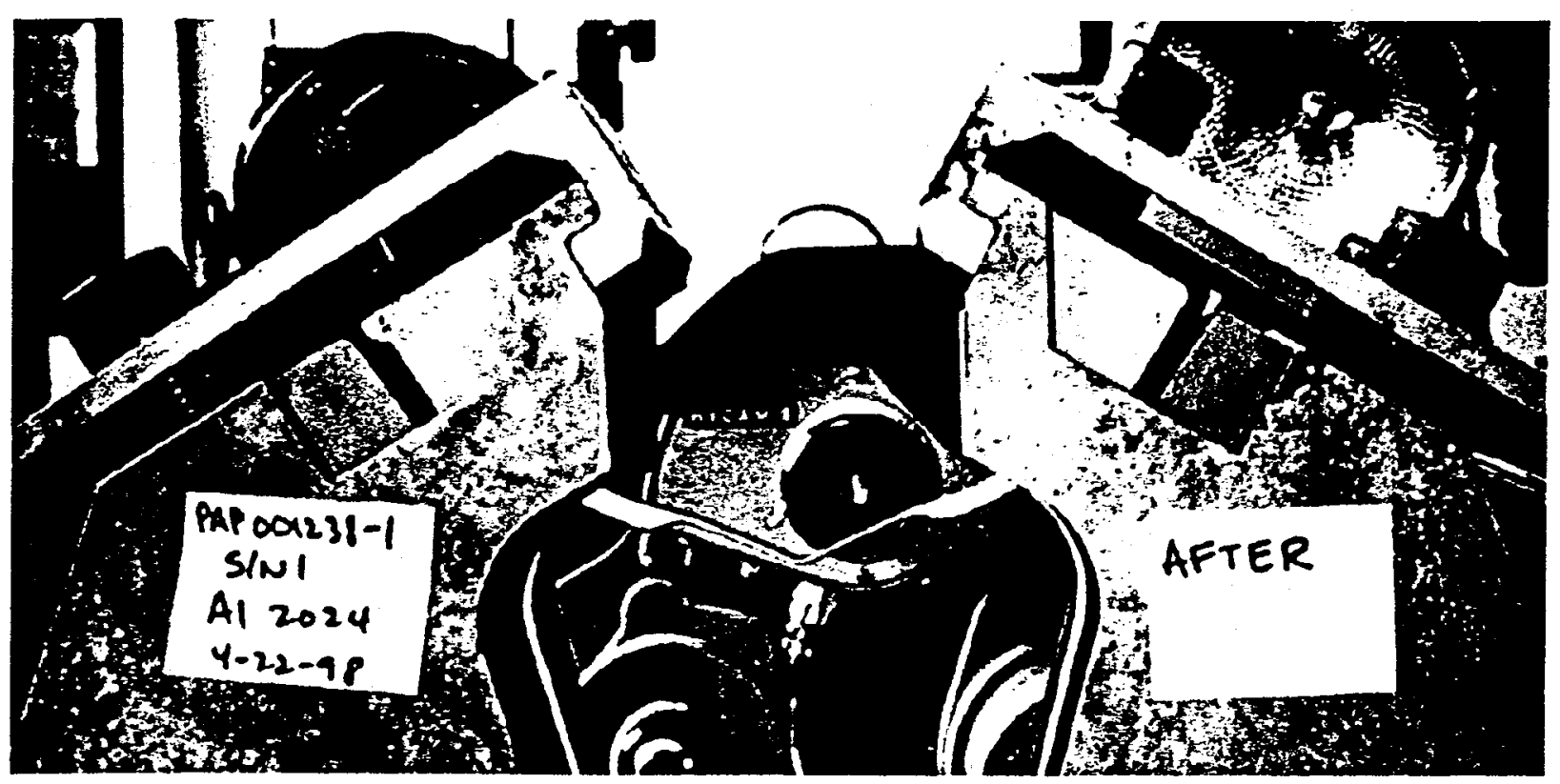

Figure V-5. PAP001238-1 S/N 1: Thin Aluminum 2024 Sample After Test Run No. 7, Drop Height 0.25 Inch.

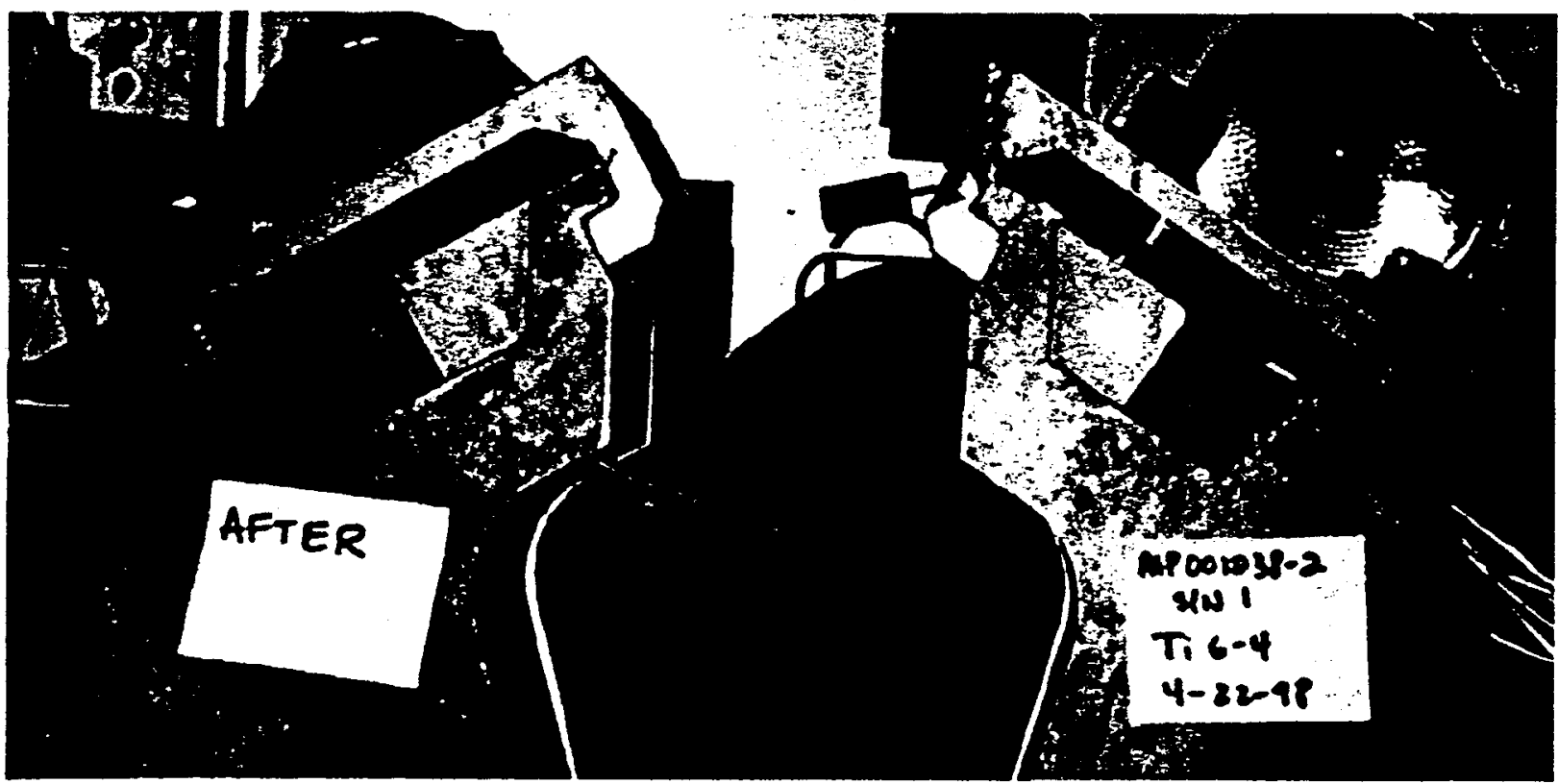

Figure V-6. PAP001238-2 S/N 1: Thin Titanium 6-4 Sample After Test Run No. 8, Drop Height, 0.25 Inch. 


\section{$\Delta$ SlliedSignal \\ A E IOS PACE}

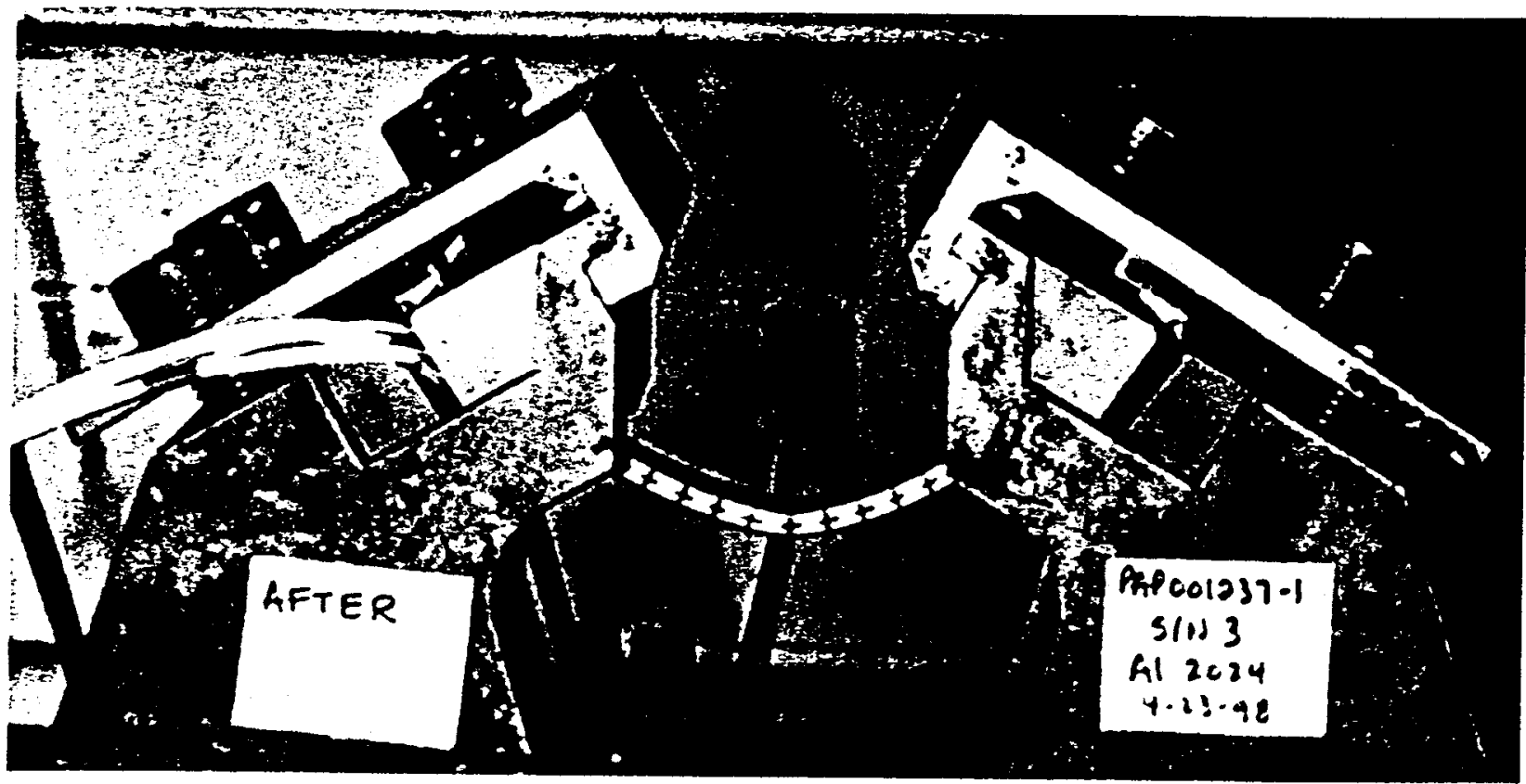

Figure V-7. PAP001237-1 S/N 3: Thick Aluminum 2024 Sample After Test Run No. 9, Drop Height 1.00 Inch.

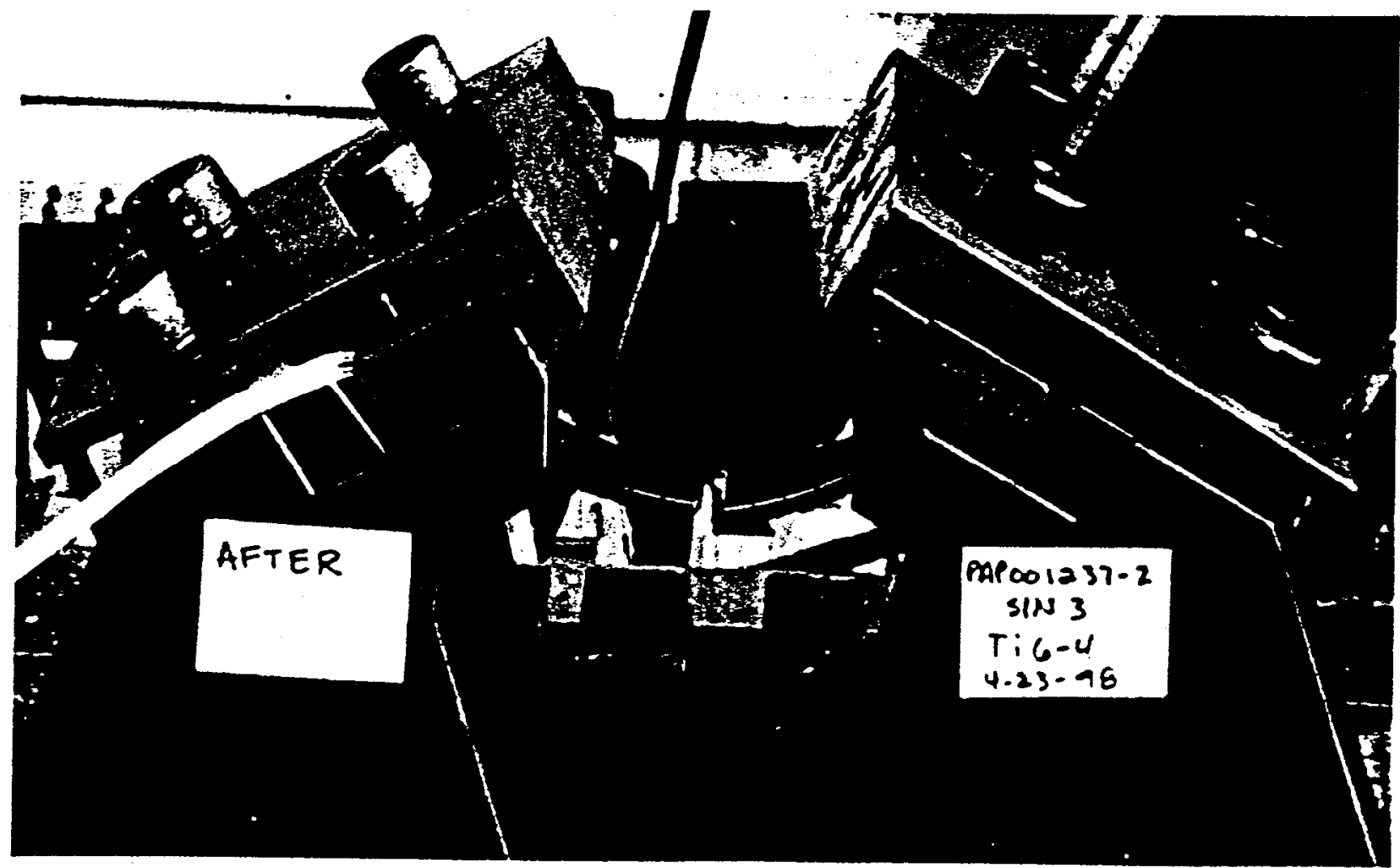

Figure V-8. PAP001237-2 S/N 3: Thick Titanium 6-4 Sample After Test Run No. 10, Drop Height 12.00 Inches.

$$
\underset{\substack{21-10392 \\ \text { V-6 }}}{2}
$$




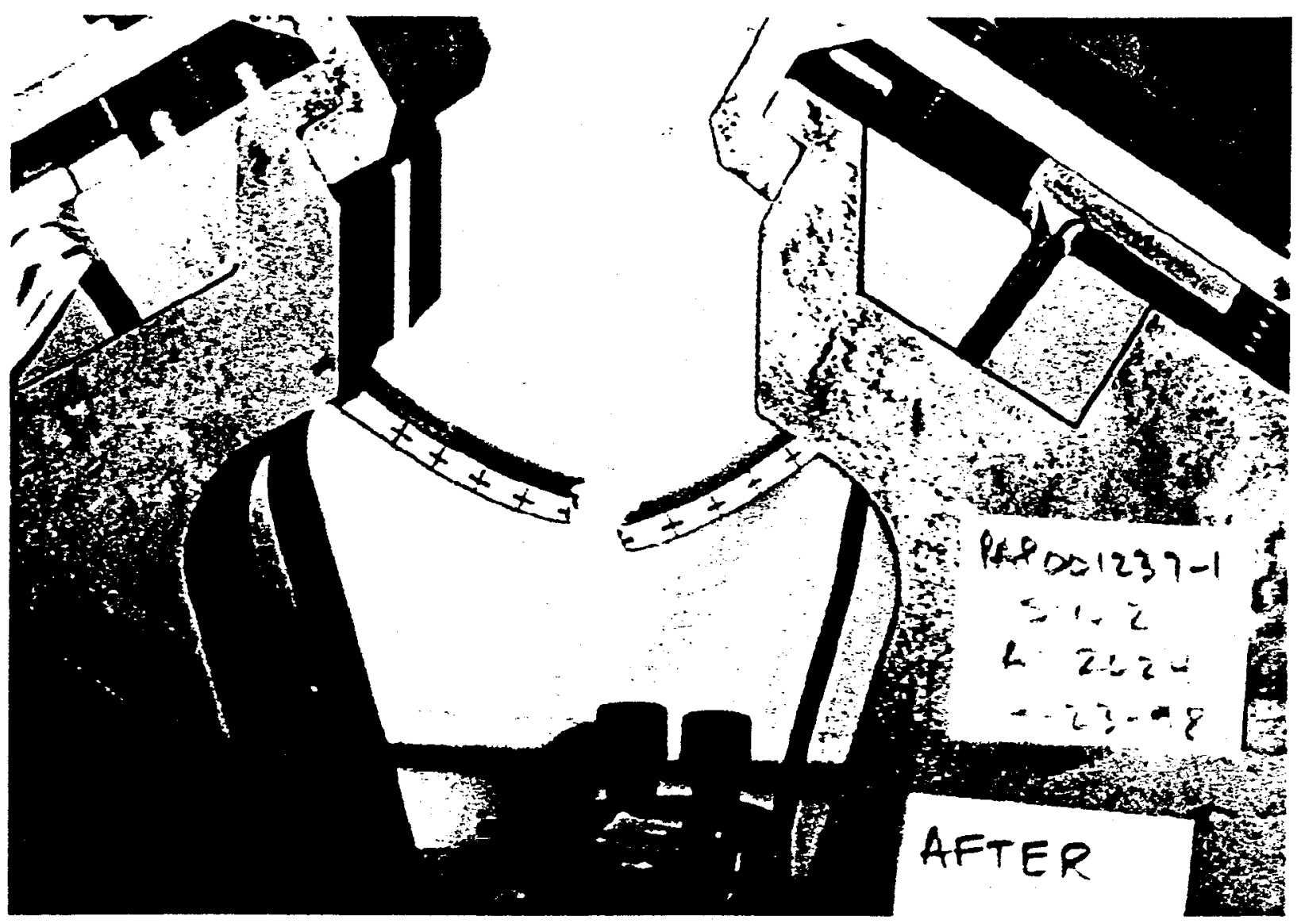

Figure V-9. PAP001237-1 S/N 2: Thick Aluminum 2024 Sample After Test Run No. 11, Drop Height 5.00 Inches. 


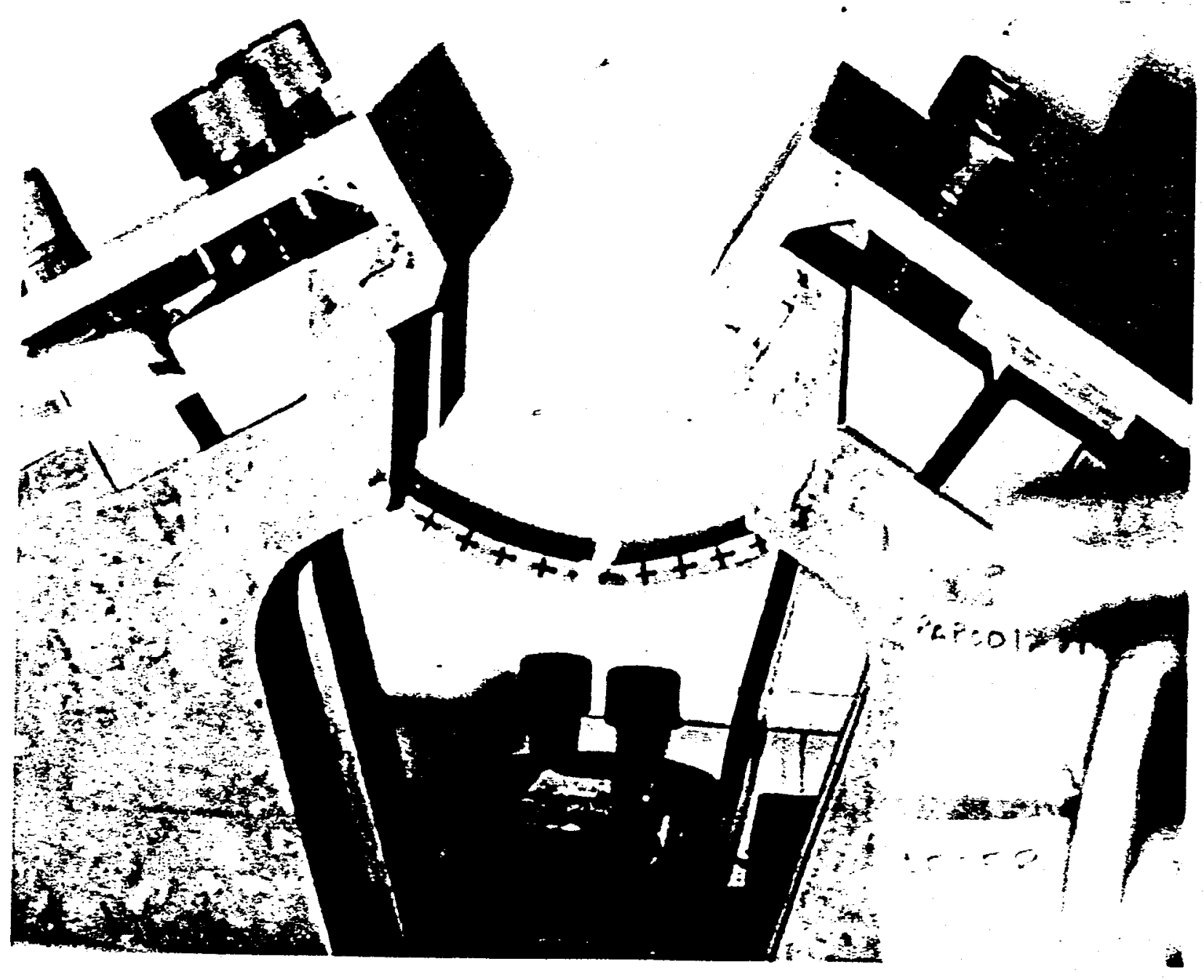

Figure V-10. PAP001237-2 S/N 4: Thick Titanium 6-4 Sample After Test Run No. 12, Drop Height 8.00 Inches. 


\section{AlliedSignal}

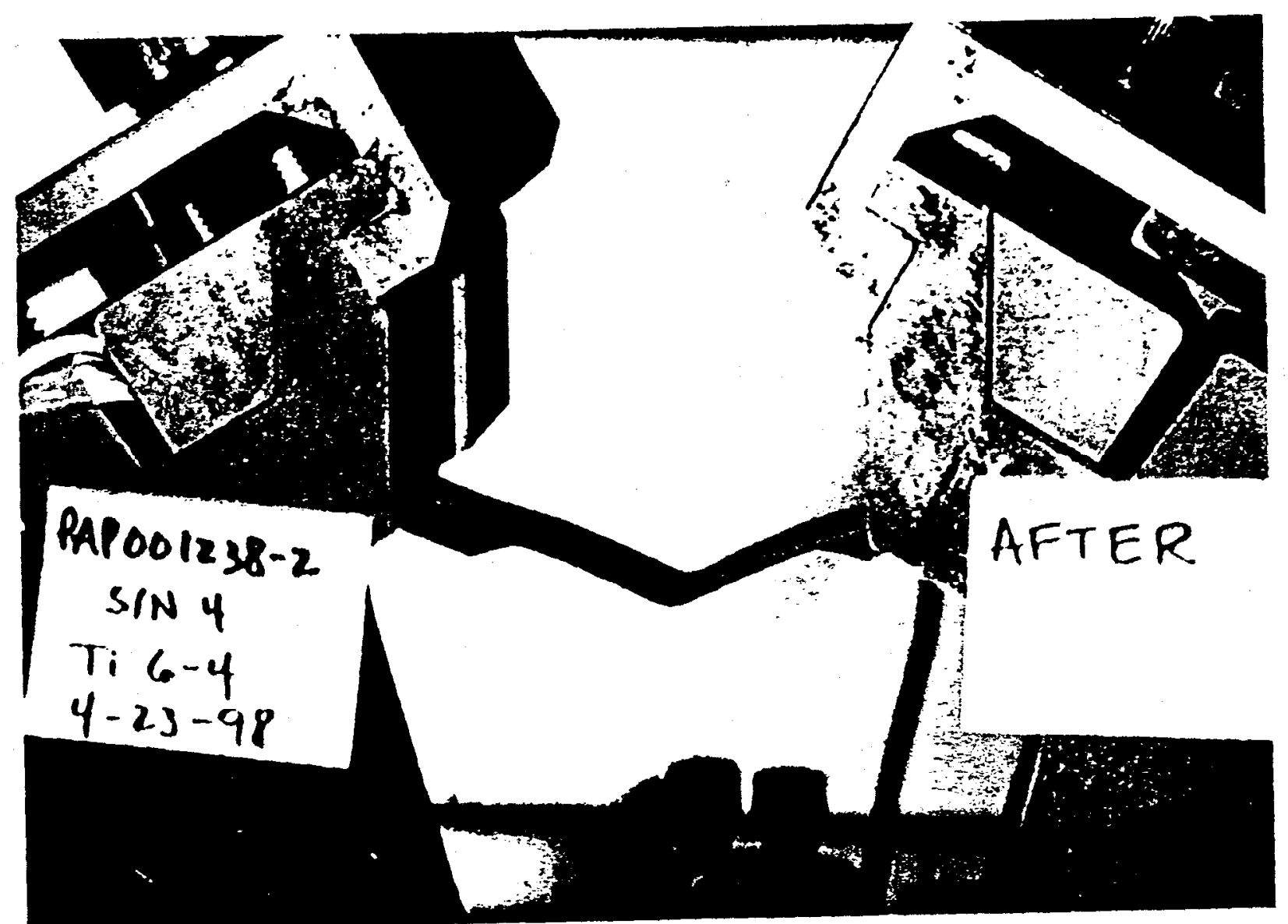

Figure V-11. PAP001238-2 S/N 4: Thin Titanium 6-4 Sample After Test Run No. 13, Drop Height 1.00 Inch. 


\section{AlliedSignal}

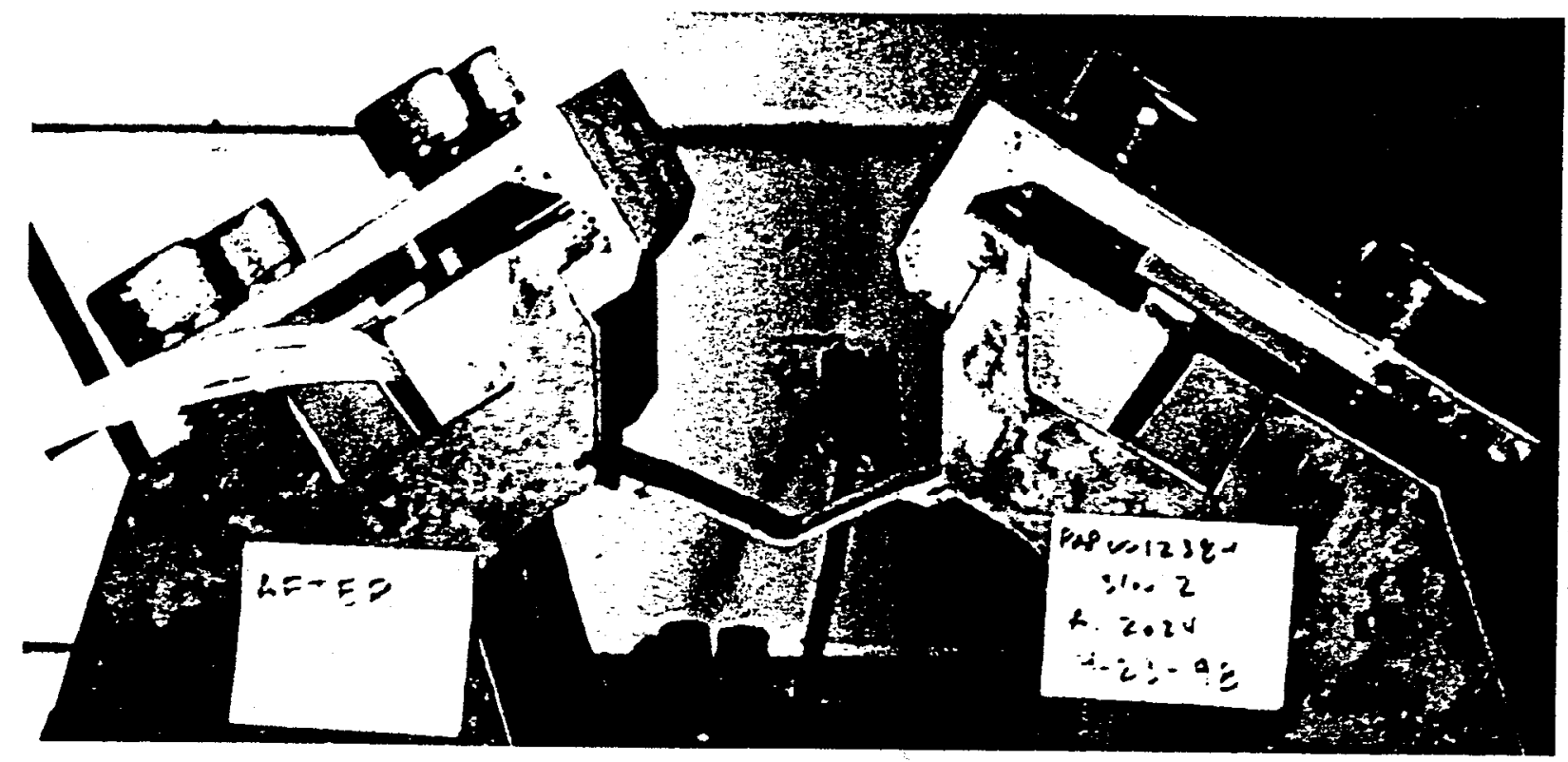

Figure V-12. PAP001238-1 S/N 2: Thin Aluminum 2024 Sample After Test Run No. 14, Drop Height, 0.50 Inch.

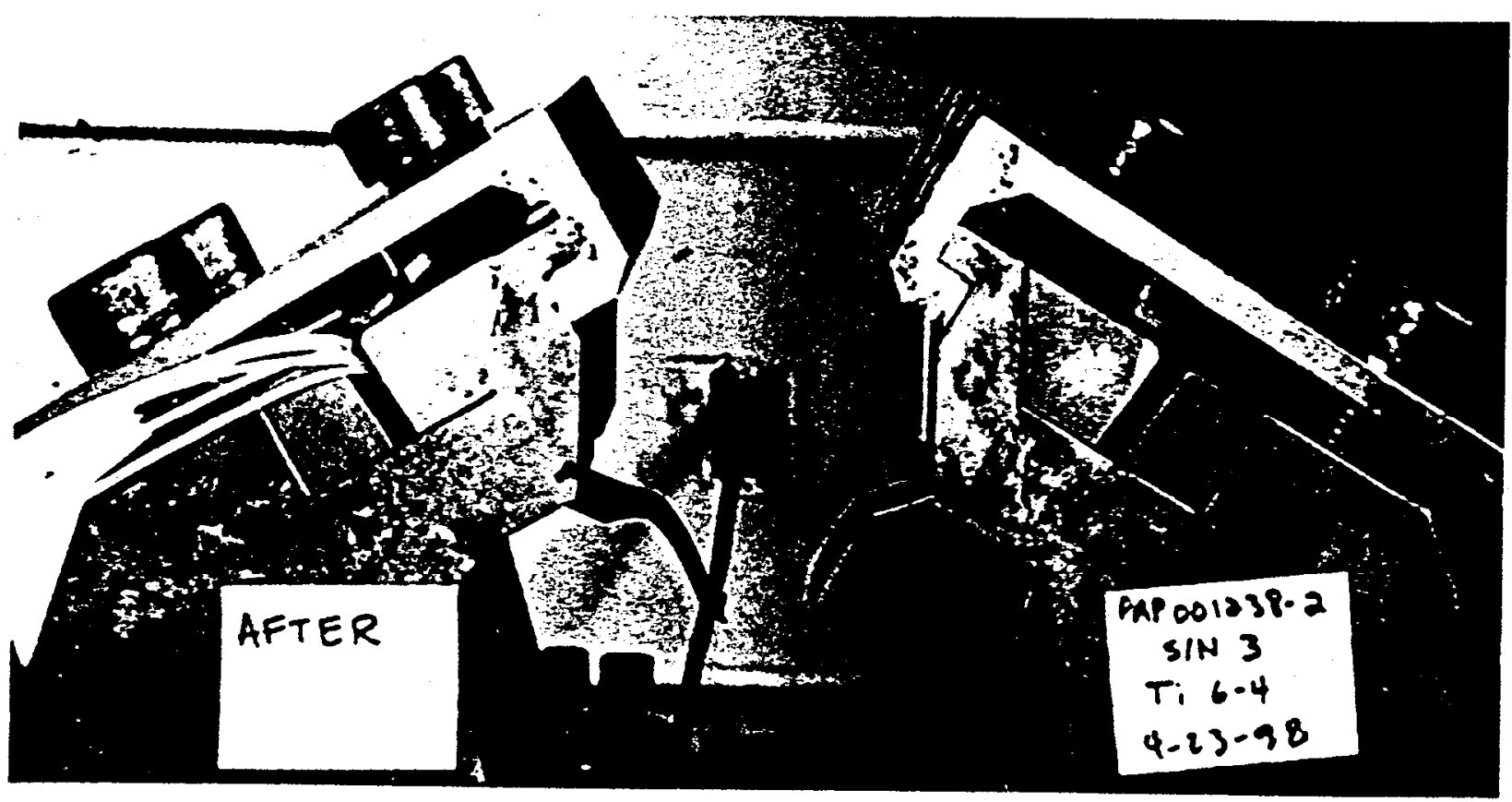

Figure V-13. PAP001238-2 S/N 3: Thin Titanium 6-4 Sample After Test Run No. 15, Drop Height 3.00 Inches. 


\section{$\Delta$ IliedSignal \\ A E ROS PACE}

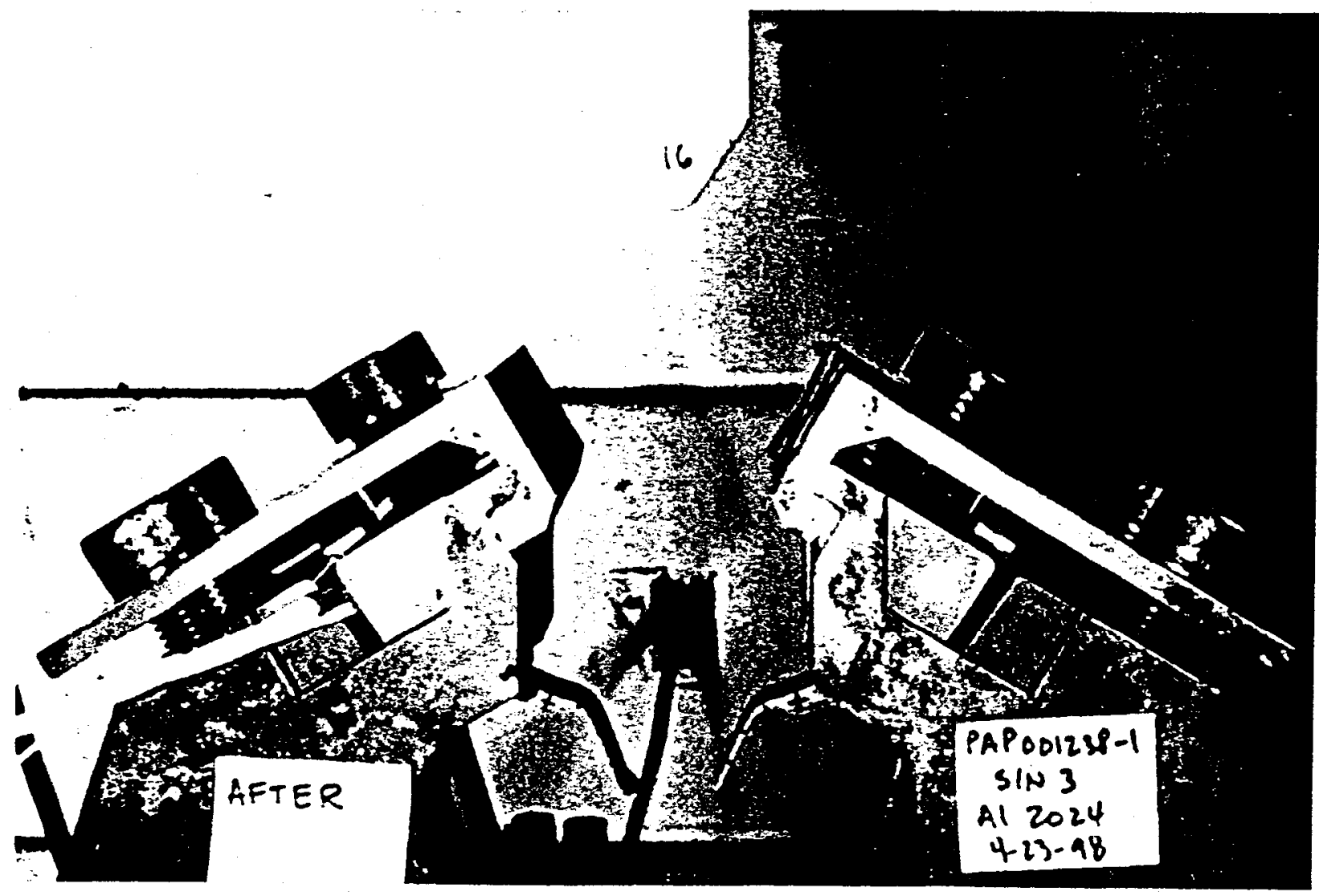

Figure V-14. PAP001238-1 S/N 3: Thin Aluminum 2024 Sample After Test Run No. 16, Drop Height 2.00 Inches. 
APPENDIX VI

PHOTOGRAPHS OF ALL SPECIMENS

AFTER TEST (FREE STANDING)

(15 pages) 

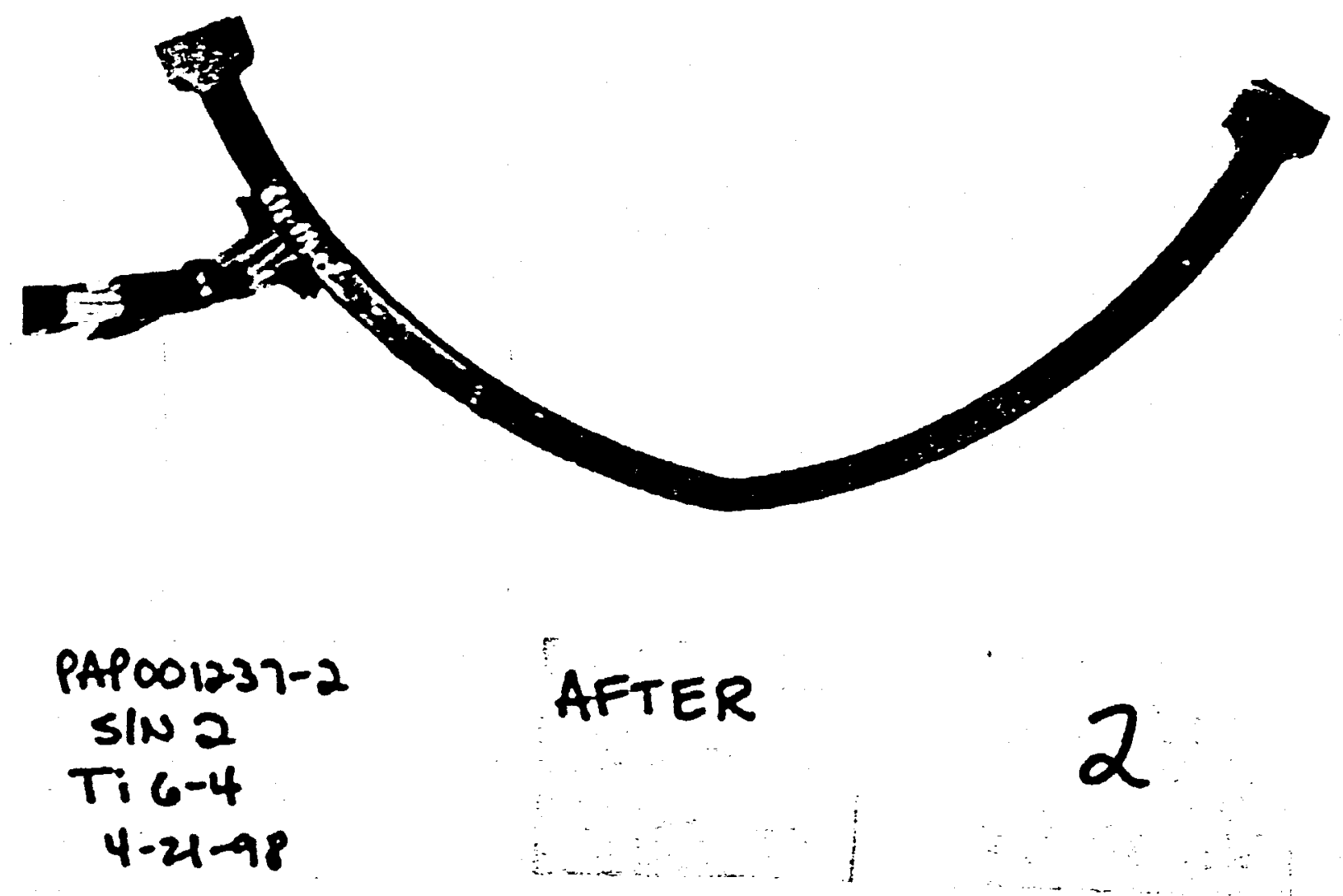

Figure VI-1. PAP001237-2 S/N 2: Thick Titanium 6-4 Sample After Test Run No. 2, Drop Height 3.25 Inches. 


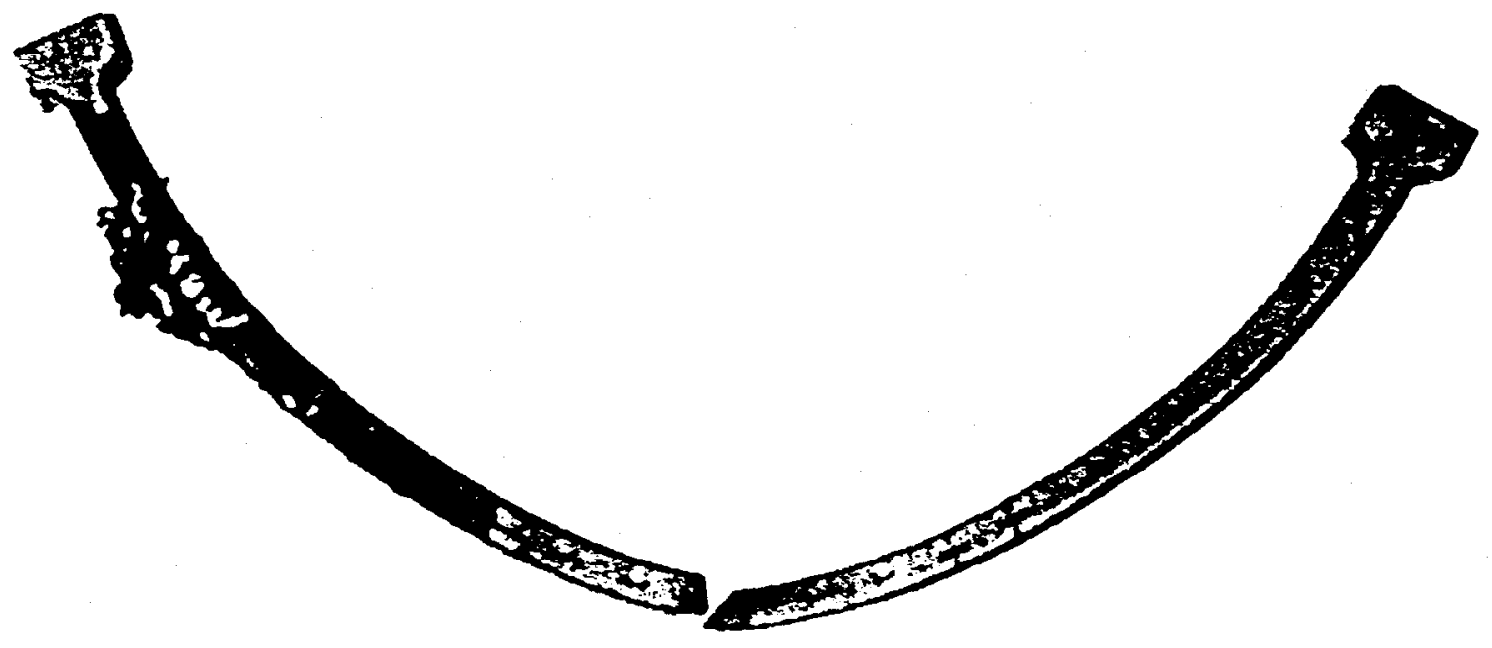

\section{PAP O01337-2 S|N $\mid$ \\ TiG-4 \\ $4-24-98$}

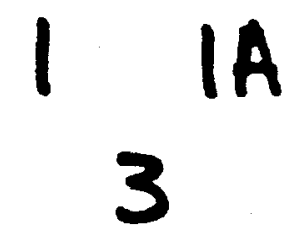
Figure VI-2. PAP001237-2 S/N 1: Thick Titanium 6-4 Sample After Test Run No. 3,
Drop Height 15.75 Inches. 

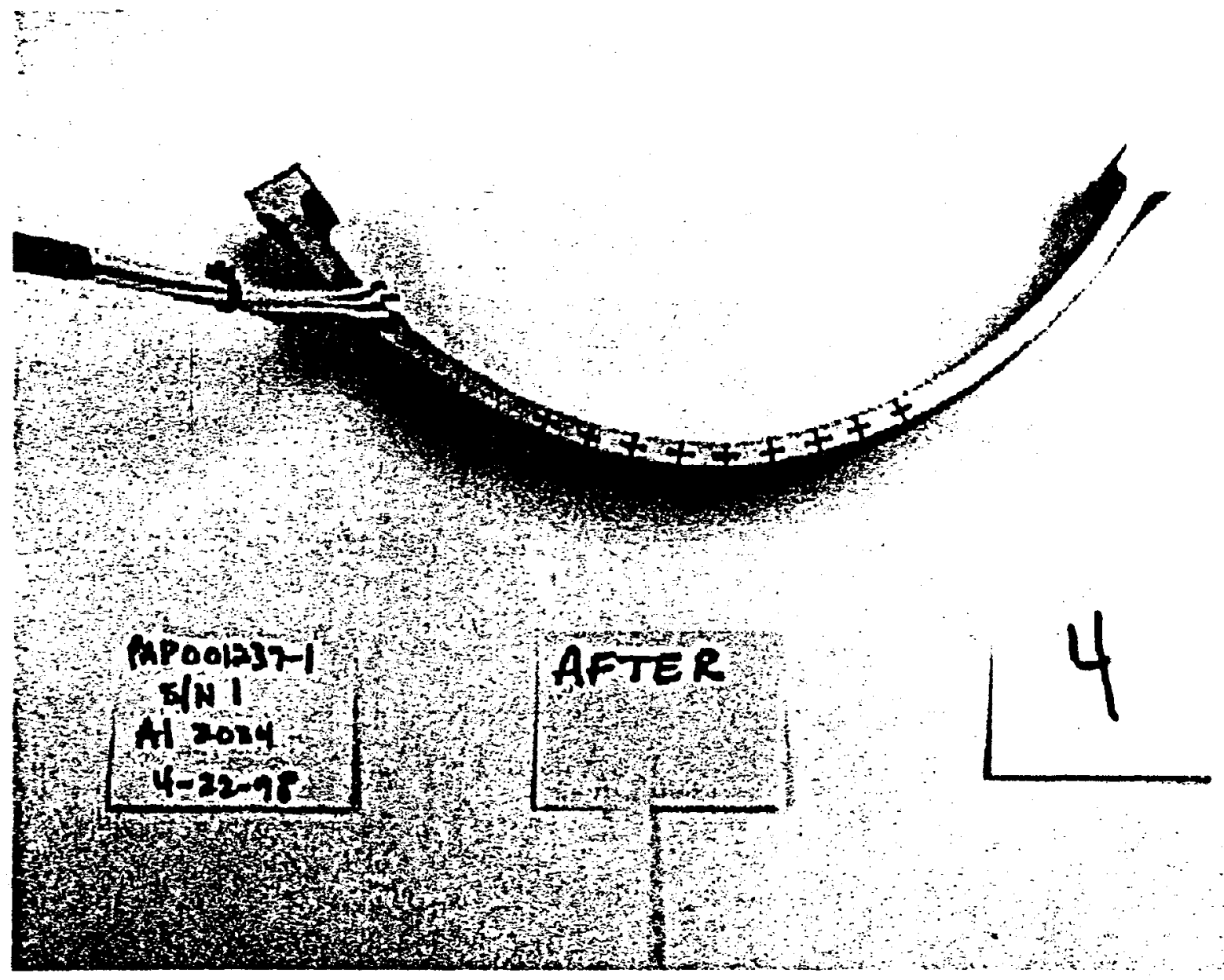

Figure VI-3. PAP001237-1 S/N 1: Thick Aluminum 2024 Sample After Test Run No. 4, Drop Height 0.25 Inch. 


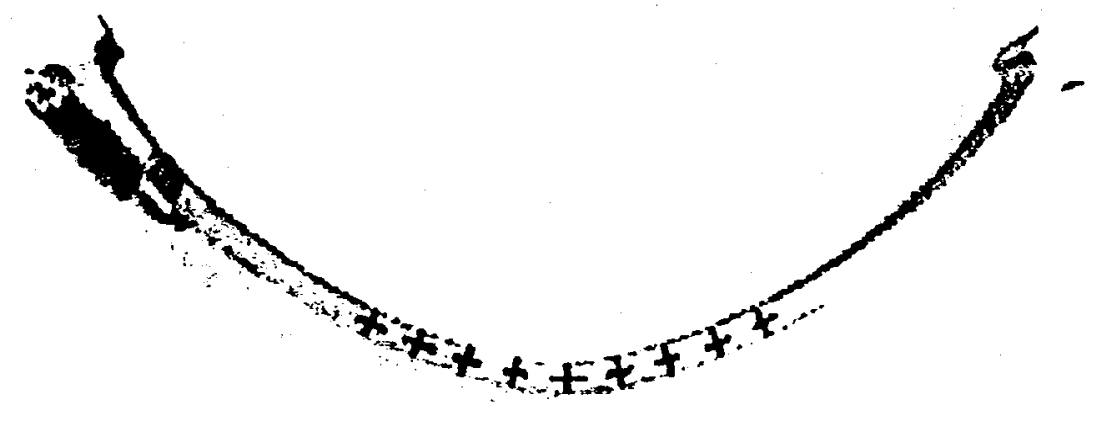

PaPoolzs7-1

SN 4

AFTER

Al 2024

$4-22-99$

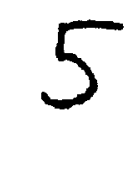

Figure VI-4. PAP001237-1 S/N 4: Thick Aluminum 2024 Sample After Test Run No. 5, Drop Height 0.50 Inch. 


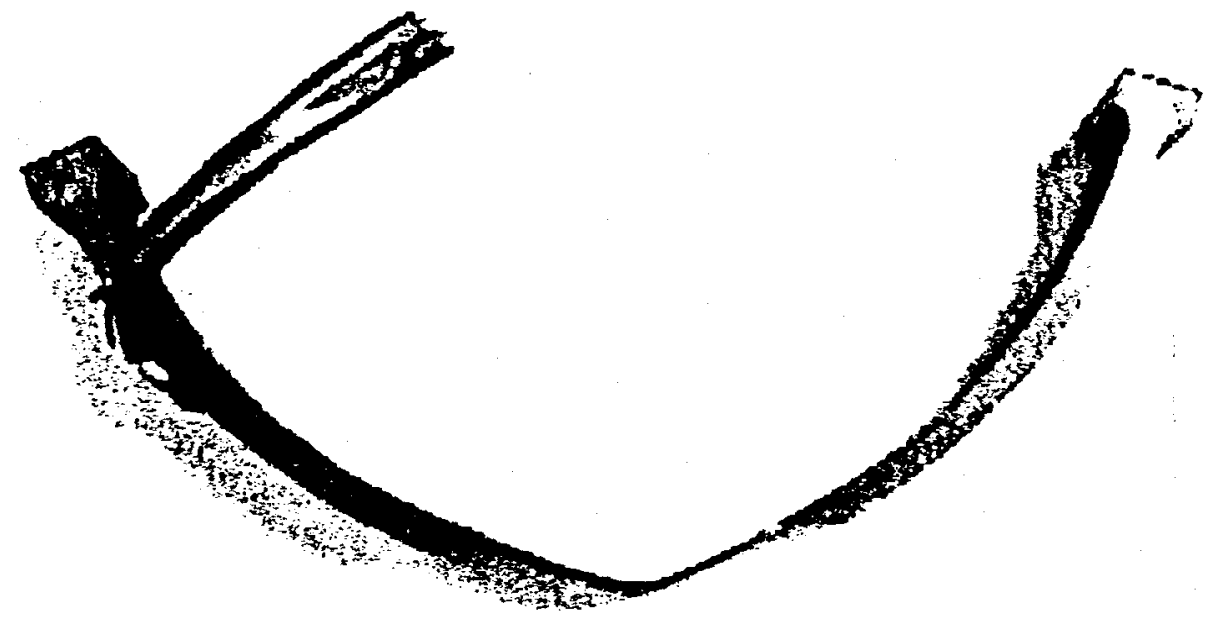

\section{PAPDoIzs:-2}

$\sin 2$

AFTER

$\mathrm{Ti} 6-4$

4-22-48

Figure VI-5. PAP001238-2 S/N 2: Thin Titanium 6-4 Sample After Test Run No. 6, Drop Height 0.25 Inch. 


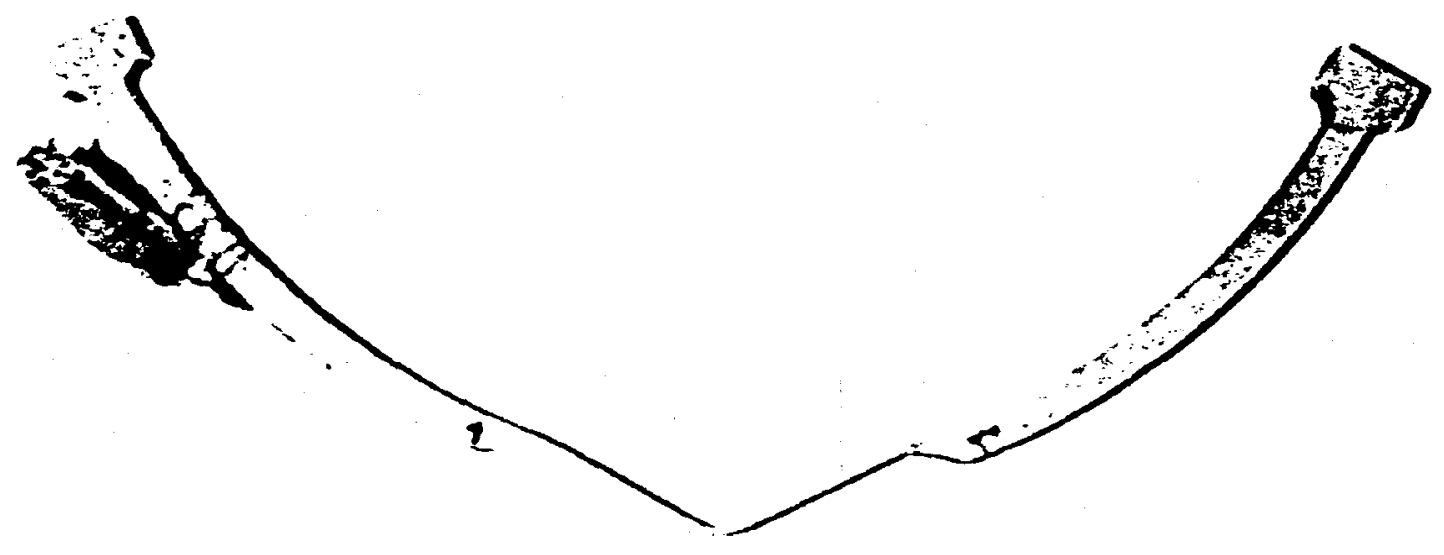

PAP OOO231-1

SIN 1

AFTER

Al 2024

$4-22-98$

Figure VI-6. PAP001238-1 S/N 1: Thin Aluminum 2024 Sample After Test Run No. 7, Drop Height 0.25 Inch. 

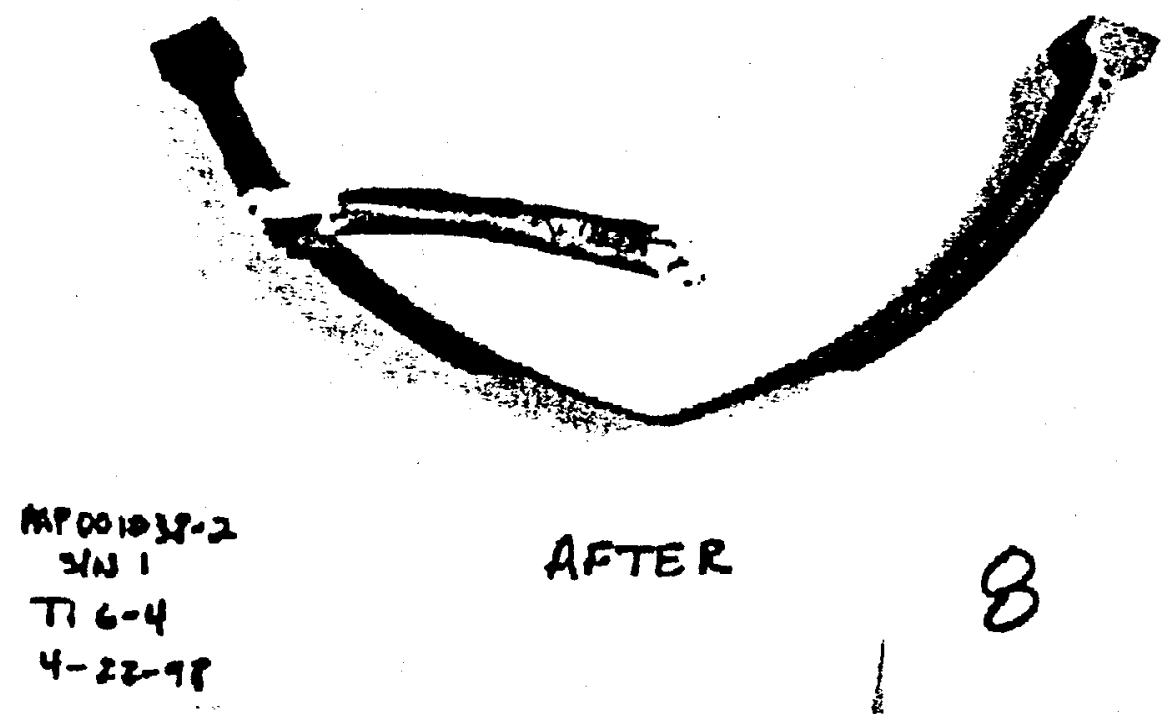

AFTER

8

$4-22-91$

Figure VI-7. PAP001238-2 S/N 1: Thin Titanium 6-4 Sample After Test Run No.8, Drop Height 0.25 Inch. 


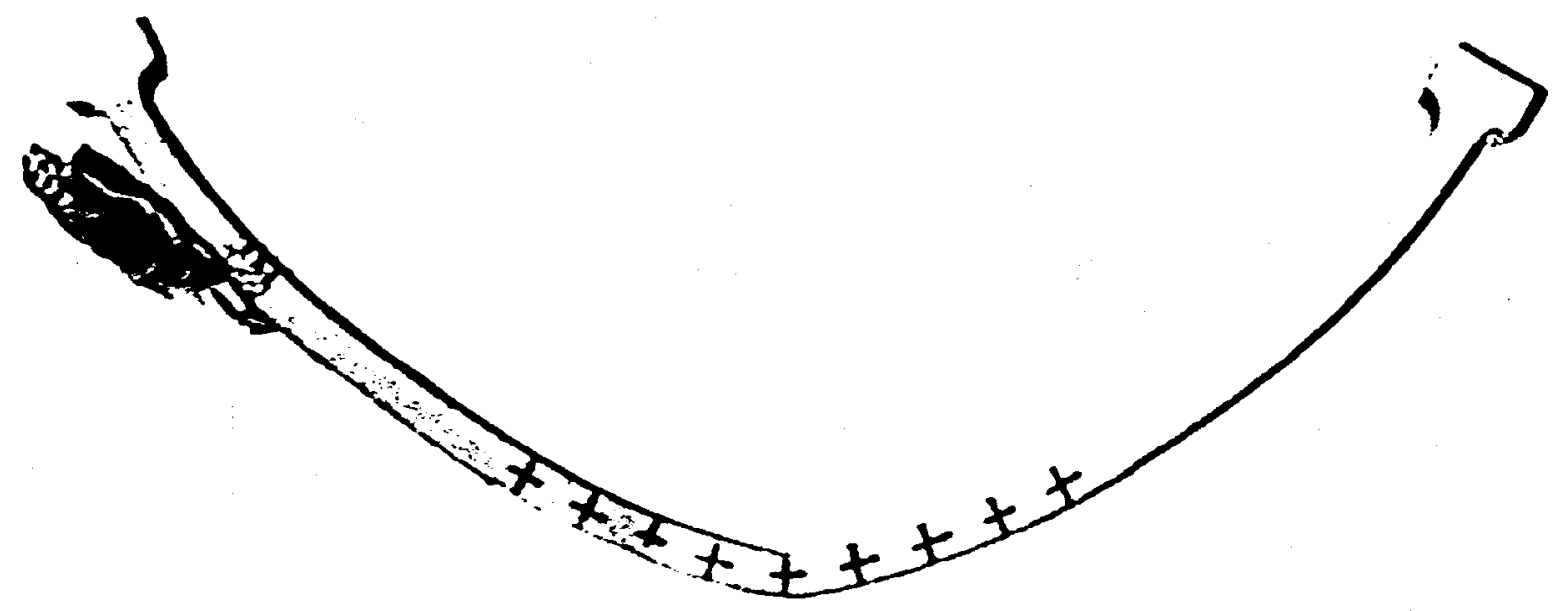

PAP0o1237-1

SIN 3

AFTER

Al 2024

$4-23-98$

9

Figure VI-8. PAP001237-1 S/N 3: Thick Aluminum 2024 Sample After Test Run No. 9, Drop Height 1.00 Inch. 

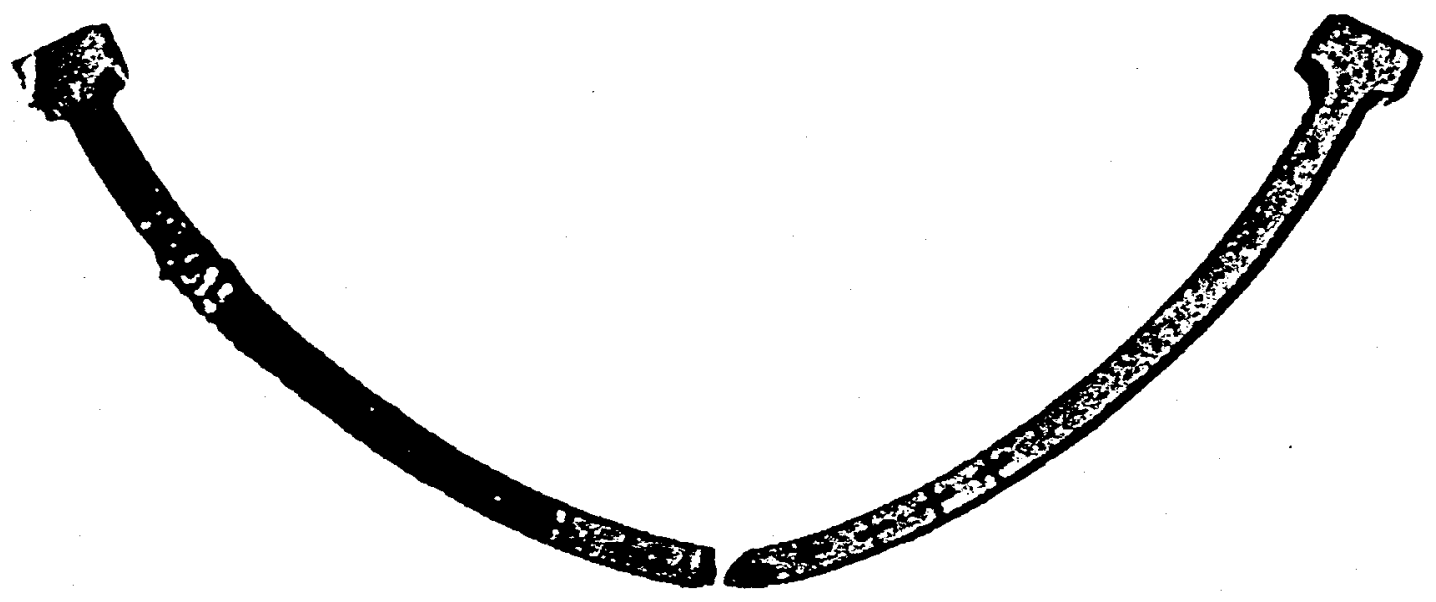

PAPOO1237-2

$\operatorname{SIN} 3$

AFTER

10

Ti $6-4$

4-23-98

Figure VI-9. PAP001237-2 S/N 3: Thick Titanium 6-4 Sample After Test Run No. 10, Drop Height 12.00 Inches. 

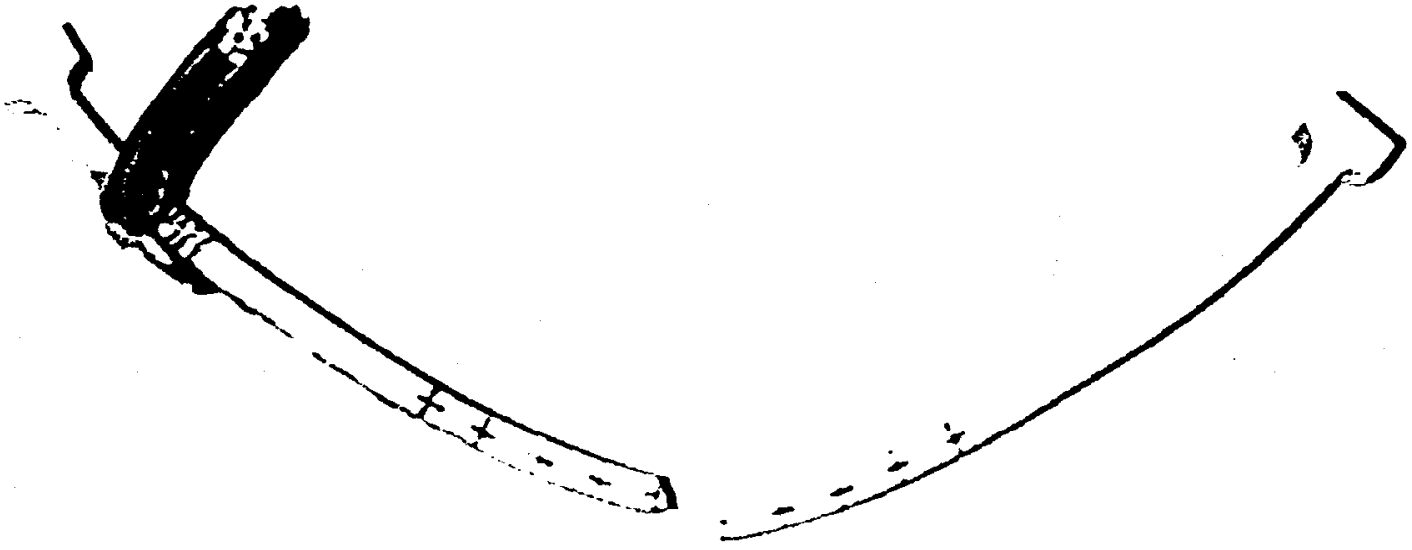

APOO1237-1

SIN 2

Al 2024

AFTER

4-23-98

Figure VI-10. PAP001237-1 S/N 2: Thick Aluminum 2024 Sample After Test Run No. 11, Drop Height 5.00 Inches. 
AlliedSignal

A E R O P A C E

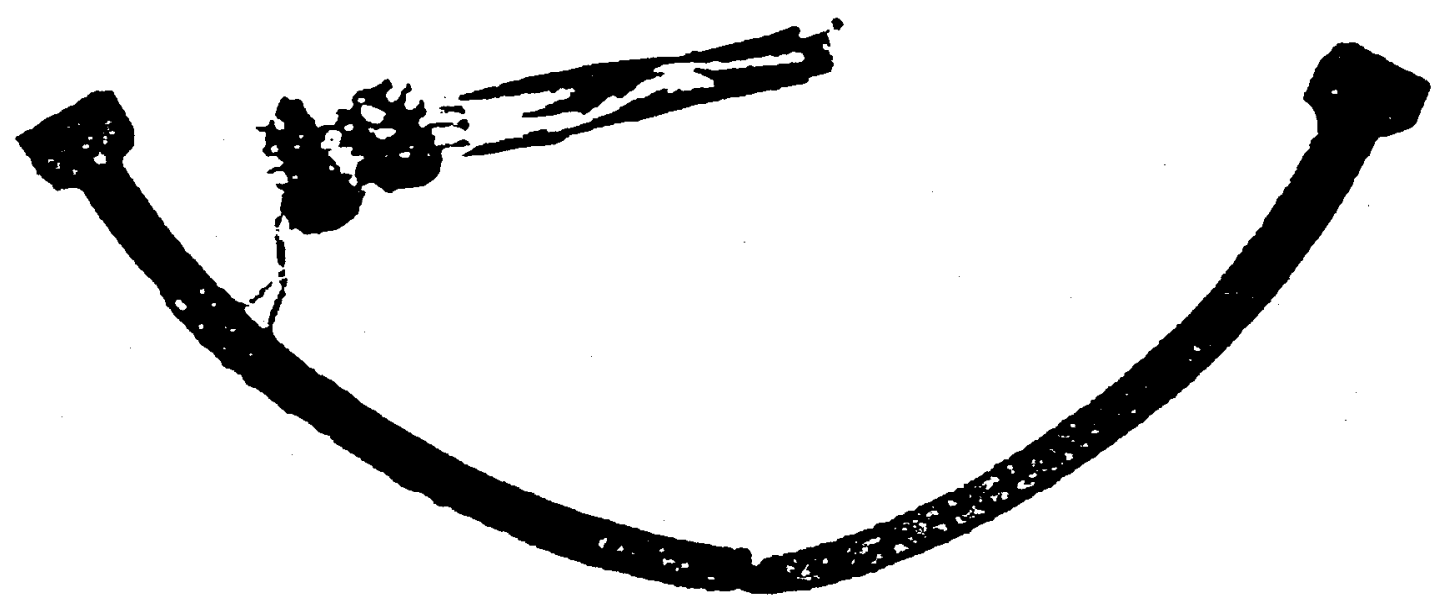

PAPool237-2

$$
\sin 4
$$

Ti $6-4$ 4-23-98

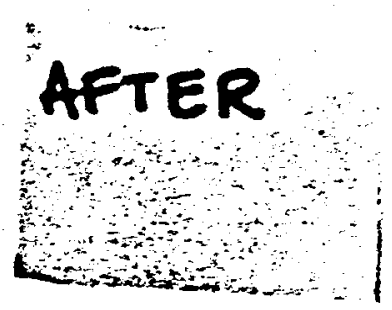

Figure VI-11. PAP001237-2 S/N 4: Thick Titanium 6-4 Sample After Test Run No. 12, Drop Height 8.00 Inches.

$$
\begin{gathered}
\text { 21-10392 } \\
\text { VI-11 }
\end{gathered}
$$



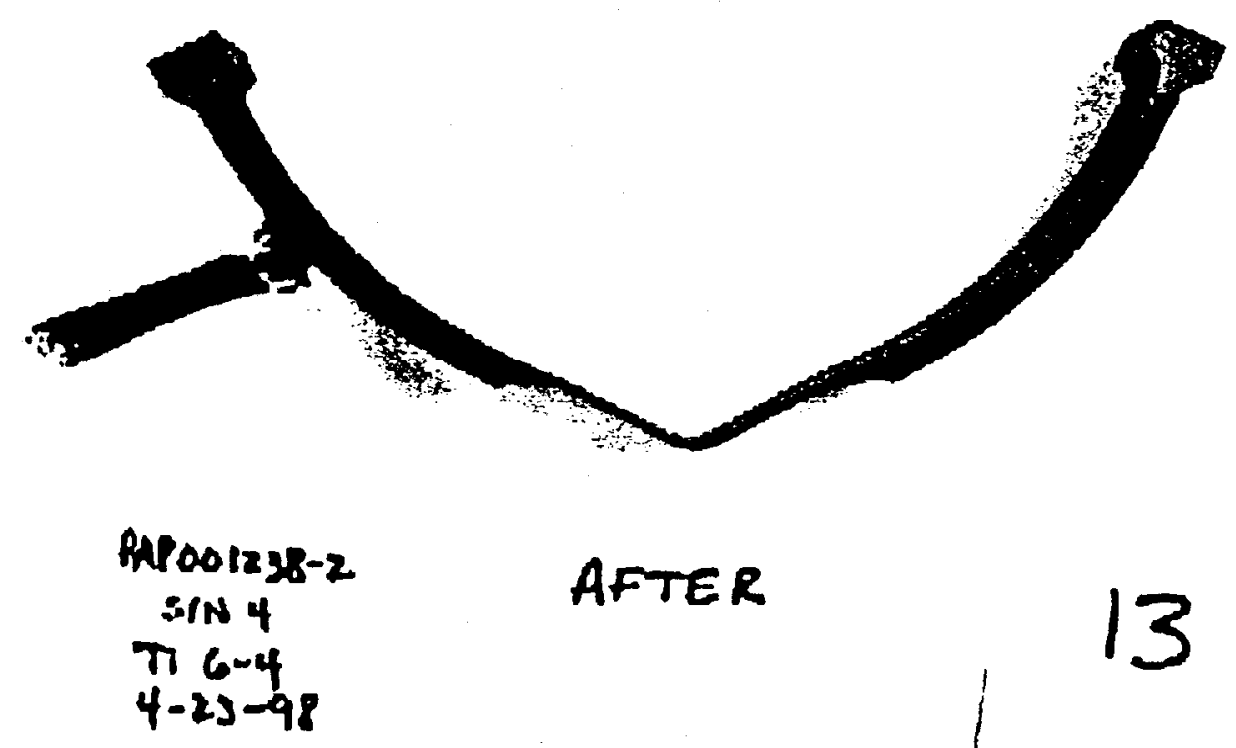

AFTER

13

Figure VI-12. PAP001238-2 S/N 4: Thin Titanium 6-4 Sample After Test Run No. 13, Drop Height 1.00 Inch. 

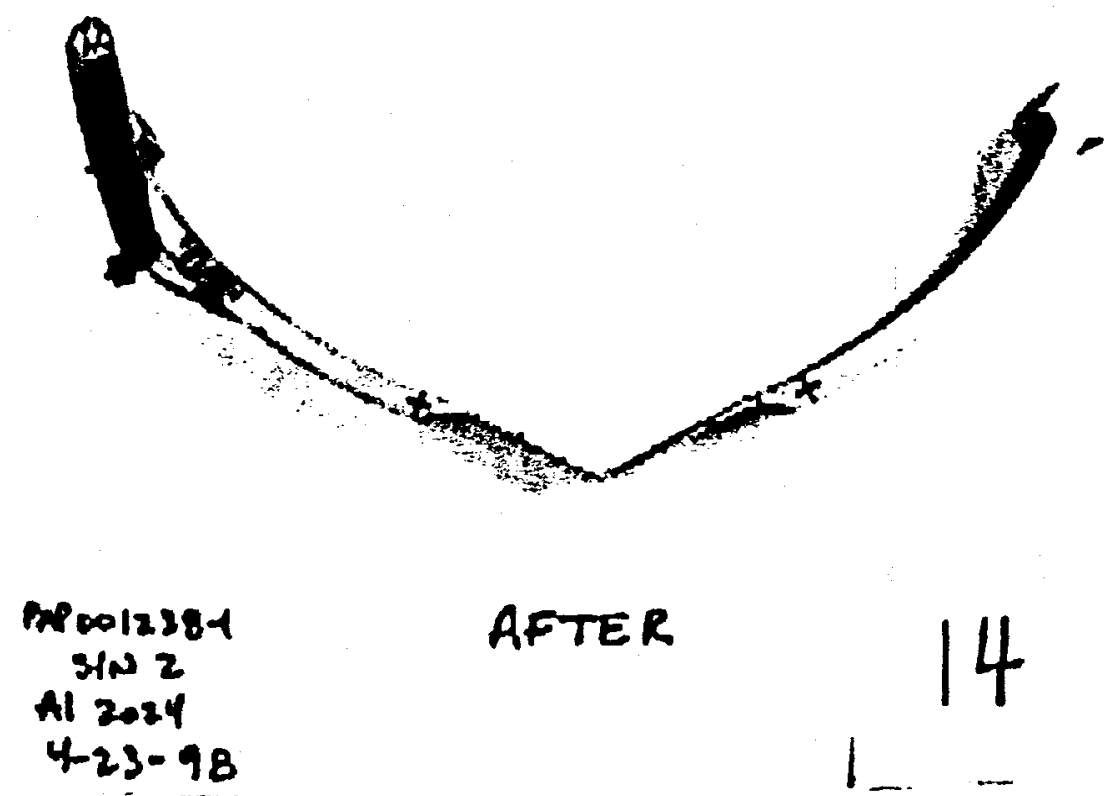

AFTER

A1 2024

$4-23-98$

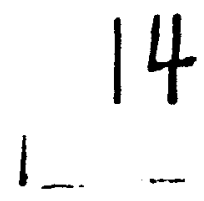

Figure VI-13. PAP001238-1 S/N 2: Thin Aluminum 2024 Sample After Test Run No. 14, Drop Height 0.50 Inches. 

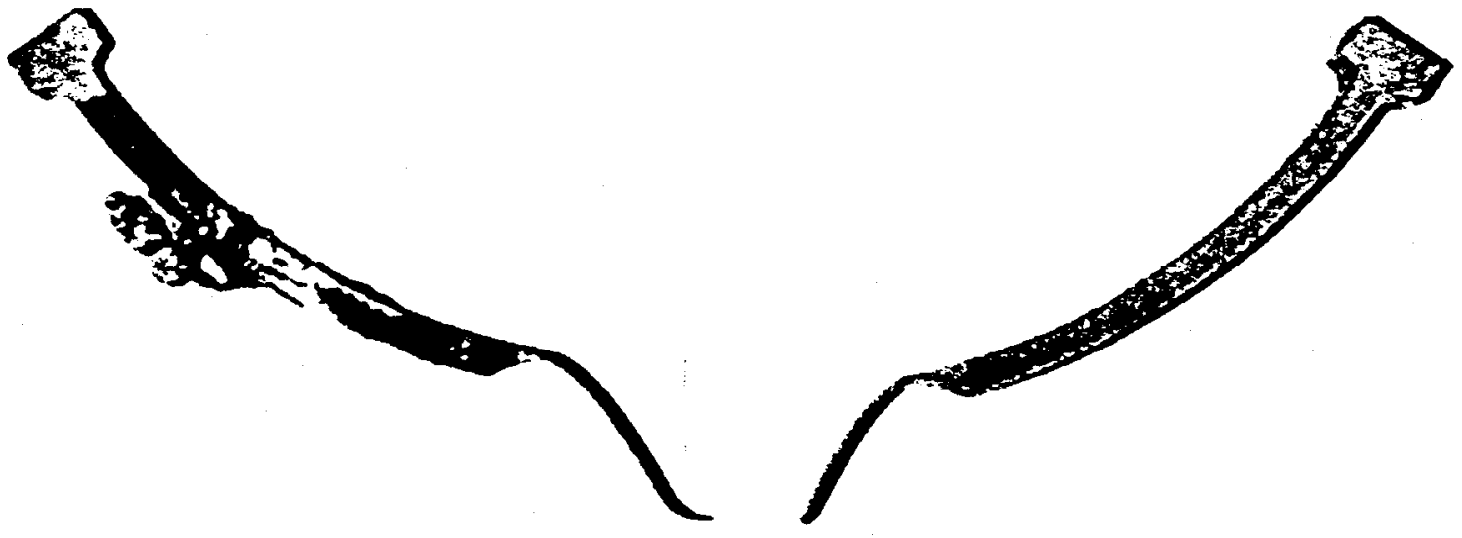

PAP OO1238-2

$$
\begin{gathered}
\sin 3 \\
T i 6-4 \\
4-23-98
\end{gathered}
$$$$
\text { AFTER }
$$

Figure VI-14. PAP001238-2 S/N 3: Thin Titanium 6-4 Sample After Test Run No. 15, Drop Height 3.00 Inches. 

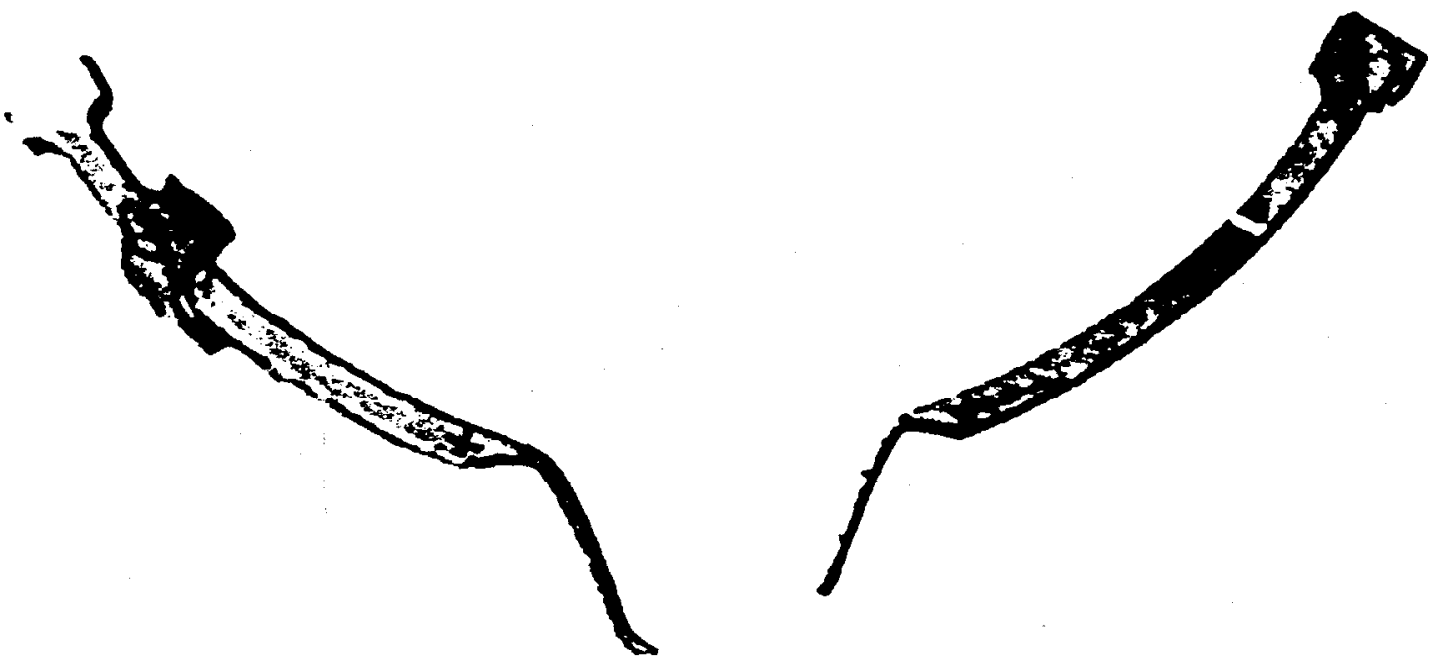

\section{PAPODI2U-1 \\ $\sin 3$ \\ Al 2024 \\ 4-23-98}

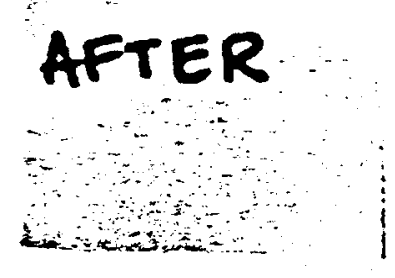

Figure VI-15. PAP001238-1 S/N 3: Thin Aluminum 2024 Sample After Test Run No. 16, Drop Height 2.00 Inches. 
SN 1

Ret $\mathrm{d}_{\mathbf{A B}}$

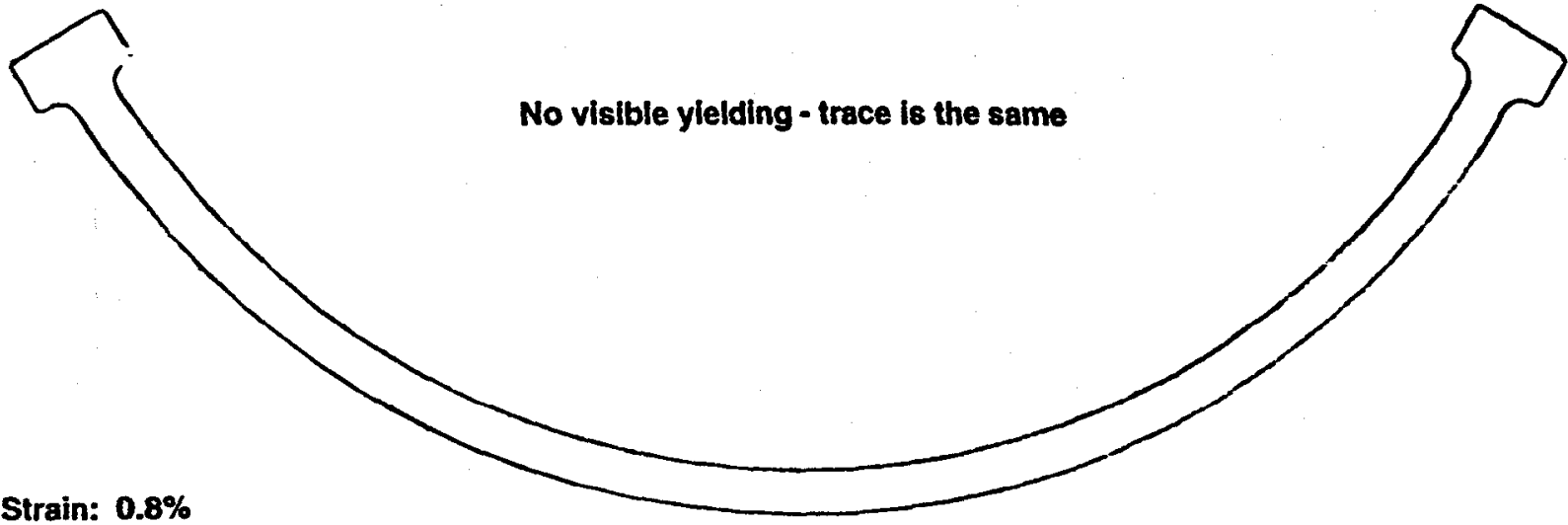

Light linear mark on top surface.

Load cell stopped recording after $7.8 \mathrm{~ms}$.

High speed video was late triggering. High speed film OK.

Strain gage data $O K$.

Part not dismounted - being re-run as $1 \mathrm{~A}$ with load cell and high speed video only.

1 A run successful. Strain gages look OK.

No noticeable material distress except shiny left end surface.

1) Max load $=3015 \mathrm{lb} \quad$ TIme to $\max$ load $7.80 \mathrm{msec}$

$V=1.16 \mathrm{ft} / \mathrm{sec}$

Eim $=10.30 \mathrm{ft}-\mathrm{lb} \quad$ Max $E=27.66 \mathrm{ft}-1 \mathrm{~b}$

1A) Max load $=3715.85 \mathrm{lb} 10.35$ milli seconds
$V=1.16 \mathrm{ft} / \mathrm{sec}$
Vel slowdown $=83.93 \%$

Eim $=10.33 \mathrm{ft}-1 \mathrm{~b}$

Emax $=18.92 \mathrm{ft}-1 \mathrm{~b}$

Etotal $=11.08 \mathrm{ft}-1 \mathrm{~b}$

G8727.23A

Figure VII-1. PAP001237-2 S/N 1: Titanium 6-4 Sample After Runs No. 1 and 1A, Drop Height 0.25 Inch. 
Ref $d_{A 1}$

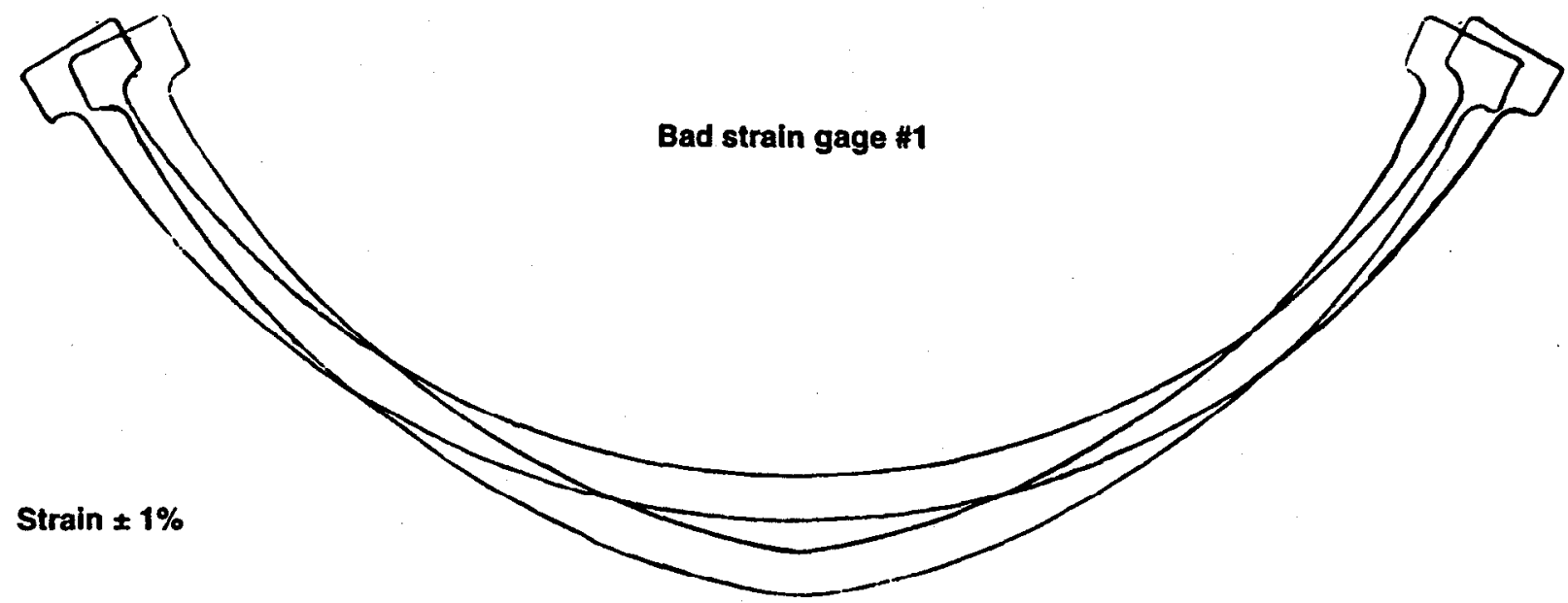

Noticeable deformation. Good run - all systems worked.

Right side plate shows some wear from specimen head.

Two wire leads from gage $\$ 3$ came off with epoxy - not sure if it affected results. Inner and outer shoulders show some degree of material distress - not much. Impact area on OD shows inward motion on edges.

Two wire leads from gage \#1 broke off.

$\begin{array}{lll}\text { Max load }=10789.26 \mathrm{lb} & \text { Time } \odot \max \text { load }=8.95 \mathrm{msec} & \text { Vel slowdown=86.83\% } \\ V=4.18 \mathrm{ft} / \mathrm{sec} & & \\ \text { Eim }=133.69 \mathrm{ft}-\mathrm{lb} & E \max =157.48 \mathrm{ft}-\mathrm{lb} & \text { Etotal }=104.82 \mathrm{ft}-\mathrm{lb}\end{array}$
68727.24A

Figure VII-2. PAP001237-2 S/N 2: Titanium 6-4 Sample After Run No. 2 , Drop Height 3.25 Inches. 
Ret $\mathbf{d}_{\mathbf{A} 2}$

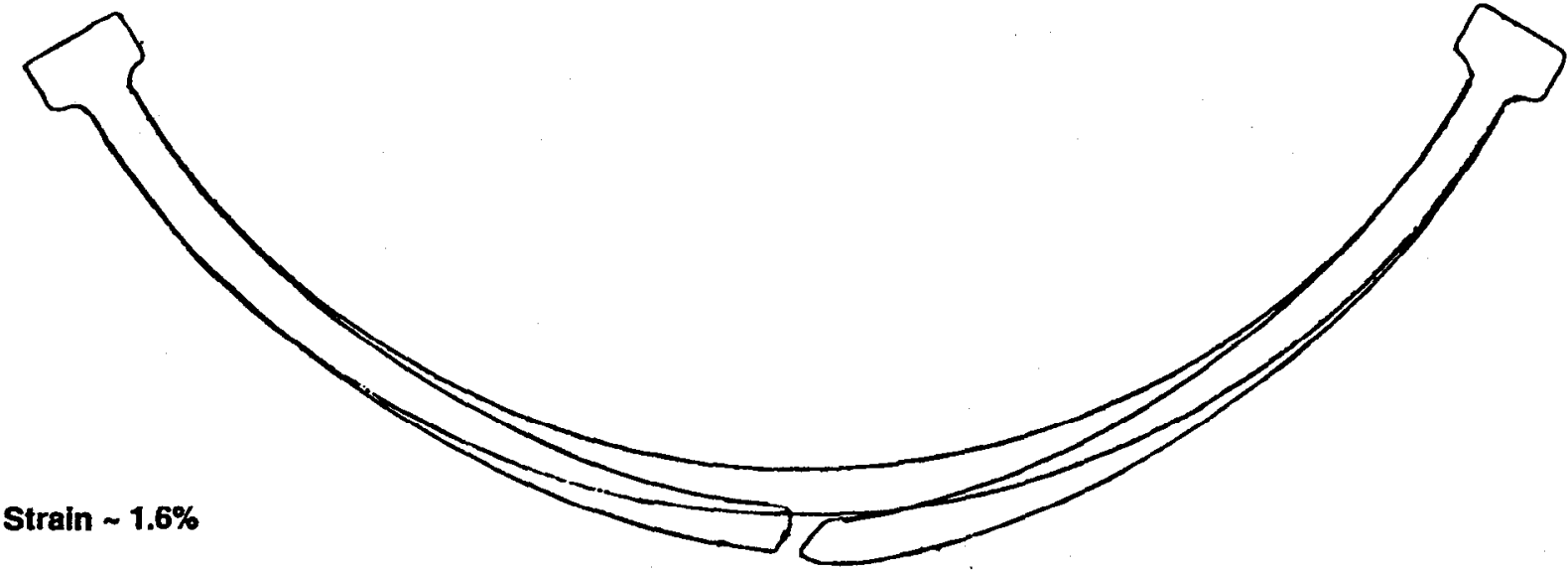

Same specimen from Run $\# 1$. Gage $\# 4$ was bad before. Now checks out OK.

Specimen broke close to bottom dead center. Considerable necking on OD at break point. Most strain gage wire loads at OD broke off at strip. Data incomplete.

Material distress shown at ID and OD shoulders.

Rub marks on end surfaces. No additional setup hardware damage.

\begin{tabular}{|c|c|c|}
\hline $\begin{array}{l}\text { Max load = } 11916.15 \mathrm{lb} \\
V=9.18 \mathrm{ft} / \mathrm{sec} \\
\mathrm{Eim}=644.43 \mathrm{ft}-\mathrm{lb}\end{array}$ & $\begin{array}{l}\text { Time } 0 \text { max load=2.97 msec } \\
\text { Emax }=165.12 \mathrm{ft}-\mathrm{lb} \text { eneray to } \max \text { load }\end{array}$ & Vel slowdown $=12.61 \%$ \\
\hline $227-258$ & & \\
\hline
\end{tabular}

Figure VII-3. PAP001237-2 S/N 1: Titanium 6-4 Sample After Run No. 3, Drop Height 15.75 Inches. 
Ref $d_{c 1}$

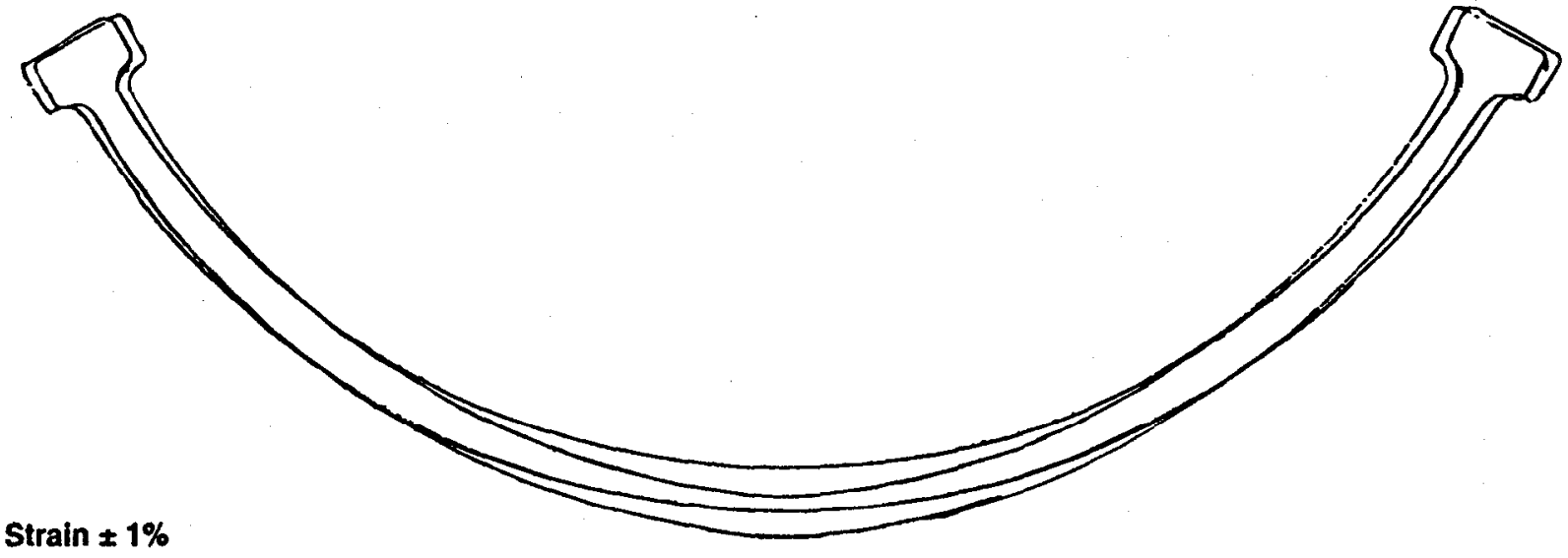

Strain gage \#1 falled balancing check prior to test.

Strain gages and wires look OK after test.

Part yielded as expected. Impact was very close to bottom dead center.

Part shows some rub marks on top surfaces.

Material distress more evident on inner shoulders than outer shoulders.

No additional damage to test fixtures.

Good run overall.

Slight necking observed on OD directly under impact area.

Max load $=2367.76 \mathrm{lb} \quad$ Time $9 \max$ load $=15.45 \mathrm{msec} \quad$ Vel slowdown $=77.78 \%$

$V=1.16 \mathrm{ft} / \mathrm{sec}$

$\operatorname{Eim}=10.30 \mathrm{ft}-1 \mathrm{~b}$

$E_{\max }=21.17 \mathrm{ft}-\mathrm{lb}$

Etotal $=17.17 \mathrm{ft}-\mathrm{lb}$ G8727-26A

Figure VII-4. PAP001237-1 S/N 1: Aluminum 2024 Sample After Test Run No. 4, Drop Height 0.25 Inches. 
SN 4

Run \#5 0.50-in. drop

Video Scene 5

Ret $\mathbf{d}_{\mathbf{C 2}}$

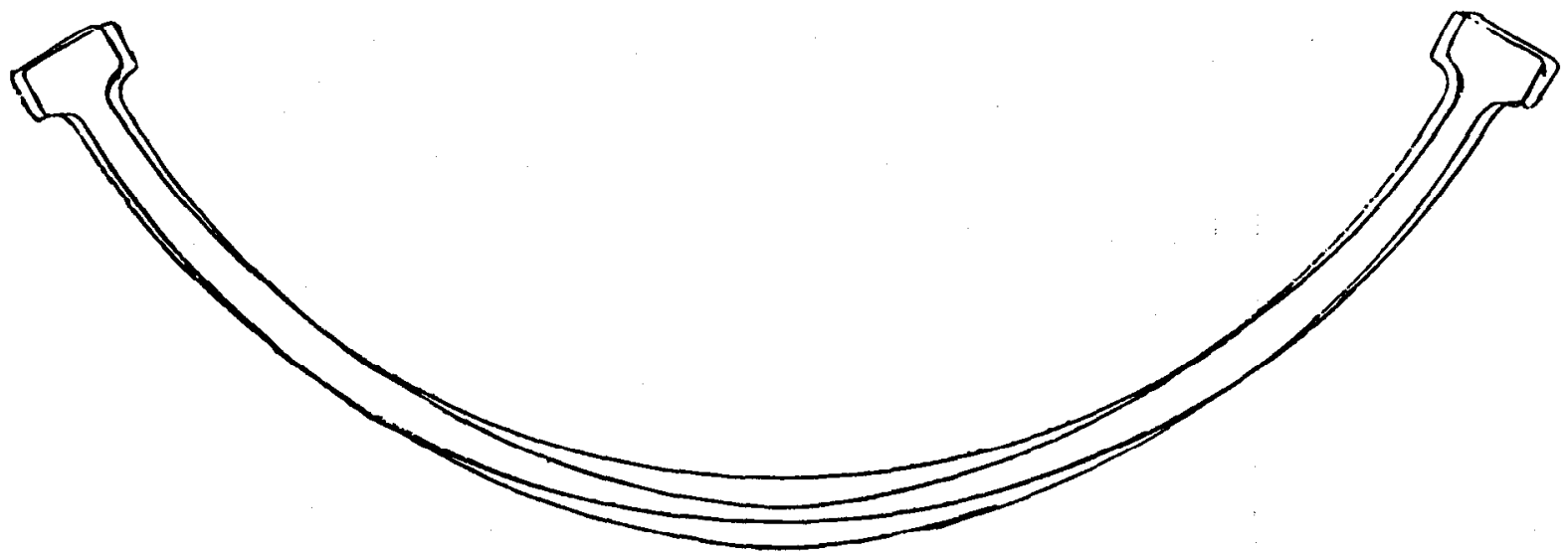

No before freestanding picture or video (didn't trigger).

Good run - all gages checked out before fest and made it through unharmed.

Part yielded as expected - hit at bottom dead center.

Rub marks on top surface edges mostly.

Material distress evident on inner shoulder and outer edges of outer shoulders.

Specimen visibly necked on OD of impact point. Material stretching evident.

Test fixture shows no additional wear marks.

SN 2 has bad strain gages $2,4,5$.

*2 2 is open. 44 and 45 are miswired.

Max load $=3013.69 \mathrm{lb} \quad$ Time $\max$ load $=14.92 \mathrm{msec}$

Vel slowdown $=83.80 \%$

$V=1.64 \mathrm{ft} / \mathrm{sec}$

Eim $=20.58 \mathrm{ft}-1 \mathrm{~b}$

$E \max =34.59 \mathrm{ft}-1 \mathrm{~b}$

Etotal $=28.41 \mathrm{ft}-\mathrm{lb}$

G8727-27A

Figure VII-5. PAP001237-1 S/N 4: Aluminum 2024 Sample After Test Run No. 5, Drop Height 0.50 Inch. 


\section{AlliedSignal \\ AEROSPACE}

PAP001238-2

TI 6-4

4/22/98

SN 2

2:30 PM

Run \#6 0.25-In. drop

GRC

Video Scene 6

Ref d $\mathbf{B 1}_{1}$

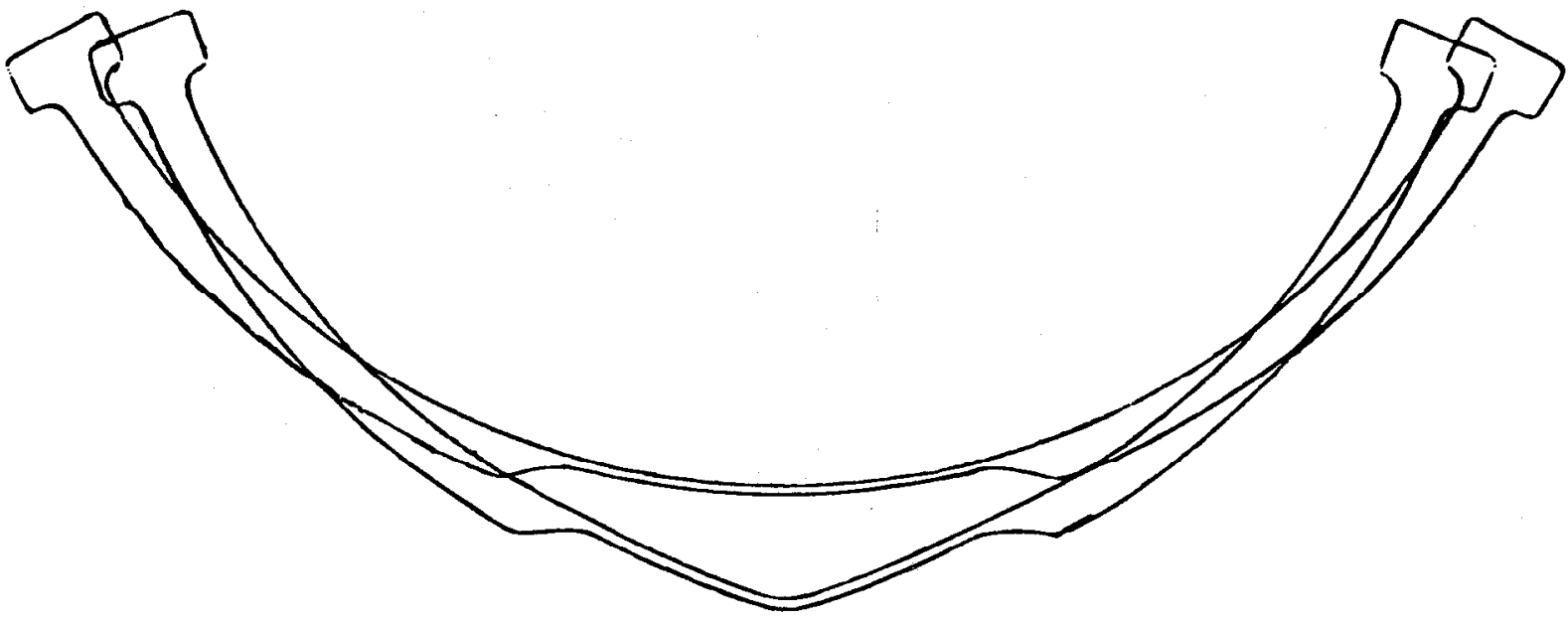

Gages \#2 and \#5 did not balance properly prior to test.

Test did not trigger load cell - no load cell data available.

Strain gages, video and film worked $O K$.

Video showed considerable stretching, especially from right side.

Small degree of material distress visible in inner and outer shoulders equally.

No new marks evident on test fixture.

68727-28A

Figure VII-6. PAP001238-2 S/N 2: Titanium 6-4 Sample After Test Run No. 6, Drop Height 0.25 Inch. 


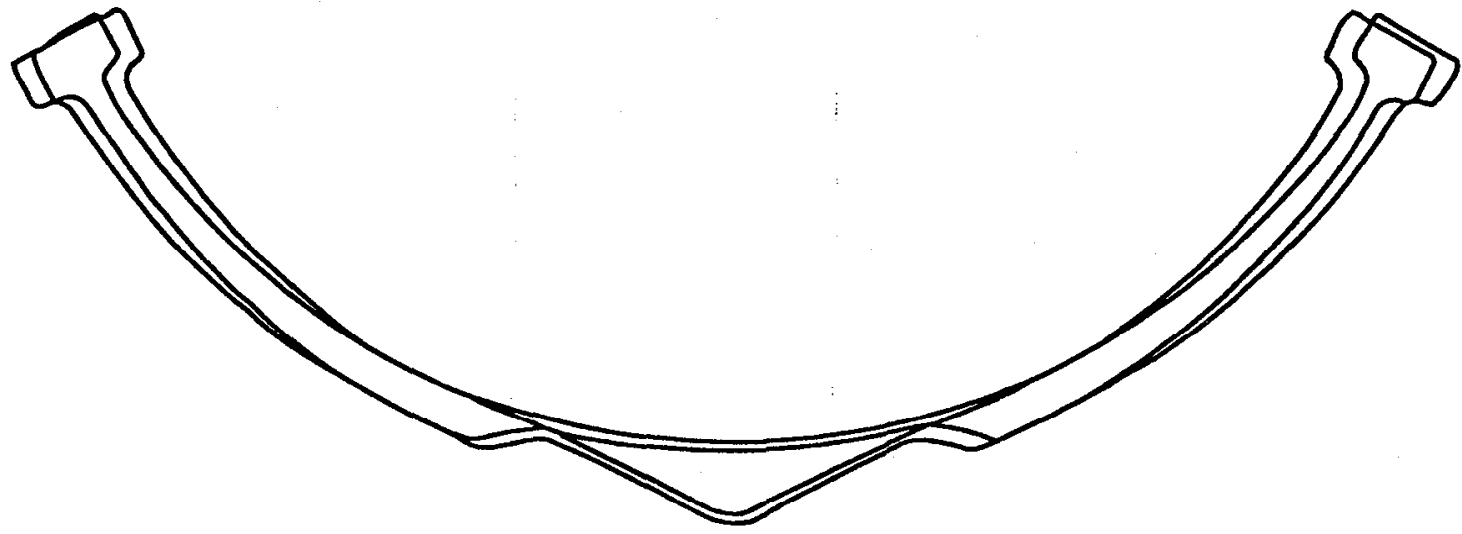

Strain gage \#7 did not balance properly before test.

Part has noticeable "soft" ylelding that absorbed most of the impact. Few bounces.

Surface cracking visible on OD under impact area.

All strain gages look OK after test.

Load cell did not trigger. No load cell data obtained.

Strain gages, video and film worked OK.

Some material distress visible in shoulders, especially outer ones. G8727-29A

Figure VI-7. PAP001238-1 S/N 1: Aluminum 2024 Sample After Test Run No. 7, Drop Height 0.25 Inch. 
SN 1

Run 8.25 -in. drop

GRC

Video Scene 8

Ret $\mathbf{d}_{\mathbf{B 2}}$

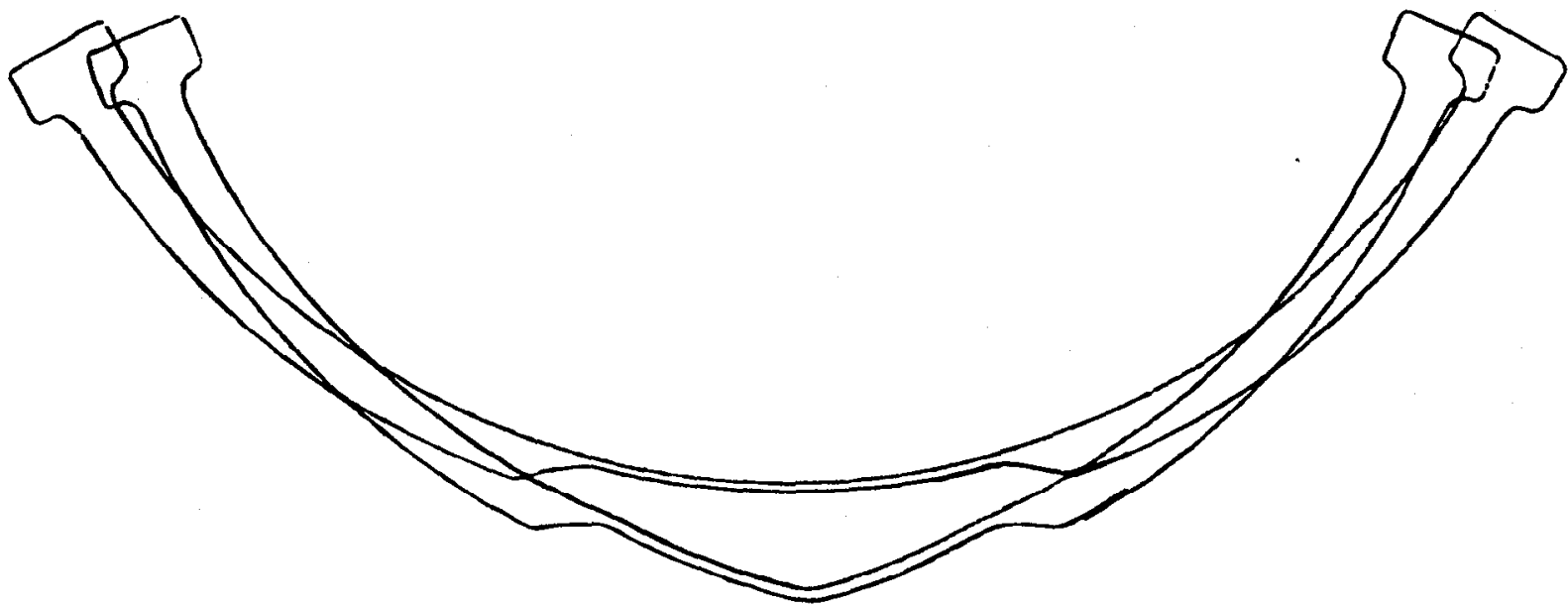

Gages \#3 and \#4 did not balance properly - data not acquired for them.

Good test - part deflected as expected.

Load cell did not trigger. All other systems OK.

No cracking visible.

Some material distress on edges of shoulders - not much.

Test flxture shows no new damage.

G8727-30A

Figure VII-8. PAP001238-2 S/N 1: Titanium 6-4 Sample After Test Run No. 8, Drop Height 0.25 Inch. 
Ref $d_{c 3}$

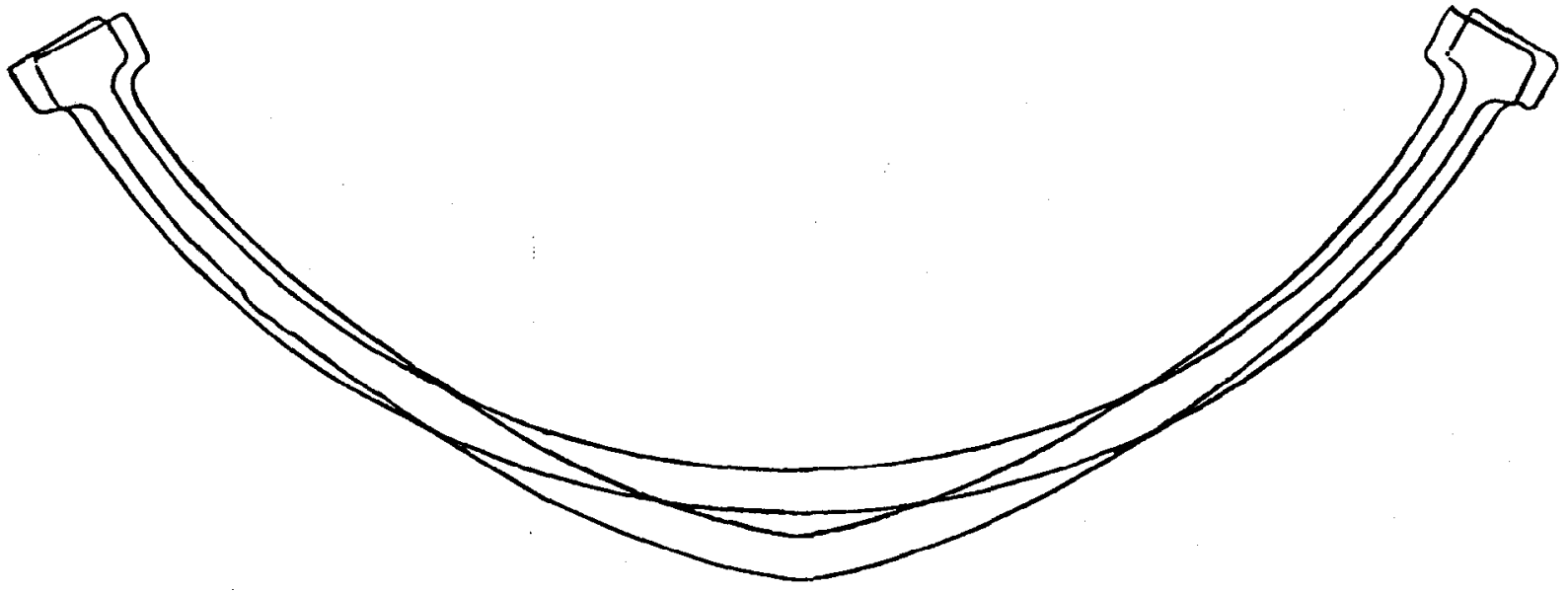

Good clean run - all systems seemed to work.

Possible break expected but did not happen.

Inner and outer shoulders show signs of material distress.

Tup hit directly on bottom dead center.

Considerable necking visible on $O D$ of part directly under impact area.

Material shows some stretching on OD of impact area but no cracks.

Test fixture shows no new damage or markings.

Max load $=4046.85 \mathrm{lb}$

$V=2.32 \mathrm{ft} / \mathrm{sec}$

Eim $=41.08 \mathrm{t} t-1 b$ G8727-31A
Time $\max$ load $=15.45 \mathrm{msec}$

Emax $=60.73 \mathrm{ft}-1 \mathrm{~b}$
Vel slowdown $=88.61 \%$

Etotal $=\mathbf{5 0 . 7 2} \mathrm{ft}-1 \mathrm{~b}$

Figure VII-9. PAP001237-1 S/N 3: Aluminum 2024 Sample After Test Run No. 9, Drop Height 1.00 Inch. 
Ref $d_{A 4}$

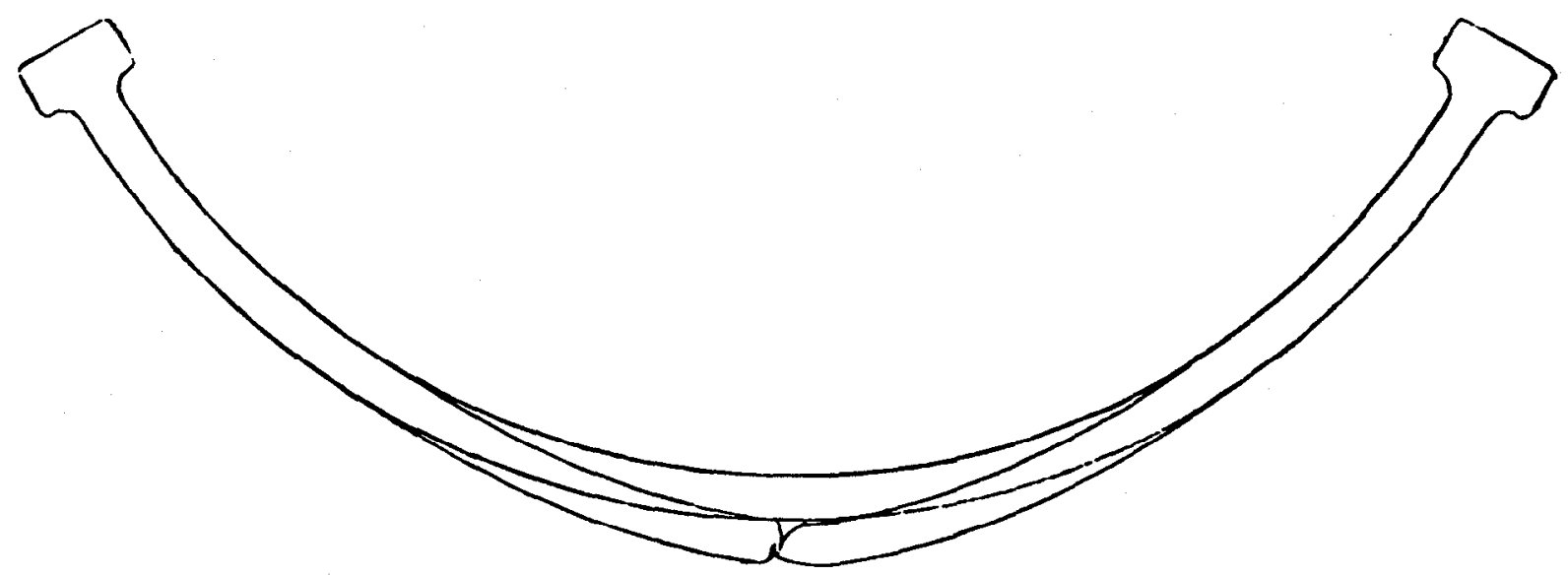

Good test - all systems worked OK.

All strain gage cables came off part rather easily after test - check if data was recorded OK - some OK. Good hit directly on bottom dead center.

Part broke In similar pattern to 15.75" drop height sample.

Material adhesion along necked sides observed at break-off point on right side piece.

High speed video shows little velocity slowdown after impact.

Test fixture shows no additional damage marks.

Material distress evident on inner and outer shoulders.

Some contact marks on edge surfaces.

Max load $=12516.79 \mathrm{lb} \quad$ Time $9 \max$ load $=3.90 \mathrm{msec} \quad$ Vel slowdown $=20.42 \%$

$V=8.07 \mathrm{ft} / \mathrm{sec}$

Eim $=497.99 \mathrm{ft}-1 \mathrm{~b}$

$E m a x=196.98 \mathrm{ft}-1 \mathrm{~b}$

Etotal $=205.99 \mathrm{ft}-1 \mathrm{~b}$

G8727-329

Figure VII-10. PAP001237-2 S/N 3: Titanium 6-4 Sample After Run No. 10, Drop Height 12.00 Inches. 
Ref d

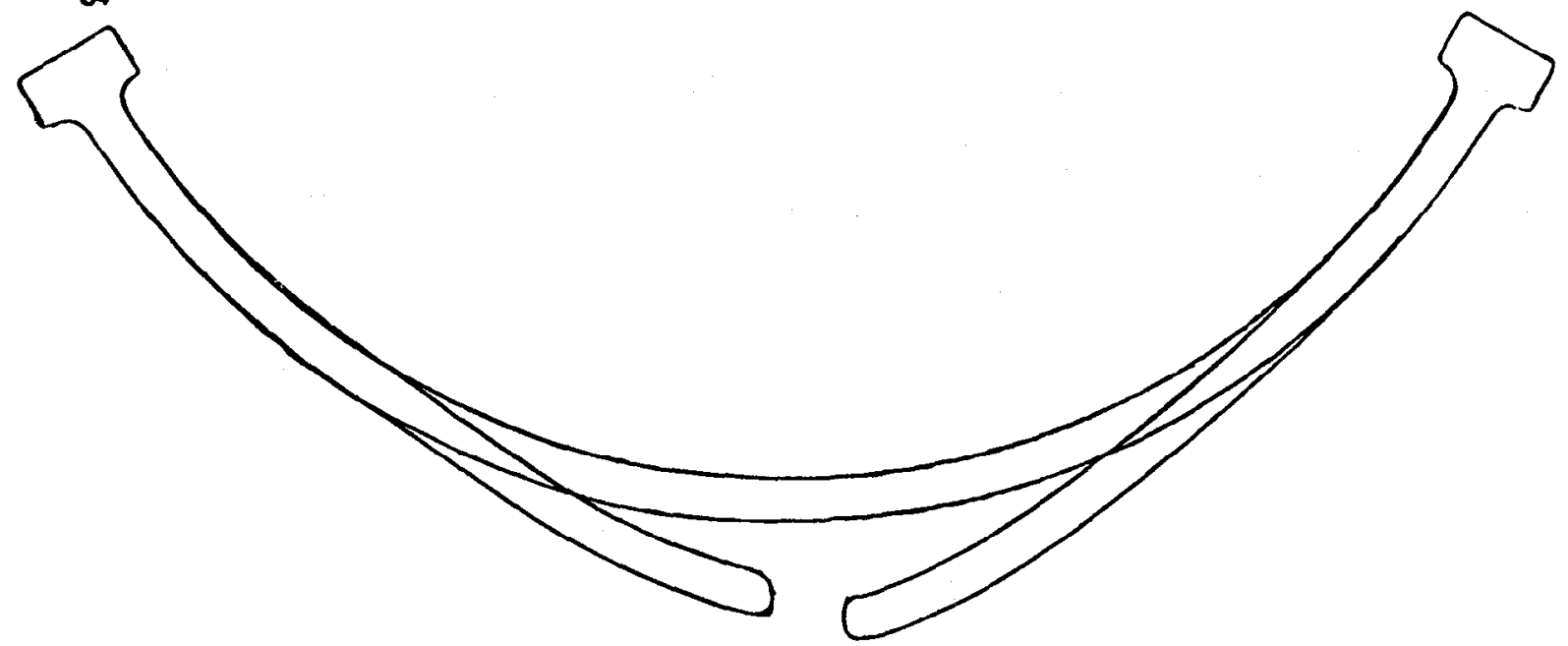

Had to rewire gages $\# 4$ and $\# 5$ before the test.

Strain gage $\$ 2$ is bad - did not record data.

All other systems worked $O K$.

Good test - specimen broke as expected directly on bottom dead center.

Specimen shows considerable deformation.

Specimen absorbed most of the impact as shown on high speed video.

Necking and heavy stretching evident around break area.

Surface marks on end surfaces and material distress on shoulders observed.

$\begin{array}{lll}\text { Max load }=4738.26 \mathrm{lb} & \text { Time } \max \text { load }=5.88 \mathrm{msec} & \text { Vel slowdown }=12.95 \% \\ V=5.18 \mathrm{ft} / \mathrm{sec} & & \\ \mathrm{Eim}=205.31 \mathrm{ft}-\mathrm{lb} & \text { Emax }=80.27 \mathrm{ft}-\mathrm{lb} & \text { Etotal }=86.44 \mathrm{ft}-\mathrm{lb}\end{array}$

Figure VII-11. PAP001237-1 S/N 2: Aluminum 2024 Sample After Test Run No. 11, Drop Height 5.00 Inches. 
SN 4

Run 12 8.00-in. drop

Ref $\mathbf{d}_{\mathbf{A S}}$

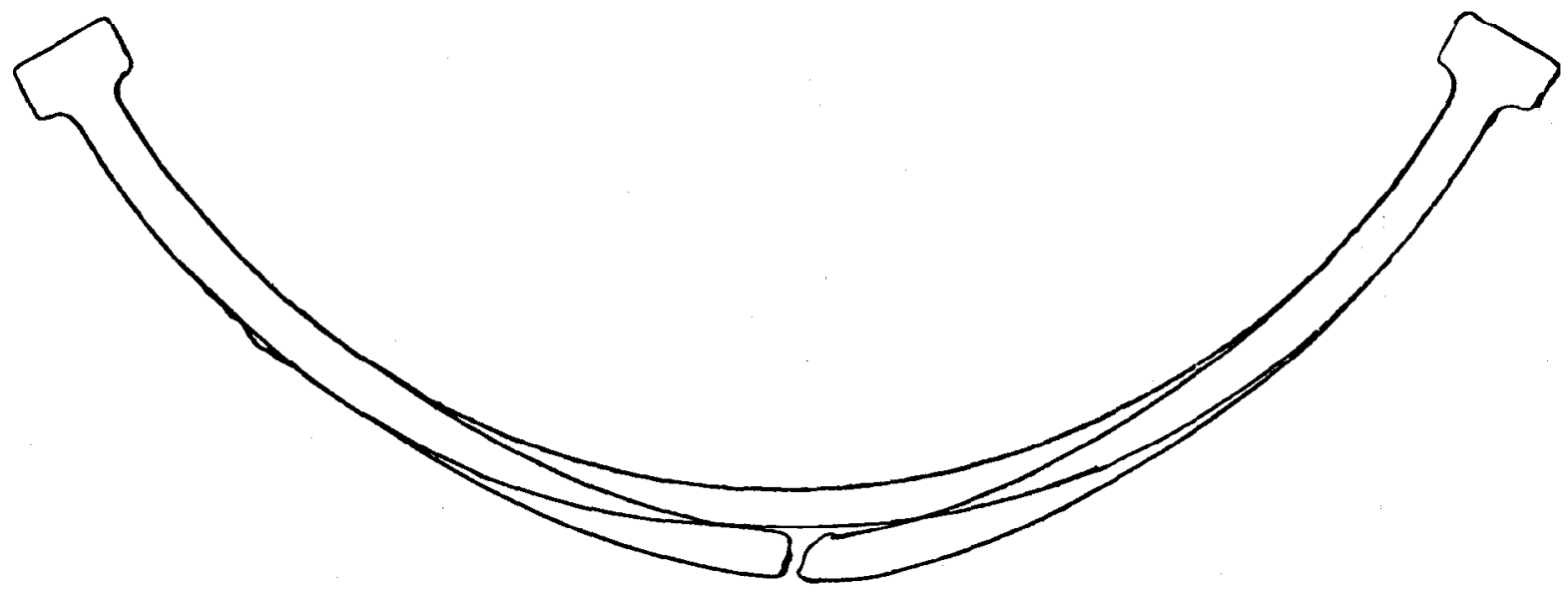

Good test - broke as expected.

High speed film lost the last 75 feet (out of 450). Lost power.

All gages and other systems worked OK.

Strain gage cables were loose after test. Some failed during test.

Specimen broke with same necking pattem as previous thick titanium specimens.

Necking and material adhesion observed at break area.

Surface marks on right end surface.

Some material distress evident on shoulders.

Test fixture shows no new damage.

$\begin{array}{lll}\text { Max load }=12105.34 \mathrm{lb} & \text { Time } \otimes \max \text { load }=4.90 \mathrm{msec} & \text { Vel slowdown }=28.06 \% \\ V=6.55 \mathrm{ft} / \mathrm{sec} & & \\ \text { Eim }=328.27 \mathrm{ft}-\mathrm{lb} & \text { Emax }=192.92 \mathrm{ft}-\mathrm{lb} & \text { Etotal }=201.05 \mathrm{ft}-\mathrm{lb}\end{array}$

Figure VII-12. PAP001237-2 S/N 4: Titanium 6-4 Sample After Test Run No. 12, Drop Height 8.00 Inches. 
Ref $\mathbf{d}_{\mathbf{B 3}}$

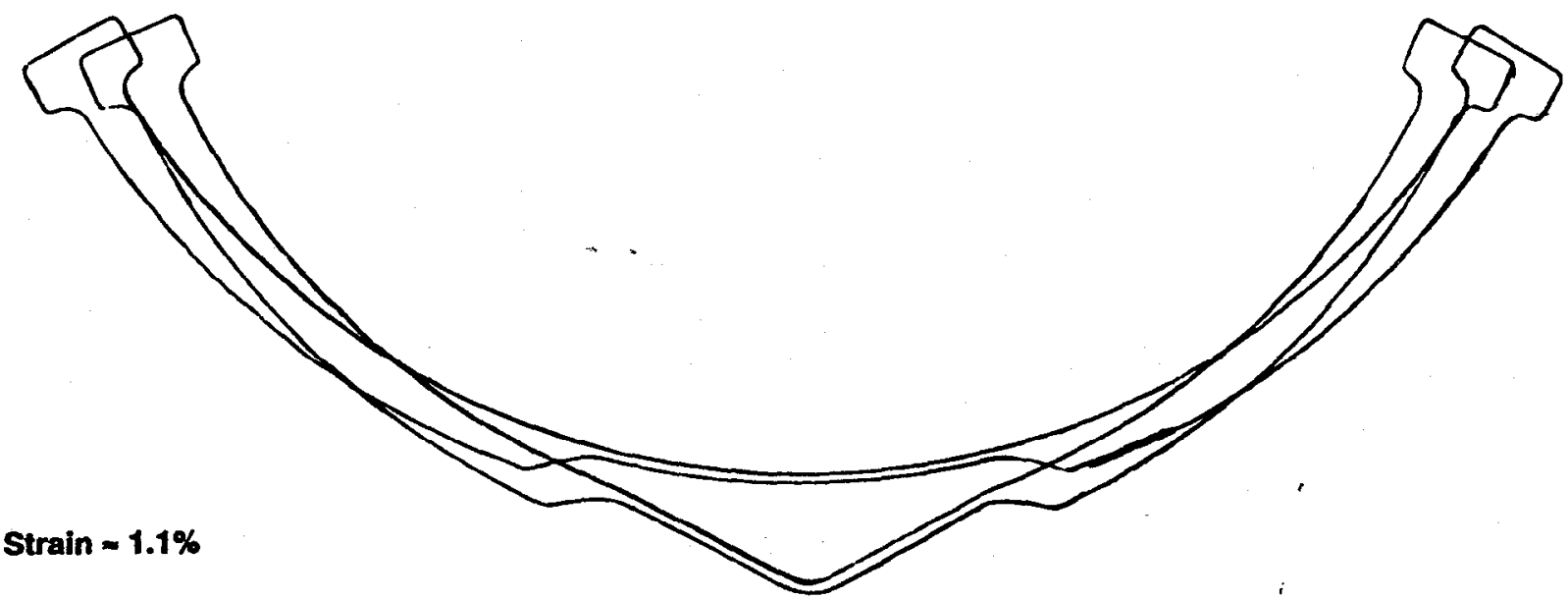

All systems worked during test.

Part did not break but stretched quite a blt.

Discoloration seen on ID Impact area.

All strain gages still attached to specimen. Impact area at $O D$ shows nothing unusual.

Material distress evident at shoulder areas.

Test fixture shows no new damage.

Analyzed video and test rig to see if it could have hit rubber stops - unilikely.

Max load $=6024.81 \mathrm{lb}$ $V=2.32 \mathrm{ft} / \mathrm{sec}$

Eim $=41.08 \mathrm{ft}-1 \mathrm{~b}$ G8727-35h
Time $\max l o a d=15.32 \mathrm{msec}$

$E \max =61.80 \mathrm{ft}-1 \mathrm{~b}$
Vel slowdown $=74.29 \%$

Etotal $=36.04 \mathrm{ft}-1 \mathrm{~b}$

Figure VII-13. PAP001238-2 S/N 4: Titanium 6-4 Sample After Test Run No. 13, Drop Height 1.00 Inch. 
Ref $d_{02}$

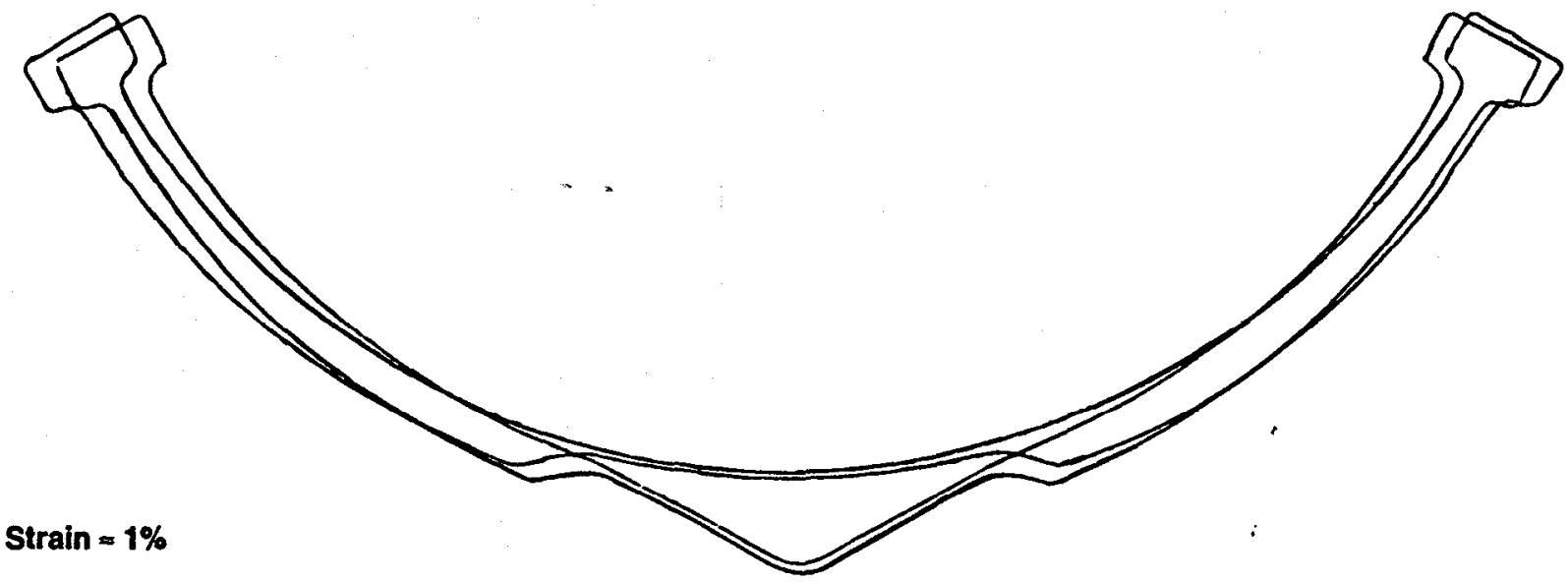

All gages balanced OK before test.

Moved rubber stops lower to ensure no accidental contact before break.

Part did not break but deformed.

Cracking observed on OD under Impact area on surface.

All systems worked OK.

Material distress evident on inner and outer shoulders, especially right side.

No additional marks or damage to test fixture.

Max load $=2433.14 \mathrm{lb} \quad$ Time $\max l o a d=24.75 \mathrm{msec}$

Vel slowdown $\mathbf{=} \mathbf{8 3 . 0 9 \%}$

$V=1.64 \mathrm{ft} / \mathrm{sec}$

$\operatorname{Eim}=20.53 \mathrm{ft}-1 \mathrm{~b}$

$E \max =\mathbf{4 2 . 9 4} \mathrm{ft-1b}$

Etotal $=36.51 \mathrm{ft-1b}$

G8727.36A

Figure VII-14. PAP001238-1 S/N 2: Aluminum 2024 Sample After Test Run No. 14, Drop Height 0.50 Inch. 
PAP001238-2

S/N 3

Run \#15 3.00-in. drop

Video Scene 15

Ref $\mathbf{d}_{\mathrm{BA}}$

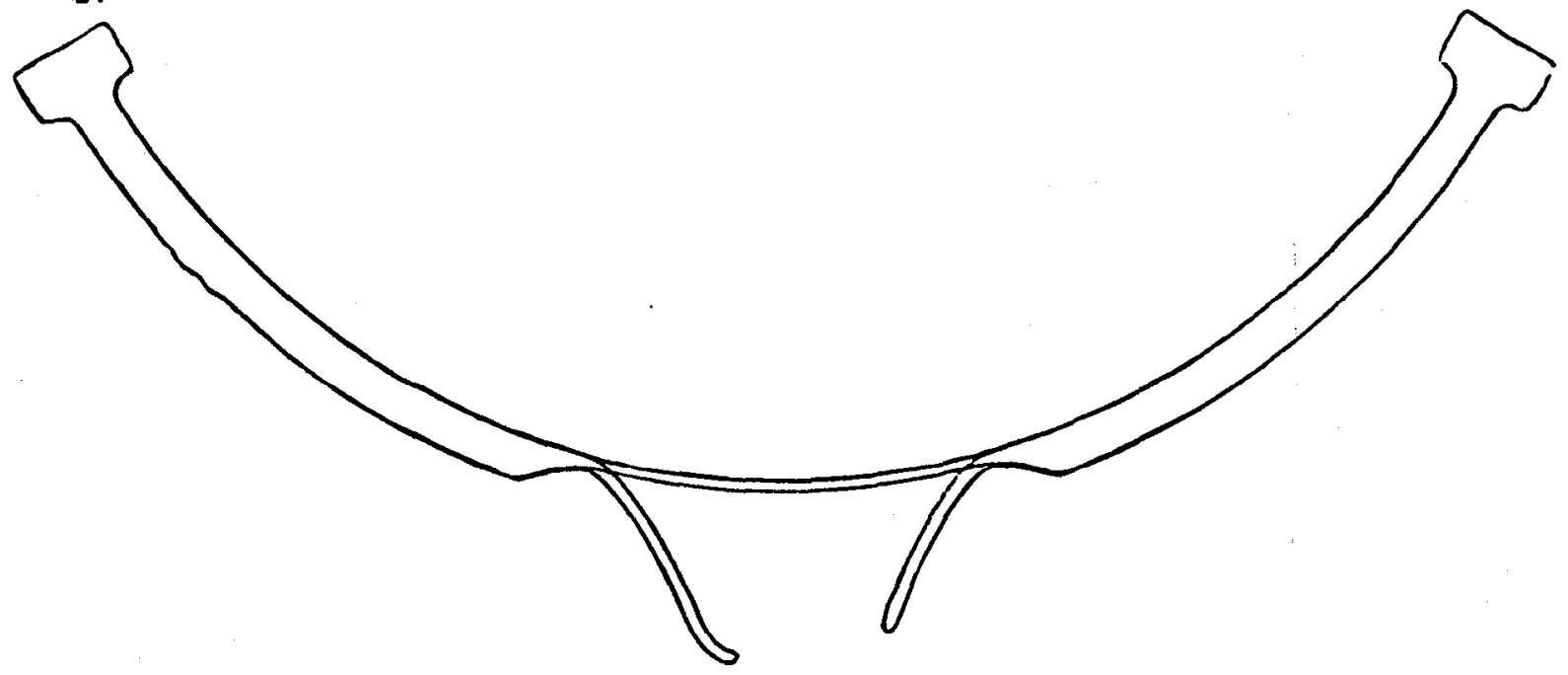

Load cell triggered but returned an error message so no data was stored.

All other systems seemed to work OK.

Part broke to the right of bottom dead center.

Video shows almost complete slowing down of tup before fallure.

Thicker areas of specimen show no permanent deformation.

Tup fell down all the way to rubber stops after fallure and deformed specimen.

Some strain gage cables broke off at impact.

Some material distress evident, especially on outer shouldere.

No damage to test flxture.

G8727.37A

Figure VII-15. PAP001238-2 S/N 3: Titanium 6-4 Sample After Test Run No. 15, Drop Height 3.00 Inches. 
Ref $d_{03}$

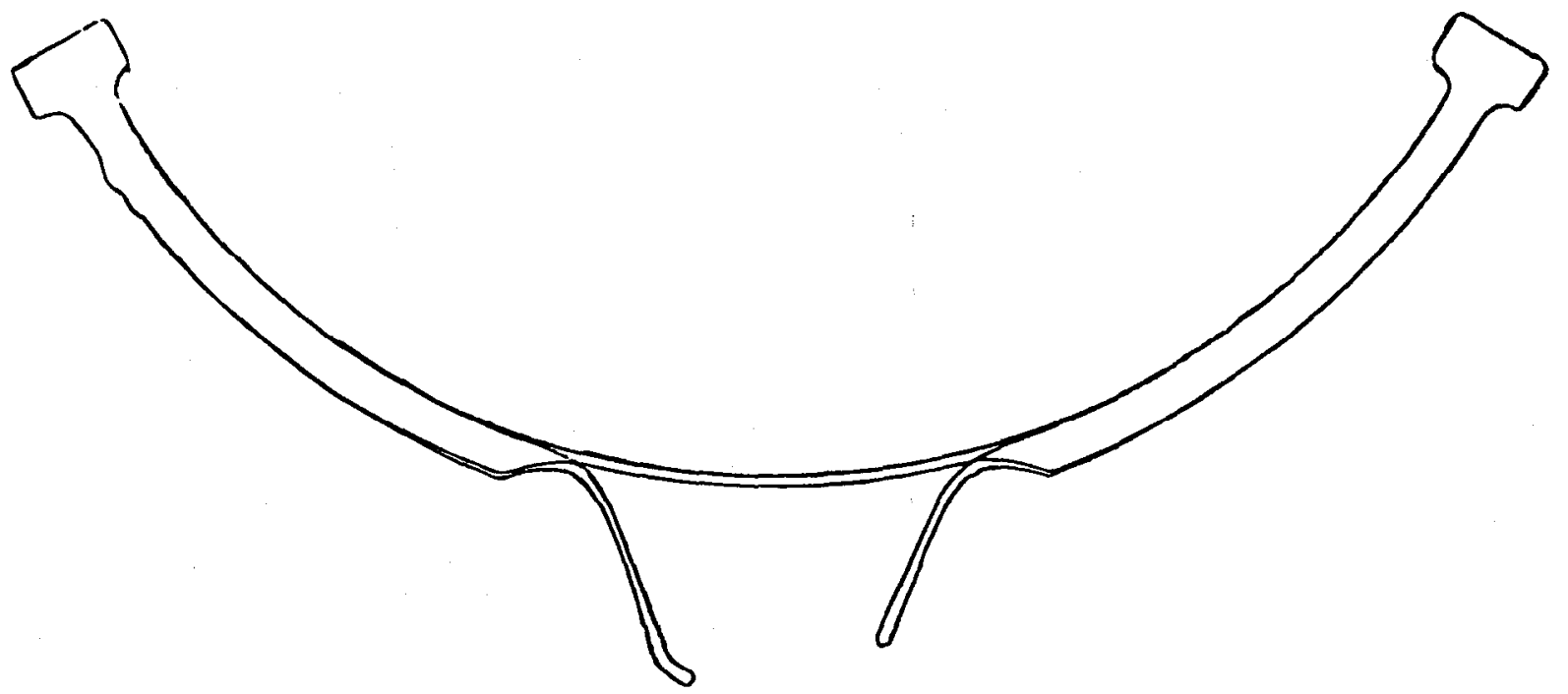

Gages \#1 and \#4 were giving balancing problems but were apparently fixed.

Load cell triggered OK but gave error - no load center data stored.

All other systems recorded OK.

Part hit at bottom dead center but broke off to the right of bottom dead center.

Tup ran right through the part and deflected it some more.

Almost no permanent deflection on thicker areas of specimen.

Material distress and contact marks more evident on outer shoulder than inner.

No additional damage to test fixture.

G8727.38n

Figure VII-16. PAP001238-1 S/N 3: Aluminum 2024 Sample After Test Run No. 16, Drop Height 2.00 Inches. 
APPENDIX VIII

RAW LOAD CELL DATA

(11 pages) 


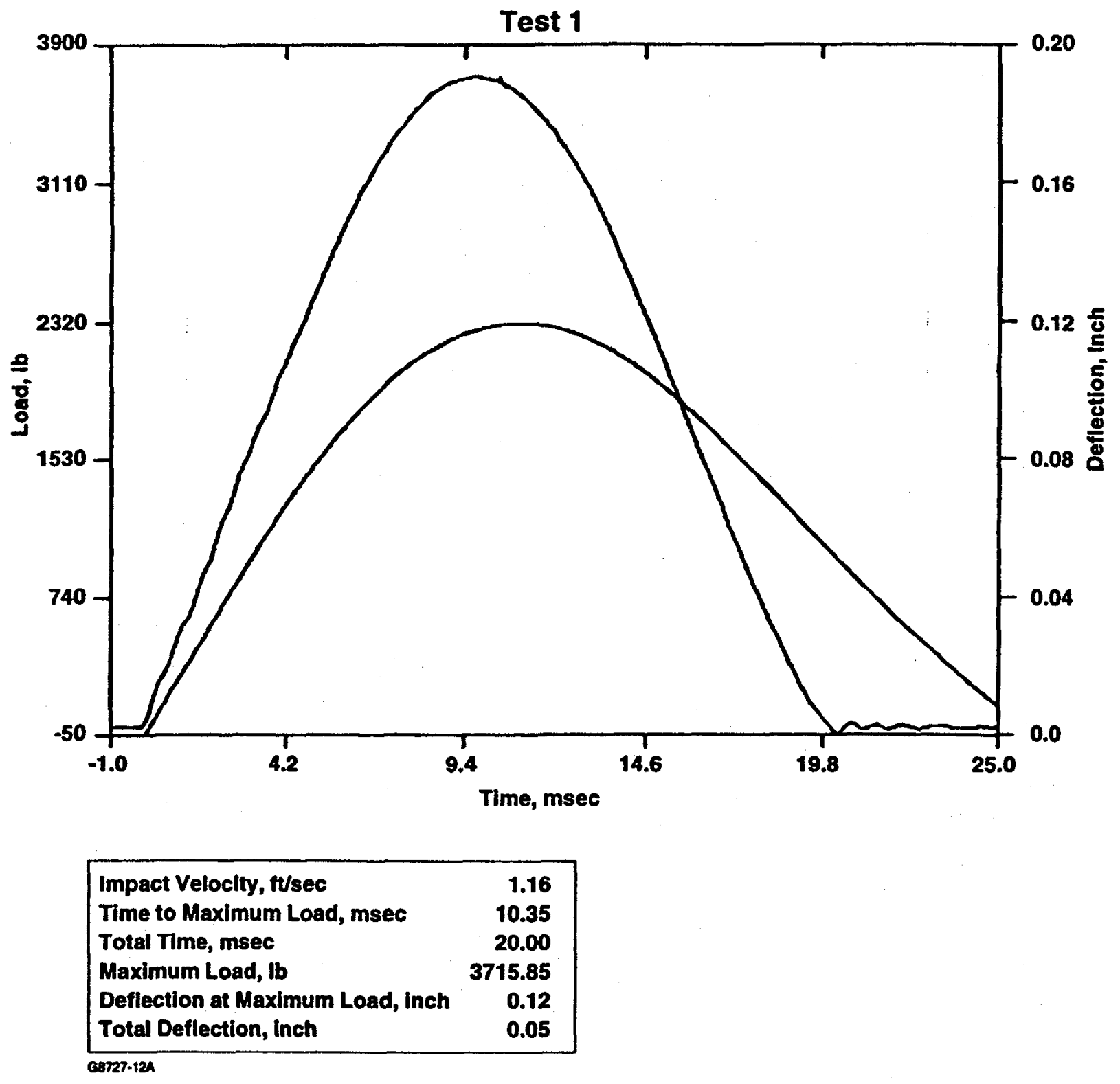

Figure VIII-1. Load vs. Time, Test No. 1. 


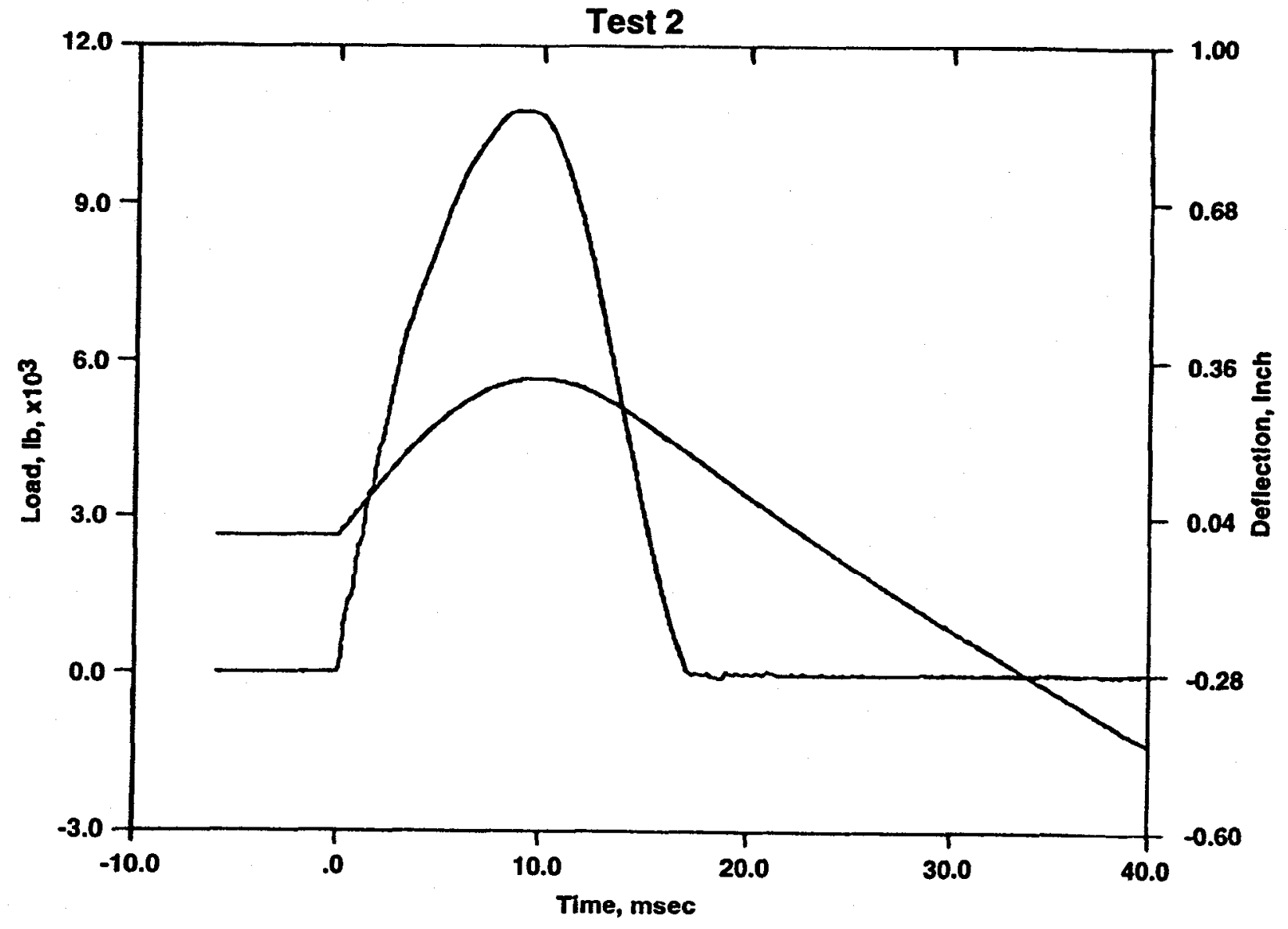

\begin{tabular}{|lr|}
\hline Impact Velocity, ft/sec & 4.18 \\
Time to Maximum Load, msec & 8.95 \\
Total Time, msec & 17.17 \\
Maximum Load, Ib & $10,789.26$ \\
Deflectlon at Maximum Load, inch & 0.32 \\
Total Deflection, inch & 0.17 \\
\hline
\end{tabular}

Figure VIII-2. Load vs. Time, Test No. 2. 


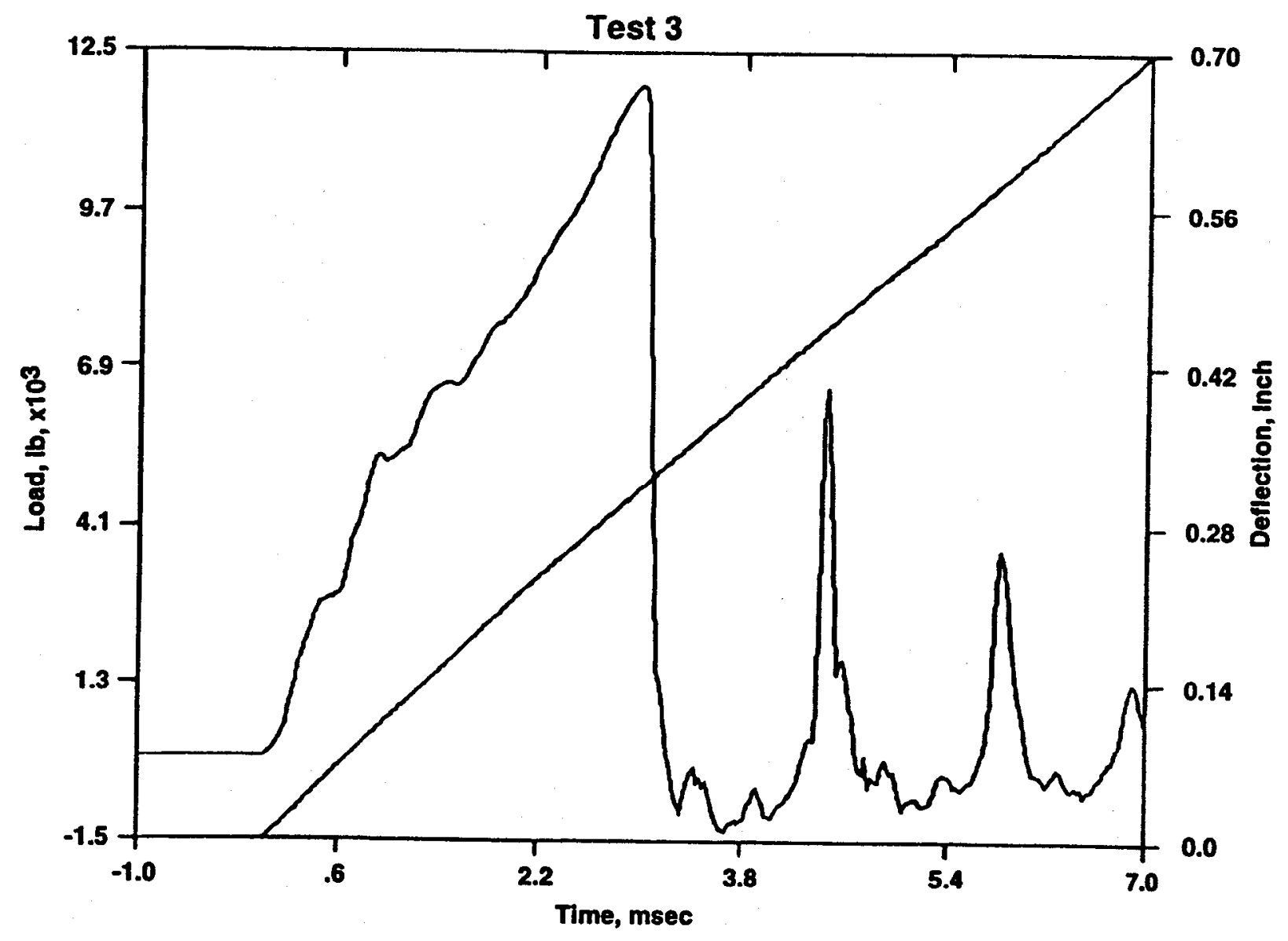

\begin{tabular}{lc}
\hline Impact Velocity, ft/sec & 9.18 \\
Time to Maximum Load, msec & 2.97 \\
Total Time, msec & 3.22 \\
Maximum Load, Ib & $11,916.15$ \\
Deflectlon at Maximum Load, Inch & 0.31 \\
Total Deflection, Inch & 0.34 \\
\hline
\end{tabular}

Figure VIII-3. Load vs. Time, Test No. 3. 


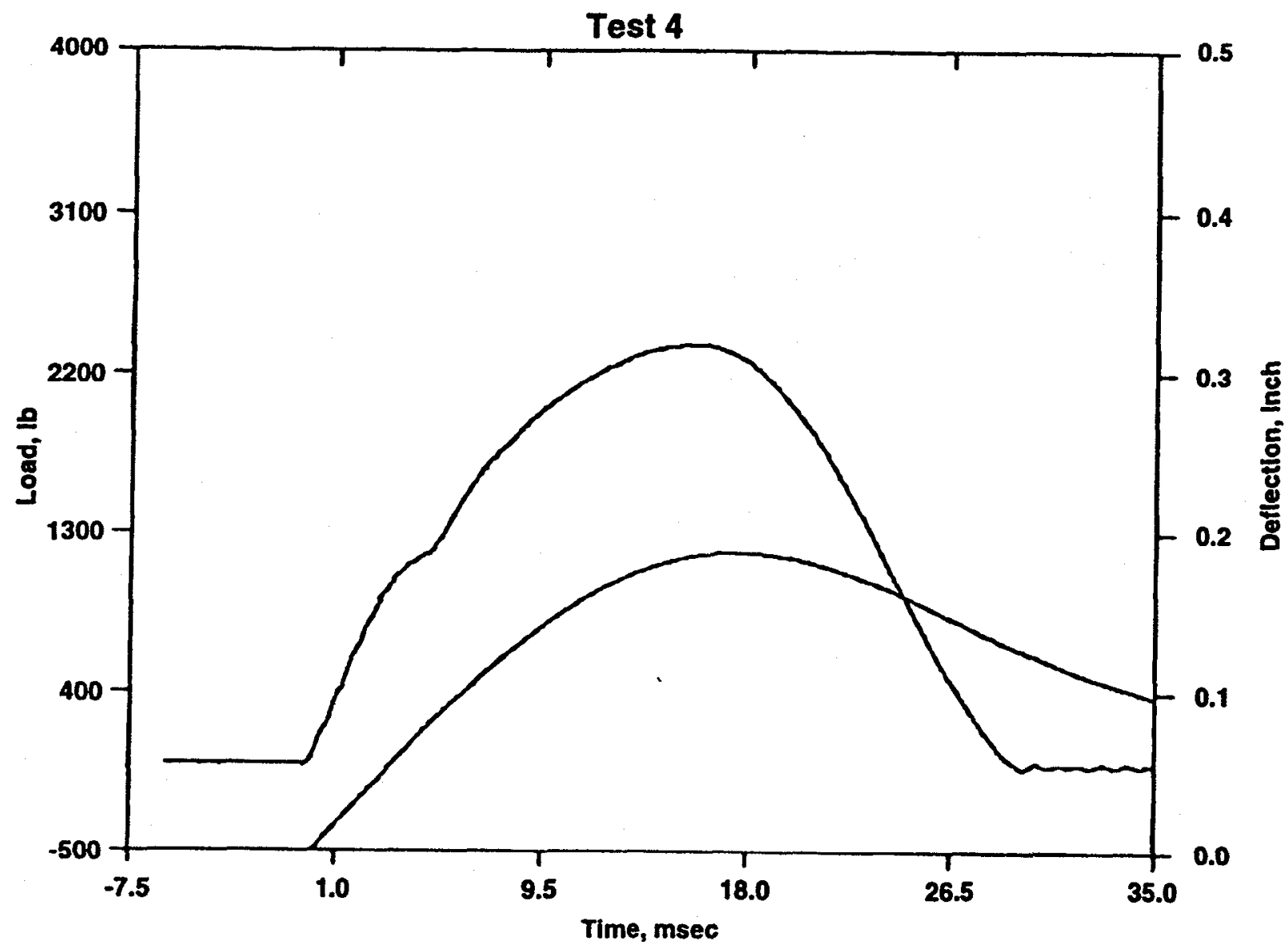

\begin{tabular}{|lr}
\hline Impact Velocity, ttsec & 1.16 \\
Time to Maximum Load, msec & 15.45 \\
Total Time, msec & 29.25 \\
Maximum Load, Ib & 2367.76 \\
Deflection at Maximum Load, inch & 0.18 \\
Total Deflection, inch & 0.13 \\
\hline
\end{tabular}

Figure VII-4. Load vs. Time, Test No. 4. 


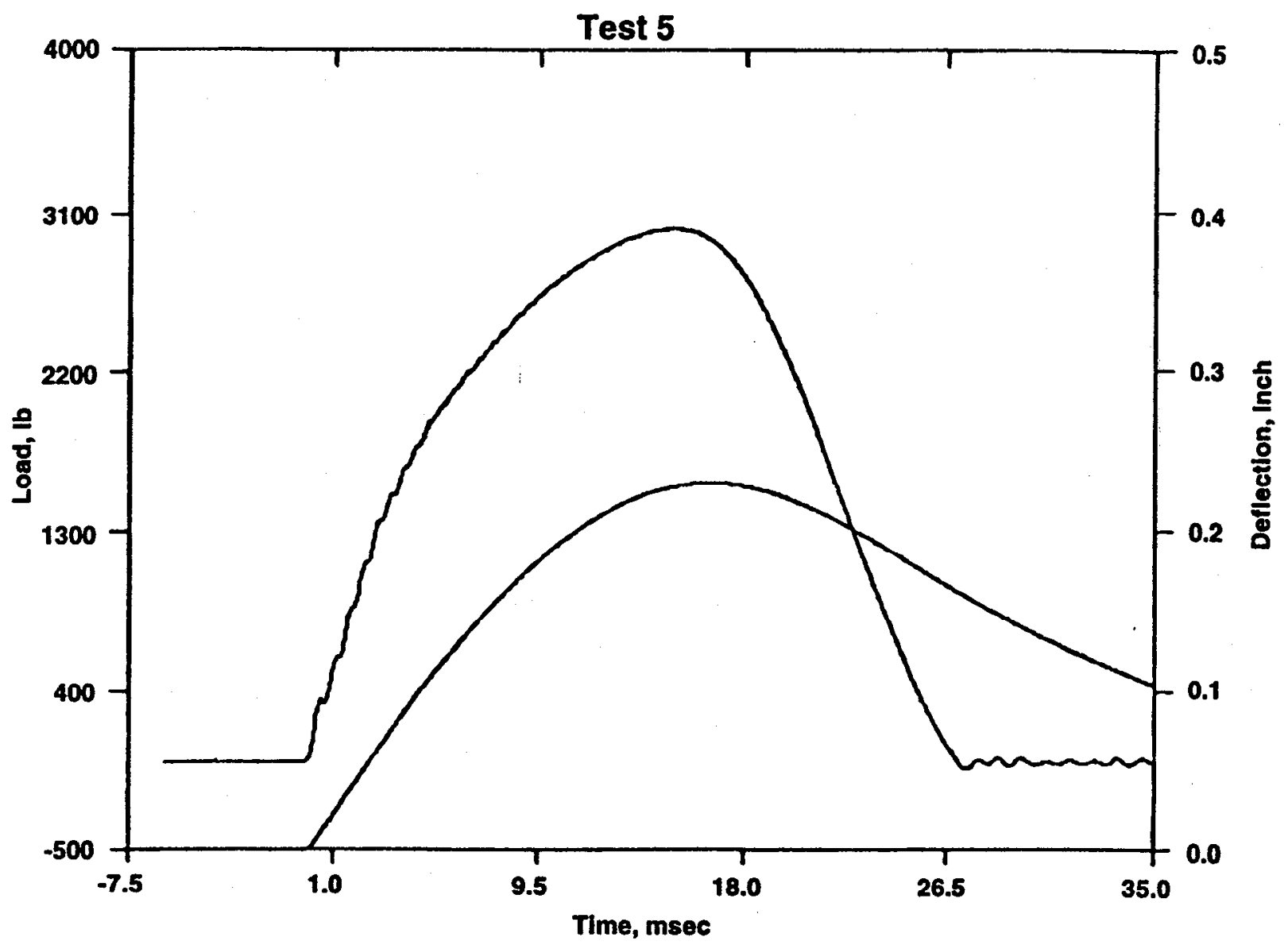

\begin{tabular}{|lr|}
\hline Impact Velocity, ft/sec & 1.64 \\
Time to Maximum Load, msec & 14.92 \\
Total Time, msec & 27.00 \\
Maximum Load, ib & 3013.69 \\
Deflection at Maximum Load, inch & 0.23 \\
Total Deflection, Inch & 0.16 \\
\hline
\end{tabular}

Figure VIII-5. Load vs. Time, Test No. 5. 


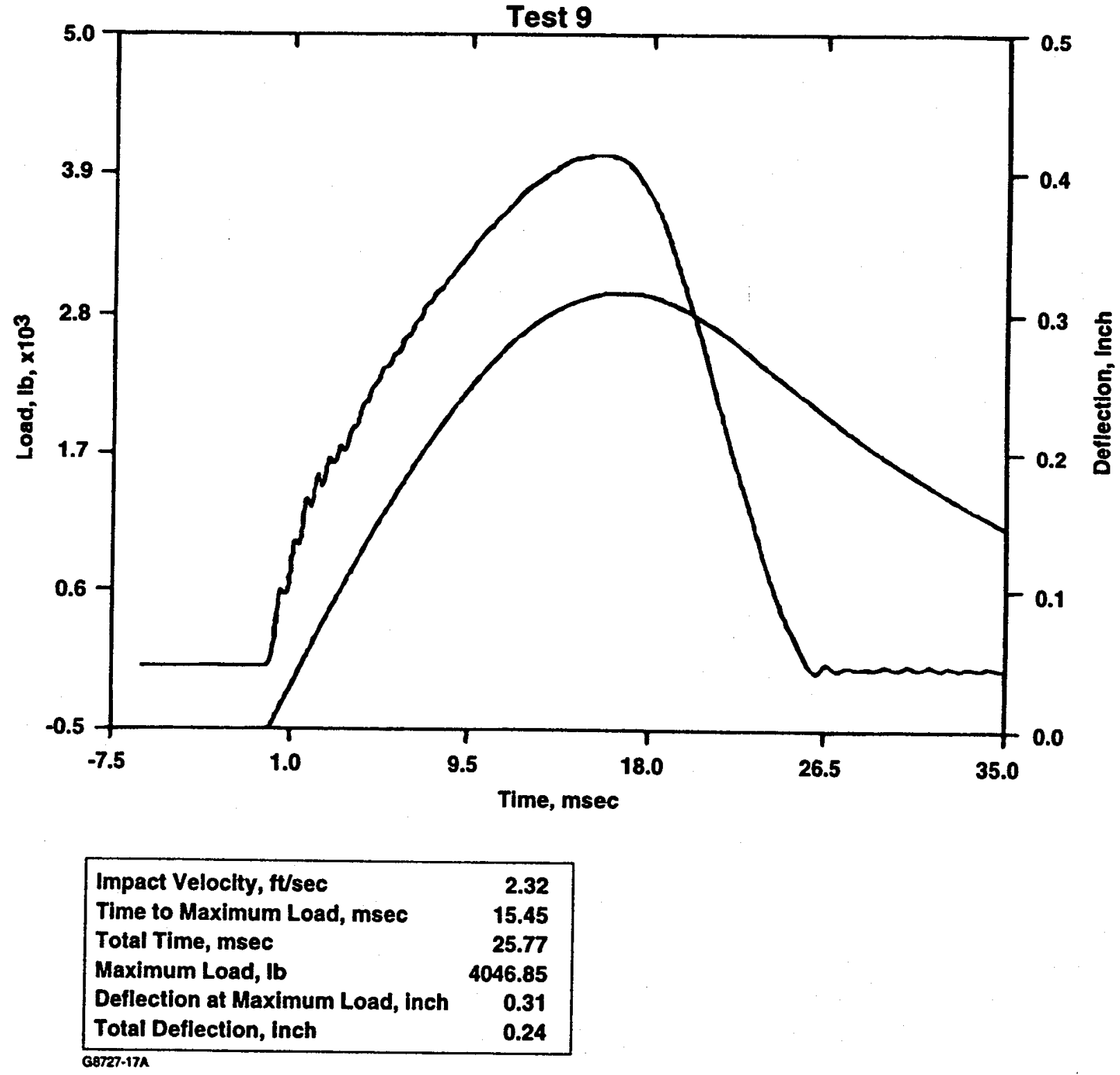

Figure VIII-6. Load vs. Time, Test No. 9. 


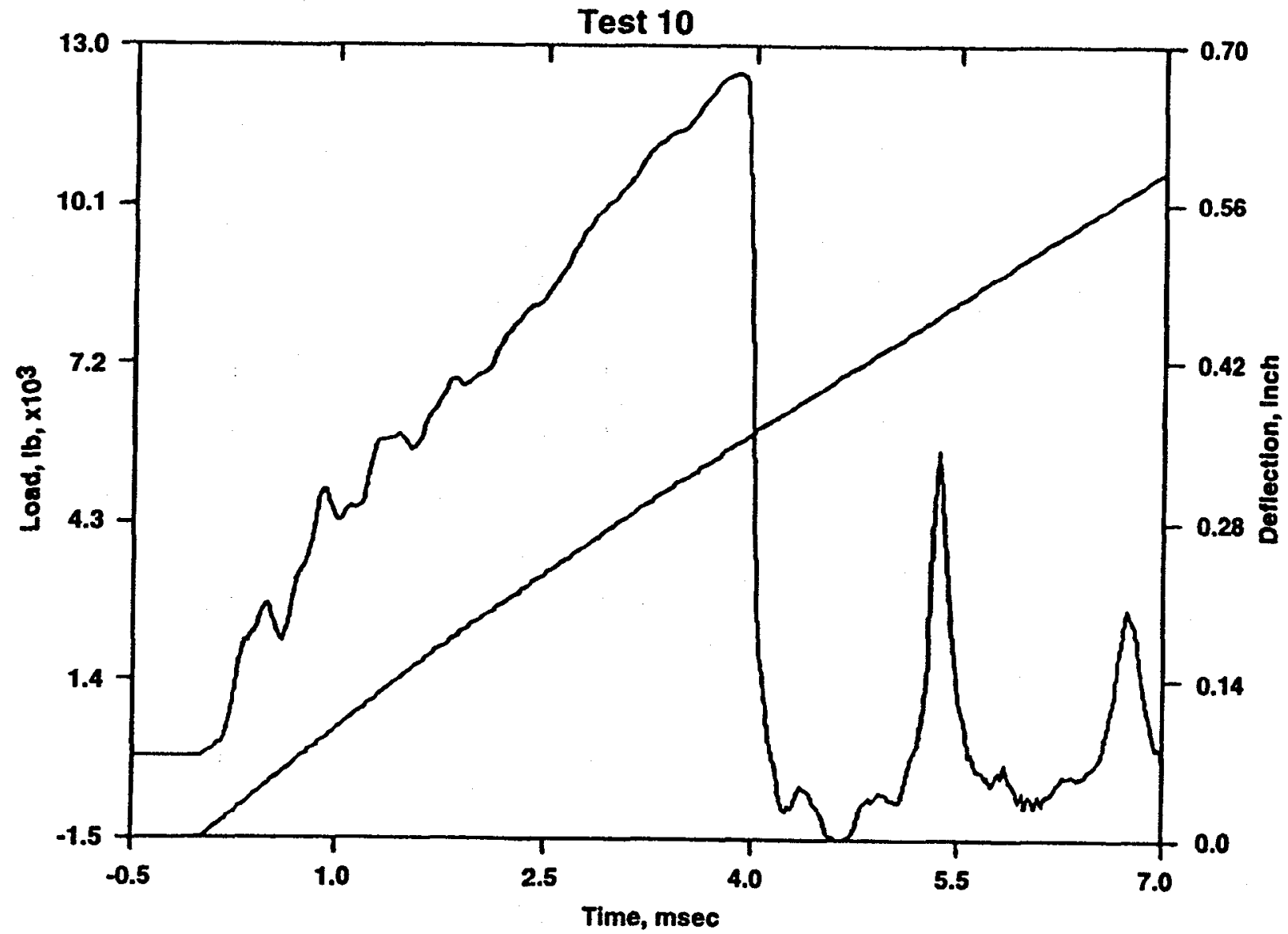

\begin{tabular}{|lc|}
\hline Impact Velocity, ft/sec & 8.07 \\
Time to Maximum Load, msec & 3.90 \\
Total Time, msec & 4.17 \\
Maximum Load, Ib & $12,516.79$ \\
Deflection at Maximum Load, inch & 0.35 \\
Total Deflection, Inch & 0.37
\end{tabular}

G8727-18A

Figure VIII-7. Load vs. Time, Test No. 10. 


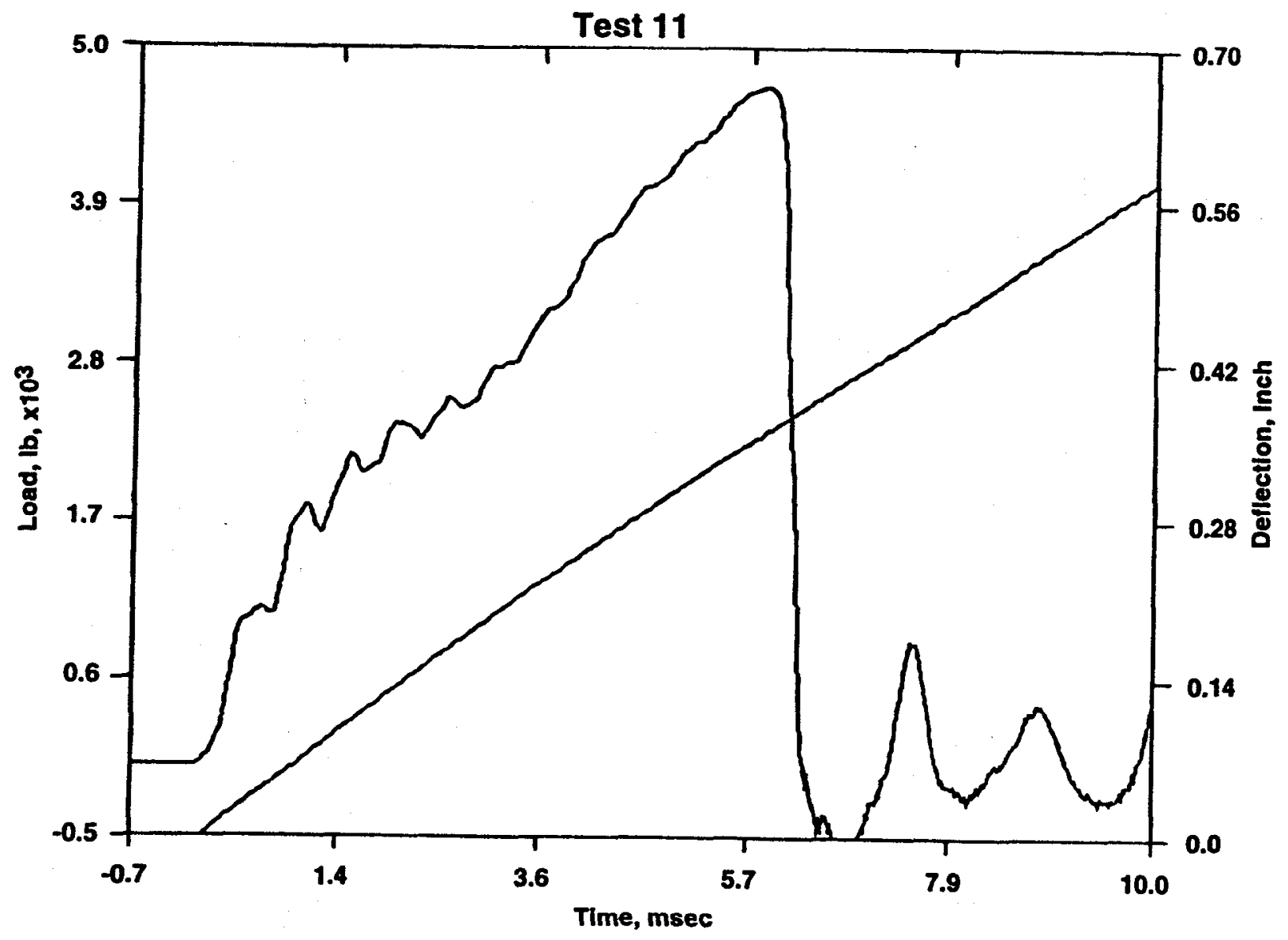

\begin{tabular}{|lr|}
\hline Impact Velocity, $\mathrm{ft} / \mathrm{sec}$ & 5.18 \\
Time to Maximum Load, msec & 5.88 \\
Total Time, msec & 6.32 \\
Maximum Load, Ib & 4738.26 \\
Deflection at Maximum Load, Inch & .36 \\
Total Deflection, inch & .38 \\
\hline
\end{tabular}

G8727-189

Figure VIII-8. Load vs. Time, Test No. 11. 


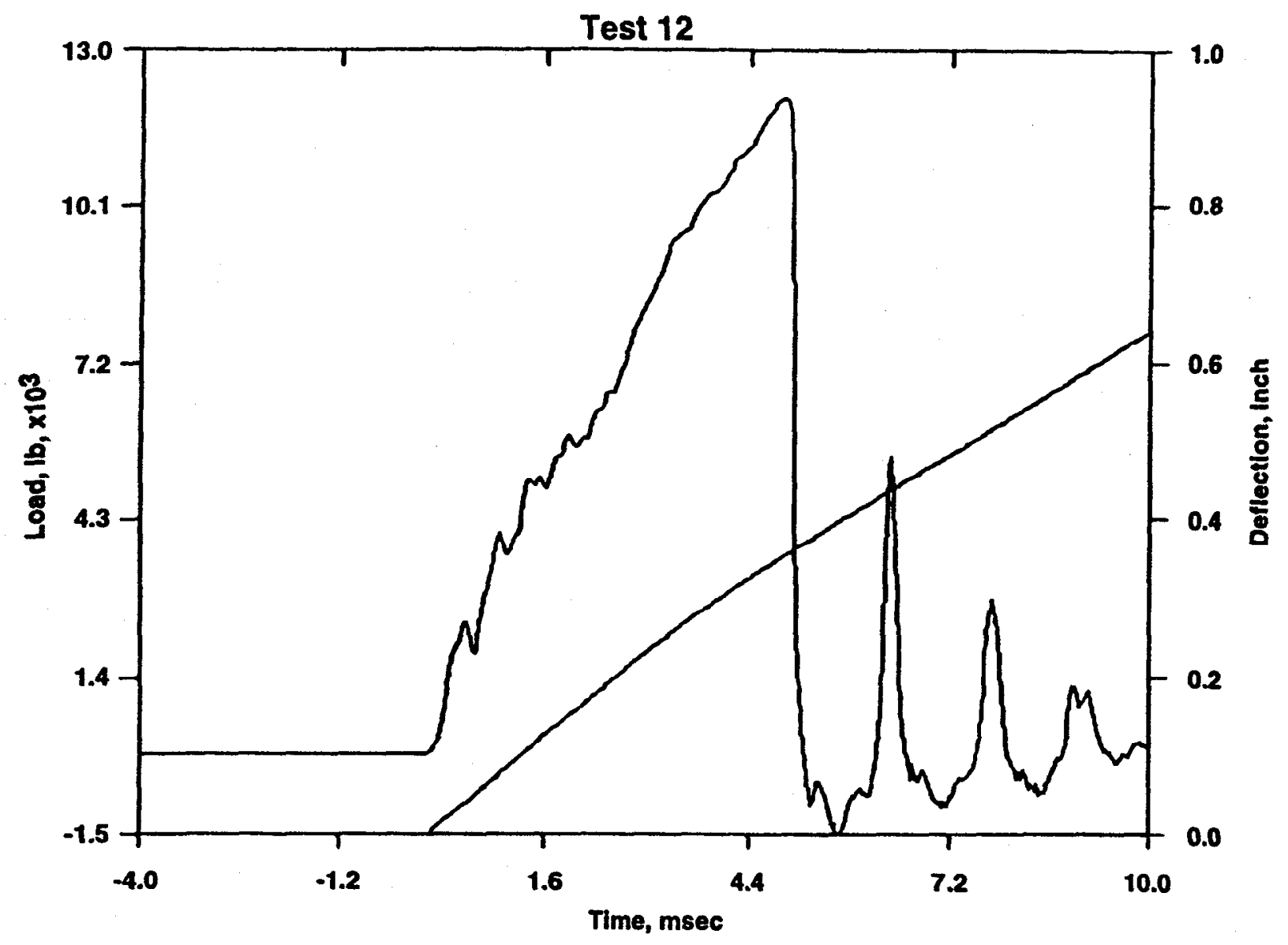

\begin{tabular}{|rr|}
\hline Impact Velocity, ft/sec & 6.55 \\
Time to Maximum Load, msec & 4.90 \\
Total Time, msec & 5.20 \\
Maximum Load, lb & $12,105.34$ \\
Deflectlon at Maximum Load, Inch & 0.36 \\
Total Deflectlon, inch & 0.37 \\
\hline
\end{tabular}

Figure VIII-9. Load vs. Time, Test No. 12. 


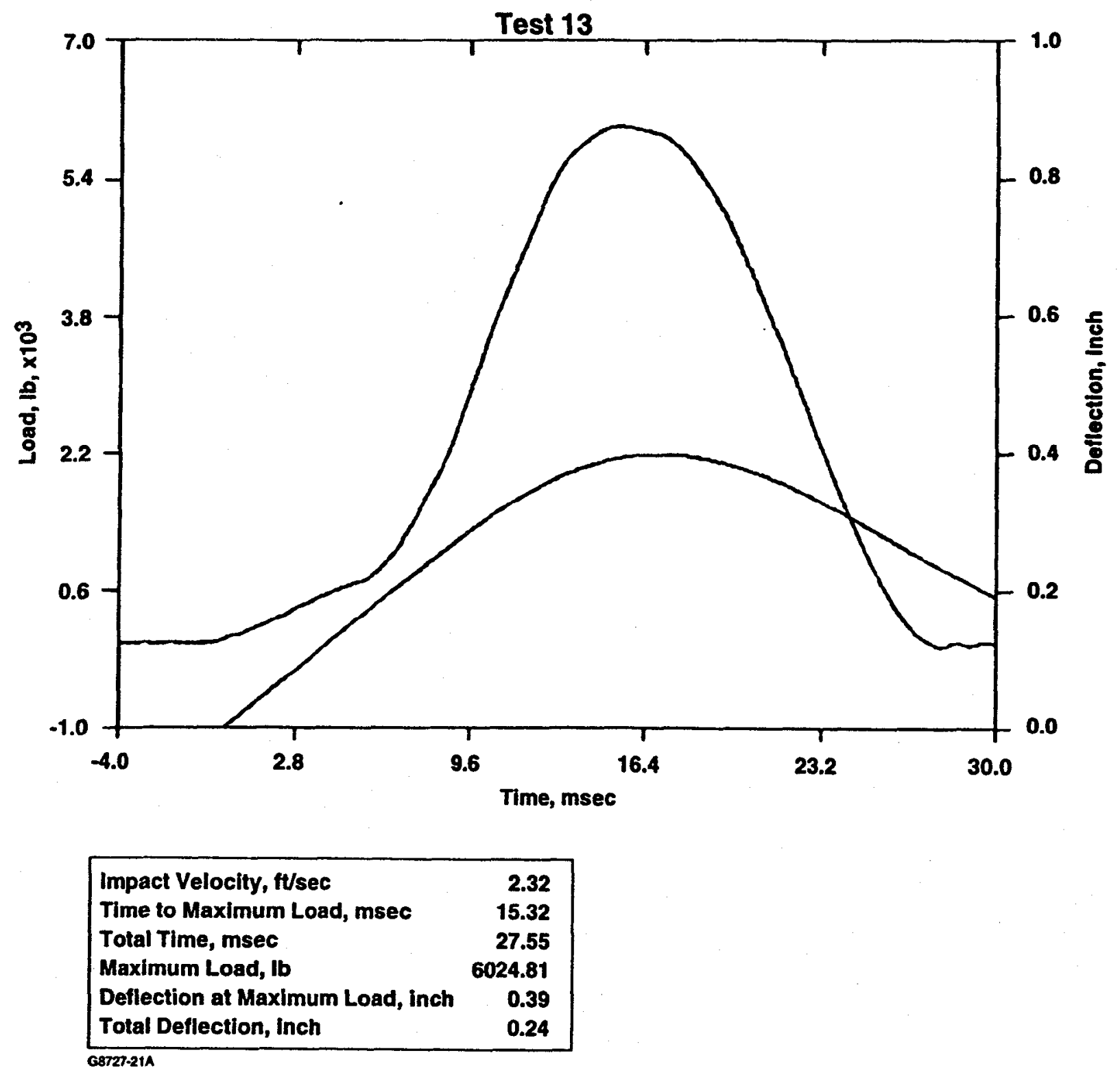

Figure VIII-10. Load vs. Time, Test No. 13. 


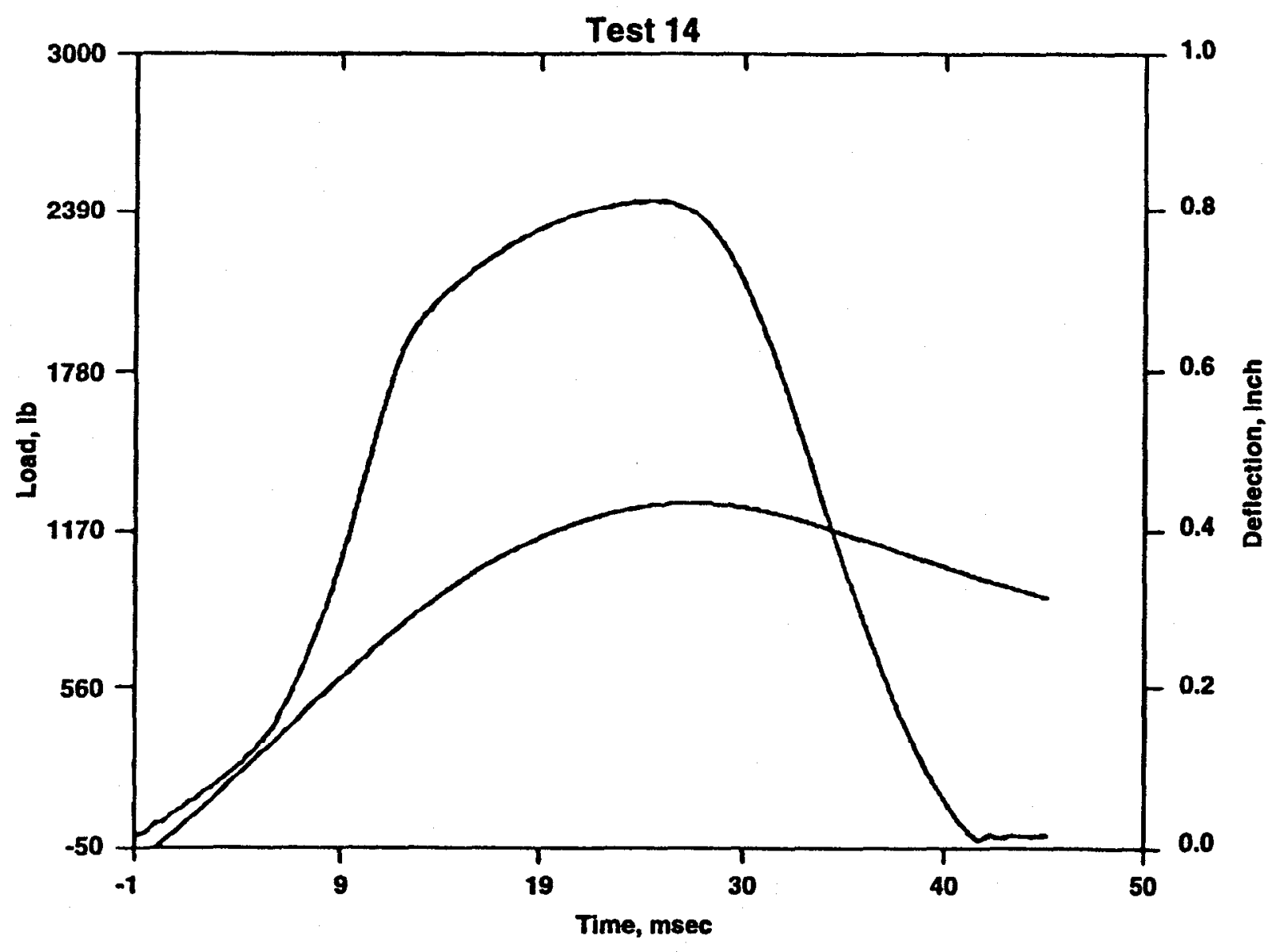

\begin{tabular}{|lr|}
\hline Impact Velocity, ft/sec & 1.64 \\
Time to Maximum Load, msec & 24.75 \\
Total Time, msec & 41.17 \\
Maximum Load, ib & 2433.14 \\
Deflection at Maximum Load, inch & 0.43 \\
Total Deflection, inch & 0.34 \\
\hline
\end{tabular}

Figure VIII-11. Load vs. Time, Test No. 14. 


\title{
AlliedSignal
}

A EROSPACE

\author{
APPENDIX LX \\ STRAIN GAGE VS. TIME PLOTS AND \\ MAXIMUM STRAIN PLOTS \\ ( 9 pages)
}

DX-i 
Test No. 2

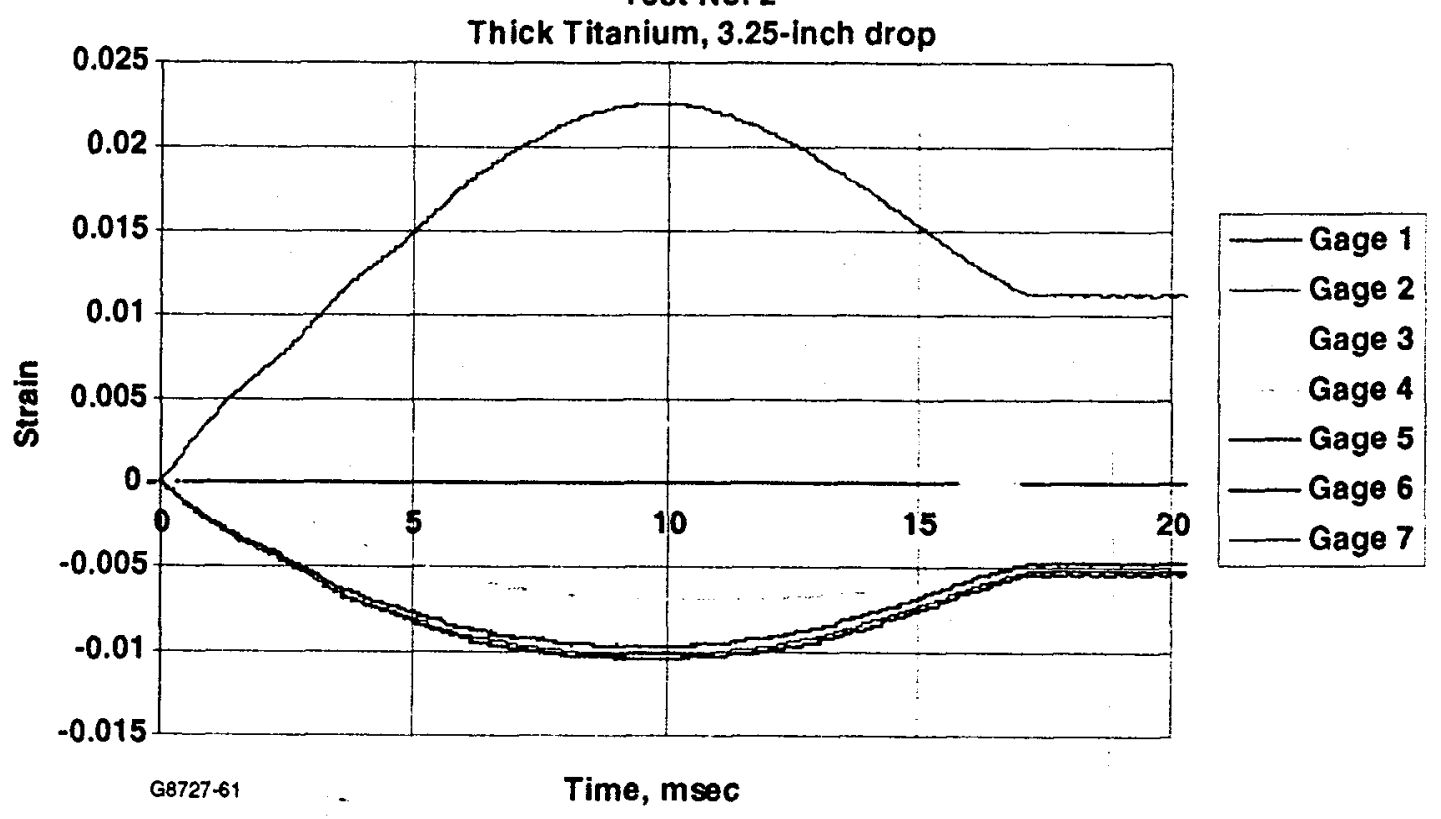

Figure IX-1. Strain Gage vs. Time, Test No. 2, Thick Titanium Sample, 3.25-Inch Drop.

Test No. 3

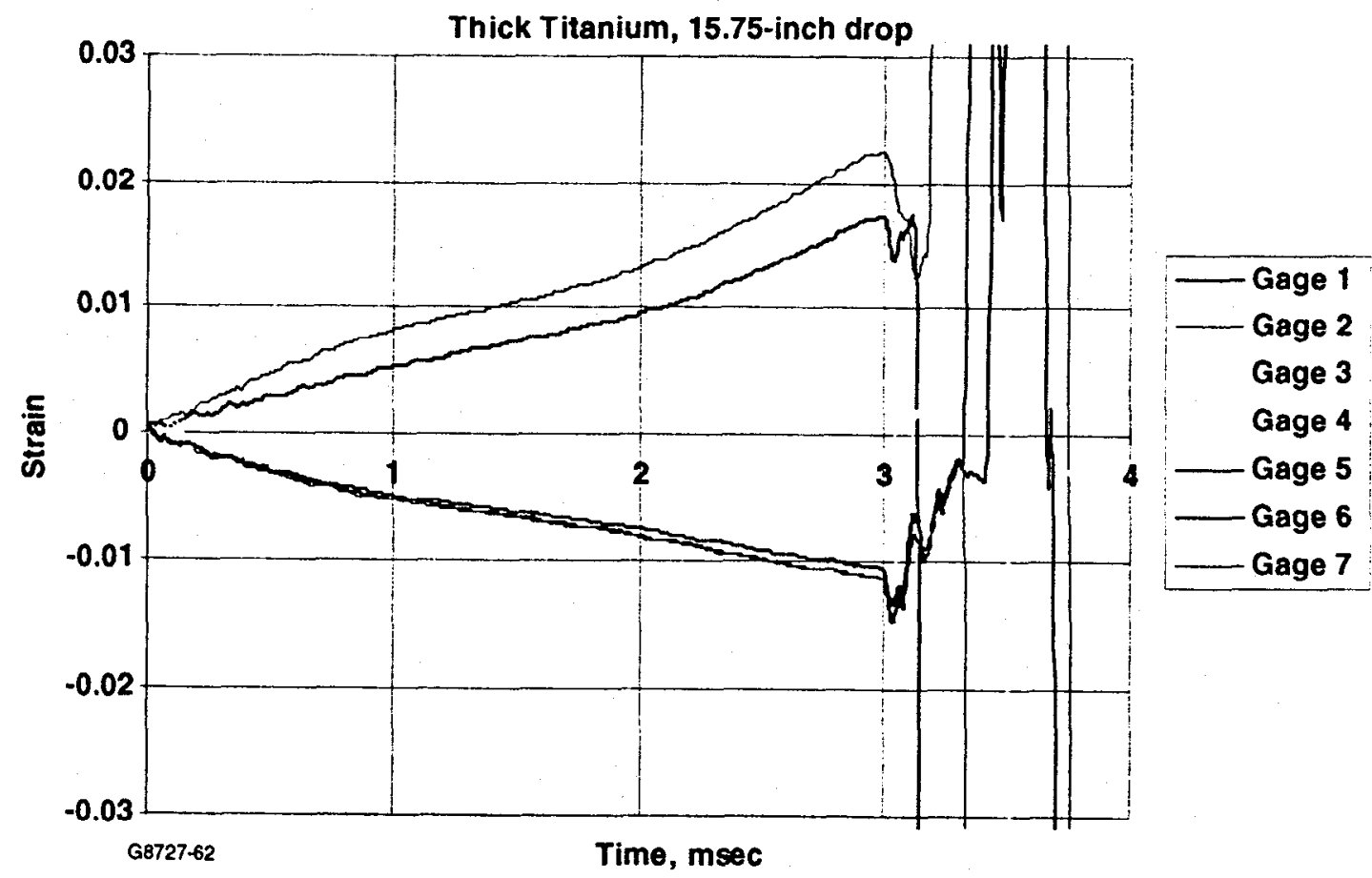

Figure IX-2. Strain Gage vs. Time, Test No. 3, Thick Titanium Sample, 15.75-Inch Drop. 
Test No. 4

Thick Aluminum, 0.25-inch drop

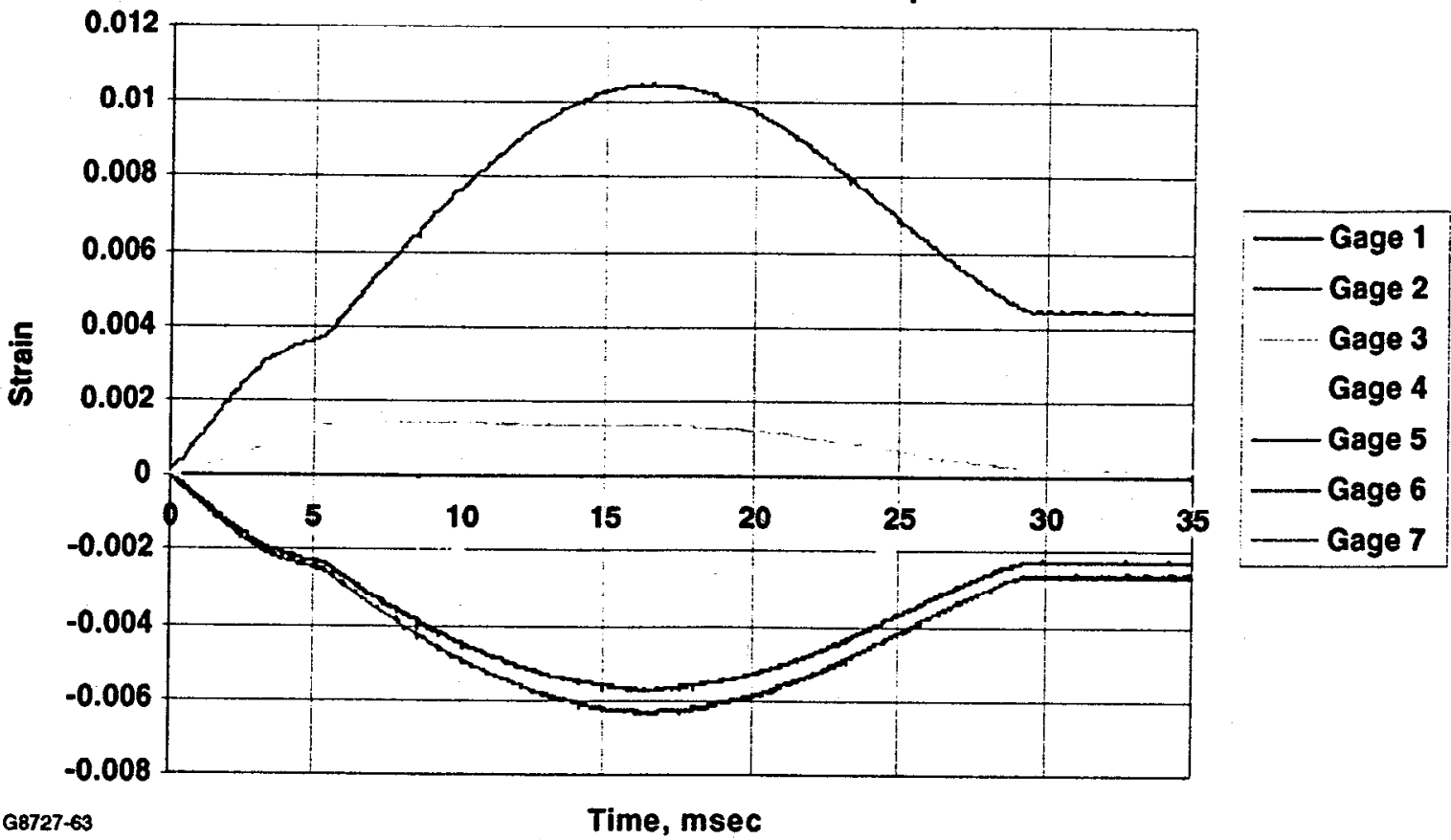

Figure IX-3. Strain Gage vs. Time, Test No. 4, Thick Aluminum Sample, 0.25-Inch Drop.

Test No. 5

Thick Aluminum, 0.50-inch drop

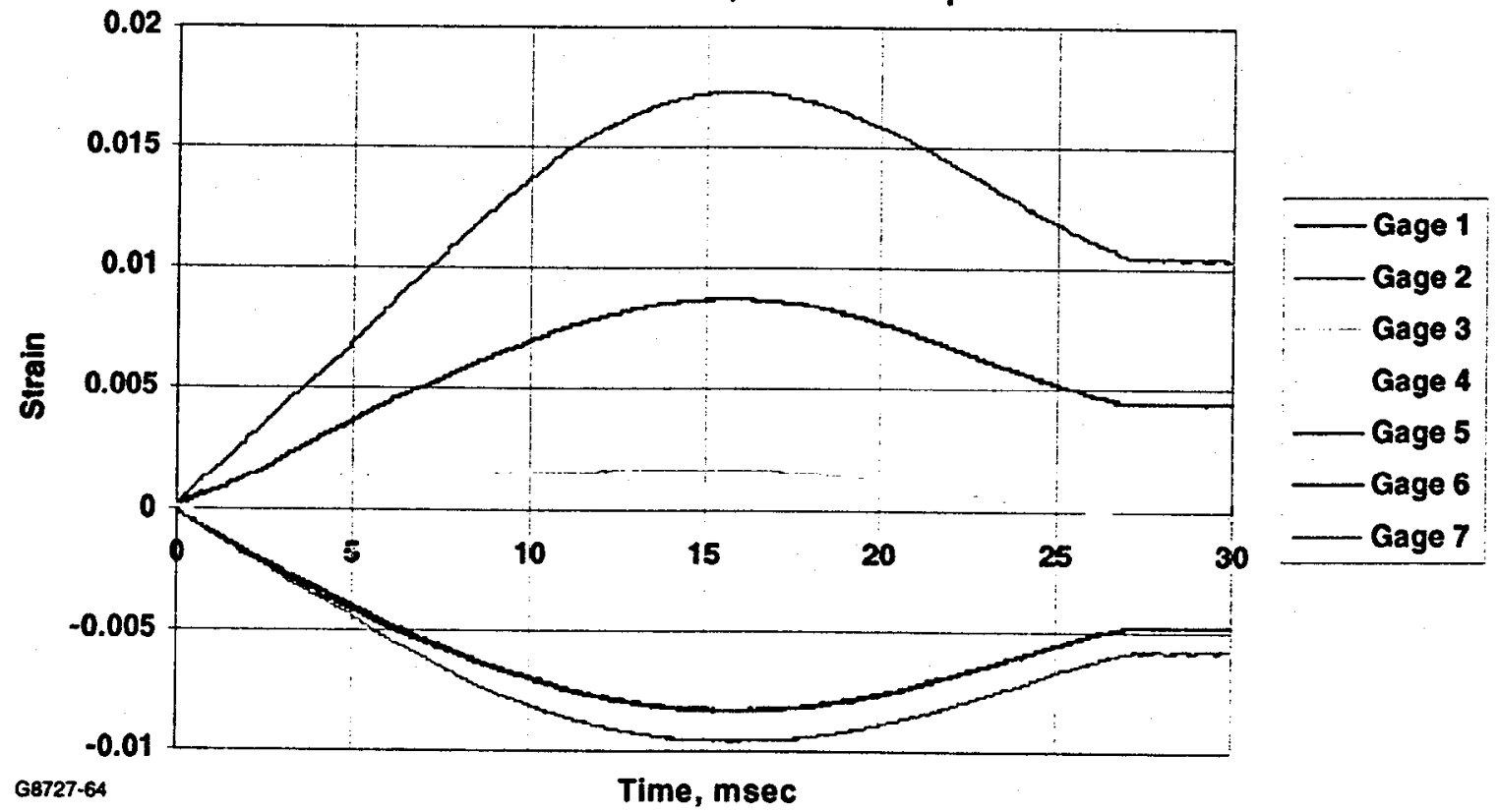

Figure IX-4. Strain Gage vs. Time, Test No. 5, Thick Aluminum Sample, 0.50-Inch Drop. 
Test No. 6

Thin Titanium, 0.25 -inch drop

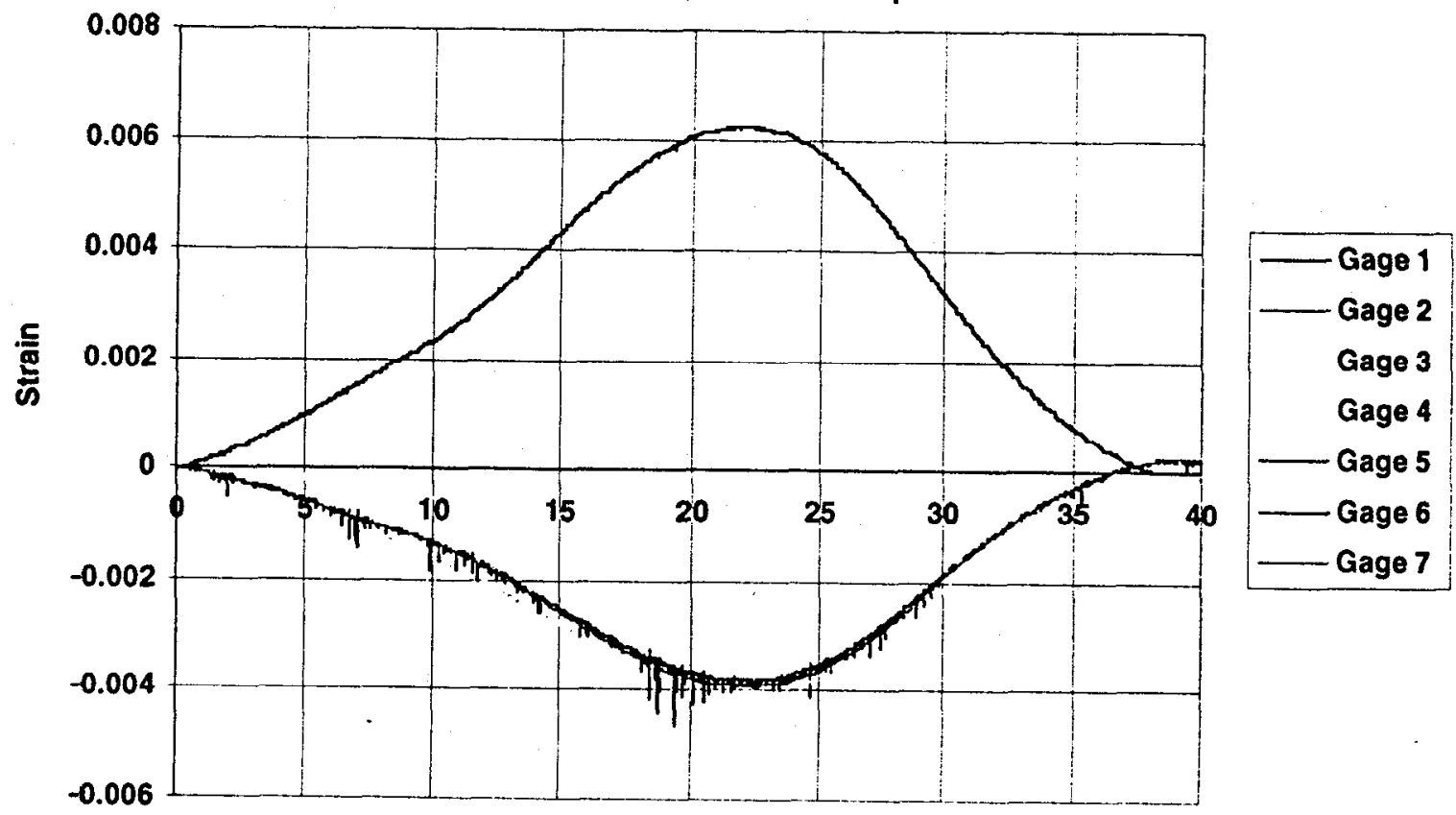

G8727-65

Time, msec

Figure IX-5. Strain Gage vs. Time, Test No. 6, Thin Titanium Sample, 0.25-Inch Drop.

Test No. 7

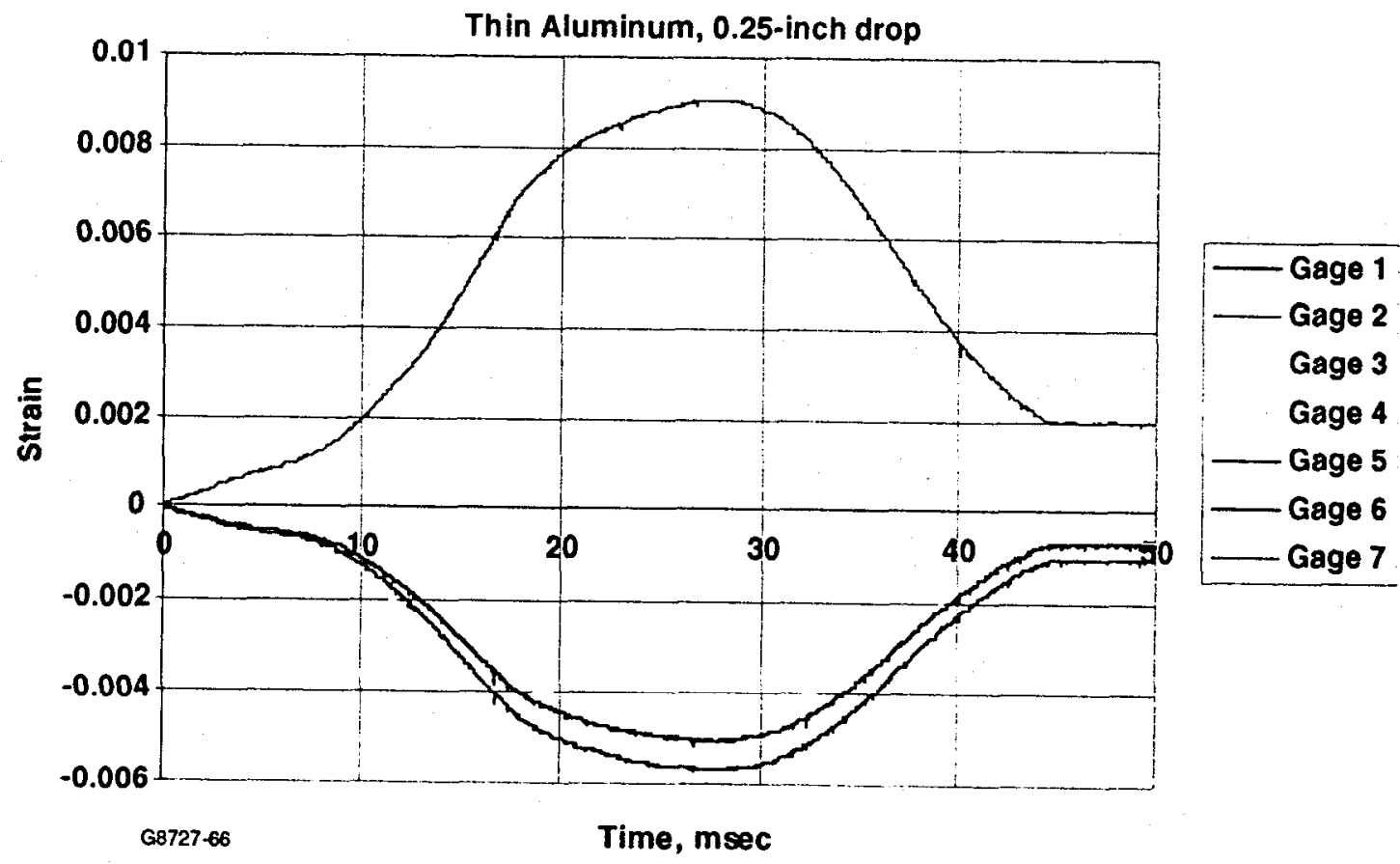

Figure IX-6. Strain Gage vs. Time, Test No. 7, Thin Aluminum Sample, 0.25-Inch Drop. 
Test No. 8

Thin Titanium, 0.25-inch drop

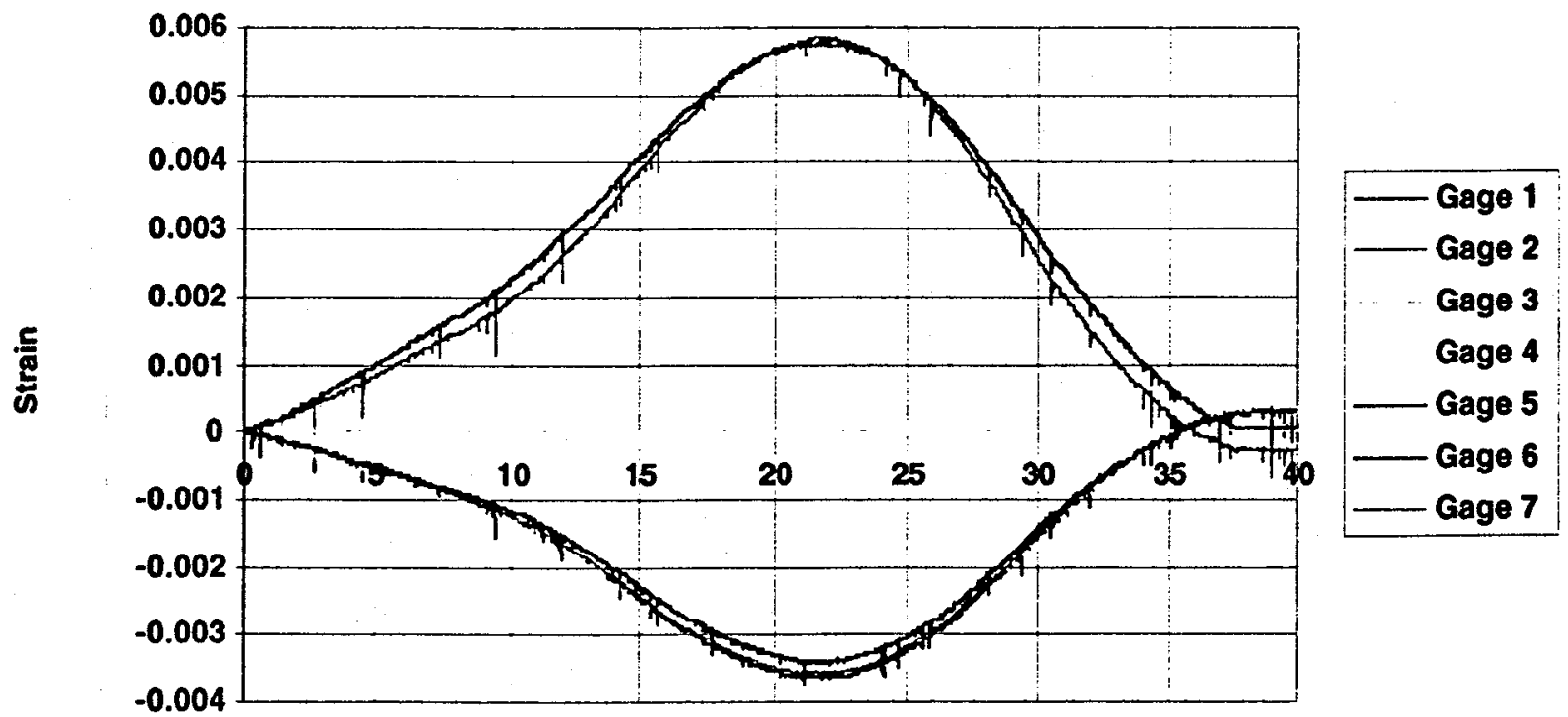

G8727-67

Time, msec

Figure IX-7. Strain Gage vs. Time, Test No. 8, Thin Titanium Sample, 0.25-Inch Drop.

Test No. 9

Thick Aluminum, 1.00-inch drop

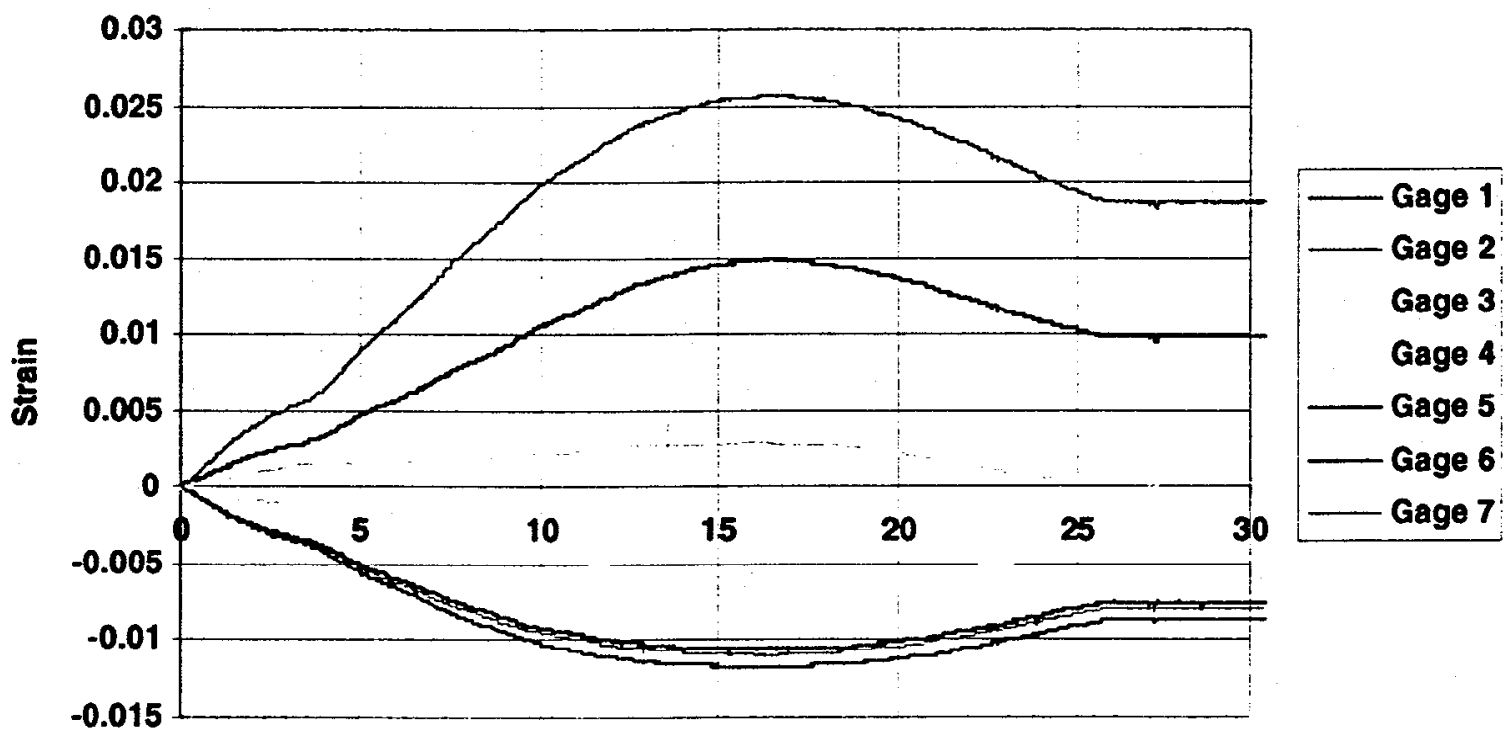

G8727.68

Time, msec

Figure IX-8. Strain Gage vs. Time, Test No. 9, Thick Aluminum Sample, 1.00-Inch Drop. 
Test No. 10

Thick Titanium, 12.00-inch drop

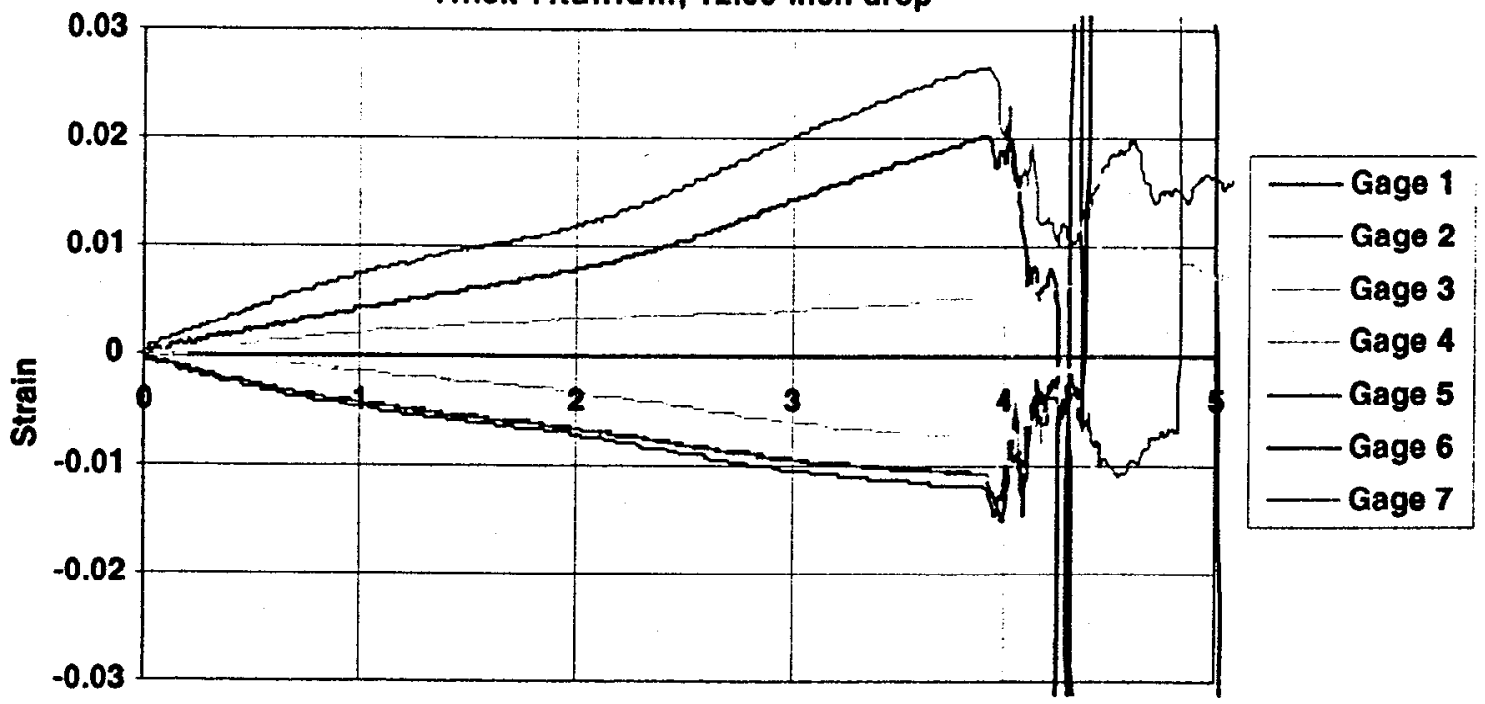

G8727-69 Time, msec

Figure IX-9. Strain Gage vs. Time, Test No. 10, Thick Titanium Sample, 12.00-Inch Drop.

Test No. 11

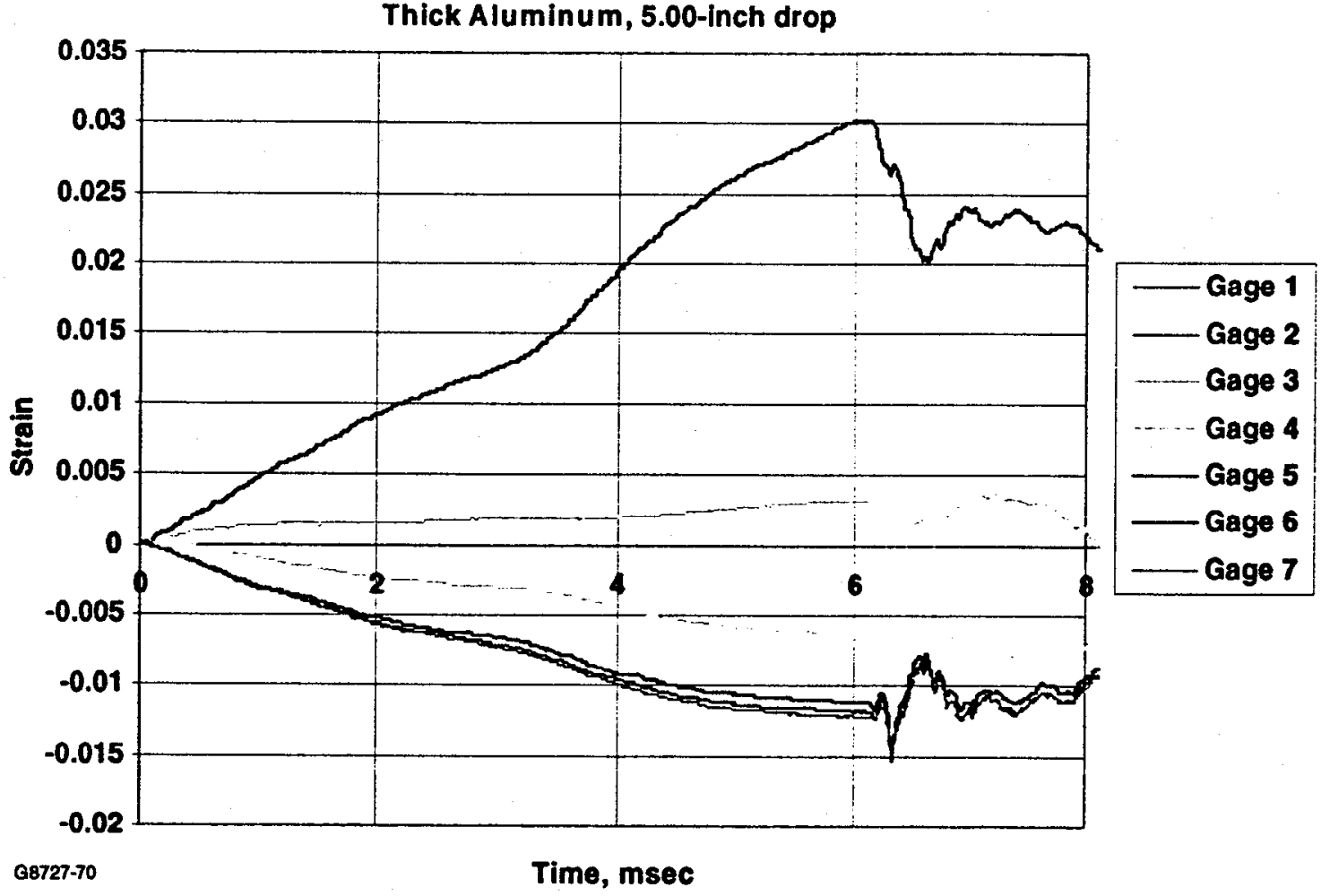

Figure IX-10. Strain Gage vs. Time, Test No. 11, Thick Aluminum Sample, 5.00-Inch Drop. 
Test No. 12

Thick Titanium, 8.00-inch drop

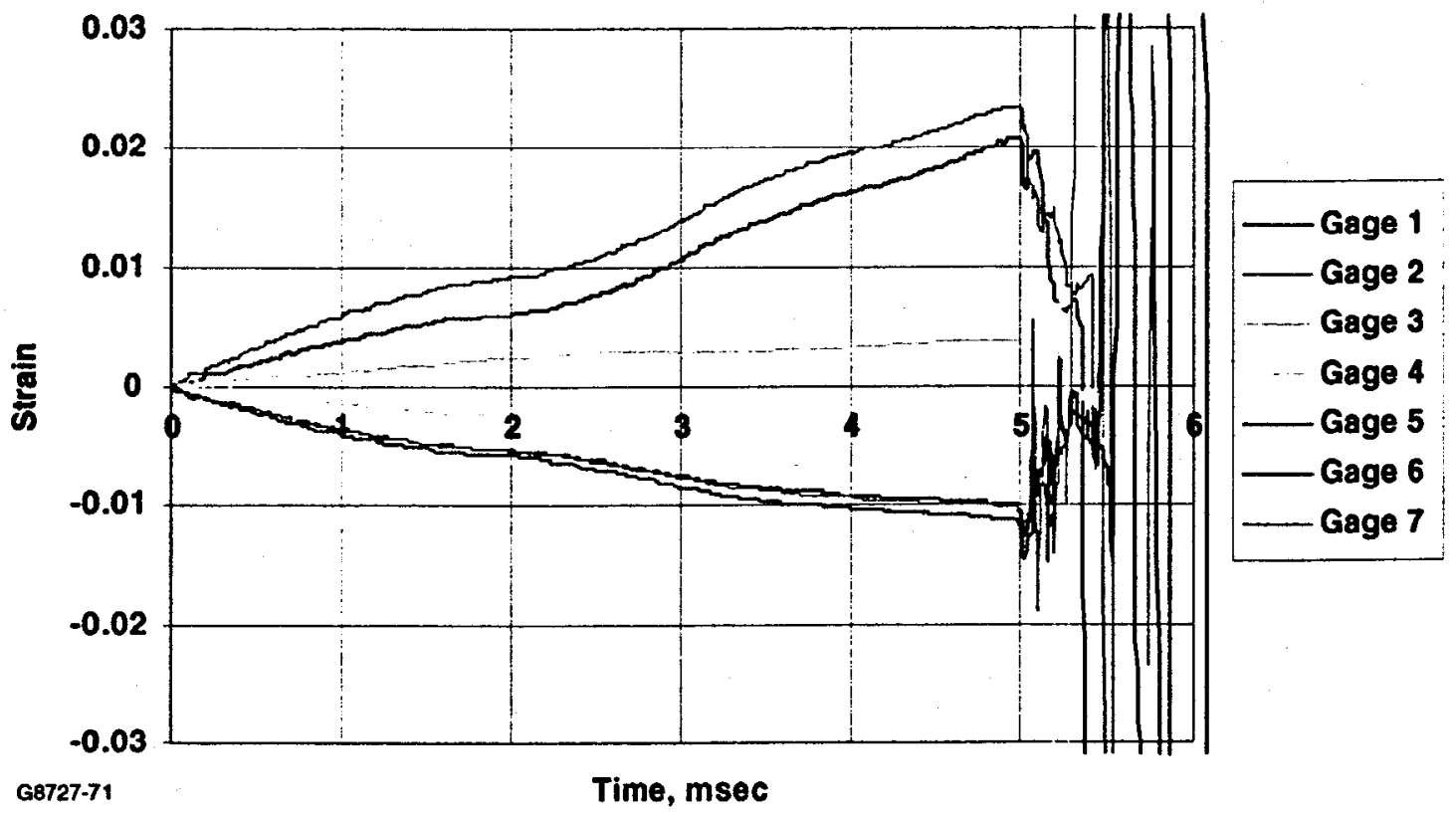

Figure IX-11. Strain Gage vs. Time, Test No. 12, Thick Titanium Sample, 8.00-Inch Drop.

Test No. 13

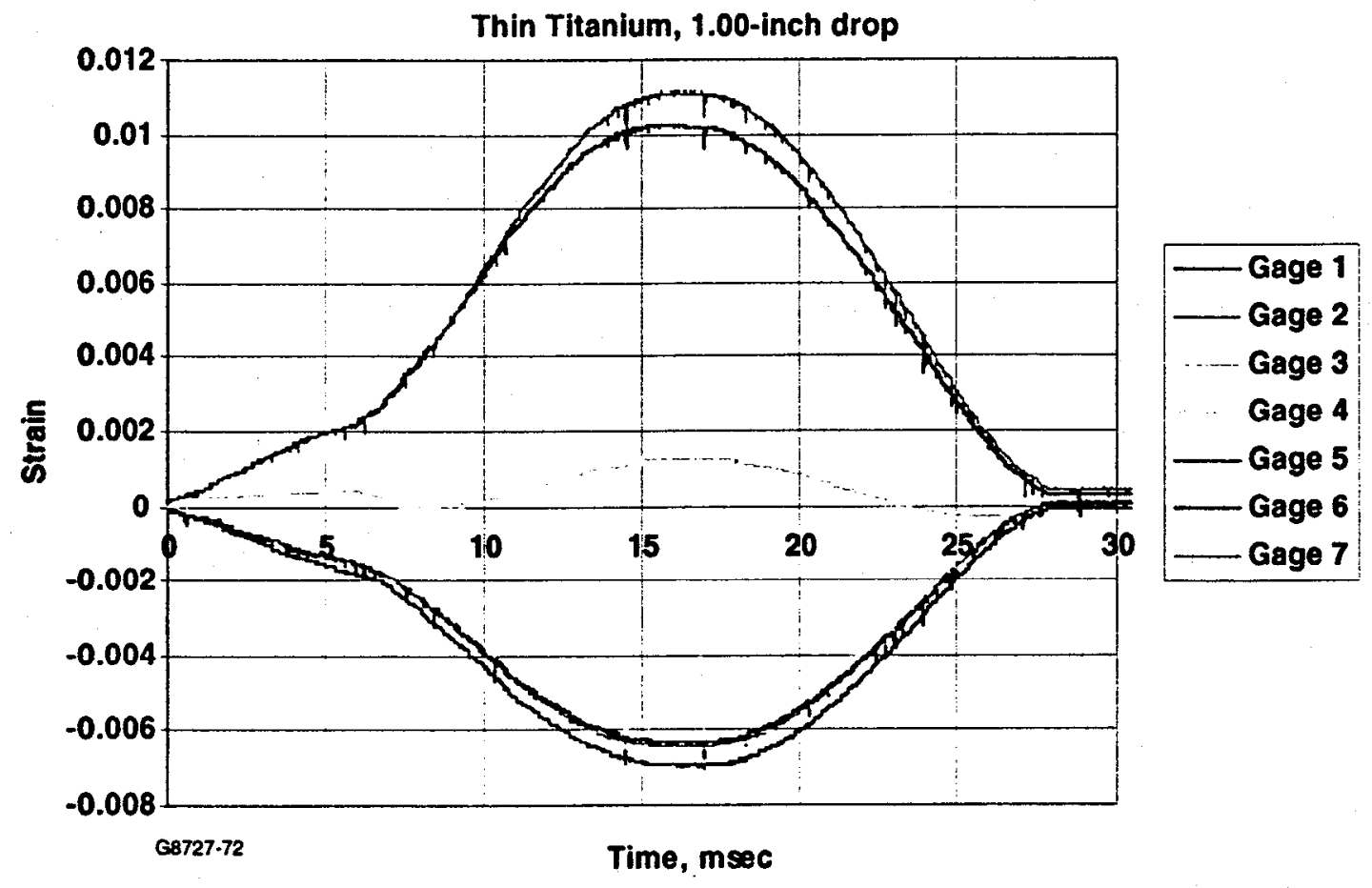

Figure IX-12. Strain Gage vs. Time, Test No. 13, Thin Titanium Sample, 1.00-Inch Drop. 


\section{AlliedSignal}

Test No. 14

Thin Aluminum, 0.50-inch drop

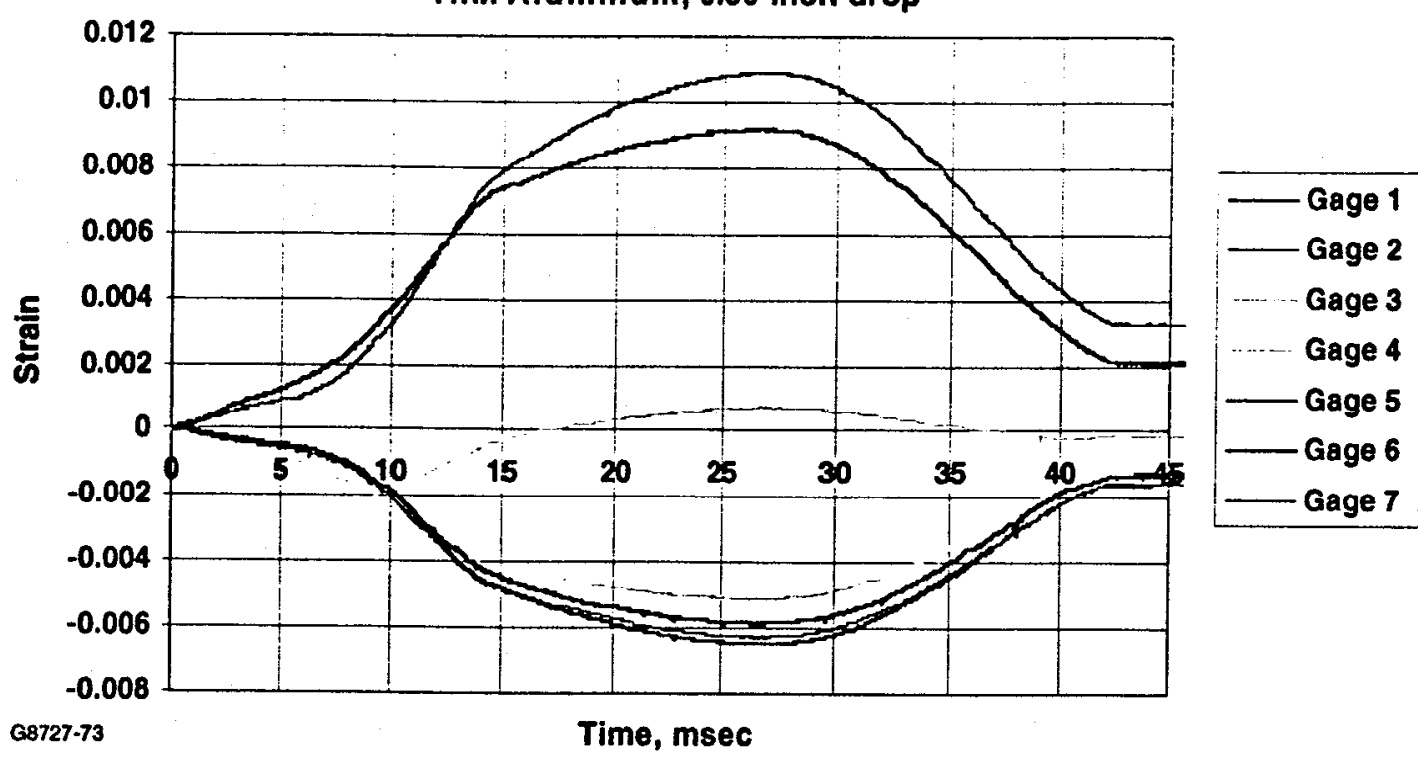

Figure IX-13. Strain Gage vs. Time, Test No. 14, Thin Aluminum Sample, 0.50-Inch Drop.

Test No. 15

Thin Titanium, 3.00-inch drop

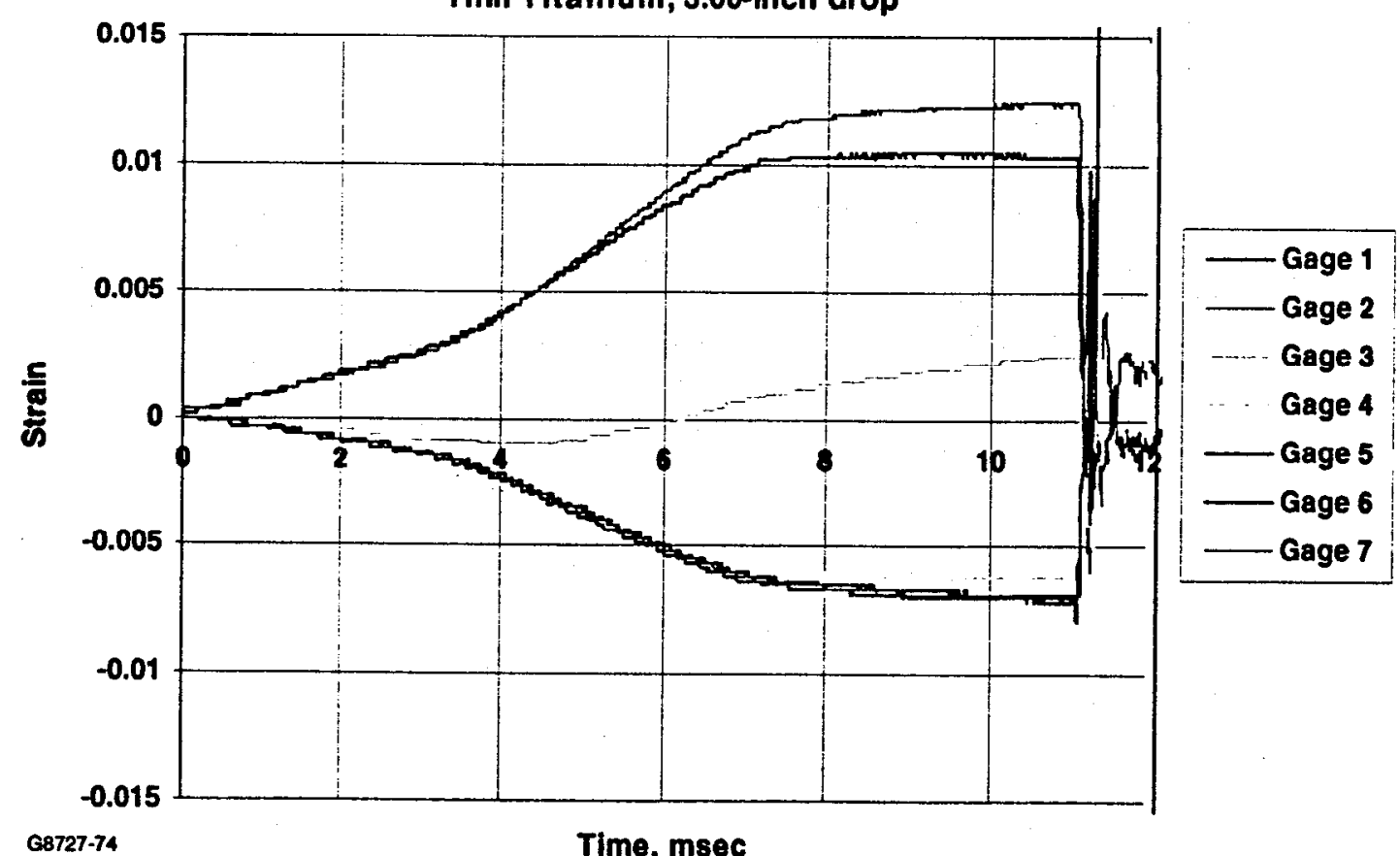

Figure IX-14. Strain Gage vs. Time, Test No. 15, Thin Titanium Sample, 3.00-Inch Drop. 
Test No. 16

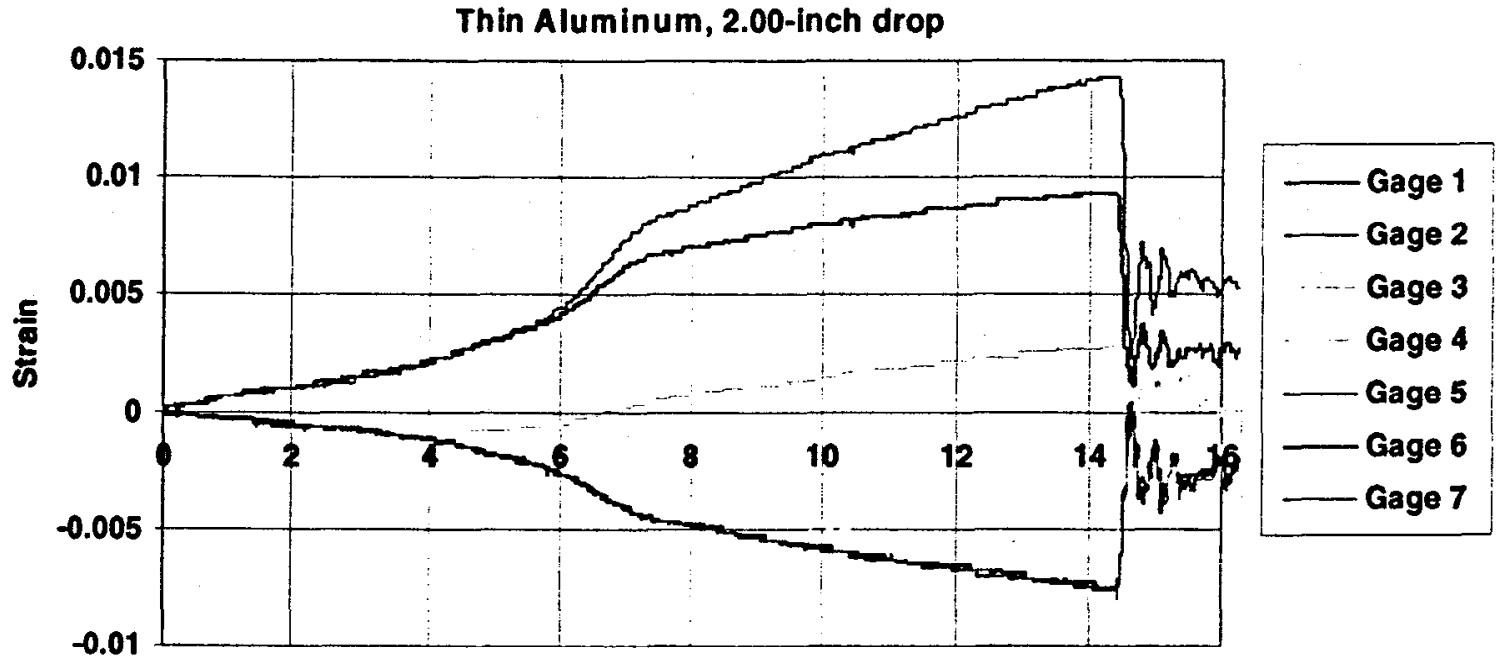

68727.75

Time, msec

Figure IX-15. Strain Gage vs. Time, Test No. 16, Thin Aluminum Sample, 2.00-Inch Drop. 


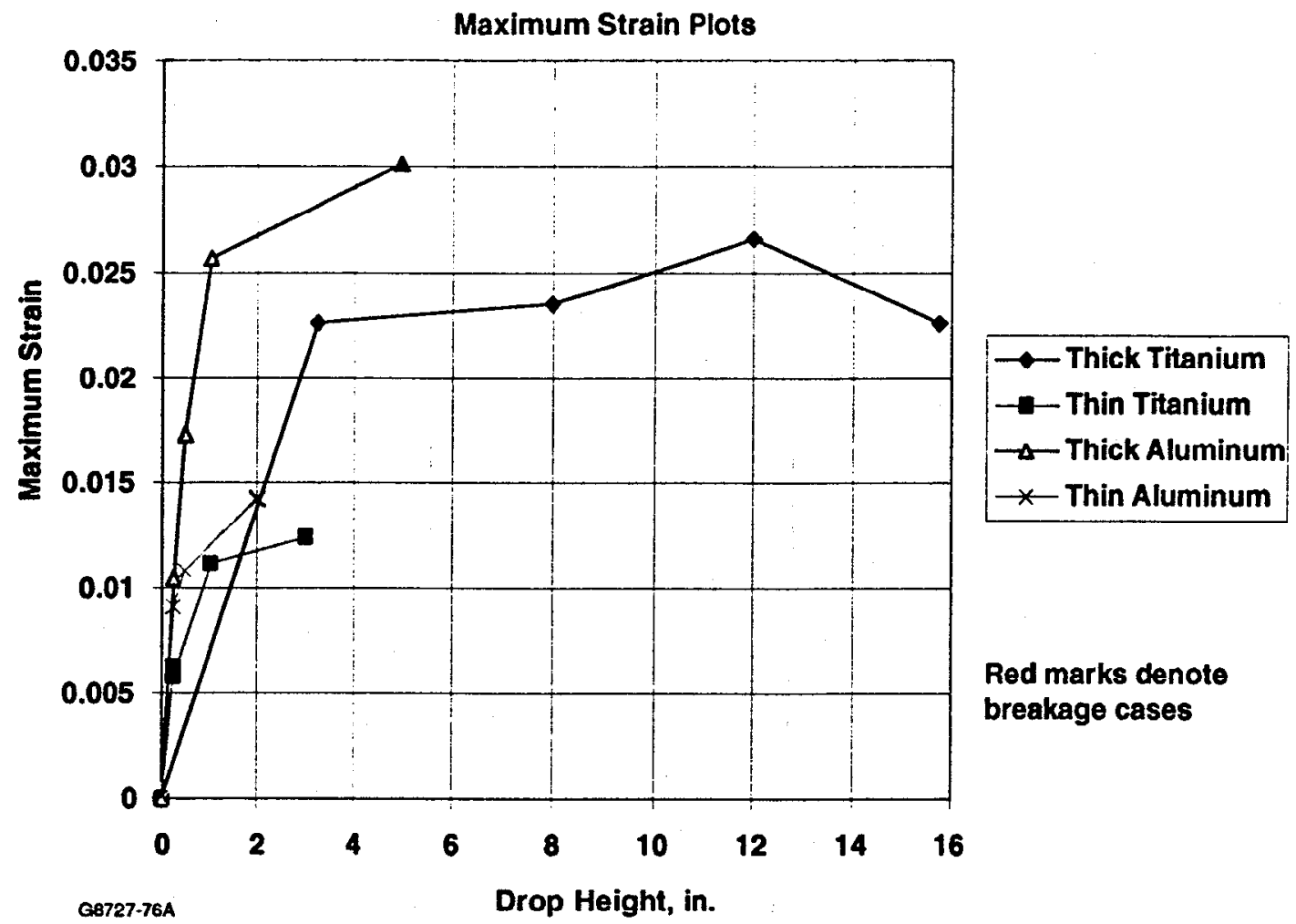

Figure IX-16. Maximum Strain vs. Drop Height.
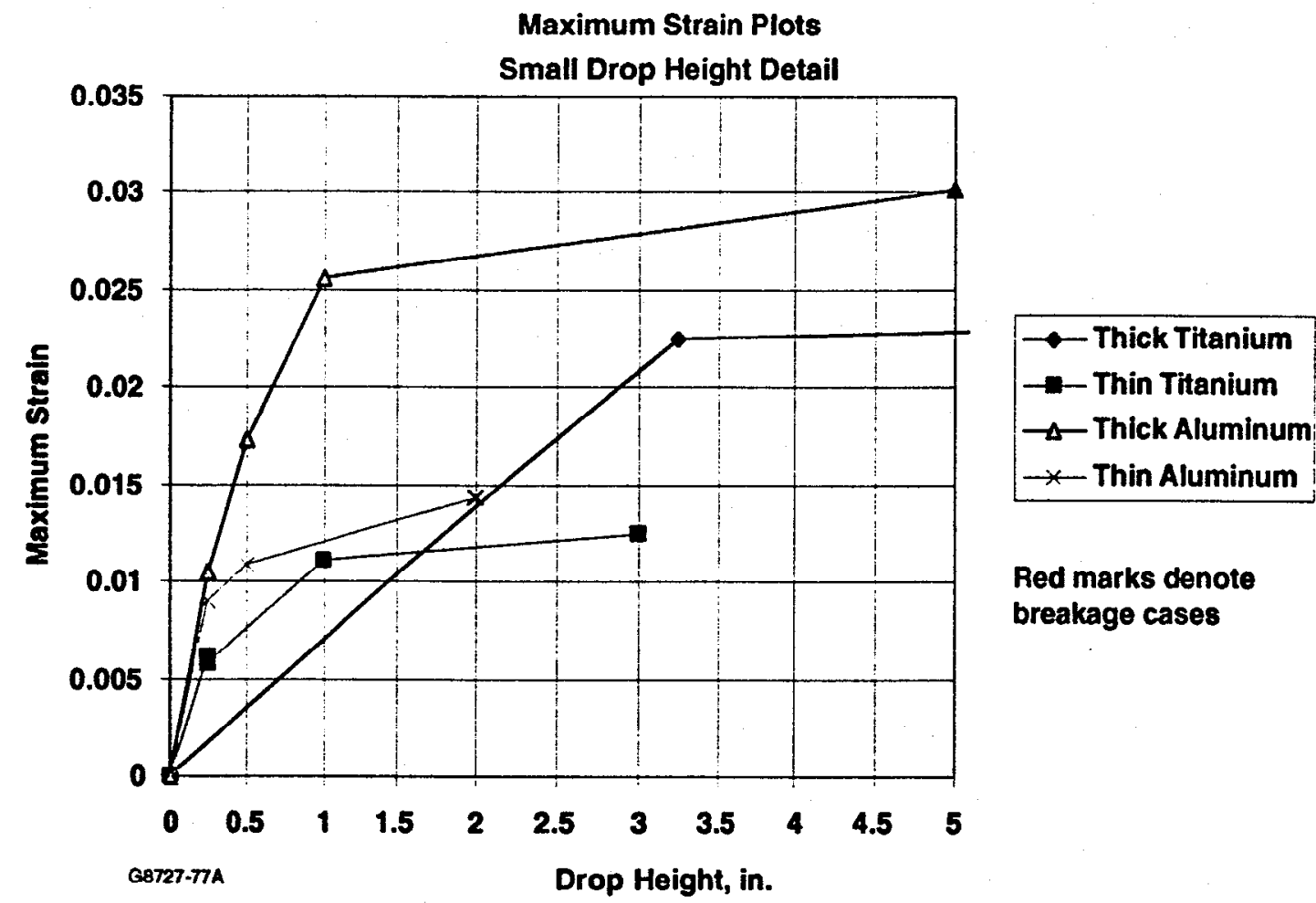

Red marks denote breakage cases

Figure IX-17. Maximum Strain vs. Drop Height, Small Drop Height Detail. 
APPENDIX X

DEFLECTION VS. TIME PLOTS AND

MAXIMUM DEFLECTION PLOTS

(9 pages) 
Test No. 1

Thick Titanlum, 0.25-inch drop

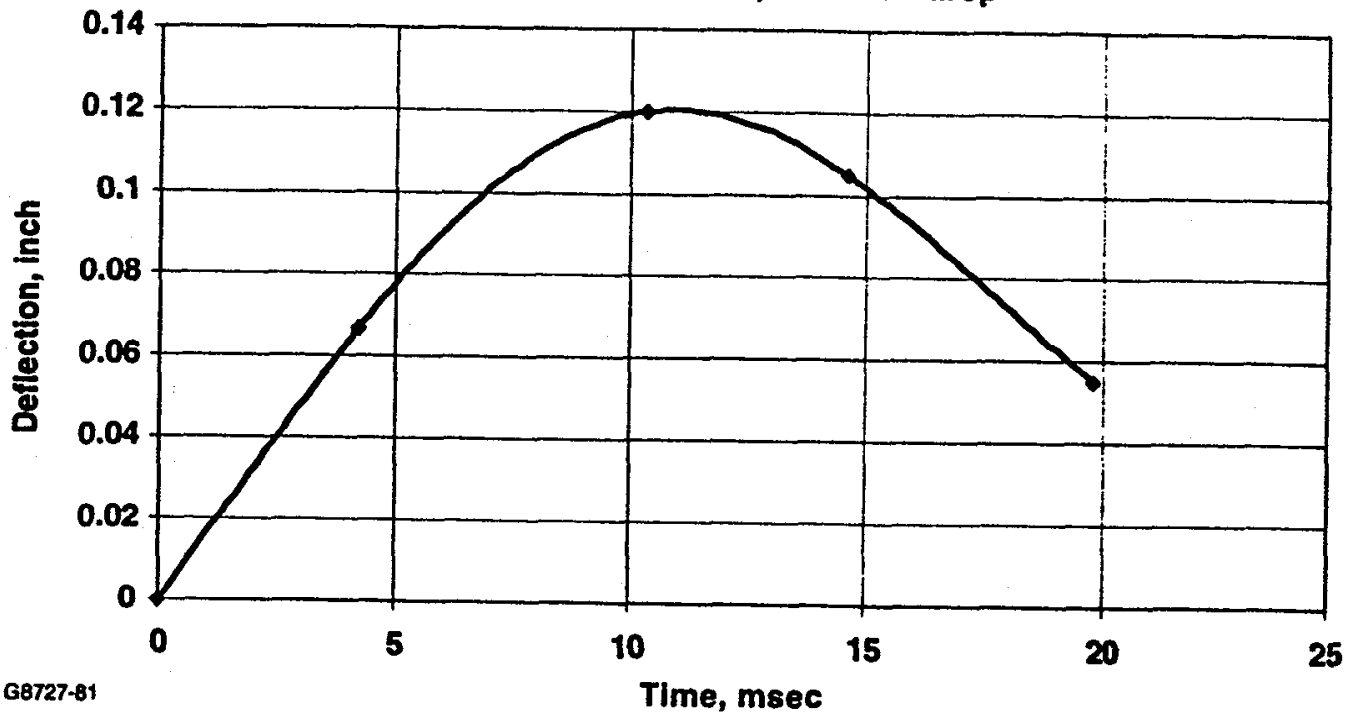

Figure X-1. Deflection vs. Time, Test No. 1, Thick Titanium Sample, 0.25-Inch Drop.

Test No. 2

Thick Titanium, 3.25-inch drop

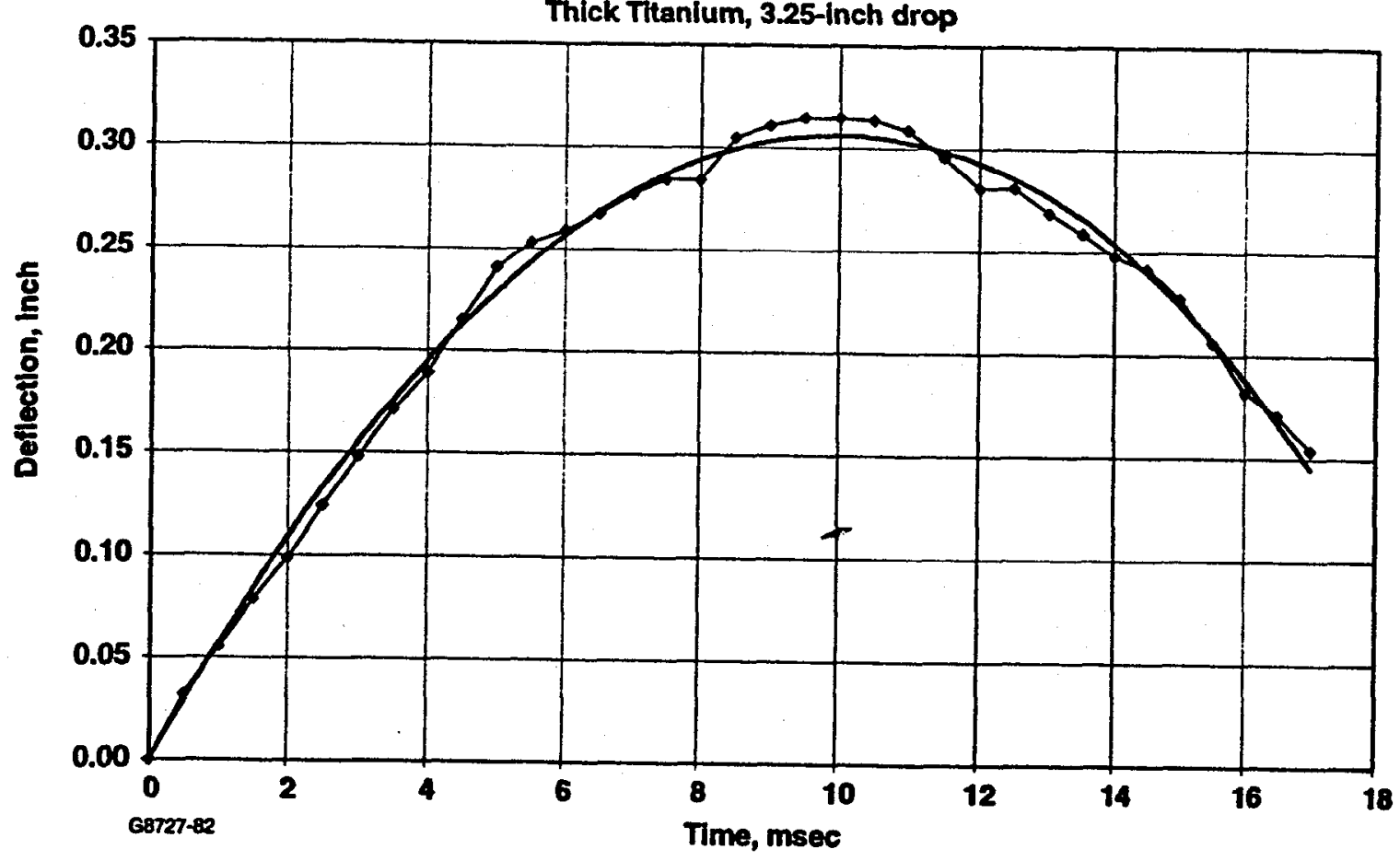

Figure X-2. Deflection vs. Time, Test No. 2, Thick Titanium Sample, 3.25-Inch Drop. 
Test No. 3

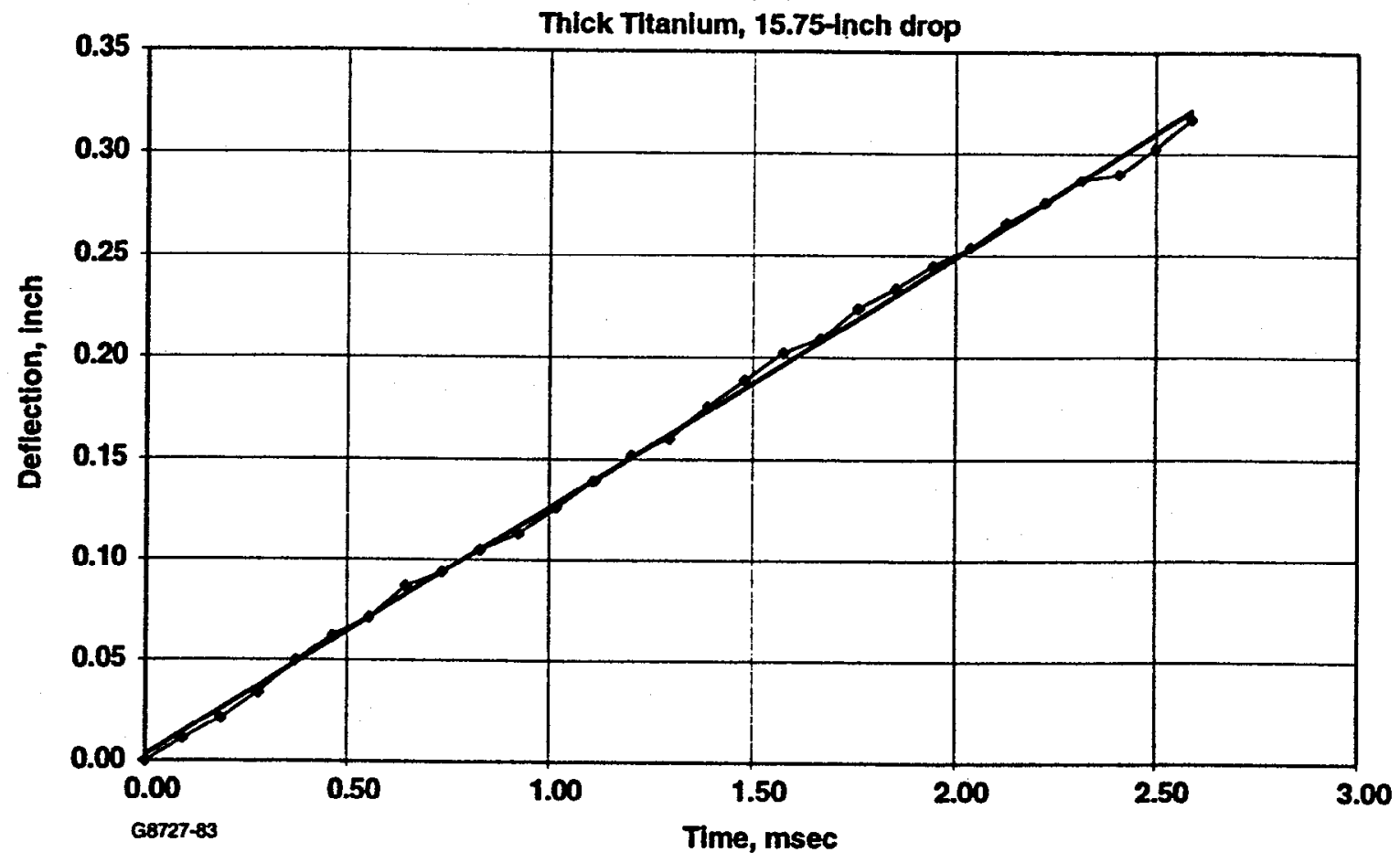

Figure X-3. Deflection vs. Time, Test No. 3, Thick Titanium Sample, 15.75-Inch Drop.

Test No. 4

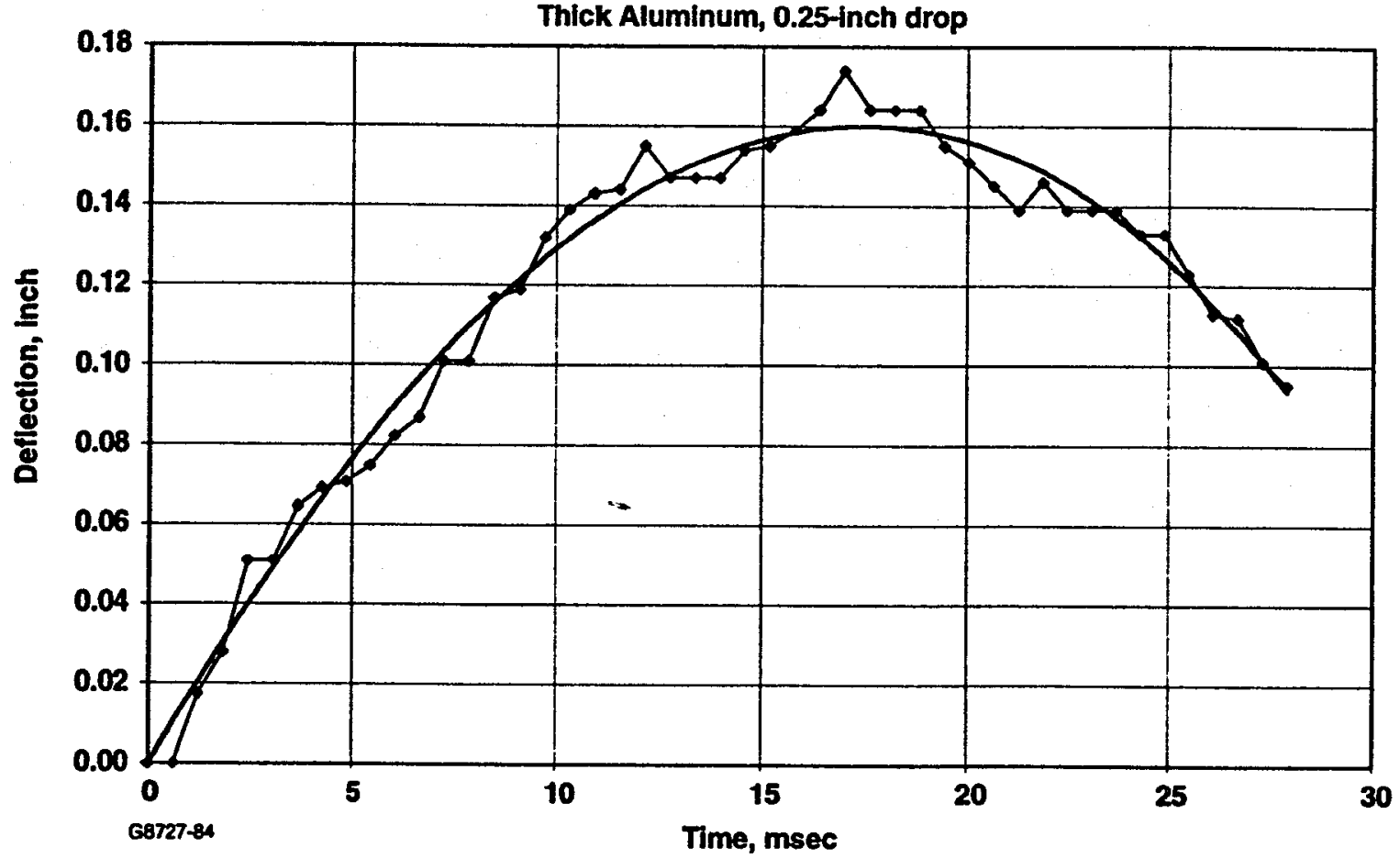

Figure X-4. Deflection vs. Time, Test No. 4, Thick Aluminum Sample, 0.25-Inch Drop. 
Test No. 5

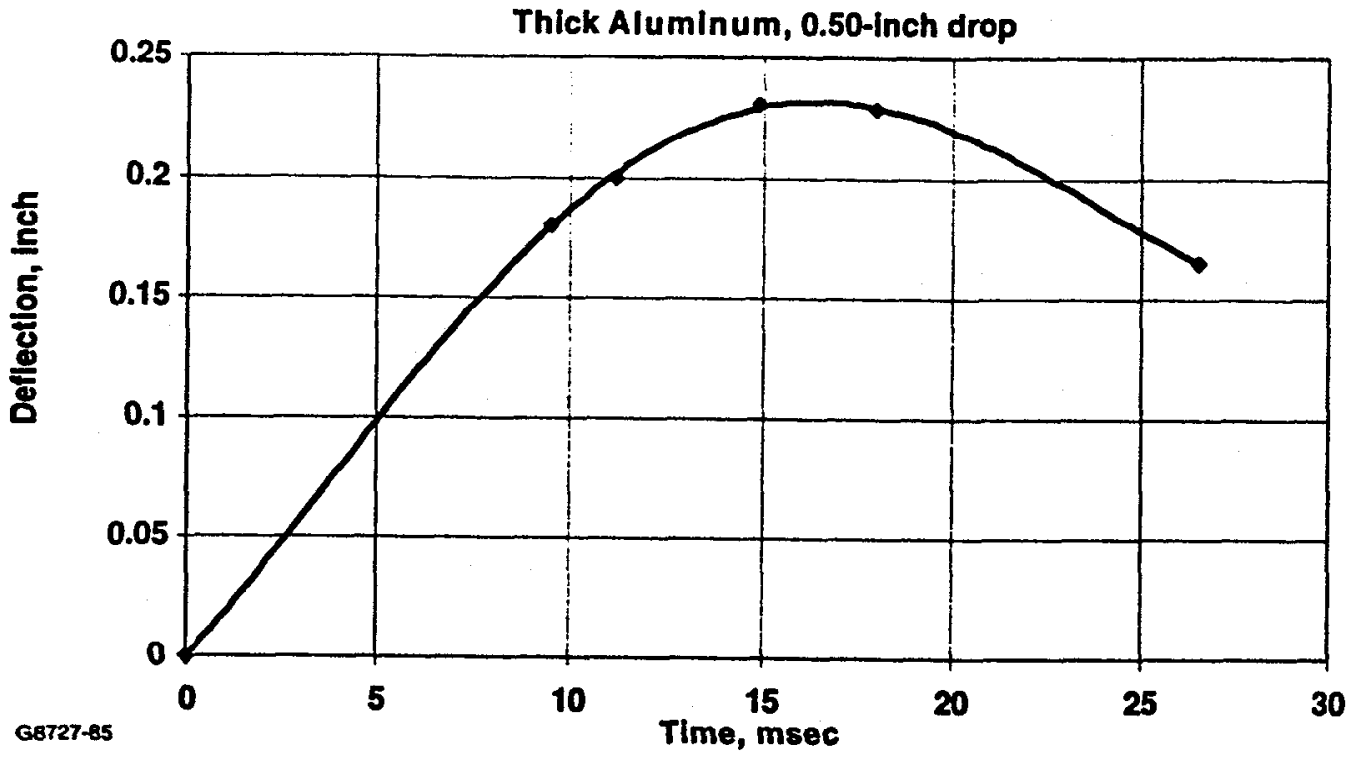

Figure X-5. Deflection vs. Time, Test No. 5, Thick Aluminum Sample, 0.50-Inch Drop.

Test No. 6

Thin Titanium, 0.25-inch drop

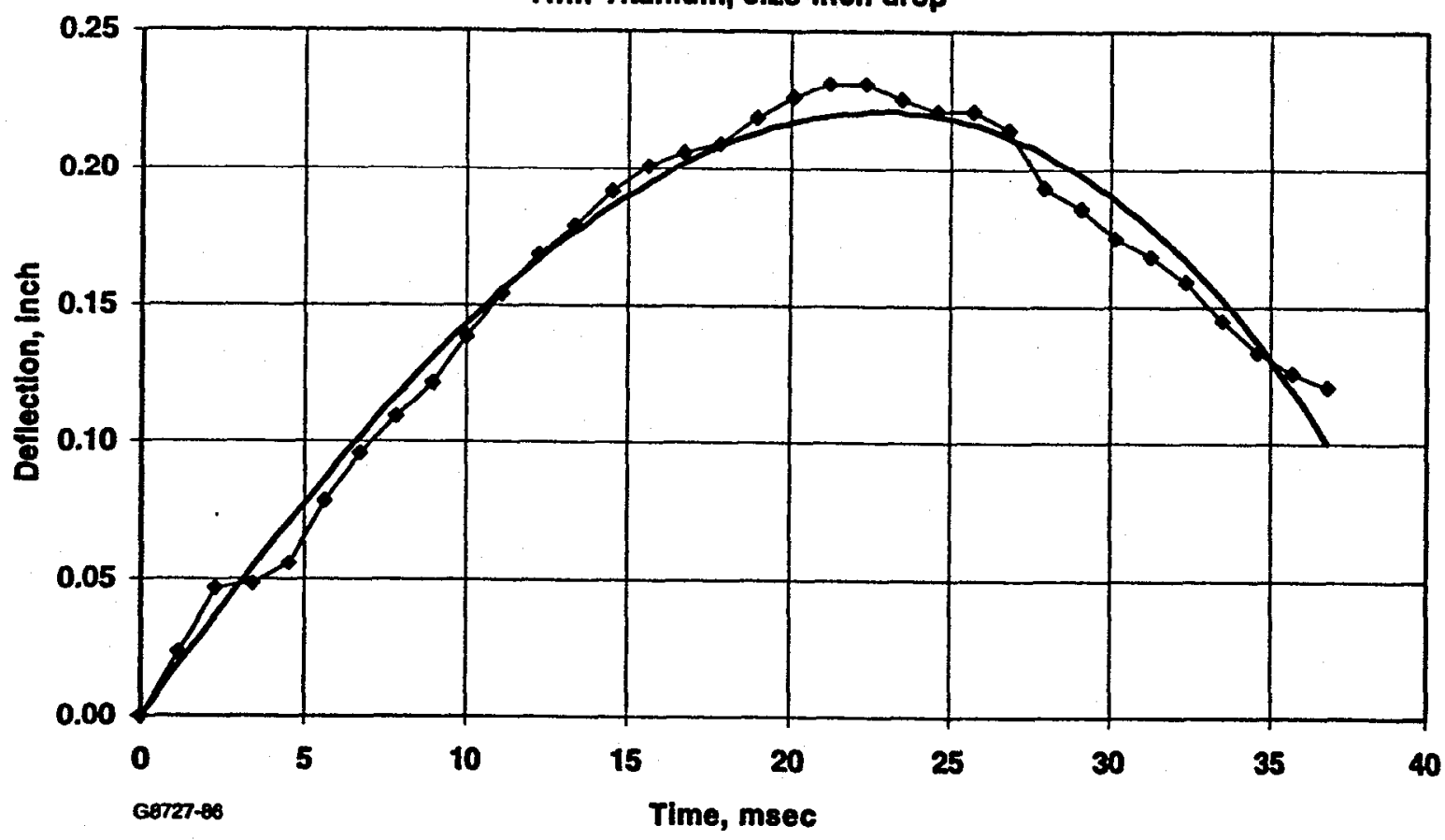

Figure X-6. Deflection vs. Time, Test No. 6, Thin Titanium Sample, 0.25-Inch Drop. 
Test No. 7

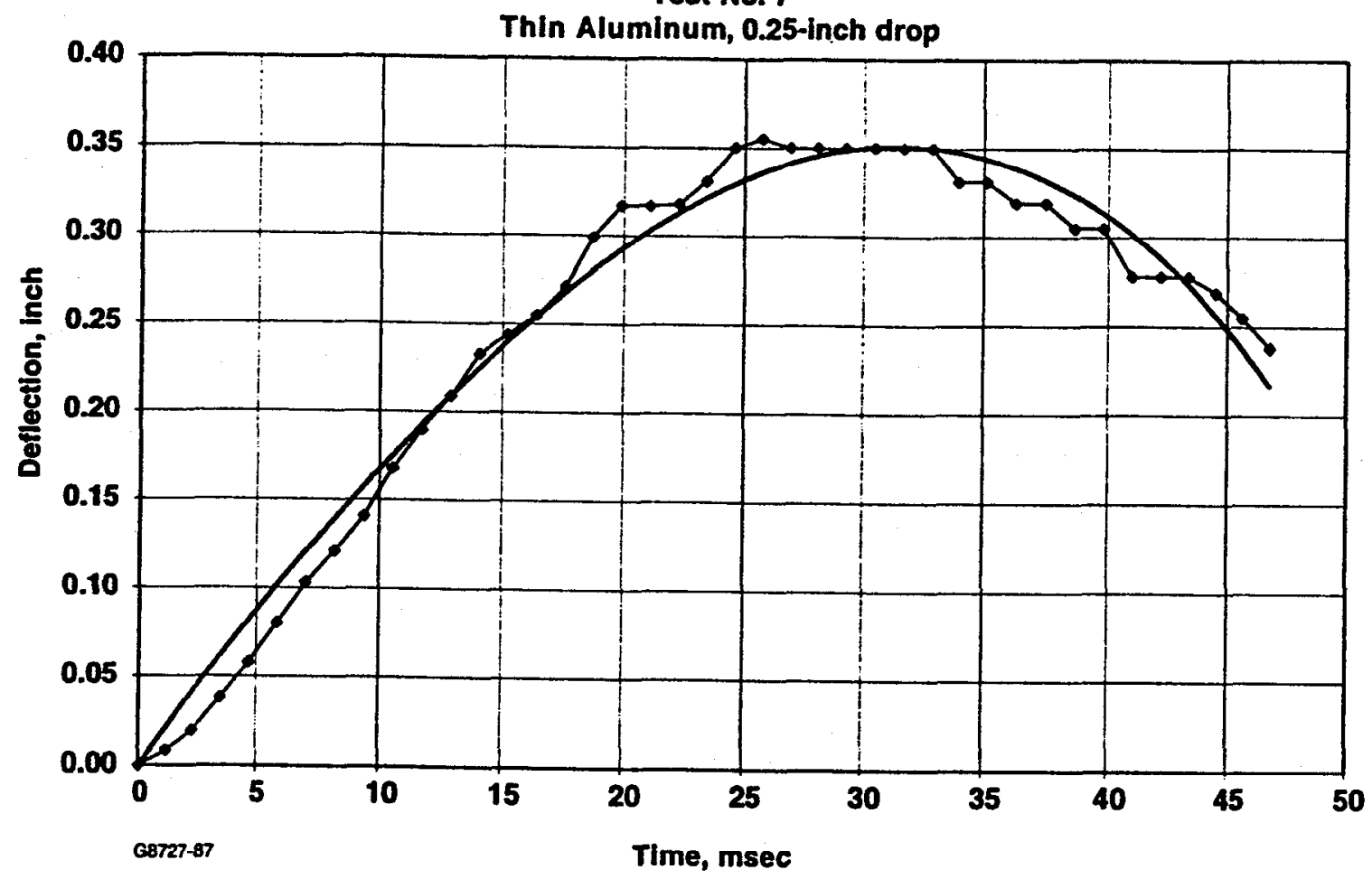

Figure X-7. Deflection vs. Time, Test No. 7, Thin Aluminum Sample, 0.25-Inch Drop.

Test No. 8

Thin Titanium, 0.25-inch drop

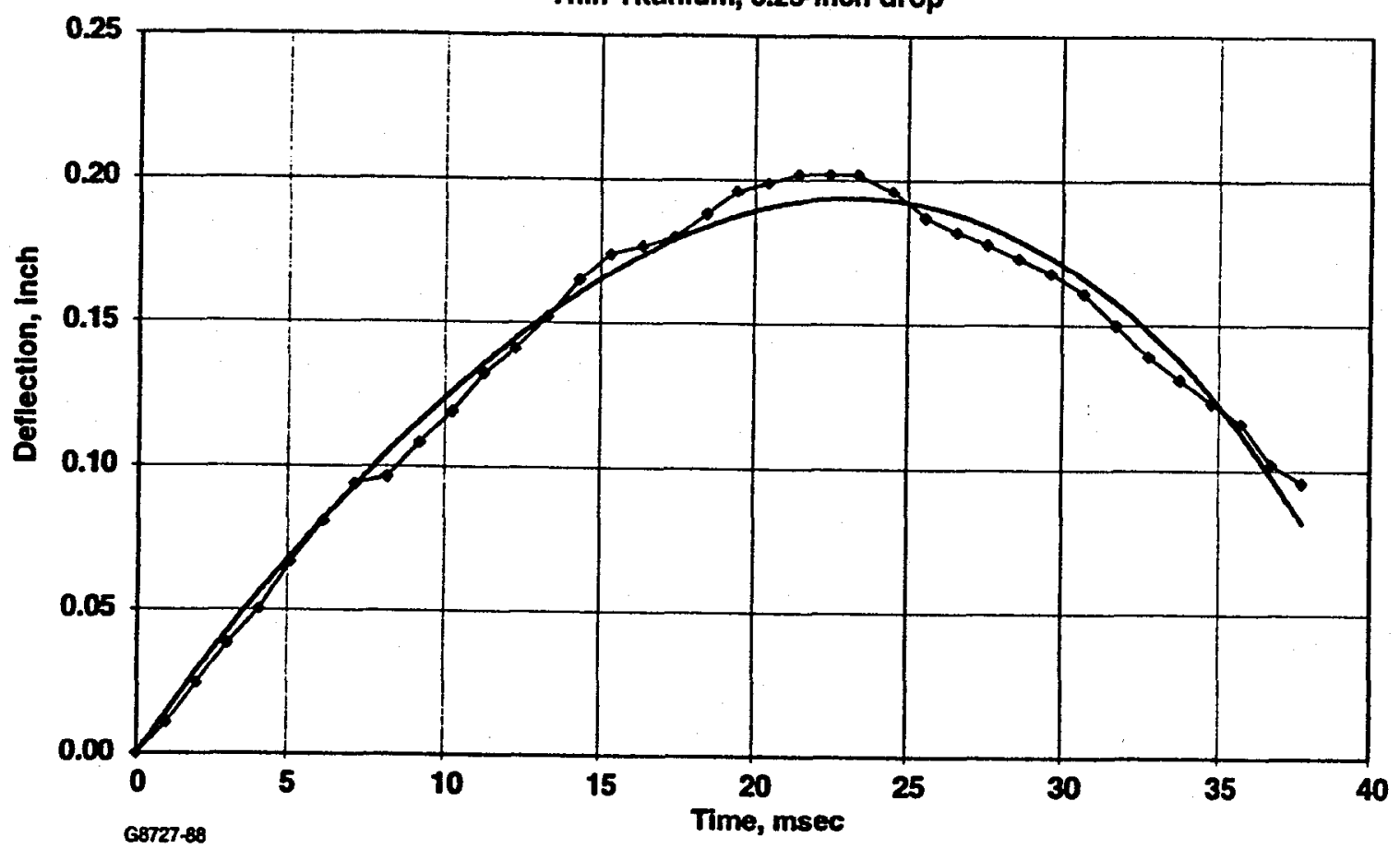

Figure X-8. Deflection vs. Time, Test No. 8, Thin Titanium Sample, 0.25-Inch Drop. 
Test No. 9

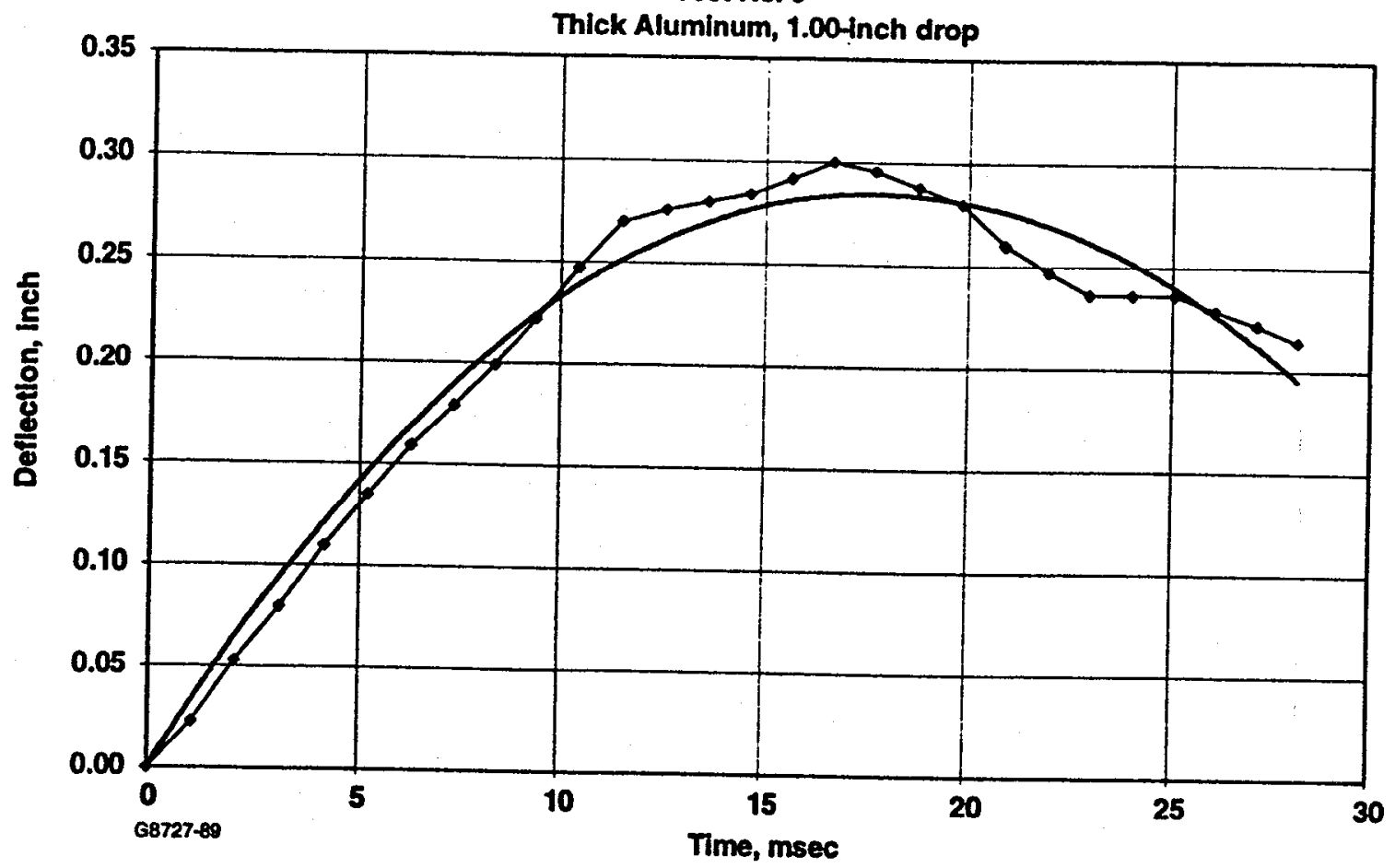

Figure X-9. Deflection vs. Time, Test No. 9, Thick Aluminum Sample, 1.00-Inch Drop.

Test No. 10

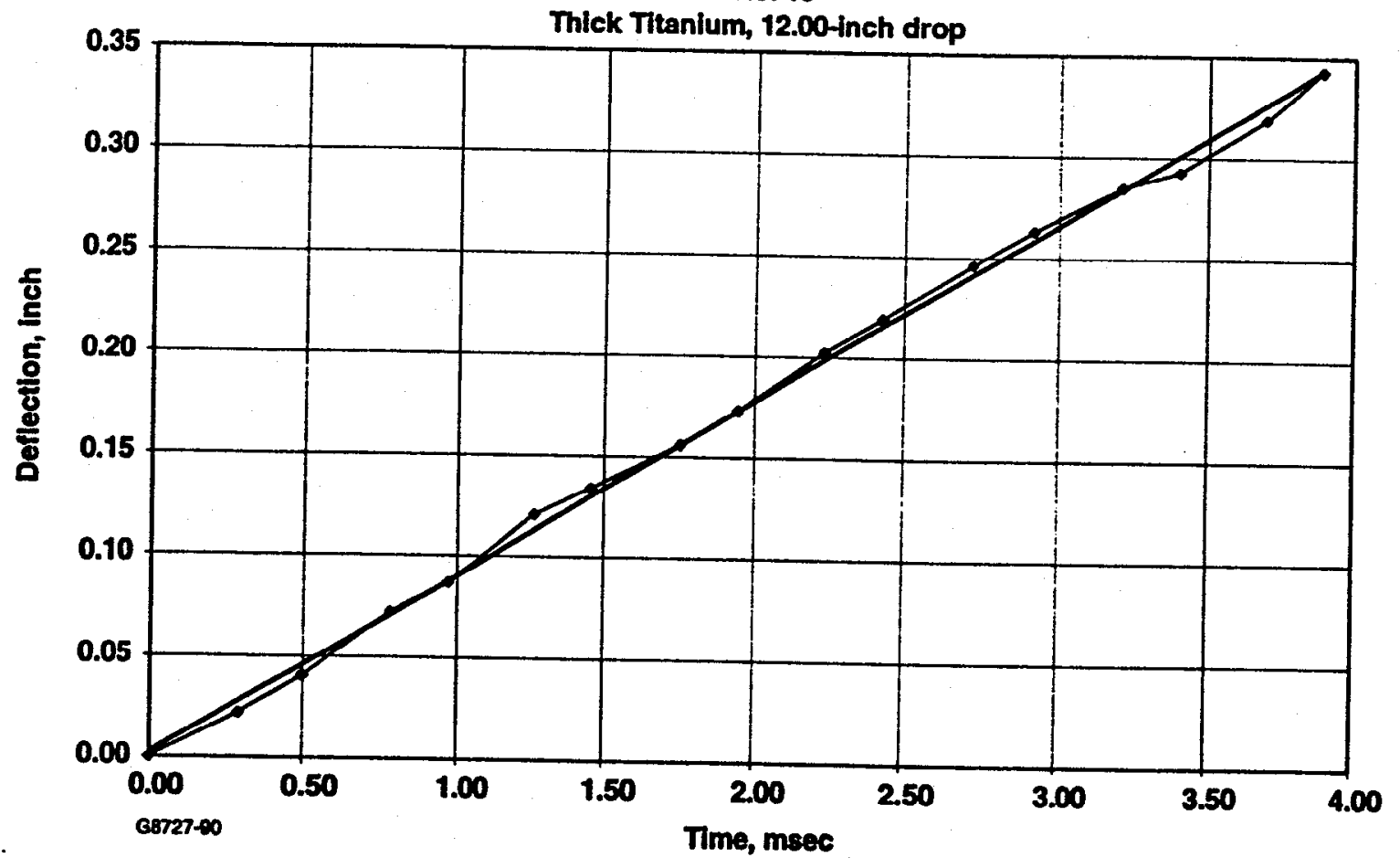

Figure X-10. Deflection vs. Time, Test No. 10, Thick Titanium Sample, 12.00-Inch Drop. 
Test No. 11

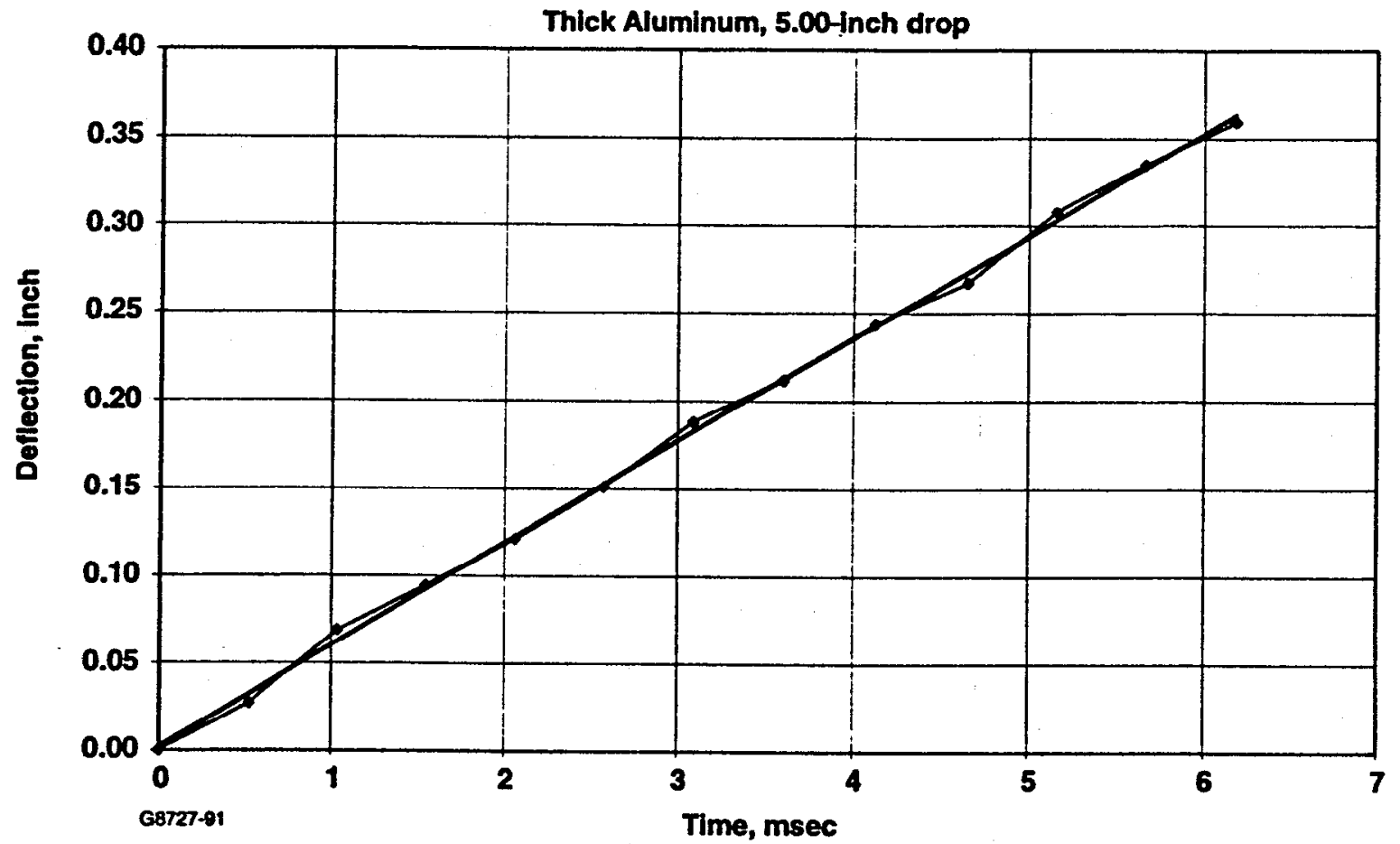

Figure X-11. Deflection vs. Time, Test No. 11, Thick Aluminum Sample, 5.00-Inch Drop.

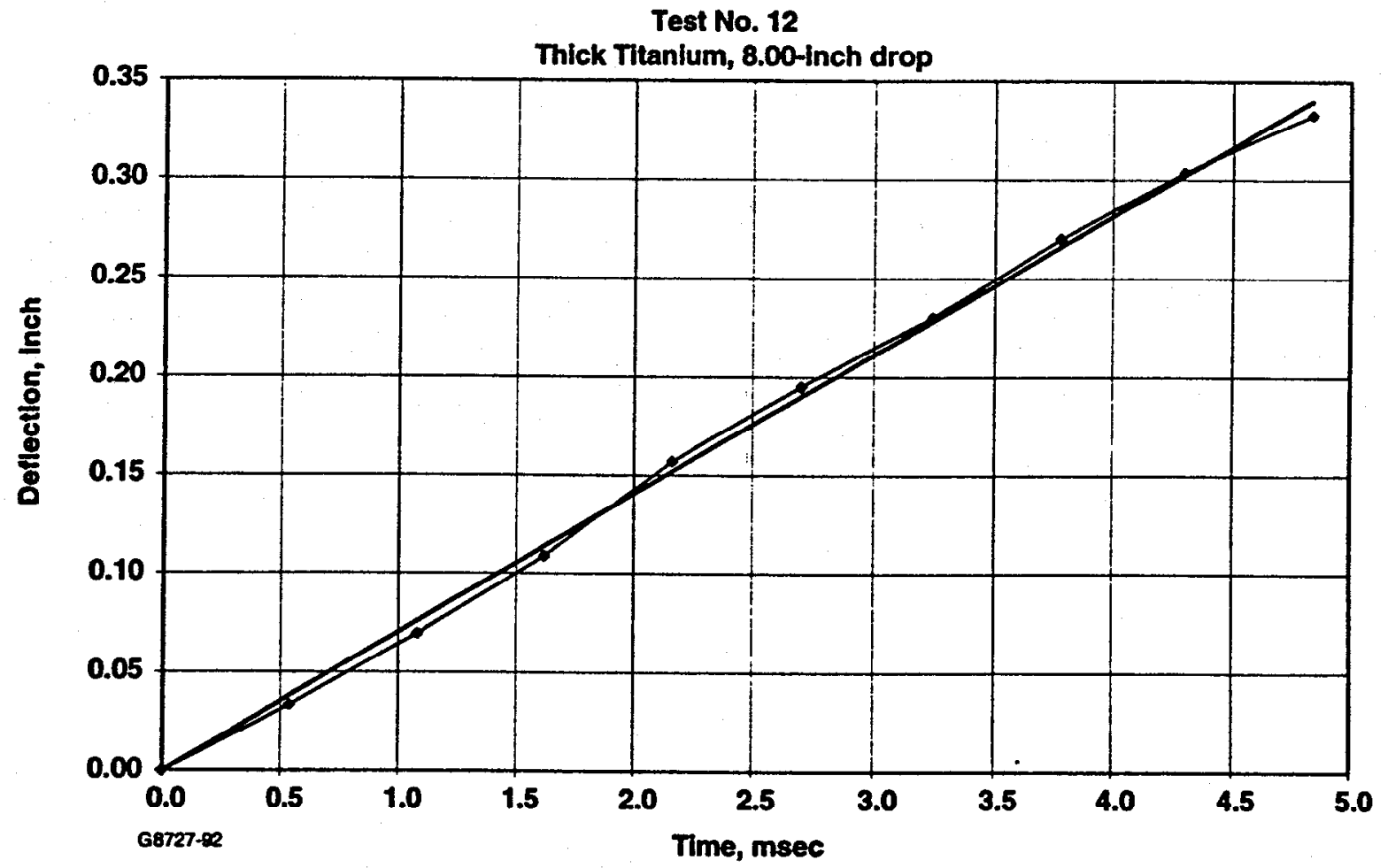

Figure X-12. Deflection vs. Time, Test No. 12, Thick Titanium Sample, 8.00-Inch Drop.

$$
\begin{gathered}
21-10392 \\
X-6
\end{gathered}
$$


Test No. 13

Thin Titanium, 1.00-inch drop

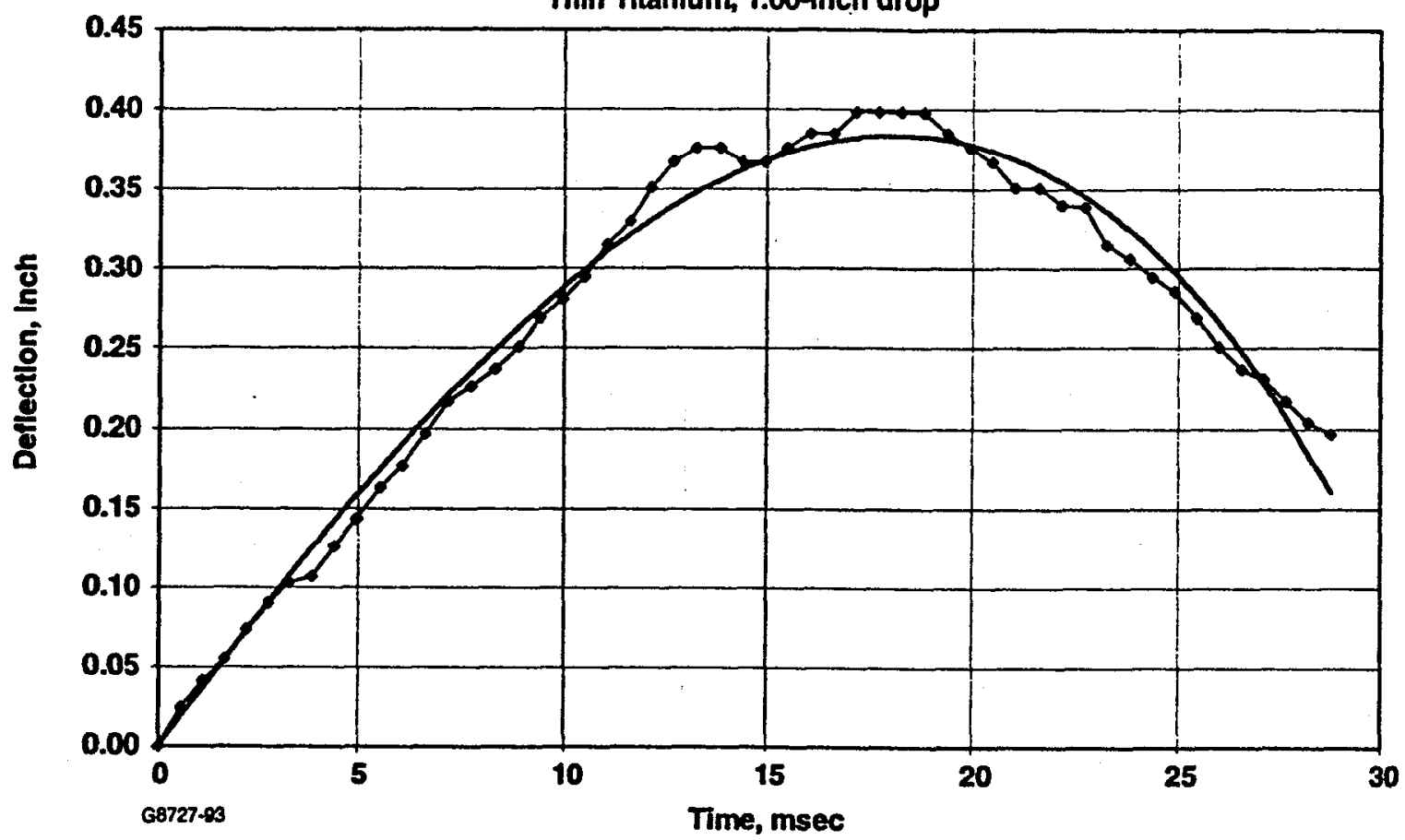

Figure X-13. Deflection vs. Time, Test No. 12, Thin Titanium Sample, 1.00-Inch Drop.

Test No. 14

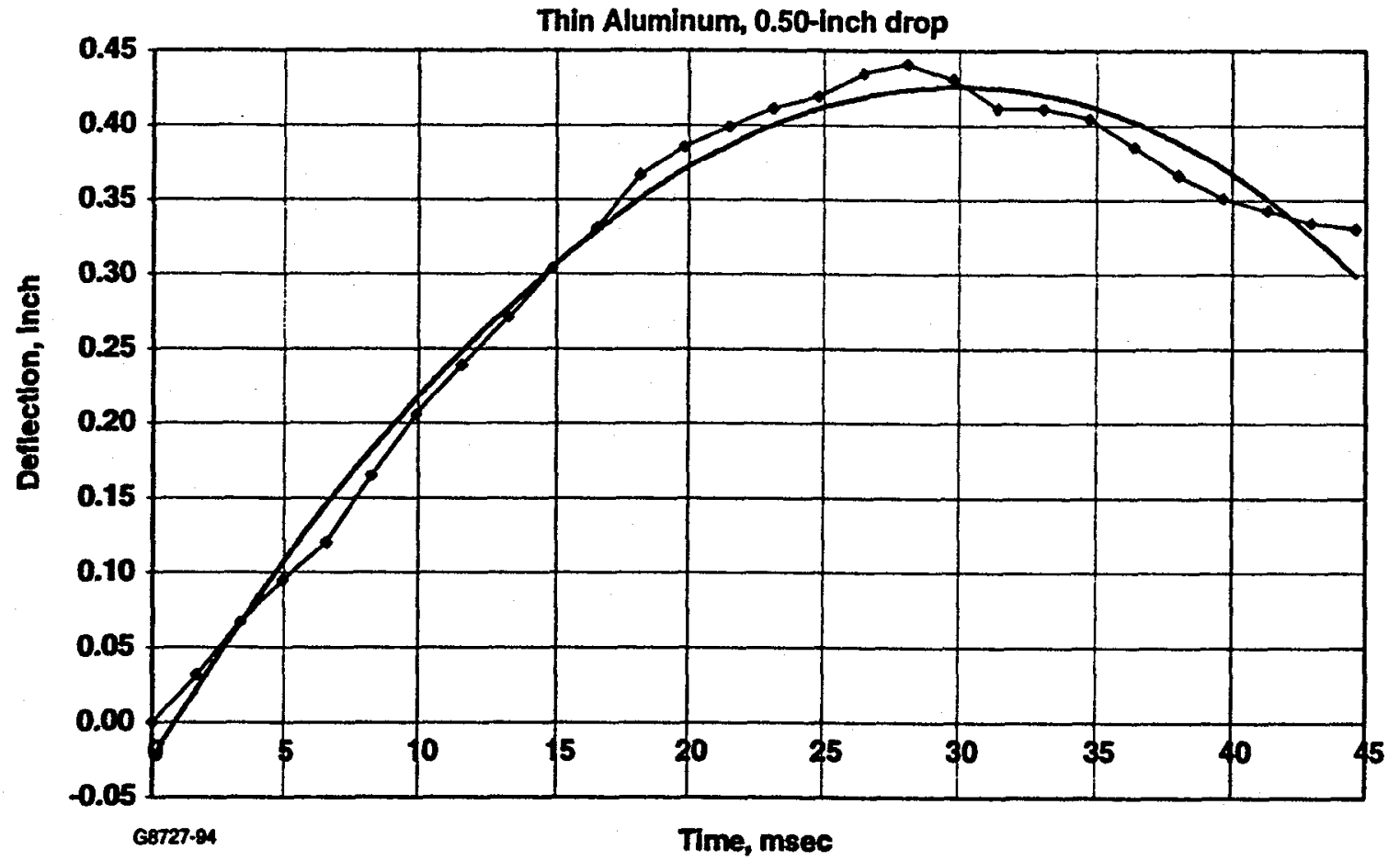

Figure X-14. Deflection vs. Time, Test No. 14, Thin Aluminum Sample, 0.50-Inch Drop. 
Test No. 15

Thin Titanlum, 3.00-inch drop

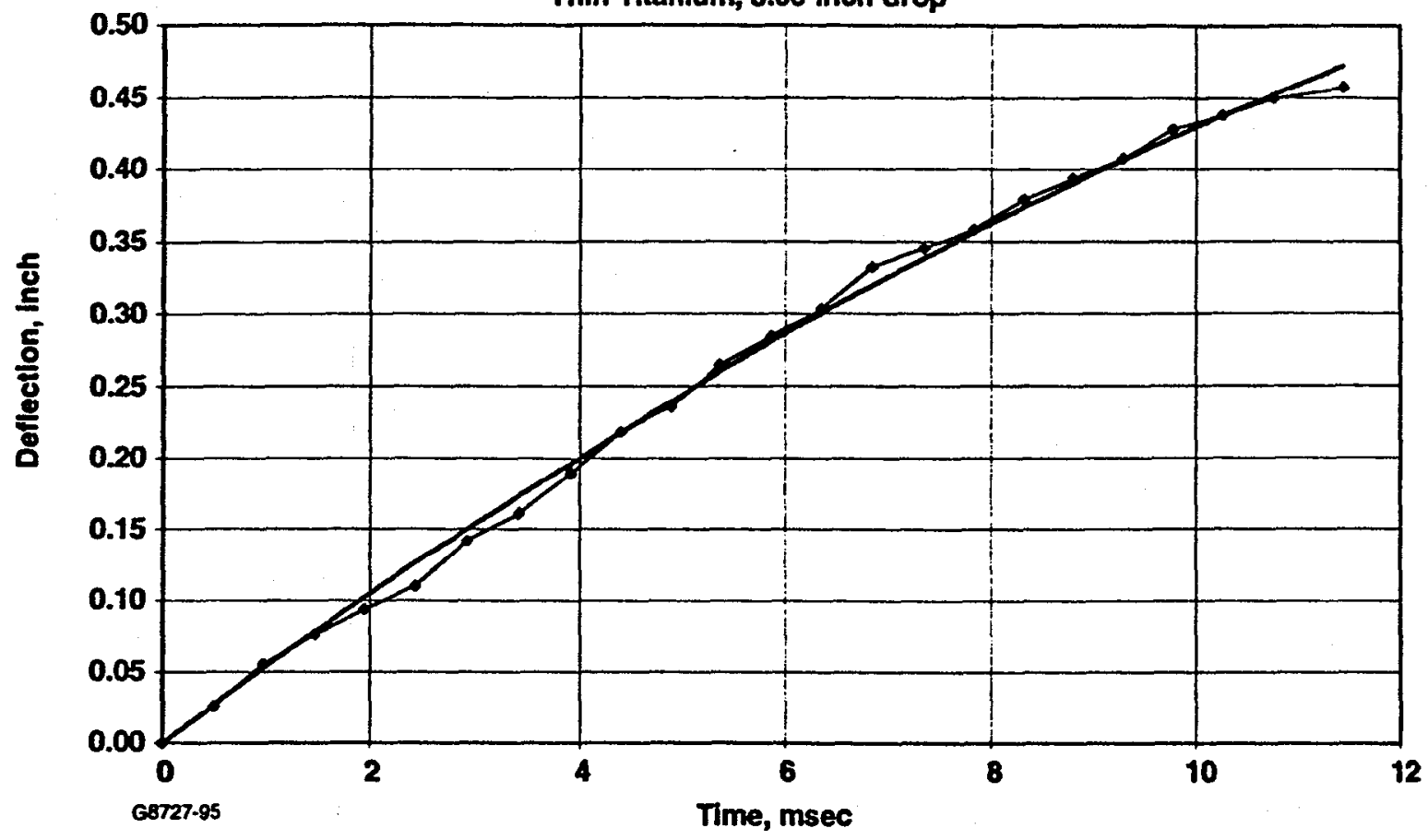

Figure X-15. Deflection vs. Time, Test No. 15, Thin Titanium Sample, 3.00-Inch Drop. 


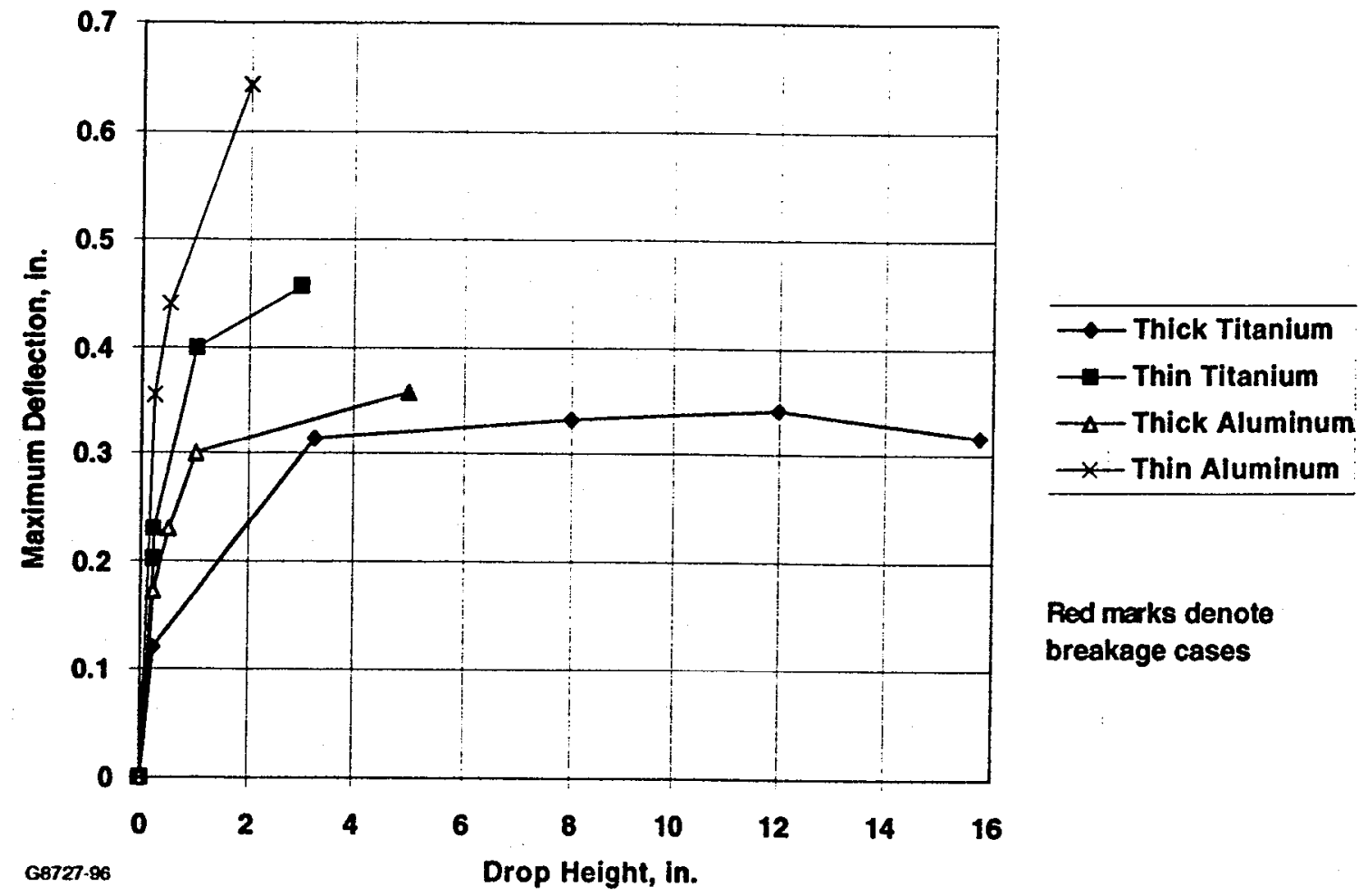

Figure X-16. Maximum Deflection Plots.
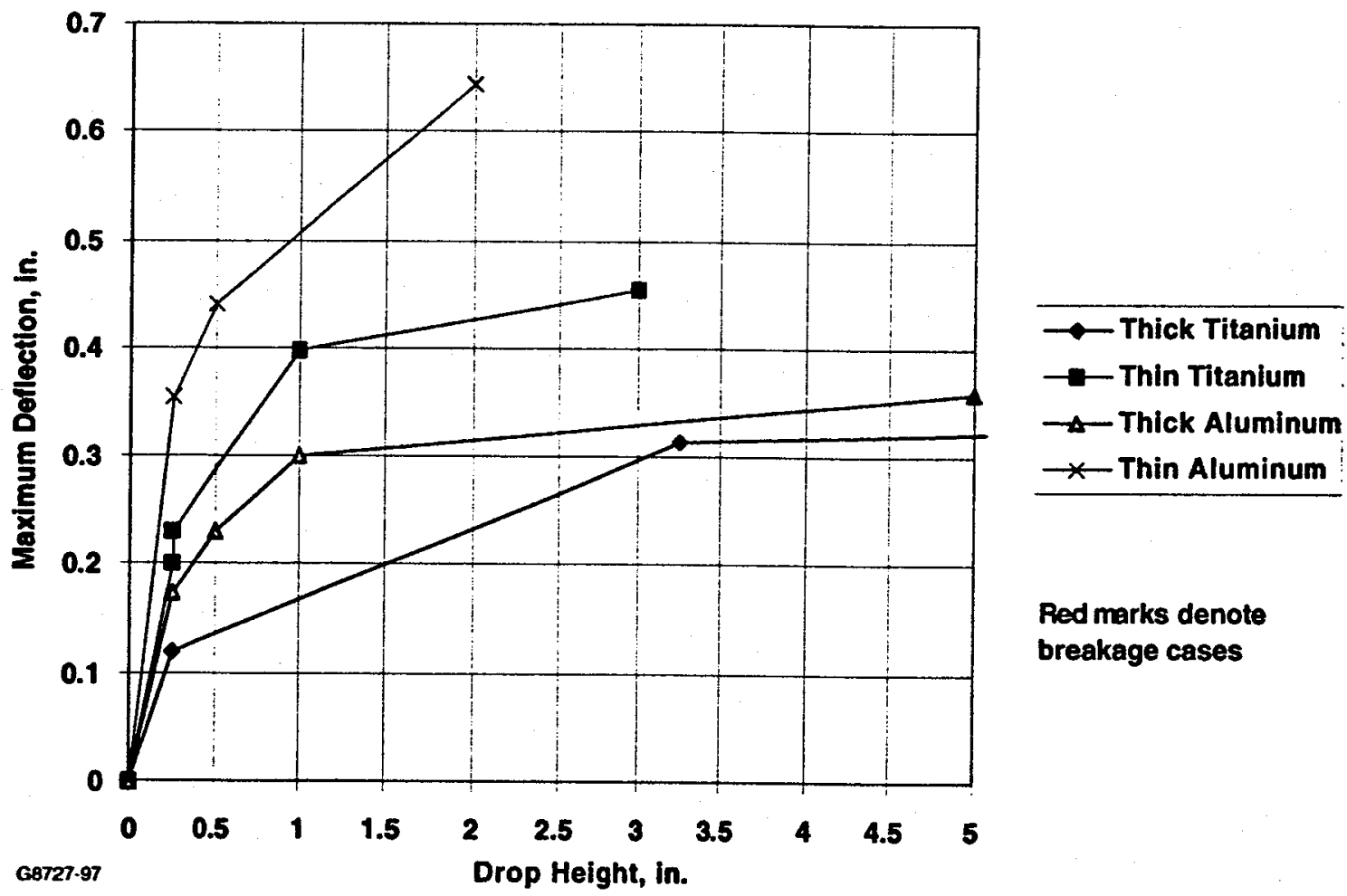

Red marks denote breakage cases

Figure X-17. Maximum Deflection Plots, Small Drop Height Detail. 
AlliedSignal

A E OSPACE

\section{APPENDIX XI \\ LOAD VS. TIME PLOTS \\ AND MAXIMUM LOAD PLOTS \\ (9 pages)}


Test No. 1

Thick TItanium, 0.25-Inch drop

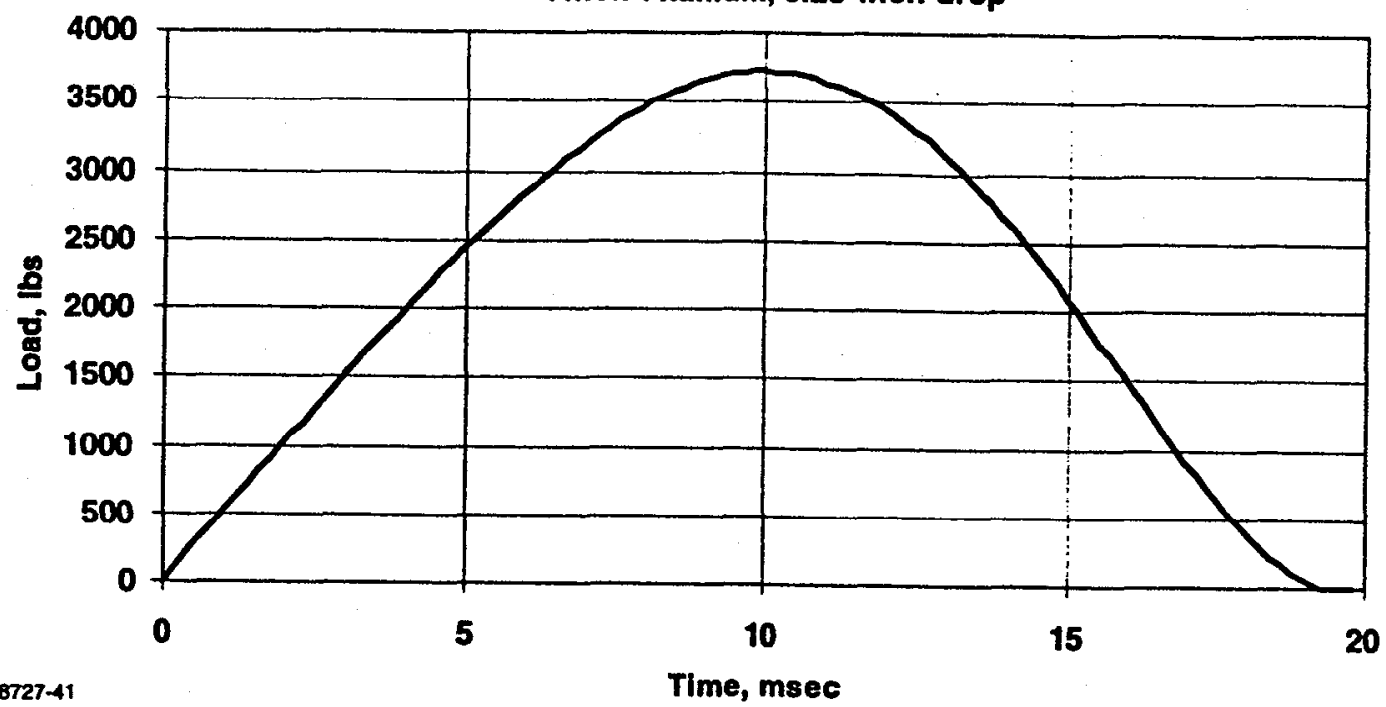

Figure XI-1. Load vs. Time, Test No. 1, Thick Titanium Sample, 0.25-Inch Drop.

Test No. 2

Thick Titanium, 3.25-inch drop

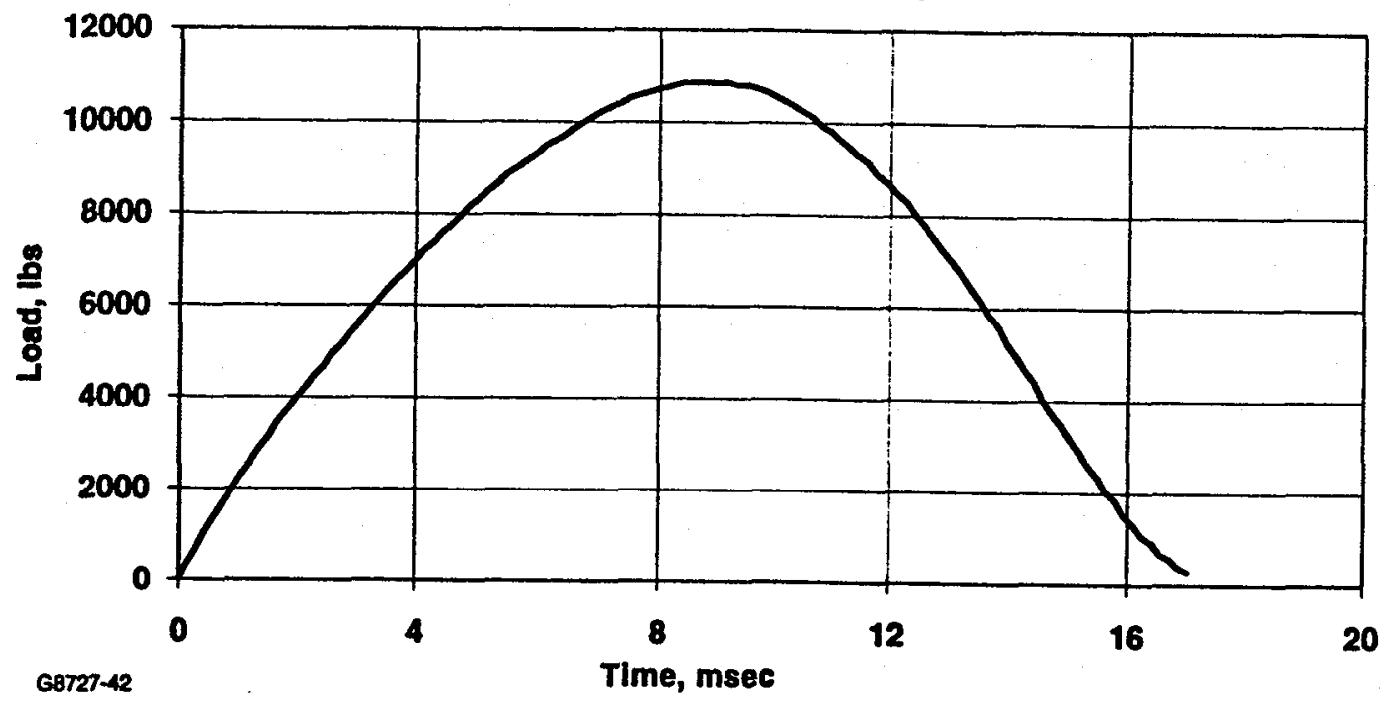

Figure XI-2. Load vs. Time, Test No. 1, Thick Titanium Sample, 3.25-Inch Drop. 
Test No. 3

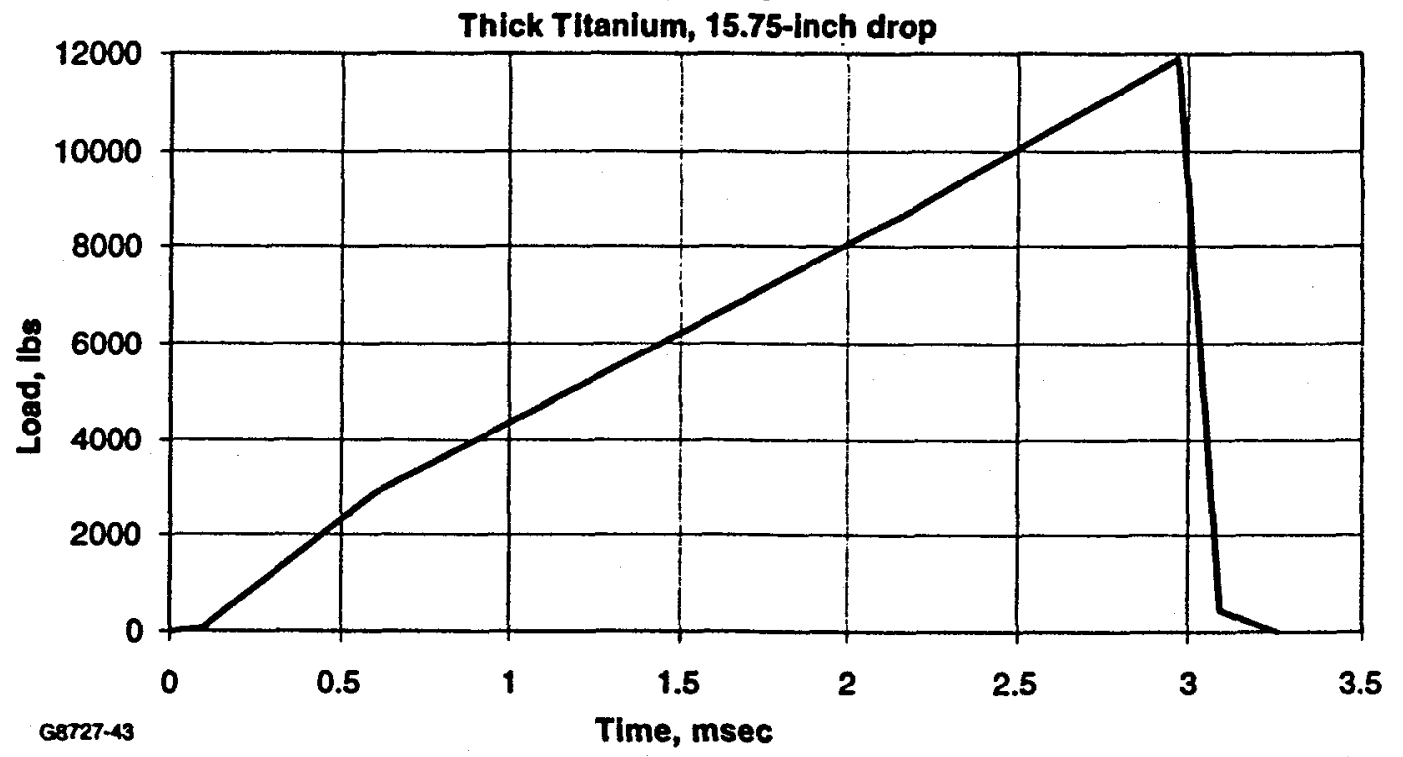

Figure XI-3. Load vs. Time, Test No. 3, Thick Titanium Sample, 15.75-Inch Drop.

Test No. 4

Thick Aluminum, 0.25-inch drop

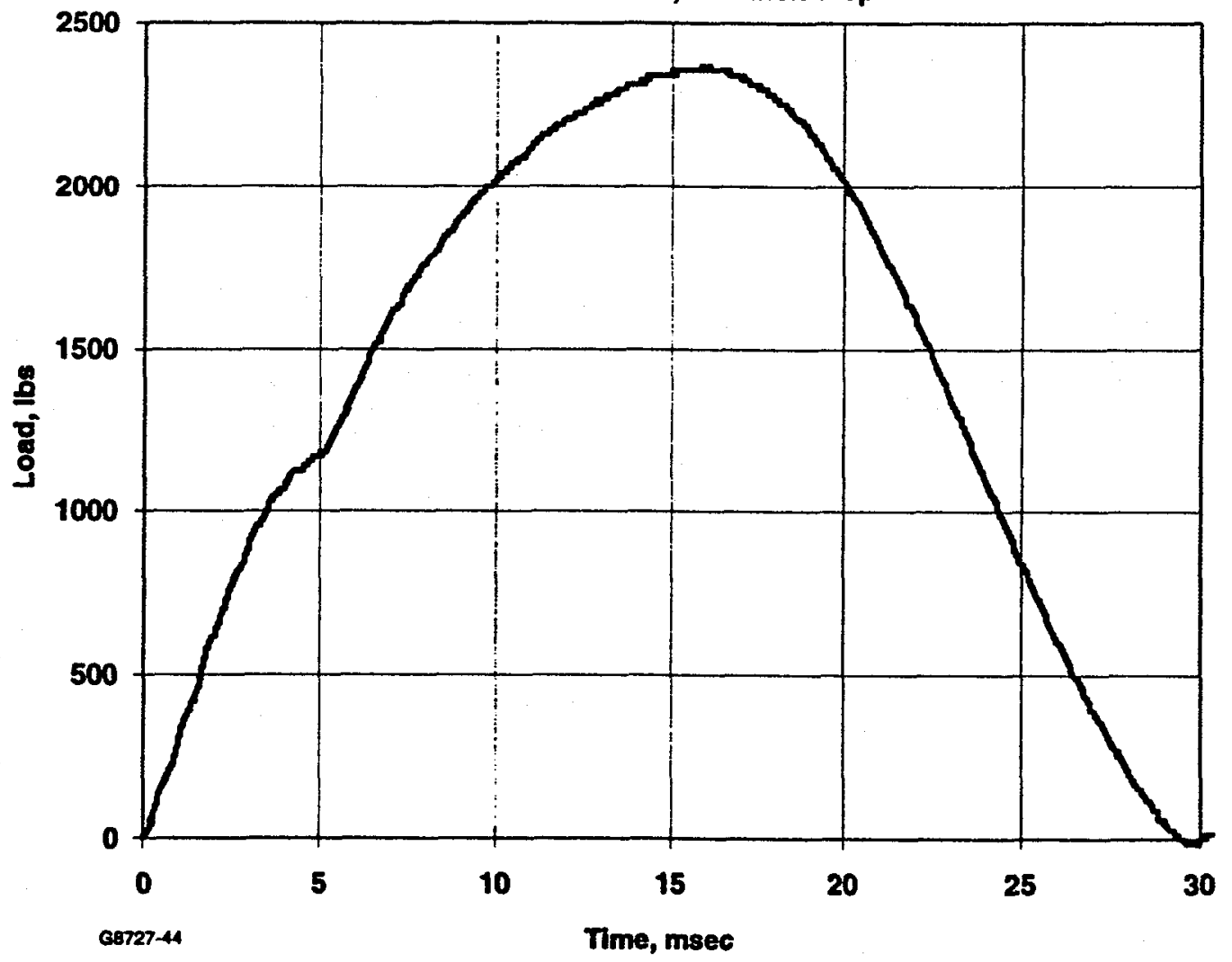

Figure XI-4. Load vs. Time, Test No. 4, Thick Aluminum Sample, 0.25-Inch Drop. 
Test No. 5

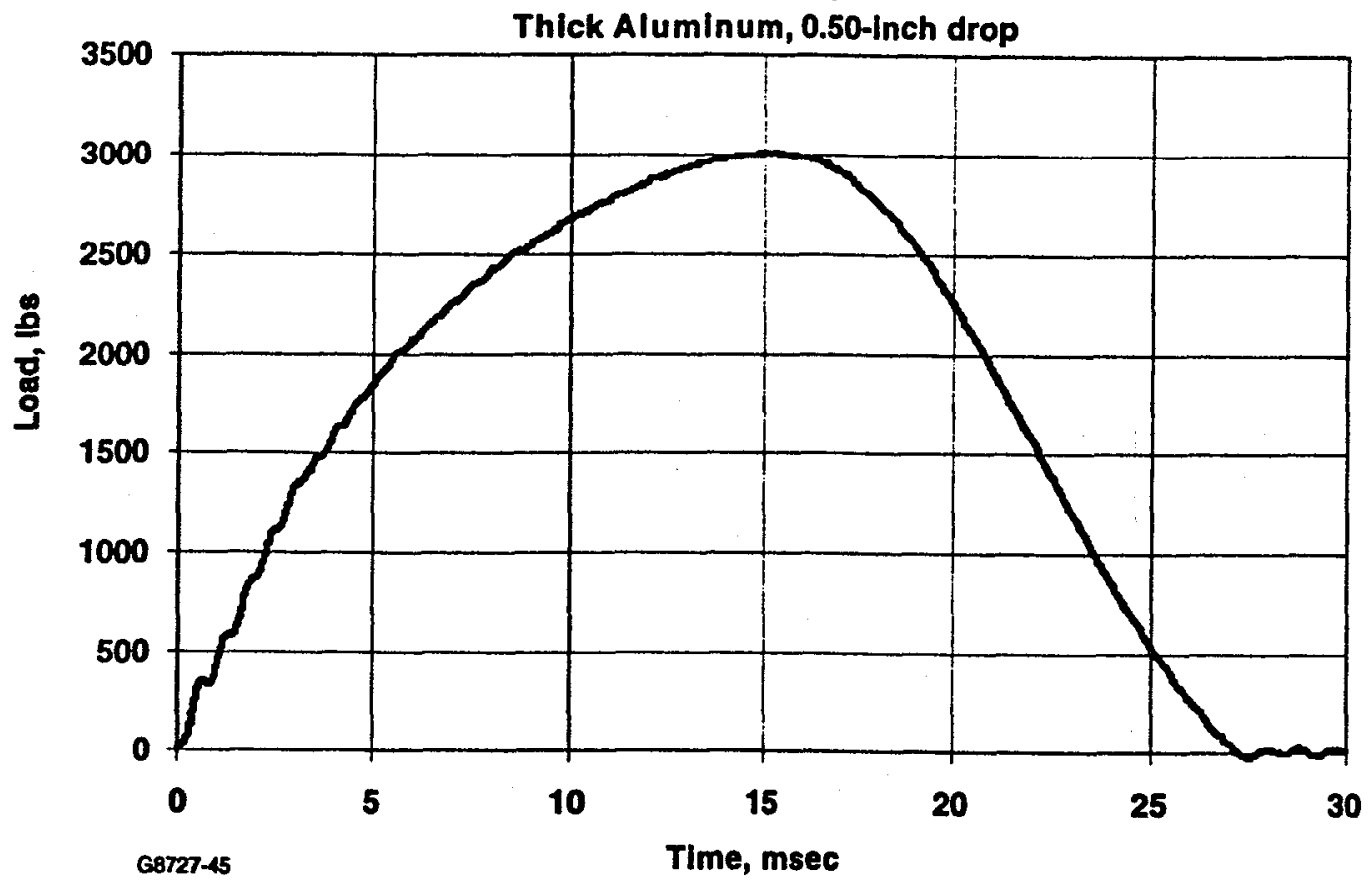

Figure XI-5. Load vs. Time, Test No. 5, Thick Aluminum Sample, 0.50-Inch Drop.

Test No. 6

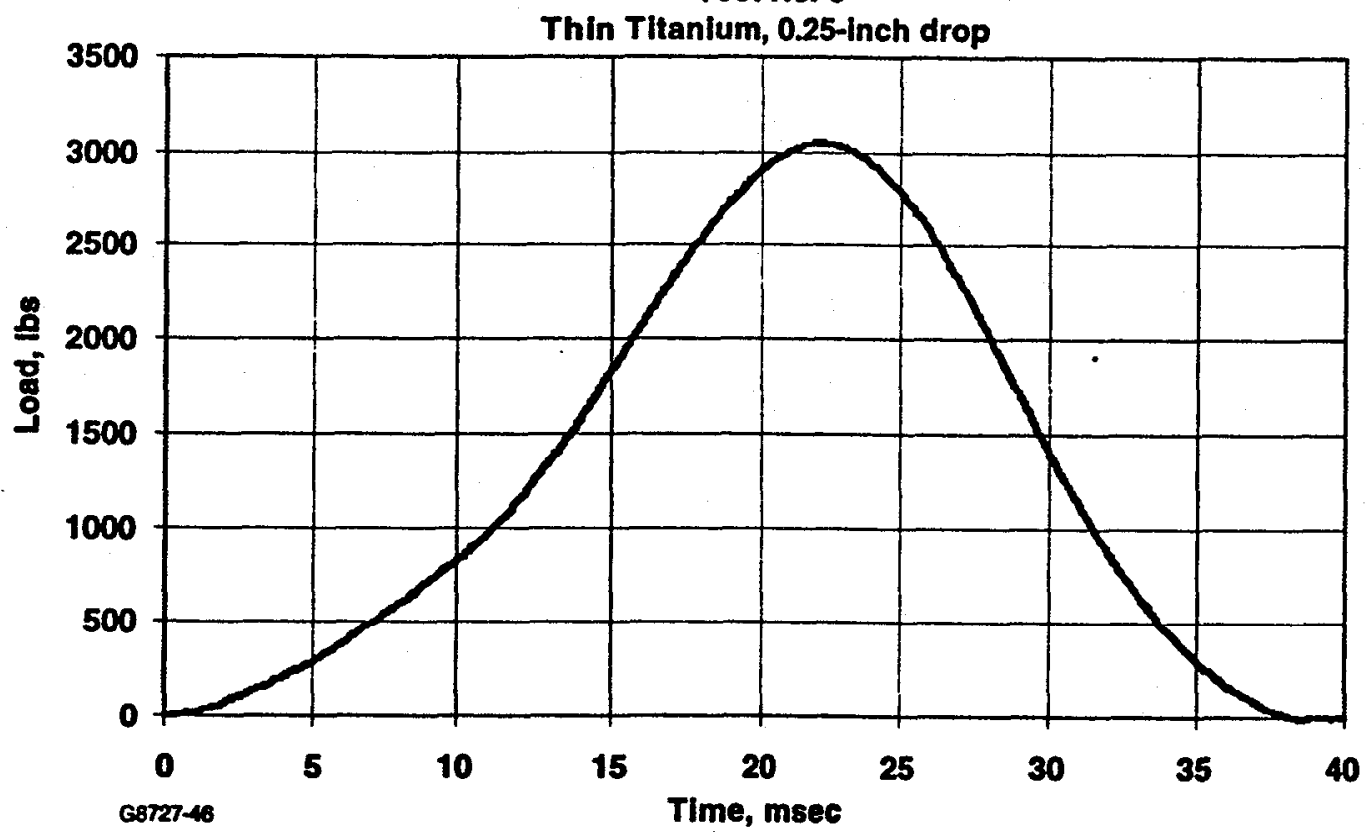

Figure XI-6. Load vs. Time, Test No. 6, Thin Titanium Sample, 0.25-Inch Drop. 
Test No. 7

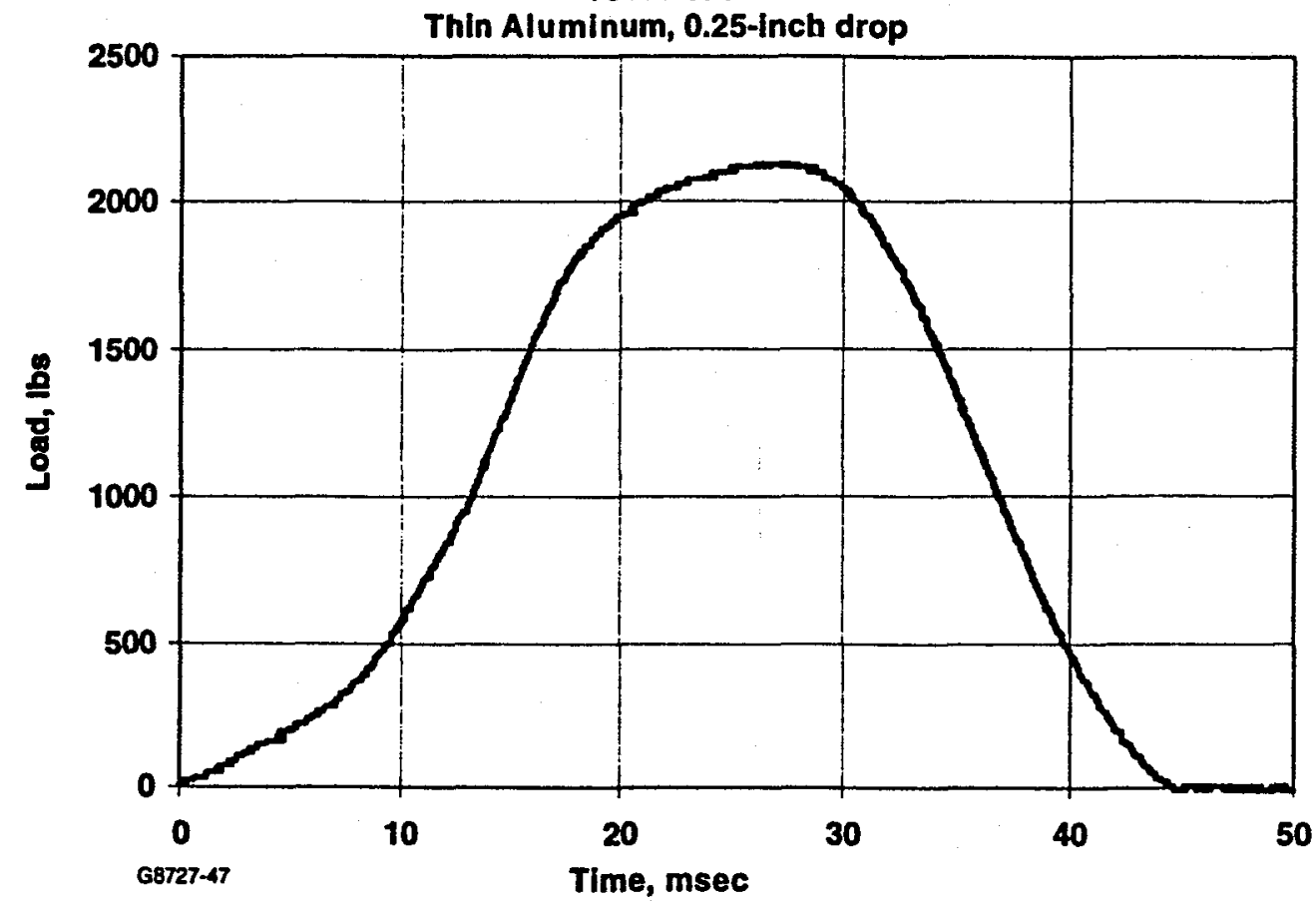

Figure XI-7. Load vs. Time, Test No. 7, Thin Aluminum Sample, 0.25-Inch Drop.

Test No. 8

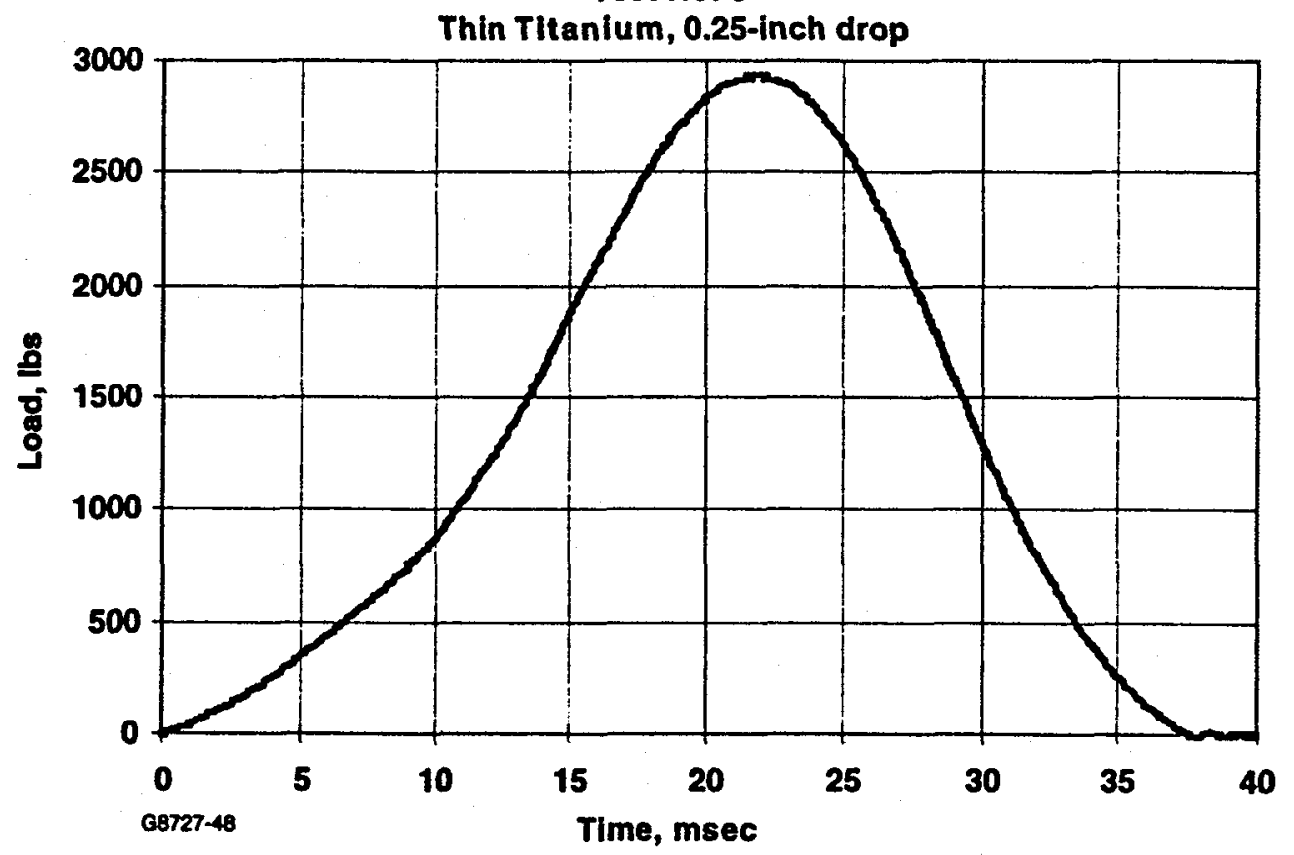

Figure XI-8. Load vs. Time, Test No. 8, Thin Titanium Sample, 0.25-Inch Drop. 
Test No. 9

Thick Aluminum, 1.00-inch drop

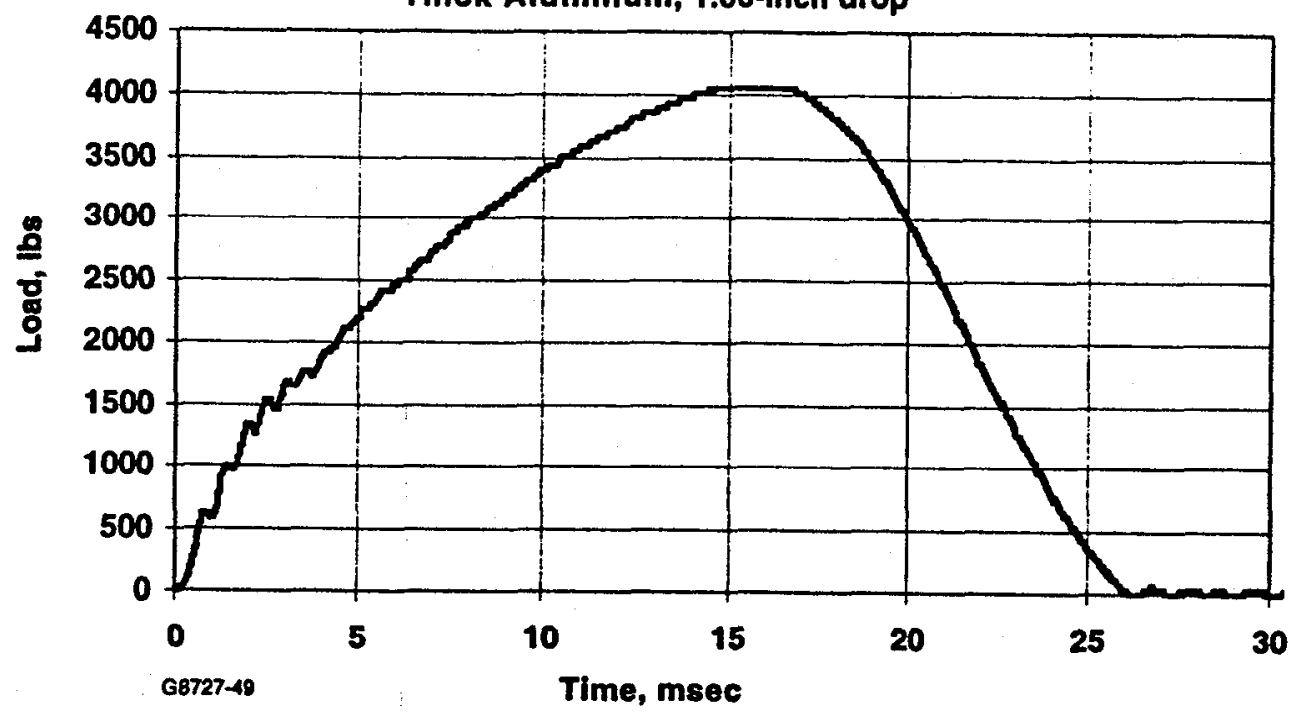

Figure XI-9. Load vs. Time, Test No. 9, Thick Aluminum Sample, 1.00-Inch Drop.

Test No. 10

Thick Titanlum, 12.00-inch drop

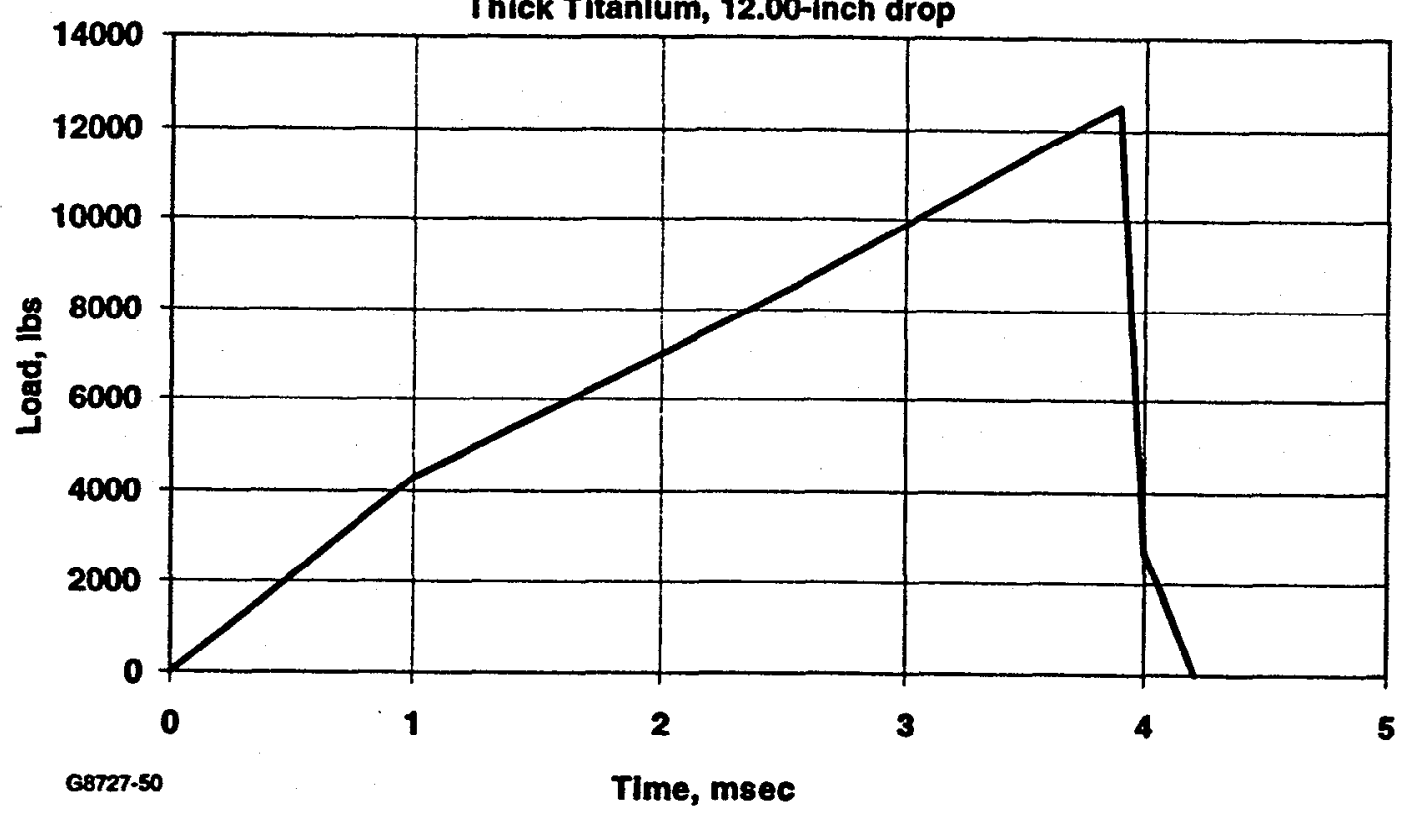

Figure XI-10. Load vs. Time, Test No. 10, Thick Titanium Sample, 12.00-Inch Drop. 
Test No. 11

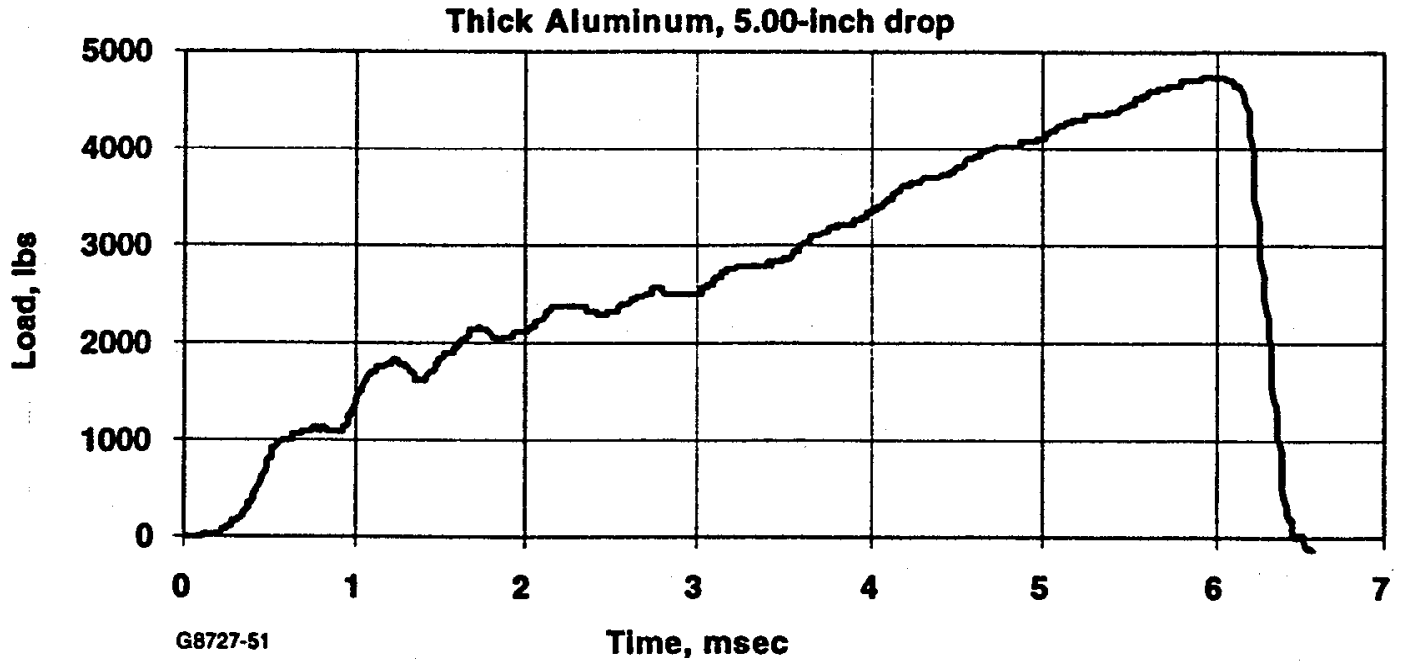

Figure XI-11. Load vs. Time, Test No. 11, Thick Aluminum Sample, 5.00-Inch Drop.

Test No. 12

Thick Titanium, 8.00-inch drop

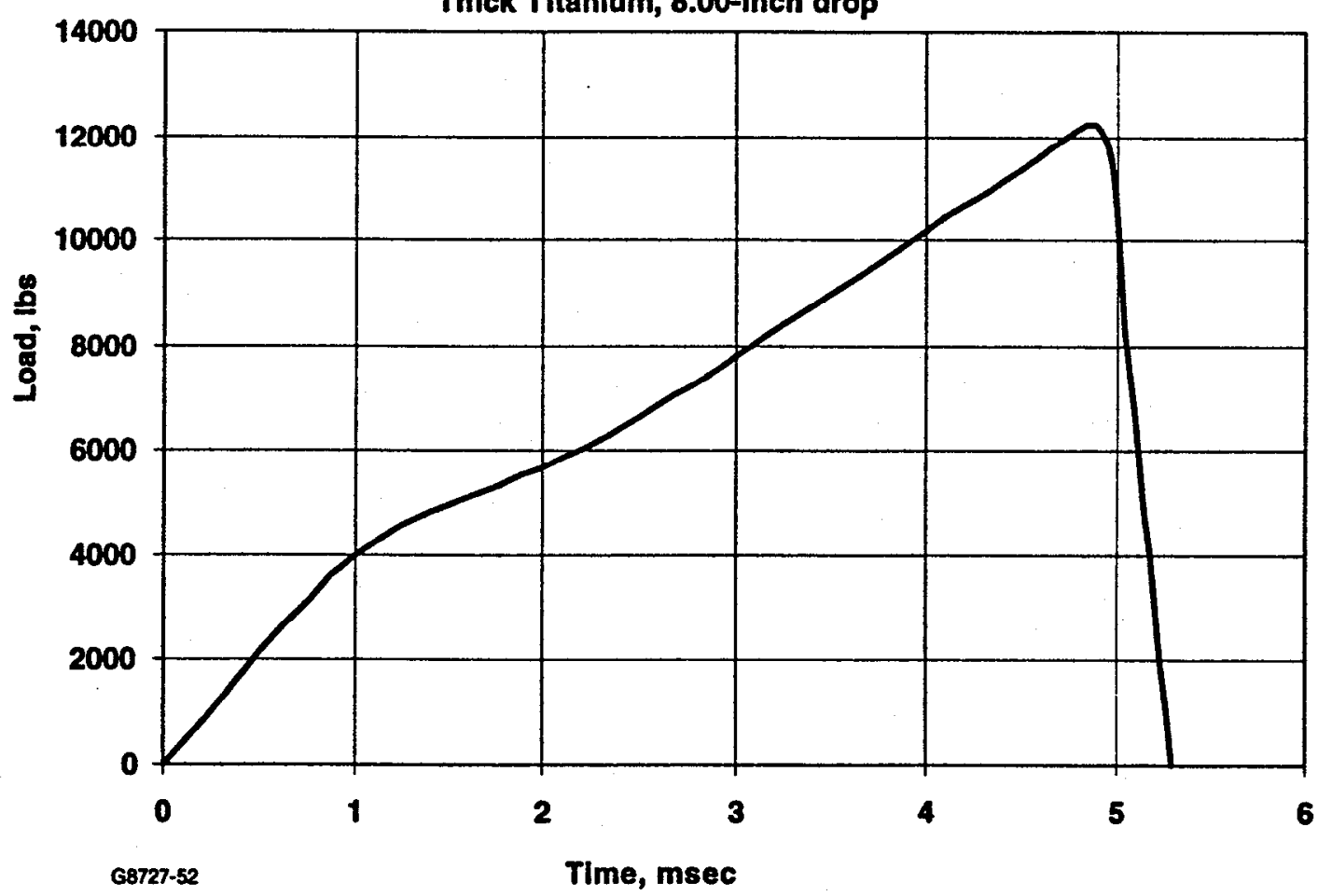

Figure XI-12. Load vs. Time, Test No. 12, Thick Titanium Sample, 8.00-Inch Drop. 
Test No. 13

Thin Titanium, 1.00-Inch drop

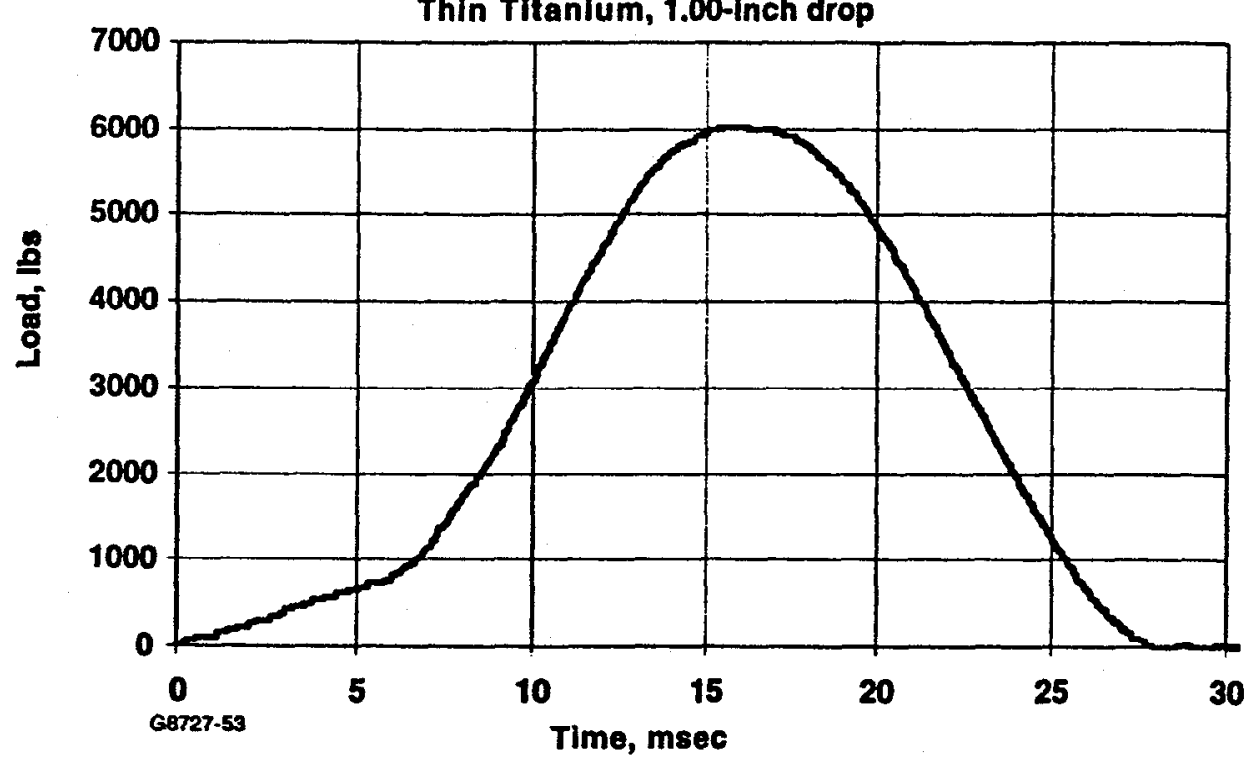

Figure XI-13. Load vs. Time, Test No. 13, Thin Titanium Sample, 1.00-Inch Drop.

Test No. 14

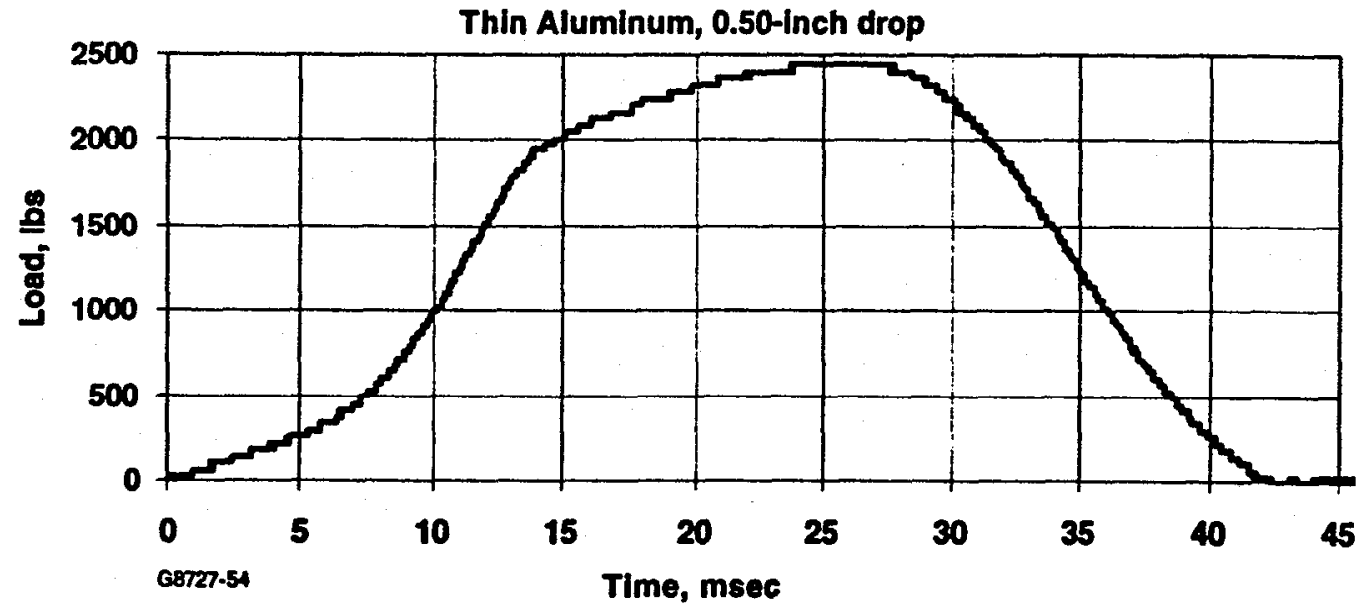

Figure XI-14. Load vs. Time, Test No. 14, Thin Aluminum Sample, 0.50-Inch Drop. 
Test No. 15

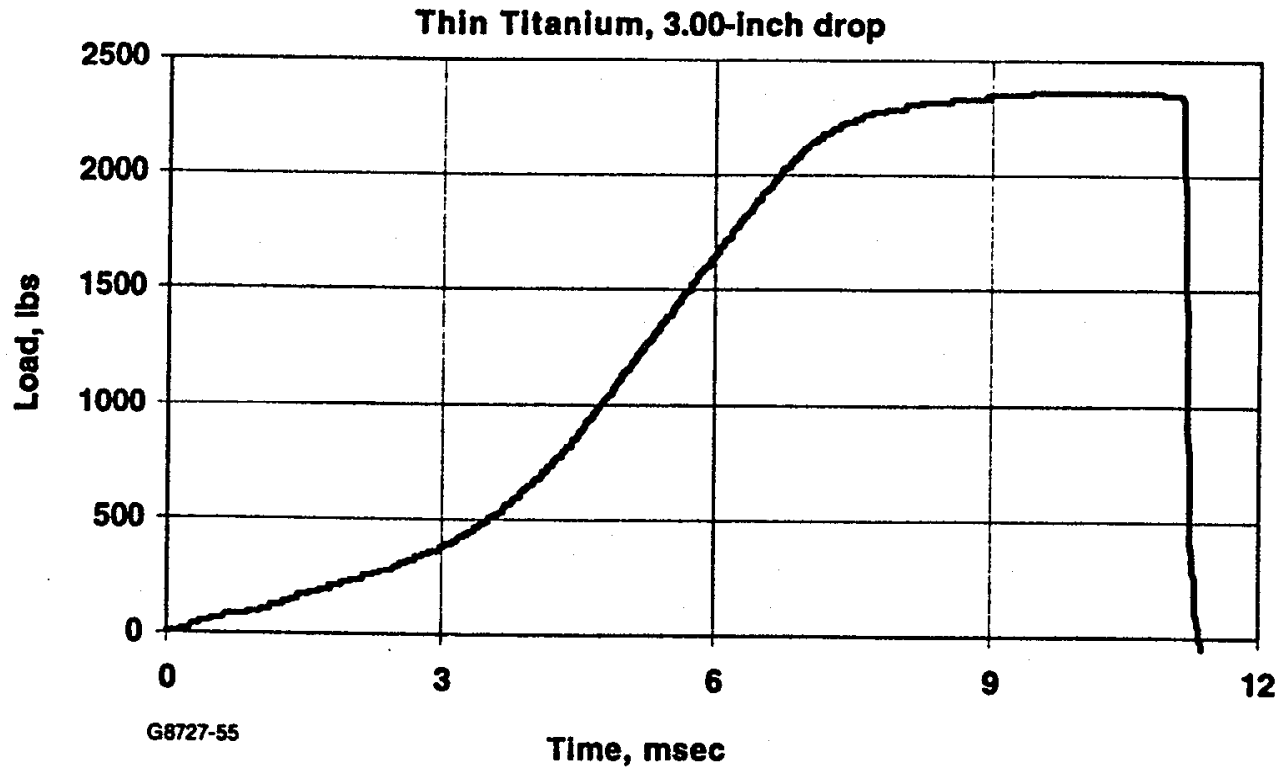

Figure XI-15. Load vs. Time, Test No. 15, Thin Titanium Sample, 3.00-Inch Drop.

Test No. 16

Thin Aluminum, 2.00-inch drop

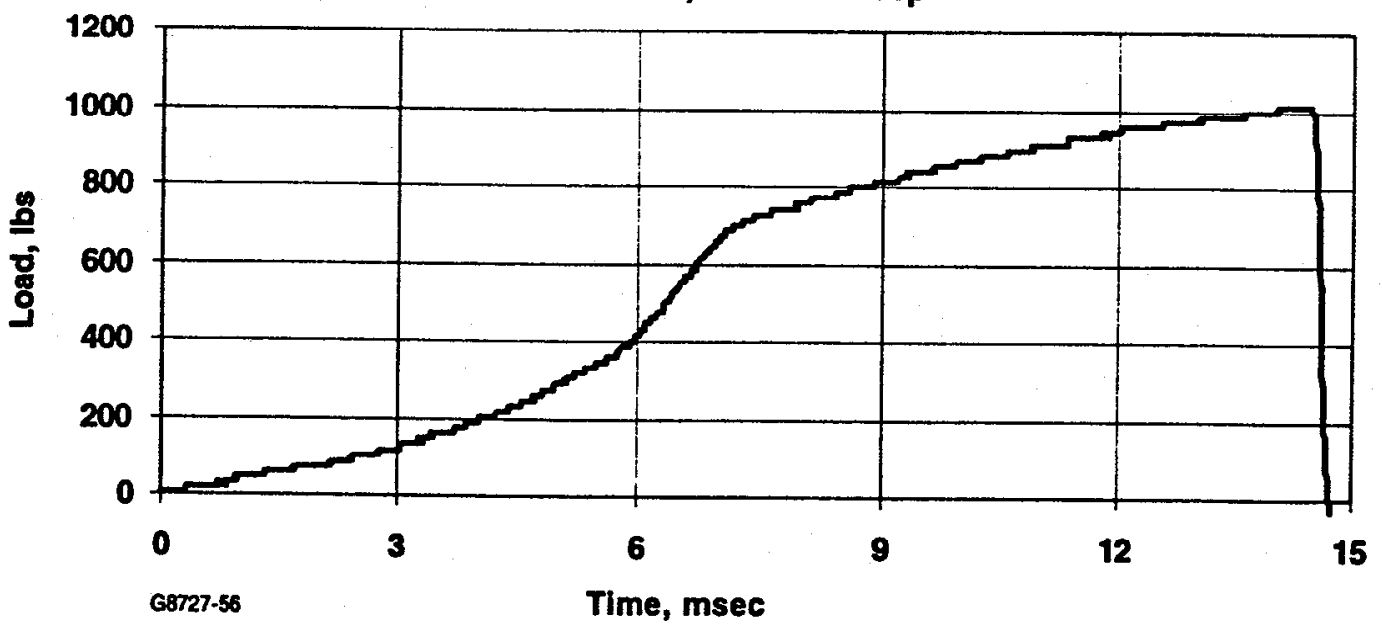

Figure XI-16. Load vs. Time, Test No. 16, Thin Aluminum Sample, 2.00-Inch Drop. 


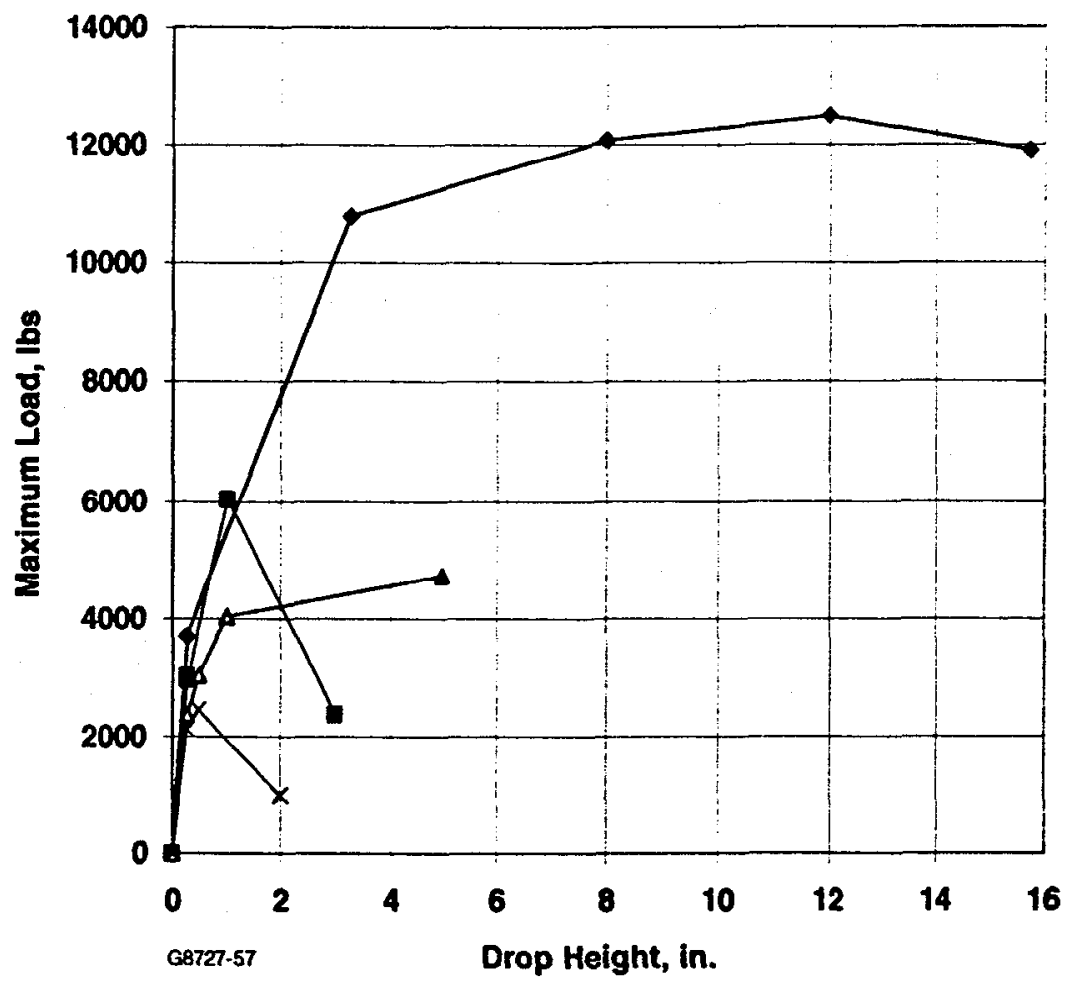

Figure XI-17. Maximum Load Plots.

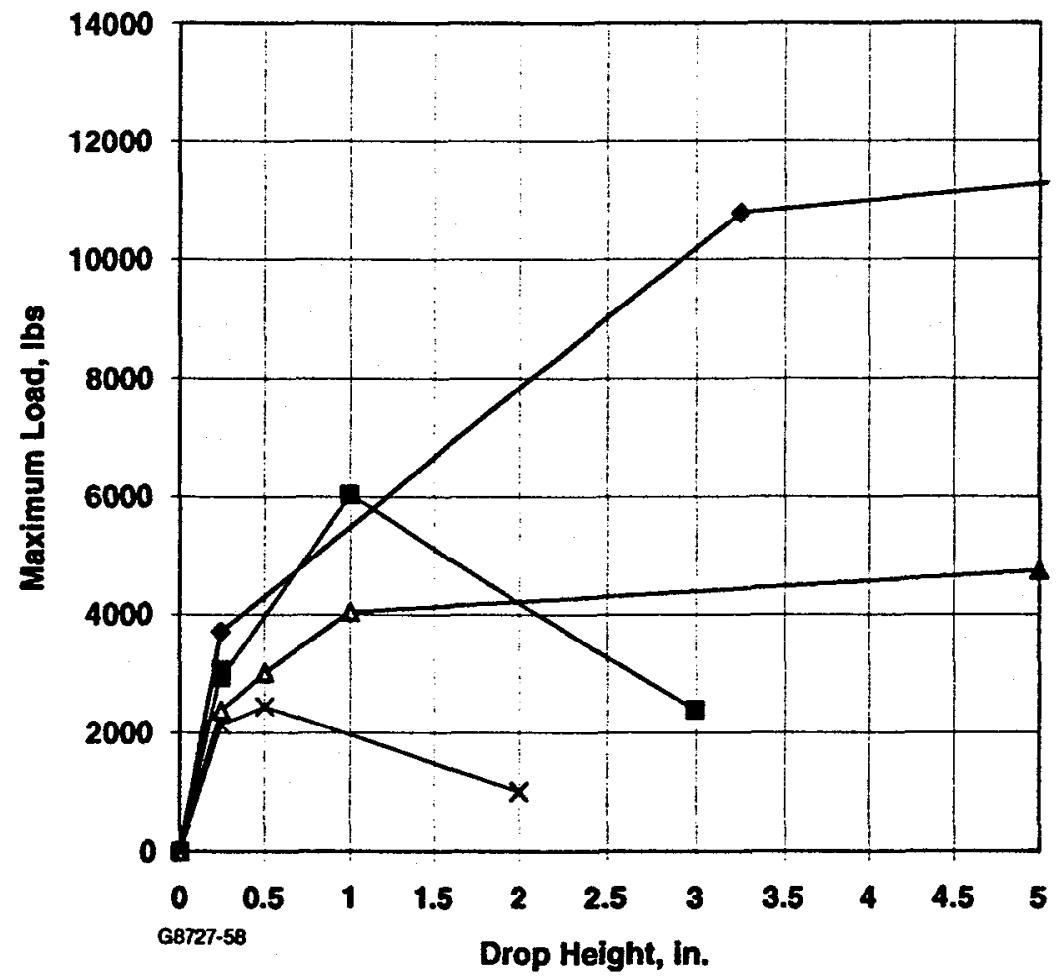

$\rightarrow-$ Thick Titanium

$\rightarrow$-Thin Titanium

$\rightarrow-$ Thick Aluminum

* Thin Aluminum

Red marks denote breakage cases
-Thick Titanium

- - Thin Titanium

$\rightarrow-$ Thick Aluminum

$\rightarrow$ Thin Aluminum

Red marks denote breakage cases

Figure XI-18. Maximum Load Plots, Small Drop Height Detail. 
AlliedSignal

APPENDIX XII

MISCELLANEOUS PLOTS

(1 page)

21-10392

XII-i 


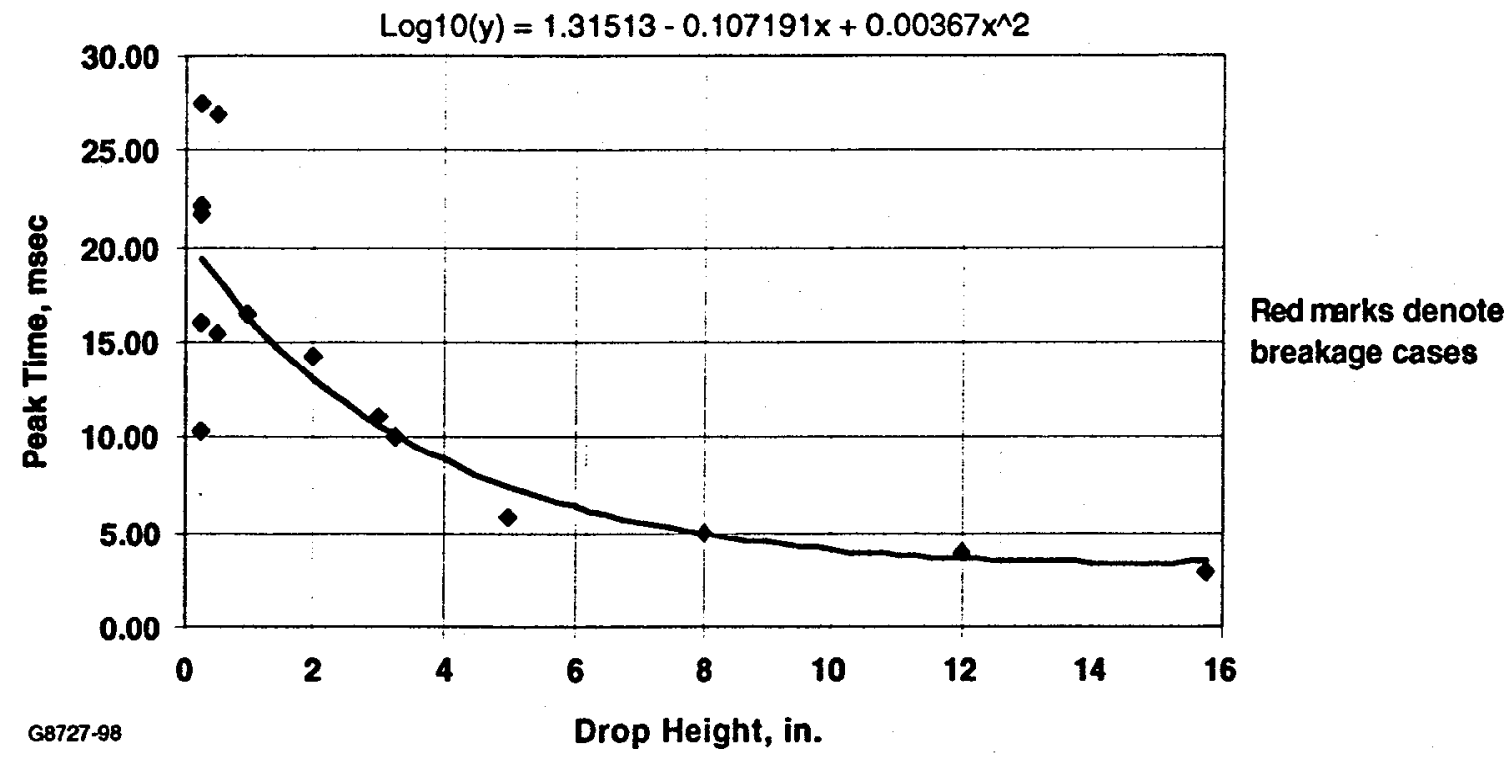

Figure XII-1. Peak Time Regression Plot.
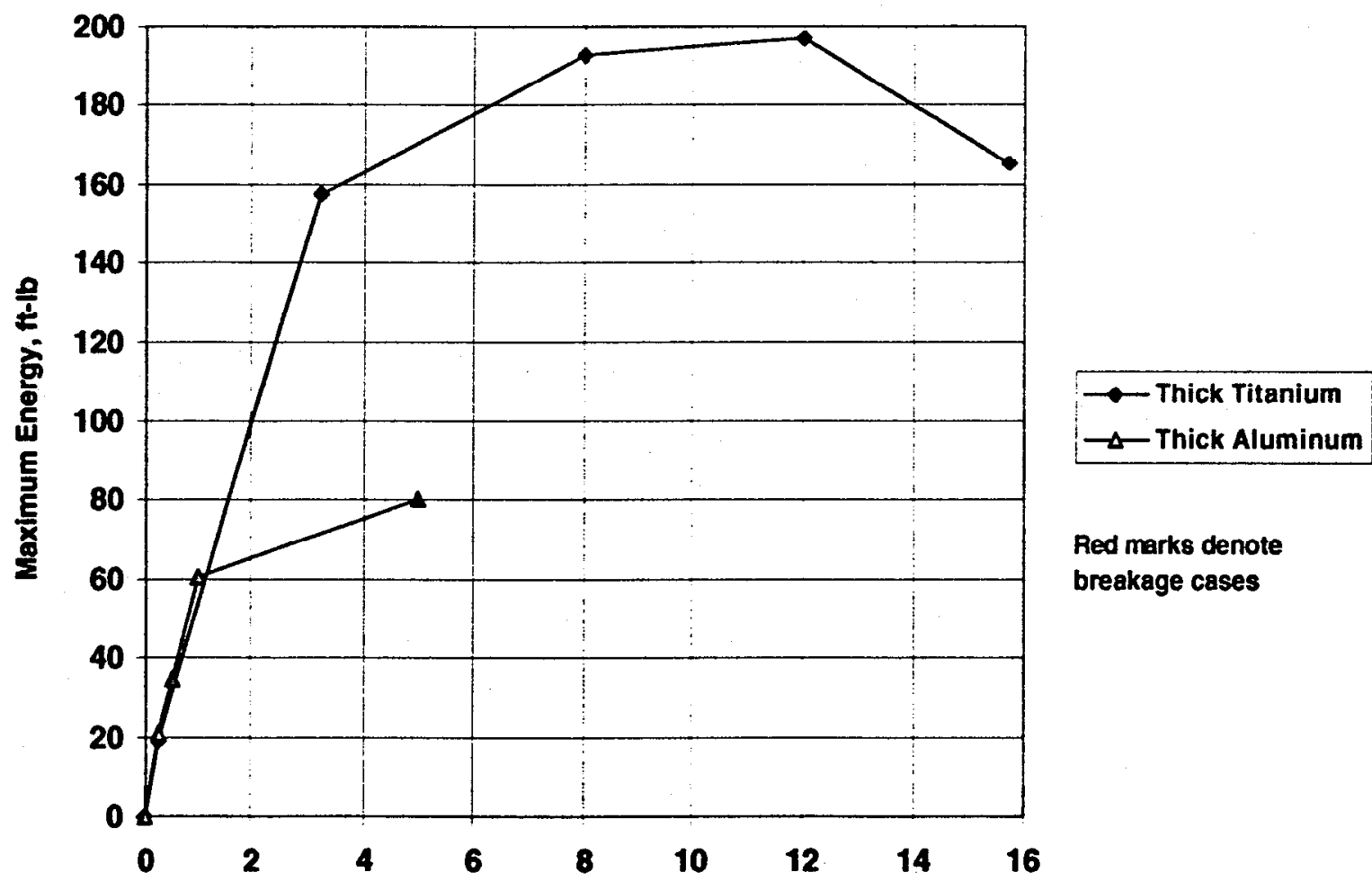

Red marks denote

breakage cases

Drop Height, in.

Figure XII-2. Maximum Energy Plots. 


\section{ATTACHMENT 1}

COMPONENT DESIGN DOCUMENT

13-CDD-STRU0199-0055

(29 pages) 


\section{COMPONENT DESIGN DOCUMENT}

Date: $12 / 01 / 98$

Approved By_Norm Lagasse

$\begin{array}{llllll}\text { TO: } & \text { Brian Gracias } & \text { EXT. 3625 } & \text { DEPT. 93-36 } & \text { M.S. } & \text { 301-124 } \\ \text { FROM: } & \text { Shen-Yeh Chen } & \text { EXT. 4887 } & \text { DEPT. 93-36 } & \text { M.S. } & \text { 301-124 }\end{array}$

Title: FAA Debris Mitigation, Phase I Anslysis

Introduction

\section{Statement of Problem}

This effort was funded by Lawrence Livermore National Lab, through the FAA Debris Mitigation Program. The goal was to improve the capability of LL-DYNA3D to model impact events of uncontained engine debris on aircraft structures. AE's contribution was modeling and correlation of two impact events. The first of these, a curved-beam impact test, is described here. The second phase will be a study of the TFE731-20/40 fan blade-out cert test.

\section{Statement of Work}

Two types of material models were used on specimens of two different configurations (thick and thin specimens), with two different material types (Al 2024 and Ti 6-4). For each material model, three multiplication factors were applied. These varaibles were chosen to support a design-of-experiments (DOE) study of their effect on the analytical correlation to test. See appendix $C$ for details. Impact tests were performed, and the data for strain, displacement and velocity versus time were obtained. Then the experimental data were compared against the simulation result from LL-DYNA. The material models are (1) (Static) Piecewise Linear Plasticity; (2) Johnson-Cook Model (strain-rate sensitive). The report focuses on the effect of the material model on the simulation result. Suggestions were made on selection of the material model and improvements to the program.

\section{Conclusions}

- The static piecewise linear plasticity material model performs better than the Johnson-Cook model. Numerical simulation results are reasonably close to the laboratory test for the piecewise linear plasticity model.

- Strain-rate effects are observed: the penetrating energy is not only a material constant, but also a function of impacting velocity.

- The material properties scale factor does not affect the local behavior on the observed location significantly, which implies that the response may be localized in the impacted area.

- Johnson-Cook model performance may be a result of poorly defined parameter values, or are inappropriate for the strain-rates and failure modes investigated here.

\section{Recommendations}

- The static piecewise linear plasticity material model works well for impact simulation.

- Further material characterization is needed to improve the Johnson-Cook model's correlation to test.

- Global simulation (displacement, velocity, energy, etc., of the whole projectile or specimen) is more accurate then local simulation (strain, stress, etc. of a particular point inside the projectile or specimen). The differences between the global simulation and lab test results are almost negligible.

KEY WORDS:

1. CONTANNMENT

2. FINITE ELEMENT MODELING

3. MATERIAL FAILURE MODE

4. IMPACT TEST

5. STRUCTURE PRODUCT LINE:

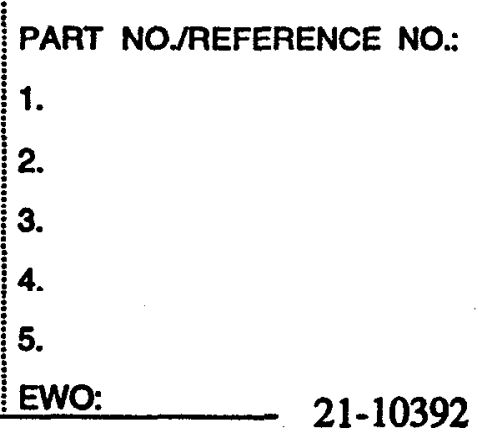

3.

5.

6. \\ ADDITIONAL DOCUMENTATION}

Test report 


\section{Test Hardware Configuration}

The configuration of test hardware and testing procedure is described in References 1 and 2.

\section{Testing Matrices}

A total of 16 tests were performed at the GRC laboratory. Table 1 shows the drop height of the projectile, visible results, material and geometry type. More details can be found in reference 2.

Table 1 Testing Matrix

\begin{tabular}{|c|c|c|c|l|}
\hline Test & Material & Config & Drop Height & \\
\hline 6 & Ti 6-4 & Thin & $0.25^{*}$ & Stretched \\
\hline 7 & Al 2024 & Thin & $0.25^{\prime \prime}$ & Stretched \\
\hline 11 & Al 2024 & Thick & $5.00^{\circ}$ & Broken \\
\hline 12 & Ti 6-4 & Thick & $8.00^{\circ}$ & Broken \\
\hline
\end{tabular}

\section{Testing Result}

The testing results can be found in document reference 2. Since this report concentrates on the comparison between numerical simulation and laboratory experiment, details will not be covered here.

\section{LL-DYNA3D Numerical Simulation Matrices}

Tests 6, 7, 11 and 12 in Table 1 were selected for simulation comparison. Table 2 shows modeling combinations of the 24 DOE runs using LL-DYNA3D. See appendix $C$ for more details of the DOE setup, analysis, and interpretation. The multiplication factor was applied in the following sense : for piecewise linear plasticity material model, the stress-strain curve was scaled by the factor, on the stress data. Then all other parameters, such as elastic modulus, failure stress and yielding stress were calculated according to the new stress-strain relationship. For the Johnson-Cook model, only elastic modulus, shear modulus and cutoff failure pressure were scaled. The parameters of failure and equation of state were obtained from Lawrence Livermore National Laboratory. Files for these materials in LS-DYNA format can be found in /users/e094729/tmp/material/sdyna.doc/mtrl01.lsd . The piecewise linear plasticity model in ANSYS format can be found in the network directory /users/e094729/tmp/material/Al6061.BIN_MPL and /users/e094729/tmp/material/Ti6-4.BIN_MPL.

\section{LL-DYNA3D Finite Element Model}

The plots of the FEM mesh are shown in Appendix A, for both thick and thin specimens. The specimen support was not modeled. Instead, fixed boundary conditions (in all directions) were applied on all clamped surfaces. To simplify the model and improve the efficiency, only one quarter of the model was described, and symmetric boundary conditions were applied. Gravity was applied on both specimen and projectile. Instead of applying a drop height on the projectile, the projectile was placed very close to the specimen, and the initial velocity was calculated according to the drop height and gravity. Table 2 also shows the initial velocity applied on the projectile model. Table A.1 shows the problem size of the models. The units used are Mega-pounds, inch, and milli-second. Density is slugs per cubic inch. 
Table 2 LS-DYNA3D Numerical Simulation Matrices

\begin{tabular}{|c|c|c|c|c|c|c|}
\hline & Material & Specimem & Material Model & Factor & Drop Height & Velocity \\
\hline ThkTiO & Ti 6-4 & Thick & Piecewise Linear Plasticity & & $8.0^{\prime \prime}$ & 0.0625 \\
\hline ThkTi1 & $\mathrm{Ti} \mathrm{6-4}$ & Thick & Piecewise Linear Plasticity & 0.9 & $8.0^{\prime \prime}$ & 0.0625 \\
\hline ThkTi2 & Ti 6-4 & Thick & Piecewise Linear Plasticity & 1.1 & $8.0^{\prime \prime}$ & 0.0625 \\
\hline ThkTi3 & Ti 6-4 & Thick & Johnson-Cook & 0.9 & $8.0^{\prime \prime}$ & 0.0625 \\
\hline ThkTi4 & Ti 6-4 & Thick & Johnson-Cook & 1.1 & 8.0" & 0.0625 \\
\hline ThkTi5 & Ti 6-4 & Thick & Johnson-Cook & & $8.0^{\prime \prime}$ & 0.0625 \\
\hline ThkAlO & Al 2024 & Thick & Piecewise Linear Plasticity & 1 & $5.0^{*}$ & 0.0787 \\
\hline ThkAl1 & Al 2024 & Thick & Piecewise Linear Plasticity & 0.9 & $5.0^{\prime \prime}$ & 0.0787 \\
\hline ThkAl2 & Al 2024 & Thick & Piecowise Linear Plasticity & $\overline{1.1}$ & $5.0^{n}$ & 0.0787 \\
\hline ThkAl3 & Al 2024 & Thick & Johnson-Cook & 0.9 & $5.0^{n}$ & 0.0787 \\
\hline ThkAl4 & $\mathrm{Al} 2024$ & Thick & Johnson-Cook & 1.1 & $5.0^{n}$ & 0.0787 \\
\hline ThkAl5 & Al 2024 & Thick & Johnson-Cook & & $5.0^{\prime \prime}$ & 0.0787 \\
\hline ThnTio & Ti 6-4 & Thin & Piecewise Linear Plasticity & 1 & $0.25^{\prime \prime}$ & 0.014 \\
\hline ThnTi1 & Ti 6-4 & Thin & Piecewise Linear Plasticity & 0.9 & $0.25^{\prime \prime}$ & 0.014 \\
\hline ThnTi2 & Ti 6-4 & Thin & Piecewise Linear Plasticity & 1.1 & $0.25^{\prime \prime}$ & 0.014 \\
\hline ThnTi3 & Ti 6-4 & Thin & Johnson-Cook & 0.9 & $0.25^{n}$ & 0.014 \\
\hline ThnTi4 & Ti 6-4 & Thin & Johnson-Cook & $\overline{1.1}$ & $0.25^{*}$ & 0.014 \\
\hline ThnTi5 & Ti $6-4$ & Thin & Johnson-Cook & & $0.25^{\prime \prime}$ & 0.014 \\
\hline ThnAlO & Al 2024 & Thin & Piecewise Linear Plasticity & & $0.25^{\mathrm{k}}$ & 0.014 \\
\hline ThnAlt & Al 2024 & Thin & Piecewise Linear Plasticity & 0.9 & $0.25^{\prime \prime}$ & 0.014 \\
\hline ThnAl2 & Al 2024 & Thin & Piecewise Linear Plasticity & 1.1 & $0.25^{\prime \prime}$ & 0.014 \\
\hline ThnAl3 & Al 2024 & Thin & Johnson-Cook & 0.9 & $0.25^{\prime \prime}$ & 0.014 \\
\hline ThnAl4 & Al 2024 & Thin & Johnson-Cook & 1.1 & $0.25^{n}$ & 0.014 \\
\hline ThnAl5 & Al2024 & Thin & Johnson-Cook & & $0.25^{\prime \prime}$ & 0.014 \\
\hline
\end{tabular}

\section{LL-DYNA3D Simulation Versus Laboratory Test Result}

Appendix B contains plotted laboratory test data with simulation results from LL-DYNA3D. The data includes velocity and displacement of the projectile as well as strain used from specified strain gages. For thick specimens, strain gage 4 is used. For thin ones, strain gage 2 is used. For laboratory test results, only the data necessary for comparison is shown. Other details can be found in Reference 2.

\section{Discussion}

1. Comparison of numerical simulation and laboratory test results

The following phenomena were observed when comparing numerical simulation with laboratory test results

(1) Johnson-Cook material model does not simulate better than static piecewise linear plasticity material model : In all cases, Johnson-Cook seems to make the material very ductile (and soft), and sometimes the material can be extremely stretched without failure. The material even provides very small stiffness in some cases. In thick specimens for both materials, the simulation with JohnsonCook model deformed seriously but did not break. This does not match the laboratory test results.

(2) Post-failure simulation does not perform well. This may be because of the noise in laboratory test recording (which makes the laboratory data incorrect), or because the failed elements are deleted, but physically they still occupy space. If the post-failure process is important and the details will affect the result considerably, this may cause an unreliable answer.

(3) Scale factor : Scale factor does not affect local behavior (strain away from impacted zone in this case) significantly. This implies that the response may be quite localized in the impacted area. 
(4) Local (strain, stress, etc. of a particular point inside the projectile or specimen) and global (displacement, velocity, energy, etc.; of the whole projectile or specimen) simulation: From current observation, the accuracy of local simulation (stress, strain, etc.) depends on the mesh quality, specimen geometry, etc (for example, Figure B.3 shows the simulation result is more conservative than test results, yet Figure B.9 shows the simulation under-predicted the test results). However, the global simulation is always observed to be more conservative then experimental data (Figure 2, Figure B.S, Figure B.8 and Figure B.11). Actually, the numerical simulation is very close to the experimental data. The difference is almost negligible in displacement-time history plot.

\section{Computational Effort}

Models using the Johnson-Cook materials are observed to save about $20 \%$ computation time than the static piecewise linear plasticity models, if the scale factor is 1.0 , and provided that all other parameters remains the same. This may be because the Johnson-Cook Model softens the stiffness, and makes the vibration wave length longer, therefore the integration time steps are longer.

\section{Impact Energy Absorption}

During the pre-lab numerical simulation, it was found that, even if the projectiles have the same shape, and the specimens have the same material properties, the yielding energy (energy required to yield the whole section) will depend on the impact velocity. That is, the energy required to yield the whole section is not a material constant. Instead, it is (at least) also a function of the impact velocity of the projectile. However, this increased rate of energy absorption is smaller than the increased rate of projectile launching energy, and finally as the launching energy increases more and more, it reaches a critical point and the specimen was penetrated. The same characteristic is also found on penetrating energy. It was observed that when the velocity is higher, the specimen will reduce more energy from the projectile, if penetrated.

\section{Recommendations}

1. To program users

(1) The global simulation result will be more accurate and reliable than the local simulation.

(2) Make the aspect ratio and shape of elements as regular as possible.

(3) Use the static linear piecewise material model instead of the Johnson-Cook model.

(4) If the post-failure effect is important, or the desired result is relatively long-period and complicated contacting, the result may not be accurate.

2. To program developers

(1) Adaptive mesh and error estimate

While it was found that the results may be quite sensitive to mesh density and quality, there is no systematic guideline for users to improve the mesh quality in explicit finite element analysis. Therefore it is suggested that the program should have adaptive mesh capacity to overcome this difficulty.

(2) Dump file control

Although the program allows up to 999999 time steps between dump files, sometimes it still creates too many files and the program was forced to terminate without completion. Therefore an additional option that forces the program to dump only one, or no, dump file is suggested. Reducing the frequency of dumping data to disk can also reduce the overhead time.

(3) Input file name

The program allows only 6 characters for the input file name, all lowercase and no numbers, underscore or other special characters. Although it does not affect performance of the program. sometimes it is inconvenient for data management. A more flexible rule is suggested. 
(4) Output control

The surface strains were difficult to get from the output. A capability to determine surface strains from the output is needed. A "strain-gage" shell element type, similar to ANSYS, might be suitable.

Include output definition in coordinate systems other than global (i.e. element, local, material, etc.).

(5) Slave/master surface definition

Currently most of the users focus on one-way slave-master eroding contact. This means the user must clearly define the slave and master part. However, sometimes the problem may not be so obvious in the definition (that which part will definitely be penetrated). Even only for the convenience, automatic identifying of slave/master part is suggested.

(6) Element deletion

Additional options for breaking element connectivity (with h-element adaptive mesh) instead of deleting failed element is suggested.

(7) Input format and error check

Although fixed-format may save time on input file processing, most of the time is spent on calculation. Put more flexibility on input file format. This would also save the time to debug the input. The same situation exists when the error check capacity is concerned. Since explicit analysis is usually computationally extensive, reducing the overhead time does help improve the overall project time. Improvements on input format flexibility and error check are suggested.

(8) Bugs report:

The following run-time exception was not handled. It is unknown whether it was intentionally left by the developer or there really bugs in the program. They are listed below for further reference.

a. Junk blank lines between nodes data and its previous data fields (in the current case, the materials) are not detected. They are interpreted as nodes and some unpredictable nodal data may occur.

b. Control-C does not bring up the sense switch screen (using Silicon Graphics, Octane).

c. In GRIZ, typing the command "gather node $n$ " will terminate the program without any warning, where $n$ is any integer number (Although this is not a correct command format).

\section{Further work}

(1) Sensitivity of the mesh density (with respect to the simulation result) should be further studied. This will be also useful for static analysis.

(2) Since penetrating energy is not a material constant, it is necessary to find the relationship between contact velocity and the absorbed energy, for a specified material property/configuration. Using this data, it is possible to find the optimal thickness of a material under impact. Tables of such data could be very useful for containment design in the future.

(3) It may be useful to study the relationship between error in a static analysis and error in an explicit dynamic analysis. If this relationship can be built, the user should be able to improve the mesh quality according to a static analysis first.

(4) Additional options for breaking element connectivity (with h-element adaptive mesh) instead of deleting failed elements may be superior in some cases. Further development and study will be valuable. 
(5) Additional work may be needed to improve the accuracy of the Johnson-Cook materials parameters (which are inputs to LL-DYNA3D).

(6) Stress-Strain Curves at higher strain rates should be developed.

(7) This study should be repeated when (5) and (6) are completed. 
APPENDIX A

Finite Element Model

21-10392

A1-7 
Table A.1 Problem Size of Finite Element Model

\begin{tabular}{|l|r|r|}
\hline Model & Node Number & Element Number \\
\hline Thick & 21541 & 18000 \\
\hline Thin & 9061 & 6960 \\
\hline
\end{tabular}

Figure A.1 Finite Element Mesh for Thick Specimen (See Figure Attached after this page) Figure A.2 Finite Element Mesh for Thin Specimen (See Figure Attached after this page) 

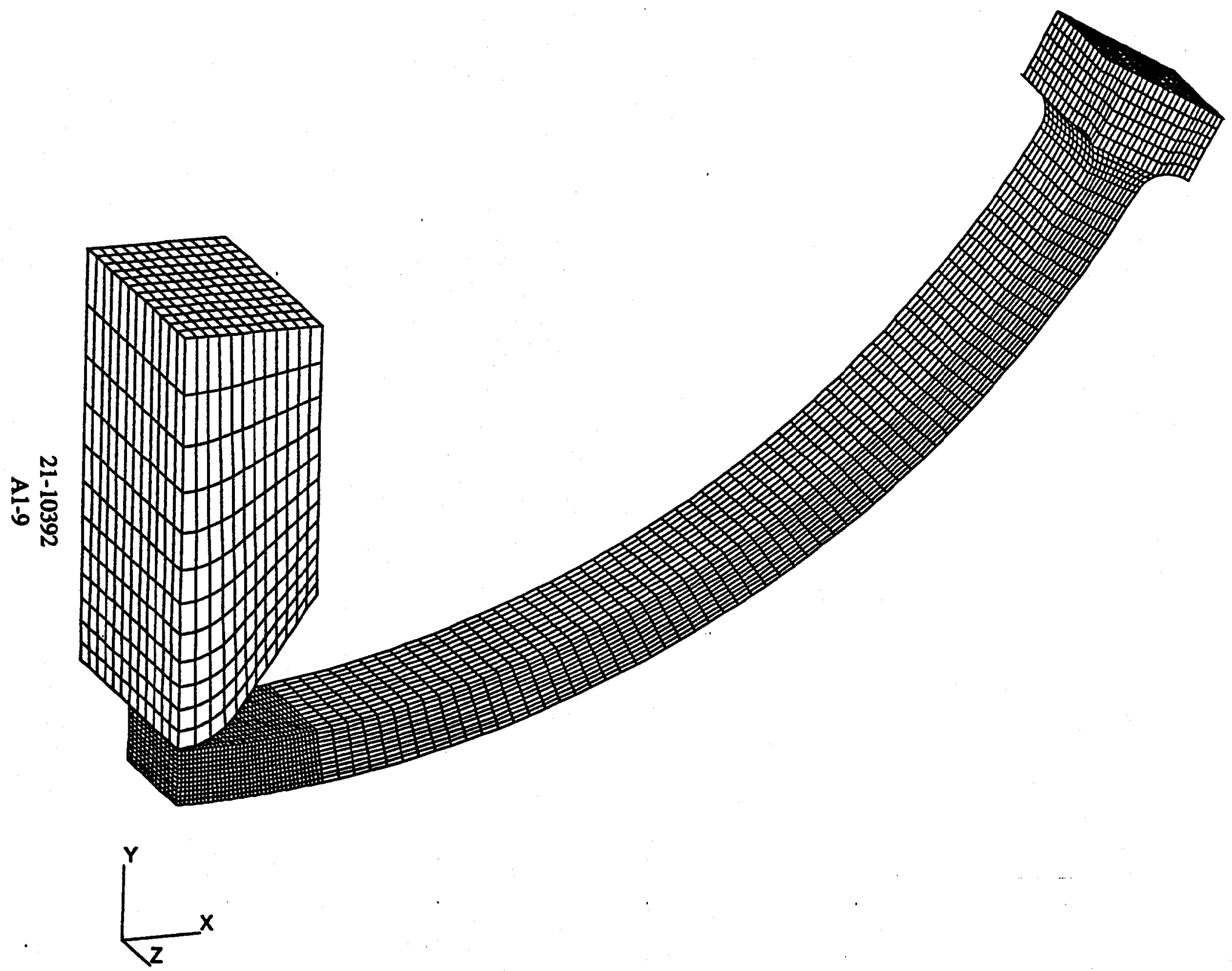

FIGURE A.1' Finite Element Mesh for Thick Specimen 


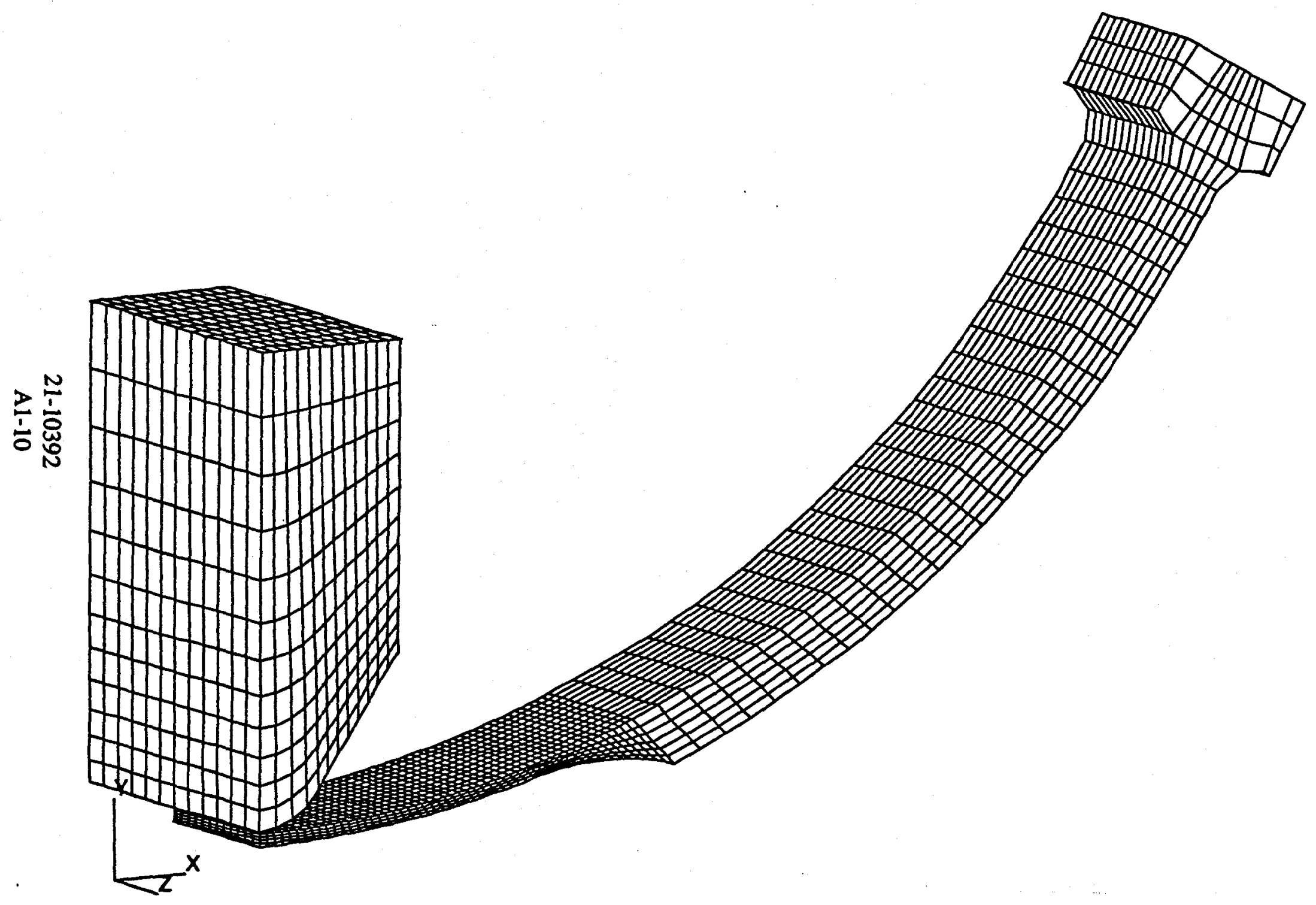

Figure A.2 Finite Element Mesh for Thin Specimen 
APPENDIX B

LL-DYNA3D Simulation Versus Laboratory Test Result

21-10392

A1-11 


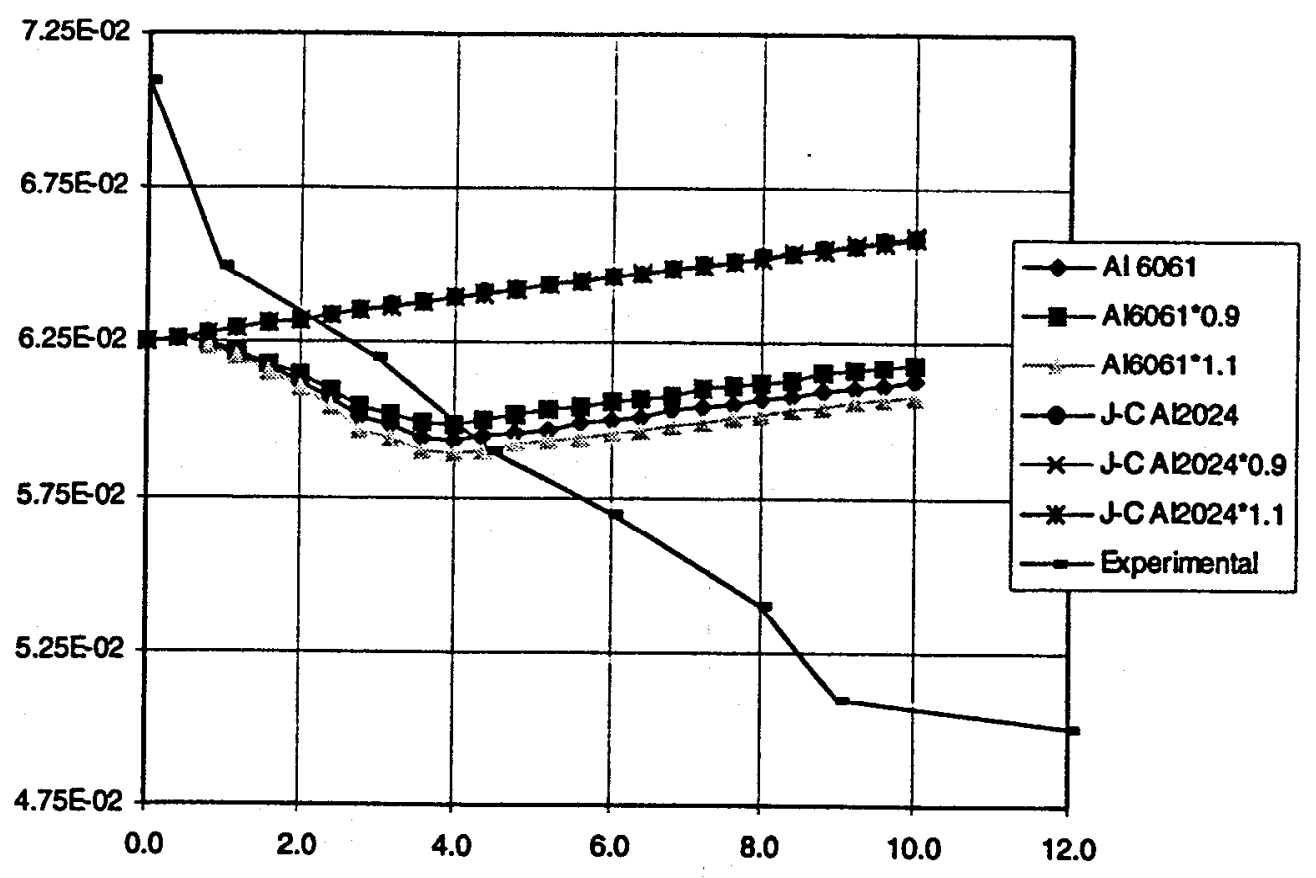

Figure B.1 Thick Specimen, Aluminum 2024, Velocity Versus Time (Experimental Data not Available)

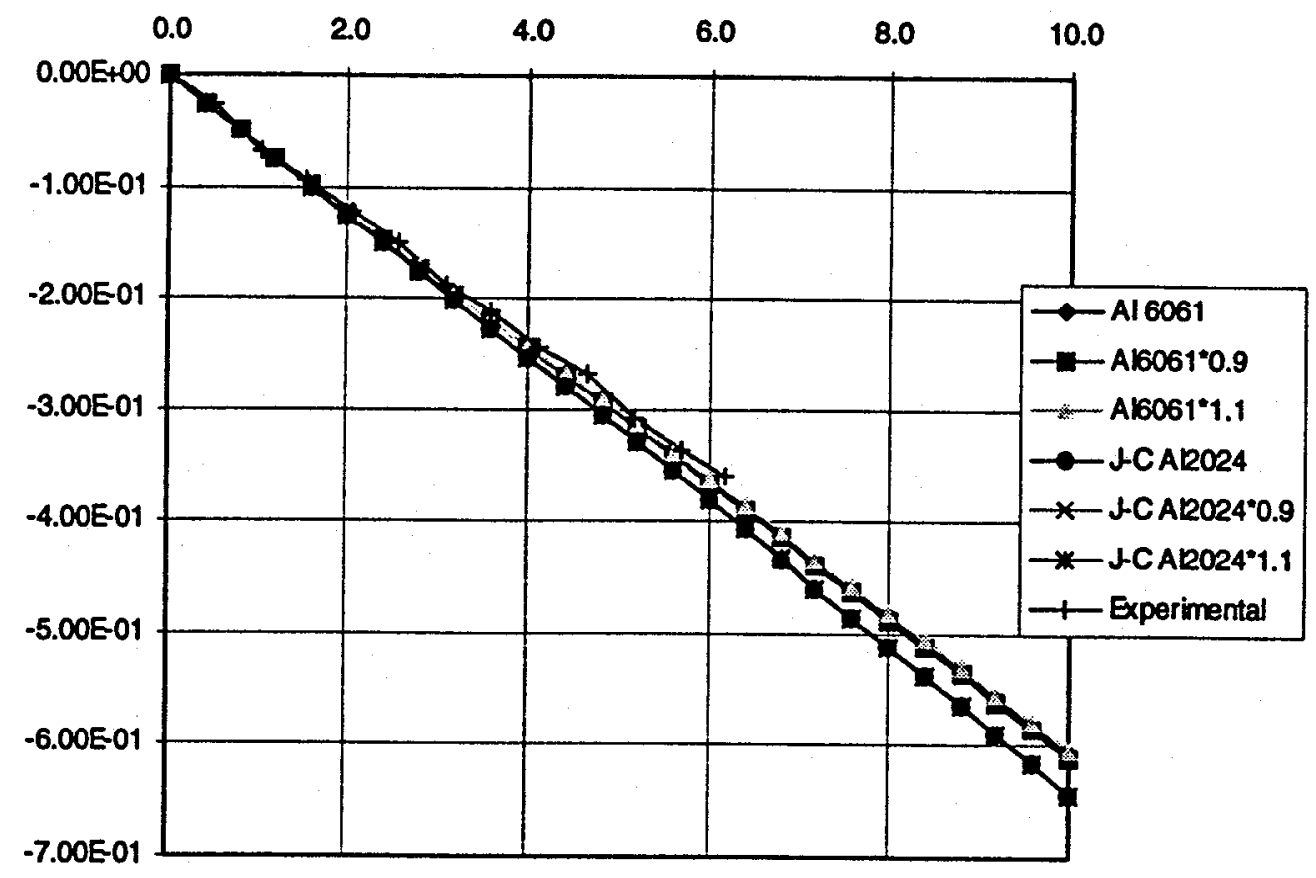

Figure B.2 Thick Specimen, Aluminum 2024, Displacement Versus Time 


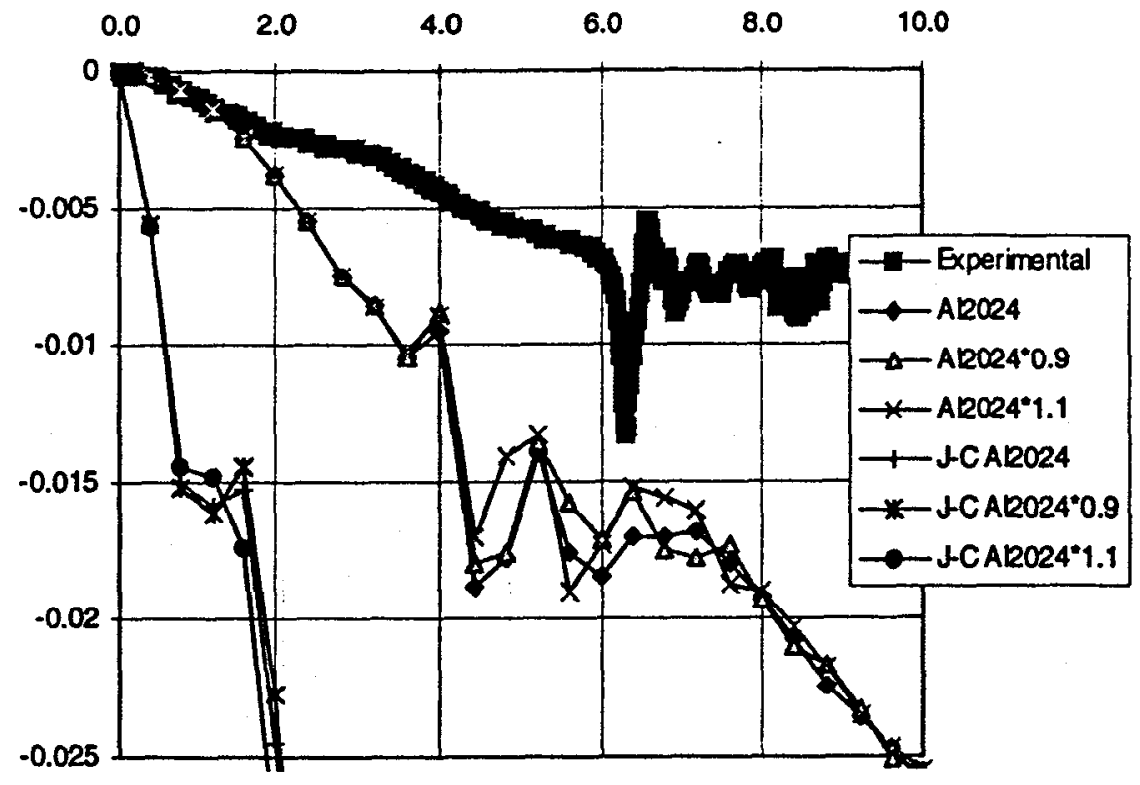

Figure B.3 Thick Specimen, Aluminum 2024, Strain at Strain Gage 4 Versus Time

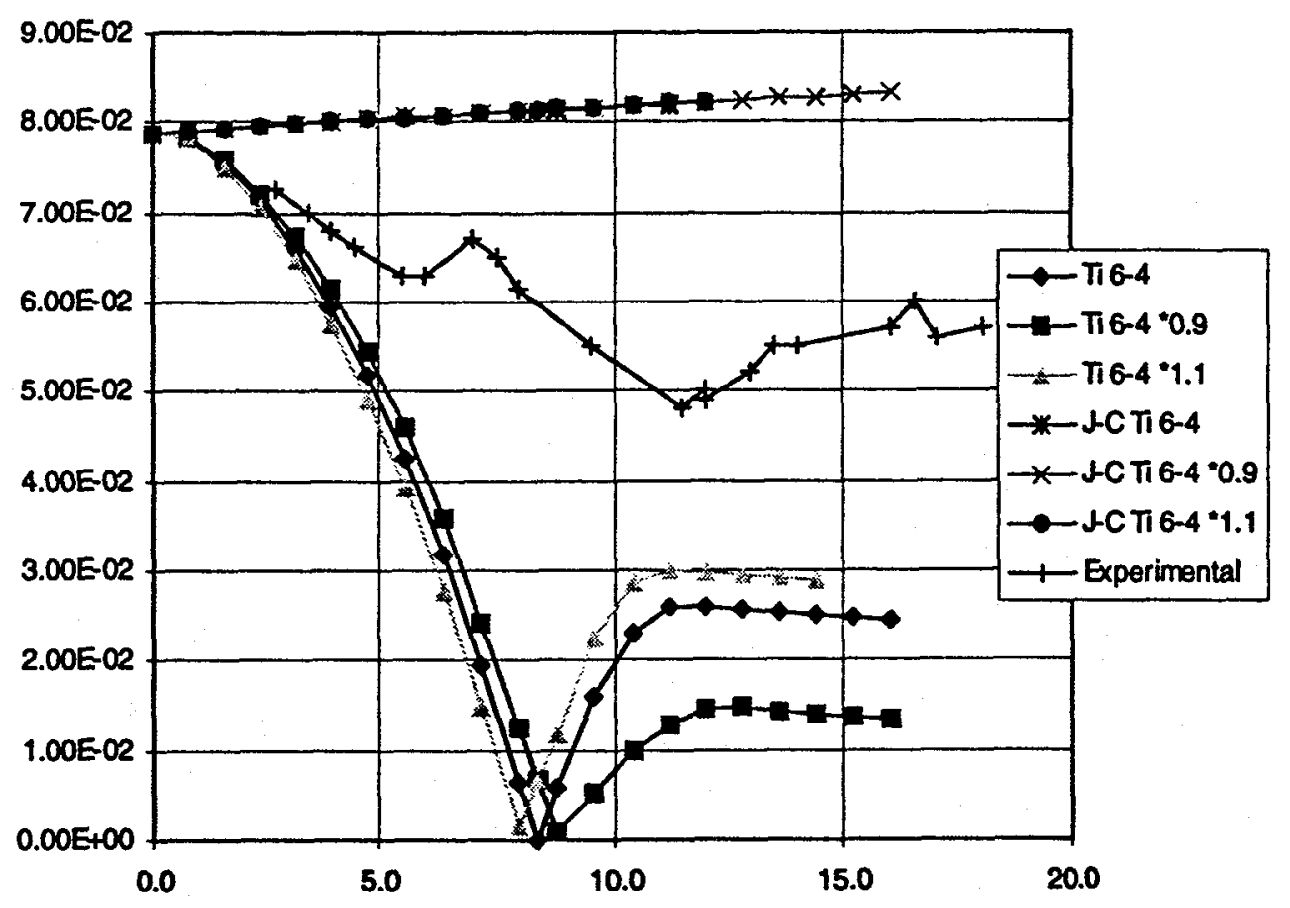

Figure B.4 Thick Specimen, Titanium 6-4, Velocity Versus Time (Experimental Data not Available) 


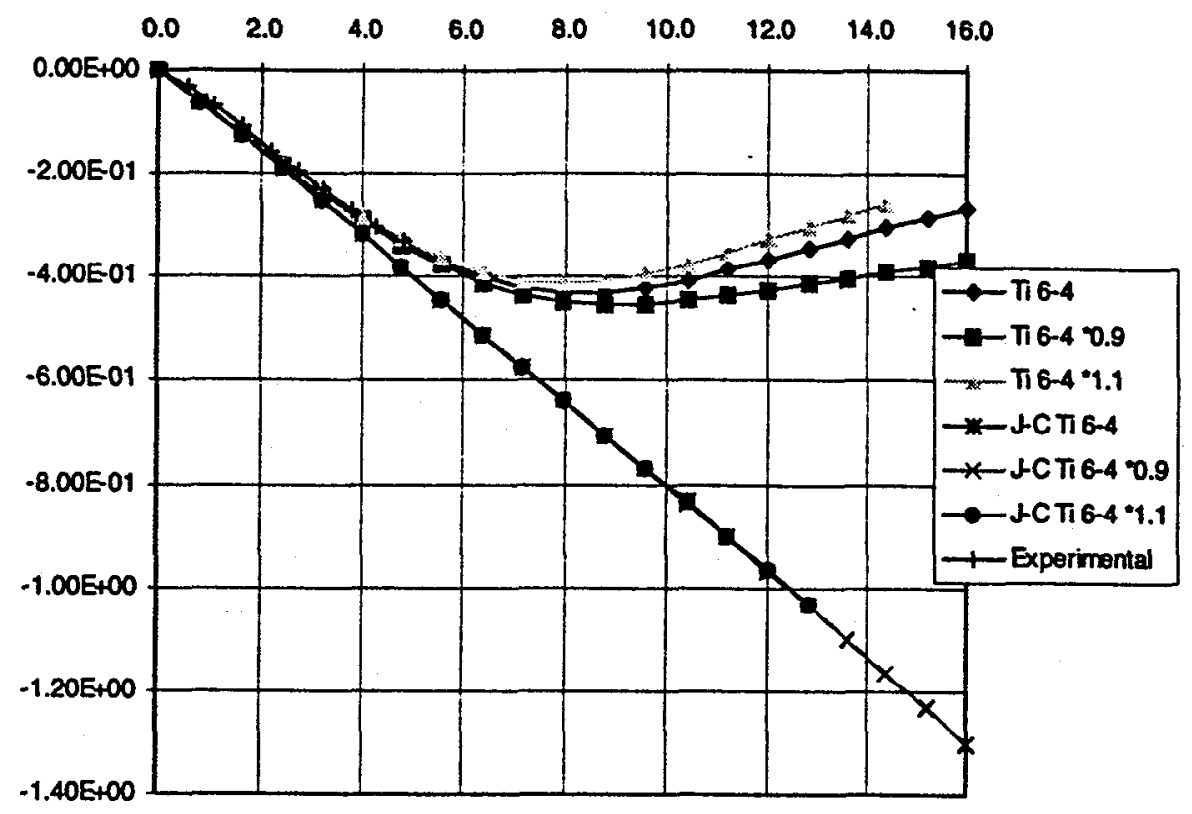

Figure B.5 Thick Specimen, Titanium 6-4, Displacement Versus Time

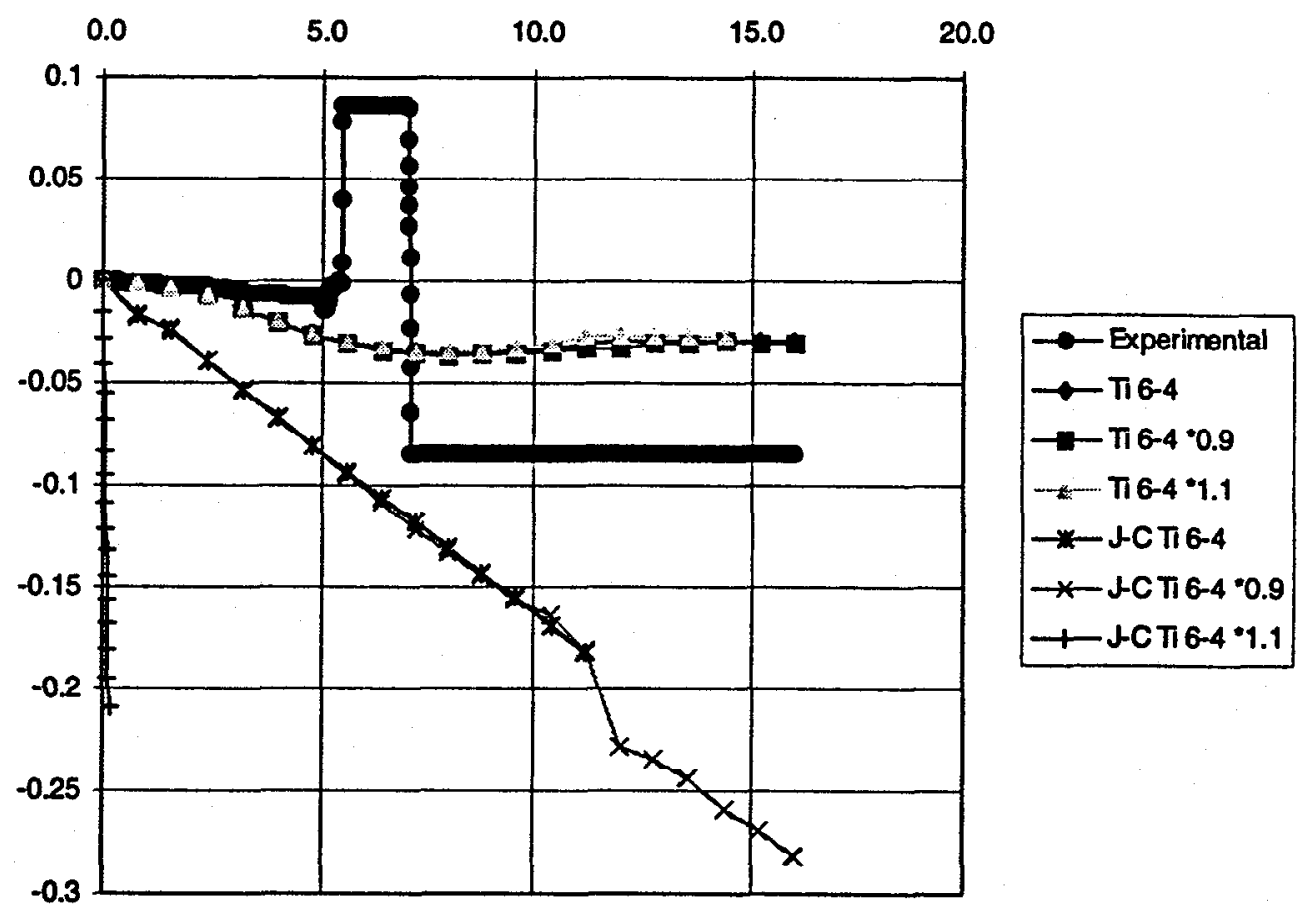

Figure B.6 Thick Specimen, Titanium 6-4, Strain at Strain Gage 4 Versus Time 


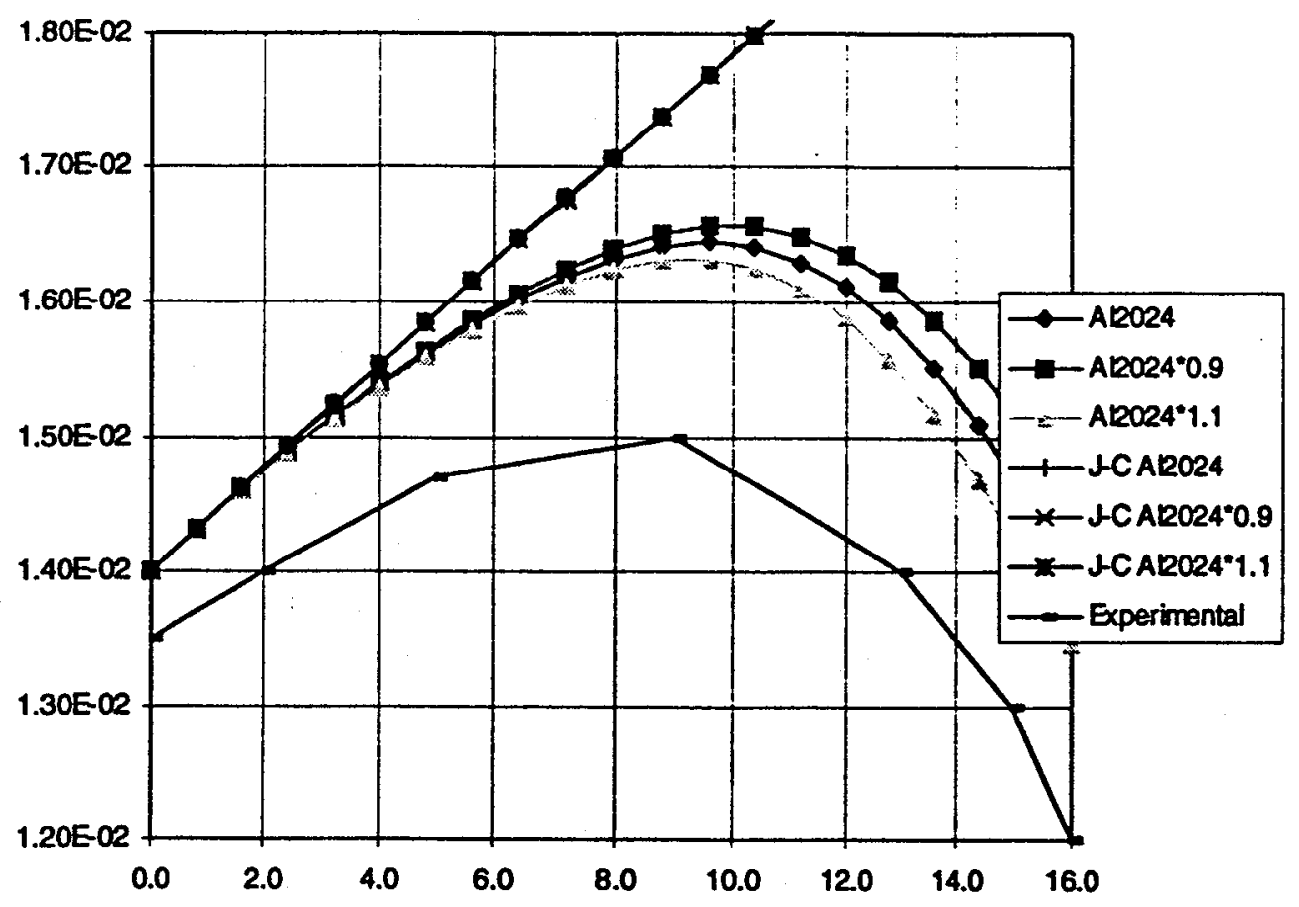

Figure B.7 Thin Specimen, Aluminum 2024, Velocity Versus Time (Experimental Data not Available)

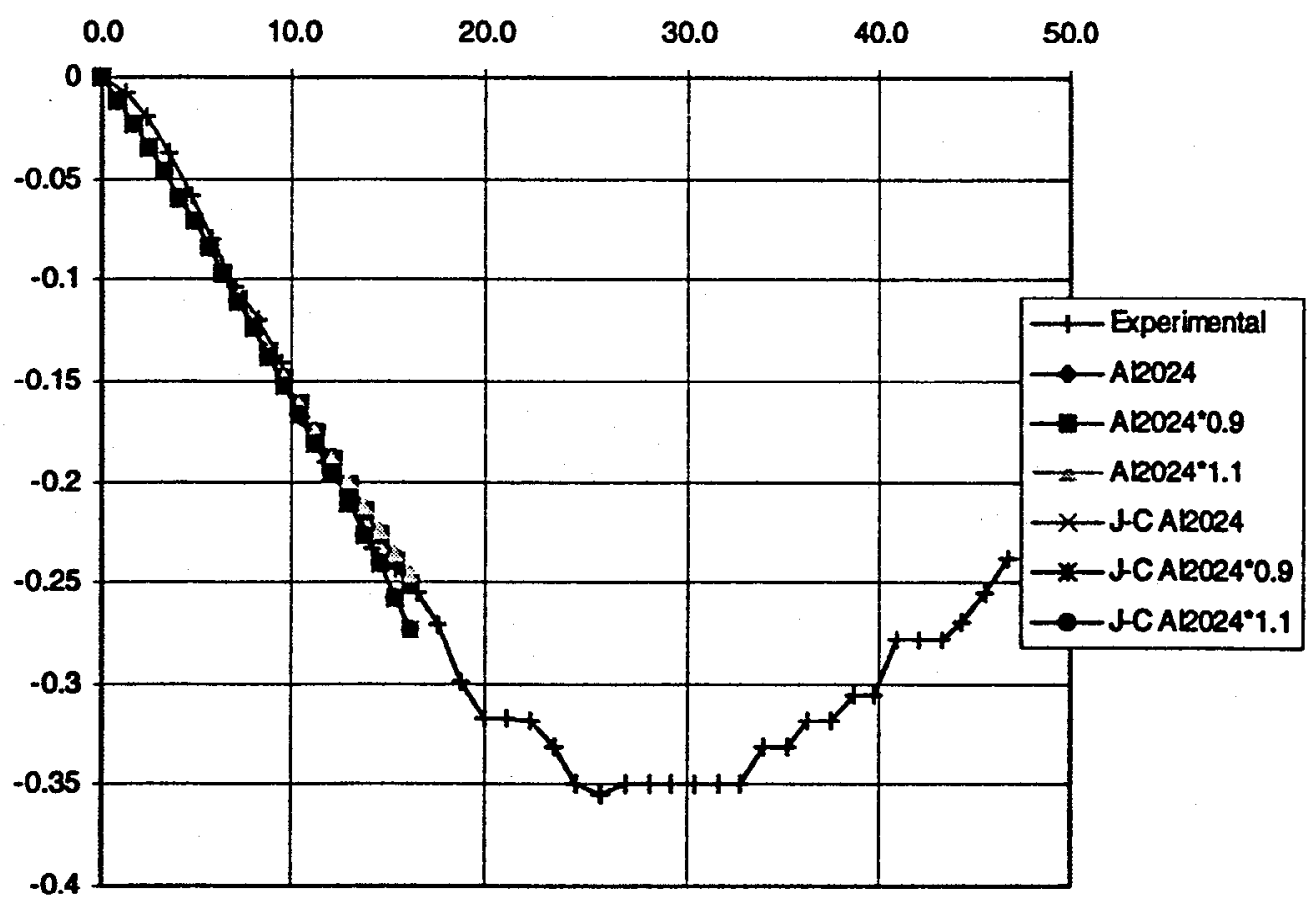

Figure B.8 Thin Specimen, Aluminum 2024, Displacement Versus Time 


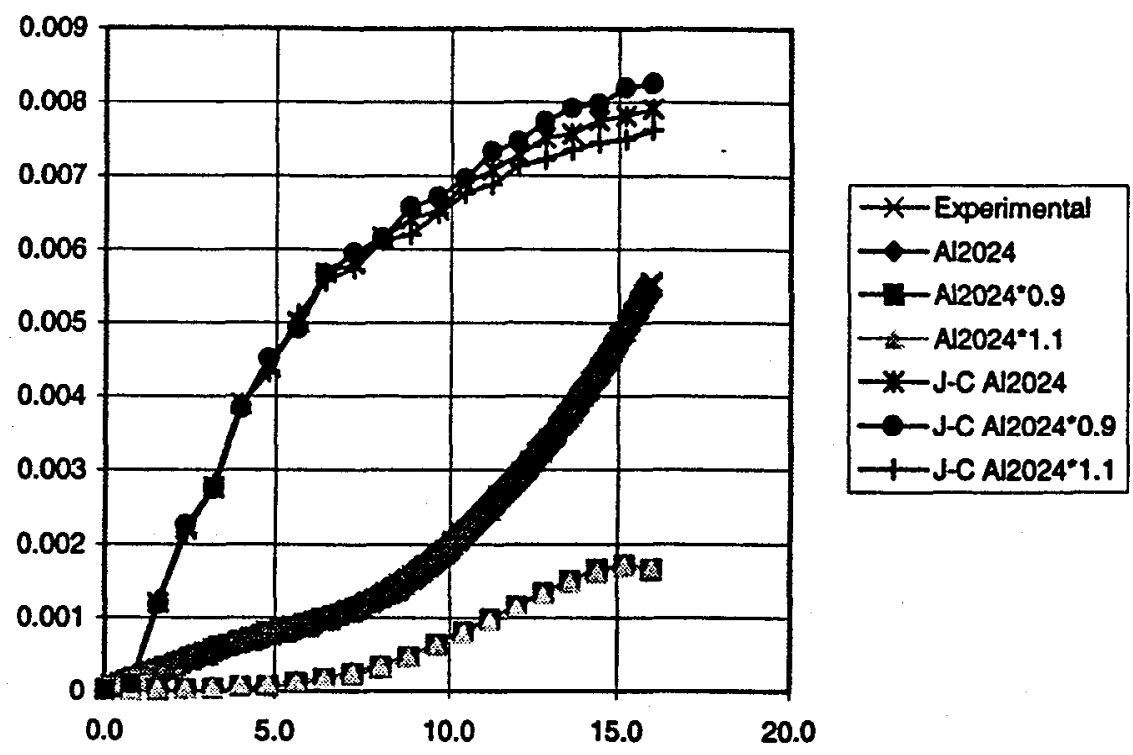

Figure B.9 Thin Specimen, Aluminum 2024, Strain at Strain Gage 2 Versus Time

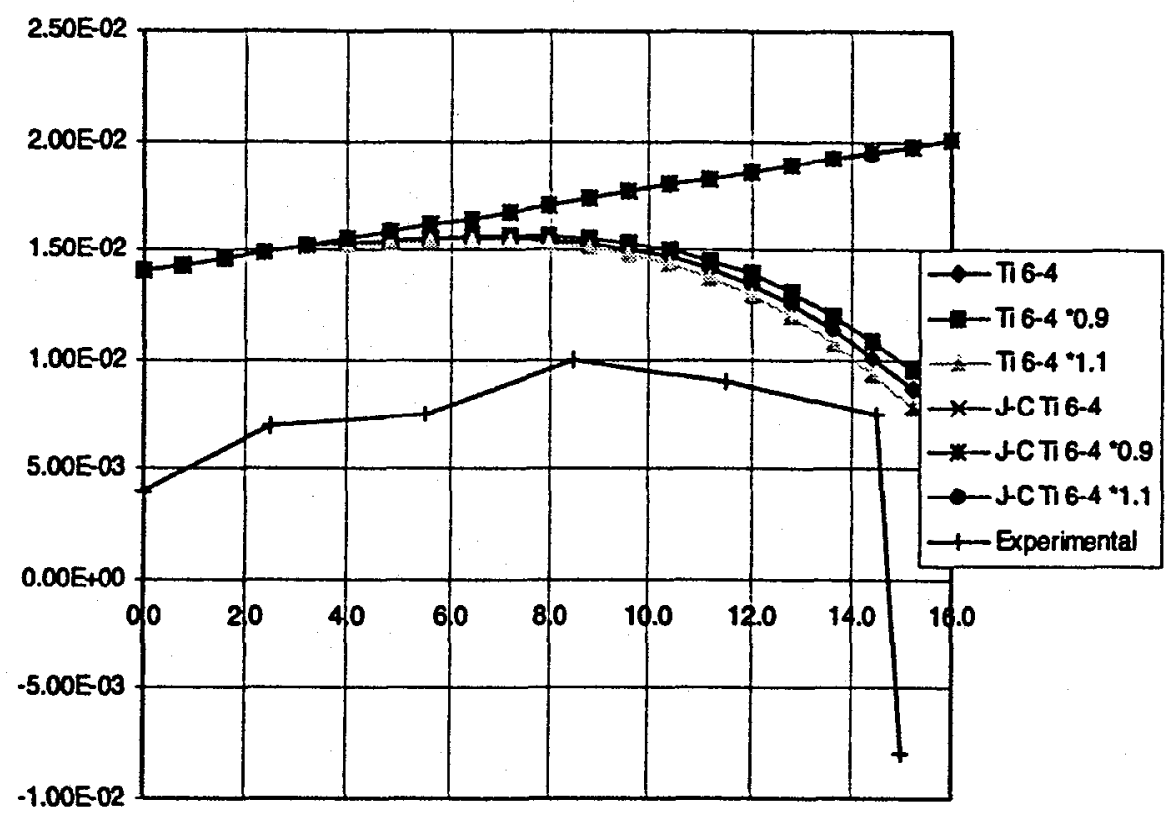

Figure B.10 Thin Specimen, Titanium 6-4, Velocity Versus Time (Experimental Data not Available) 


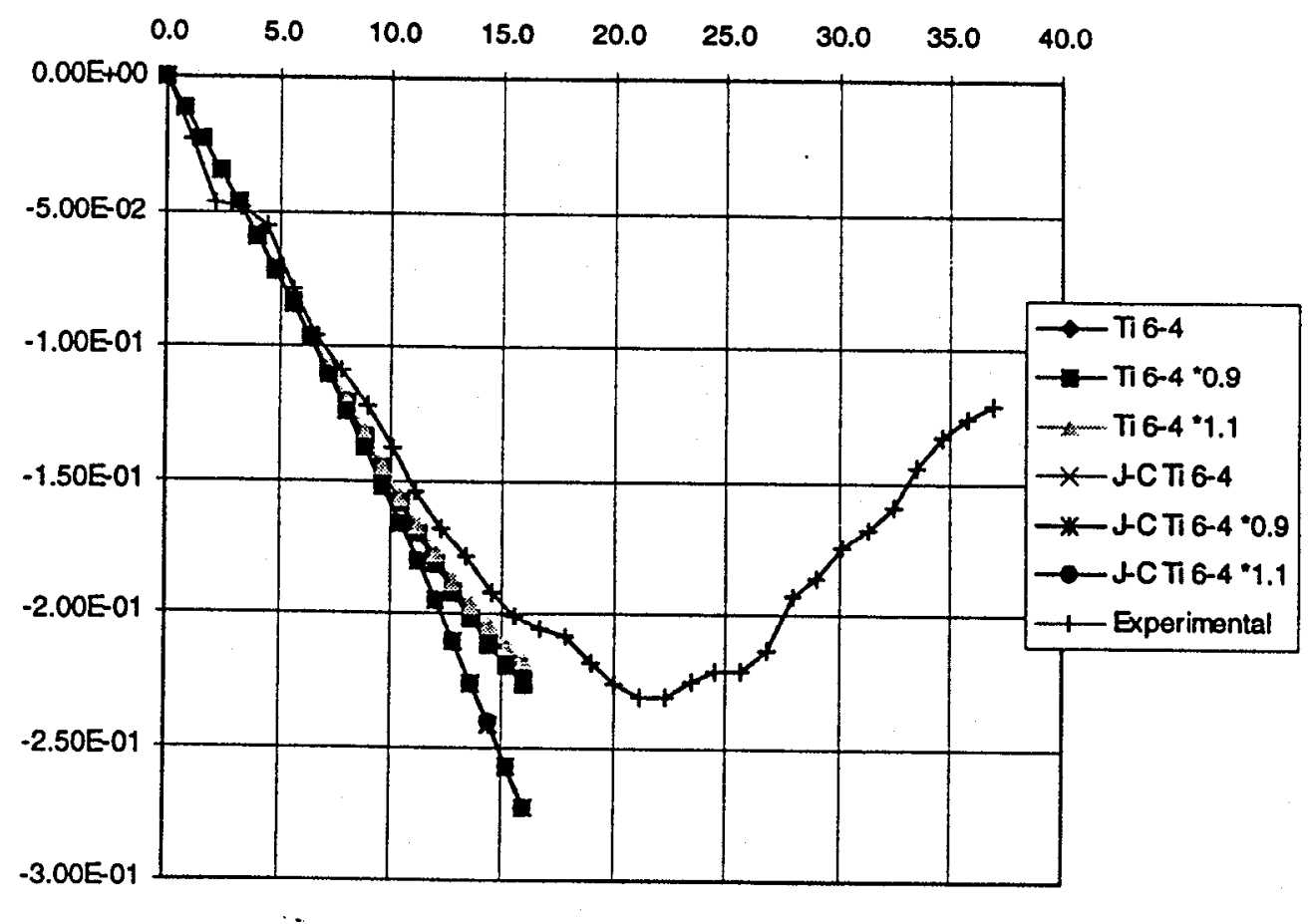

Figure B.11 Thin Specimen, Titanium 6-4, Displacement Versus Time

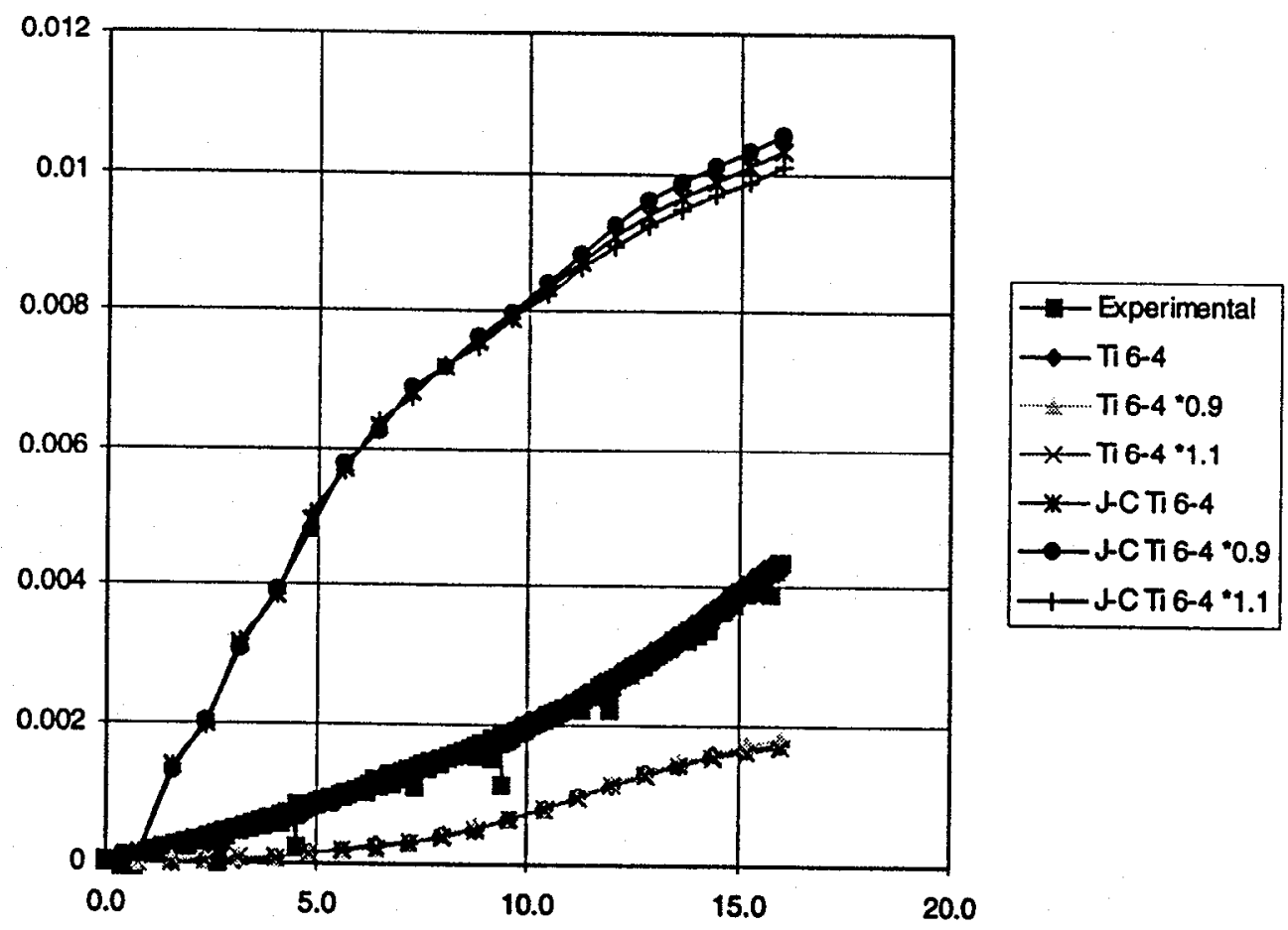

Figure B.12 Thin Specimen, Titanium 6-4, Strain at Strain Gage 2 Versus Time 
APPENDIX C

Design-Of-Experiments (DOE) Design and Analysis of the

LL-DYNA3D Simulation Versus Laboratory Test Results 


\section{APPENDIX C}

\section{Design-Of-Experiments (DOE) Design and Analysis of the LL-DYNA3D Simulation Versus Laboratory Test Results}

A design-of-experiments (DOE) study was performed on the impact specimen test results and the corresponding LLDYNA3D analyses. The DOE determines the relationship $(y=f(x))$ between the selected input and output variables. Four variables were chosen at two levels, making this a $2^{4}$ full factorial DOE. Table C.1 lists the variables and their levels.

Table C.1: DOE Matrix< LL-DYNA3D to Impact Test Correlation

\begin{tabular}{|l|l|l|l|}
\hline INPUT VARIABLE & LEVELS & COMMENTS \\
\hline & Low & High & \\
\hline Geometry & Thin & Thick & Determine effect of size on results correlation \\
\hline Material & $\mathrm{Al}$ & $\mathrm{Ti}$ & Determine quality of material properties \\
\hline Material Model & Mat 24 & Mat 15 & Determine sensitivity of results to model \\
\hline Properties Factor & 0.9 & 1.1 & Determine sensitivity of results to property variation \\
\hline
\end{tabular}

Previous work (Reference 1) confirmed the applicability of using LS-DYNA for containment failure simulation. However, it was observed that material models can play an important and sensitive role in numerical simulation. Usually a static (strain rate independent) elastoplastic model is applied for eroding contact finite element analysis, although the strain-ratedependent model is also available. There has been no evidence or experience indicating which model works better. Therefore it was suggested (Reference 1) that material modeling should be further studied. The DOE variables were chosen to answer this question.

The "geometry" variable examines the different failure modes that could occur: shear, bending, or tensile; depending on the section thickness. "Material" will contrast the performance of aluminum versus titanium under impact loading. The "material model" will demonstrate which approach works best: model 24 (piecewise linear with failure) versus model 15 (the Johnson-Cook formulation). This variable is partially confounded by the quality of data used for each model's inputs. The "properties factor" looks to capture how the variation in the material model input properties affects the correlation to test. It may also provide insight into the question raised for the material model input quality. The "levels" set for each input variable are a function of the available inference space. In this case, the geometry, material, and material model are preset by the test definition. The properties factor levels were determined by an educated guess into the natural variation that exists in the materials.

Outputs examined are the maximum displacement and first-peak strain in the test specimens. Specifically, the correlation of the test results to the analyses are calculated, and used as outputs. The correlation is defined by:

correlation $=$ analysis value $/$ test value

A correlation value of 1.0 indicates exact agreement between test and analysis. A correlation of 1.05 would indicate the analysis is $5 \%$ greater than the test value.

The data used in the DOE is shown in Table C.2. The "MINITAB" statistical analyses of the DOE follow Table C.2. One session is shown for analysis of the "strain" output variable, another is shown for the "displacement" variable. Each analysis includes a cube plot, pareto and probability charts for the main effects, and graphs of the main effects and interactions. These schematically show the relationship between the input variables and the resul;ting output.

\section{RESULTS \& CONCLUSIONS}

Analysis of the DOE points to two general conclusions. First, the two output variables are insensitive to the scale factor on material properties. This is surprising, but it is an indication that the analysis results (at a macro scale) are insensitive to variation in the input properties. This is good news for an analyst: they will not need extremely accurate properties (just "good" properties). Second, the general lack of accuracy of the Johnson-Cook model for both output variables may mean that the parameters provided are either incorrect, or not applicable to the yield and failure modes of this type of impact on aluminum and titanium. Again, the better accuracy of results obtained with material model 24 should also be good news for the analyst: stress-strain curves are cheaper and easier to generate than the more specialized tests needed for Johnson-Cook parameters. 
Specifically, the strain correlation values are not very good. This may be more of a function of obtaining the element surface strain from the analysis, than of poor agreement. The frequency content seems reasonably close. However, the DOE shows that the aluminum tests correlate better than the titanium. The thin geometry is better than the thick. Note that all the variables contribute equally to the strain results. All three variables interact with each other.

The displacement correlations are much better. These fall between $4 \%$ to $14 \%$ of the test results. The excellent agreement here reinforces the possibility that the surface strain calculation is poor. However, the conclusions above are nearly identical. The main difference is the thick specimen agreeing better than the thin. Also, the displacement results are most sensitive to the material model and the material used. Strong interactions exist between the material and the model, and the material and the configuration.

The four impact tests were selected to include all the materials and configurations and their failure modes. The remaining tests were not examined to avoid exceeding the program resources. They will be available for future correlation activities, as code developments continue. Further study should include mesh density and element type (solid versus thick shell, in particular). These were not included here because of computer hardware and schedule constraints.

Table C.2: DOE Matrix Results

\begin{tabular}{|c|c|c|c|c|c|c|c|c|c|}
\hline Material & Geometry & Model & Factor & Strain & Time & Correlation & Disp & Time & Correlation \\
\hline Al & Thick & Test & & 0.0055 & 6.5 & 1 & 0.35 & 6 & 7 \\
\hline $\bar{A}$ & Thick & static & 1 & 9.50E-03 & 4 & 2.806523 & $3.64 \mathrm{E}-01$ & 6 & 1.039047 \\
\hline Al & Thick & static & 0.9 & 8.84E-03 & 4 & 2.610341 & $3.66 E-01$ & 6 & 1.04475 \\
\hline Al & Thick & static & 1.1 & 8.95E-03 & 4 & 2.645205 & 3.62E-01 & 6 & 1.034036 \\
\hline Al & Thick & J-C & 1 & 1.53E-02 & 1.6 & 11.30852 & 3.82E-01 & 6 & 1.090286 \\
\hline Al & Thick & $J-C$ & 0.9 & 1.45E-02 & 1.6 & 10.70284 & 3.82E-01 & 6 & 1.090286 \\
\hline Al & Thick & $J-C$ & 1.1 & $1.74 E-02$ & 1.6 & 12.82273 & 3.82E-01 & 6 & 1.09 \\
\hline $\mathrm{Ti}$ & Thick & Test & & 0.01 & 4.5 & 1 & -0.333 & 4.8 & \\
\hline$\pi$ & Thick & static & 1 & 0.25 & 4.5 & 25 & $-3.33 E-01$ & 4.8 & 1.000564 \\
\hline $\mathrm{Ti}$ & Thick & static & 0.9 & 0.25 & 4.5 & 25 & $-3.38 E-01$ & 4.8 & 1.013733 \\
\hline$\pi i$ & Thick & static & 1.1 & 0.25 & 4.5 & 25 & $-3.28 E-01$ & 4.8 & 1.014987 \\
\hline$\pi i$ & Thick & $\mathrm{J}-\mathrm{C}$ & 1 & 0.8 & 4.5 & 80 & $-3.82 E-01$ & 4.8 & 1.146547 \\
\hline $\mathrm{Ti}$ & Thick & $J-C$ & 0.9 & 0.8 & 4.5 & 80 & $-3.82 E-01$ & 4.8 & 1.146547 \\
\hline $\mathrm{Ti}$ & Thick & $J-C$ & 1.1 & 0.8 & 4.5 & 80 & $-3.82 E-01$ & 4.8 & 1.146547 \\
\hline$\overline{A l}$ & Thin & Test & & 0.0025 & 11 & 1 & -0.244 & 15 & \\
\hline A & Thin & static & 1 & 0.001 & 11 & 2.5 & $-2.37 E-01$ & 15 & 1.027842 \\
\hline Al & Thin & static & 0.9 & 0.001 & 11 & 2.5 & $-2.39 E-01$ & 15 & 1.01967 \\
\hline Al & Thin & static & 1.1 & 0.001 & 11 & 2.5 & $-2.36 E-01$ & 15 & 1.036054 \\
\hline Al & Thin & $J-C$ & 1 & 0.0071 & 11 & 2.84 & $-2.57 E-01$ & 15 & 1.053736 \\
\hline Al & Thin & $J-C$ & 0.9 & 0.0074 & 11 & 2.96 & $-2.57 E-01$ & 15 & 1.053736 \\
\hline Al & Thin & $\mathrm{J}-\mathrm{C}$ & 1.1 & 0.0069 & 11 & 2.76 & $-2.57 E-01$ & 15 & 1.053736 \\
\hline$\overline{T i}$ & Thin & Test & & 0.0014 & 8 & 1 & -0.201 & 15 & 1 \\
\hline $\mathrm{Ti}$ & Thin & static & 1 & 4.07E-04 & 8 & 3.440649 & $-2.16 \mathrm{E}-01$ & 15 & 1.073448 \\
\hline $\mathrm{Ti}$ & Thin & static & 0.9 & 4.01E-04 & 8 & 3.493886 & $-2.19 E-01$ & 15 & 1.091606 \\
\hline $\mathrm{Ti}$ & Thin & static & 1.1 & 3.85E-04 & 8 & 3.640146 & $-2.12 E-01$ & 15 & 1.055789 \\
\hline $\mathrm{Ti}$ & Thin & $J-C$ & 1 & 7.16E-03 & 8 & 5.113571 & $-2.57 E-01$ & 15 & 1.278607 \\
\hline$\pi$ & Thin & $\mathrm{J}-\mathrm{C}$ & 0.9 & 7.17E-03 & 8 & 5.12 & $-2.57 E-01$ & 15 & 1.278607 \\
\hline $\mathrm{Ti}$ & Thin & J-C & 1.1 & 7.20E-03 & 8 & 5.141429 & $-2.57 E-01$ & 15 & 1.278607 \\
\hline
\end{tabular}


MINITAB 12 SESSION OUTPUT: DOE ANALYSIS FOR "STRAIN"

Worksheet size: 100000 cells

*NOTE* The number of centerpoints specified is doubled for each categorical factor. For $Q$ categorical factors, the result is $2^{\star \star} Q$ times as many centerpoints.

\section{Factorial Design}

Full Factorial Design

$\begin{array}{lrlr}\text { Factors : } & 4 & \text { Base Design: } & 4,16 \\ \text { Runs : } & 24 & \text { Replicates : } & 1 \\ \text { Blocks : } & \text { none } & \text { Center pts (total): } & 8\end{array}$

All terms are free from aliasing

*NOTE* The number of centerpoints specified is doubled for each categorical

factor. For $Q$ categorical factors, the result is $2^{\star \star} Q$ times as many centerpoints.

\section{Current worksheet: Worksheet 2}

\section{Factorial Design}

Full Factorial Design

$\begin{array}{lrlr}\text { Factors : } & 4 & \text { Base Design: } & 4,16 \\ \text { Runs: } & 24 & \text { Replicates : } & 1 \\ \text { Blocks : } & \text { none } & \text { Center pts (total): } & 8\end{array}$

All terms are free from aliasing

Worksheet size: 100000 cells

Retrieving project from file: U: ICONTAIN\FAAlPH1_ANLS.MPJ

Fractional Factorial Fit

Estimated Effects and Coefficients for Strain (coded units)

\begin{tabular}{|c|c|c|c|c|c|}
\hline $\begin{array}{l}\text { Term } \\
\text { Constant } \\
\text { Scale Fa } \\
\text { Model } \\
\text { Material } \\
\text { Config } \\
\text { Scale Fa*Model } \\
\text { Scale Fa*Material } \\
\text { Scale Fa*Config } \\
\text { Model*Material } \\
\text { Model*Config } \\
\text { Material*Config } \\
\text { Scale Fa*Model*Material }\end{array}$ & $\begin{array}{r}0.2653 \\
16.4694 \\
23.4995 \\
26.3239 \\
0.2200 \\
-0.2234 \\
0.2734 \\
11.8307 \\
15.4926 \\
21.8512 \\
-0.2512\end{array}$ & $\begin{array}{r}\text { Coef } \\
16.6810 \\
0.1327 \\
8.2347 \\
11.7497 \\
13.1619 \\
0.1100 \\
-0.1117 \\
0.1367 \\
5.9153 \\
7.7463 \\
10.9256 \\
-0.1256\end{array}$ & $\begin{array}{r}\text { StDev Coef } \\
0.03707 \\
0.03707 \\
0.03027 \\
0.03027 \\
0.03027 \\
0.03707 \\
0.03707 \\
0.03707 \\
0.03027 \\
0.03027 \\
0.03027 \\
0.03707\end{array}$ & $\begin{array}{r}\text { T } \\
449.98 \\
3.58 \\
272.06 \\
388.19 \\
434.84 \\
2.97 \\
-3.01 \\
3.69 \\
195.43 \\
255.92 \\
360.96 \\
-3.39\end{array}$ & $\begin{array}{l}P \\
0.000 \\
0.009 \\
0.000 \\
0.000 \\
0.000 \\
0.021 \\
0.020 \\
0.008 \\
0.000 \\
0.000 \\
0.000 \\
0.012\end{array}$ \\
\hline & & $\begin{array}{l}-10392 \\
1-21\end{array}$ & & & \\
\hline
\end{tabular}




$\begin{array}{lrrrrr}\text { Scale Fa*Model*Config } & 0.3012 & 0.1506 & 0.03707 & 4.06 & 0.005 \\ \text { Scale Fa*Material*Config } & -0.3153 & -0.1577 & 0.03707 & -4.25 & 0.004 \\ \text { Model*Material*Config } & 11.2073 & 5.6037 & 0.03027 & 185.13 & 0.000 \\ \text { Scale Fa*Model*Material* } & & & & & \\ \text { Config } & -0.2700 & -0.1350 & 0.03707 & -3.64 & 0.008 \\ \text { Ct Pt } & & -0.0549 & 0.06421 & -0.85 & 0.421\end{array}$

Analysis of Variance for Strain (coded units)

$\begin{array}{lrrrrrr}\text { Source } & \text { DF } & \text { Seq SS } & \text { Adj SS } & \text { Adj MS } & \text { F } & \text { P } \\ \text { Main Effects } & 4 & 9098.7 & 9098.75 & 2274.69 & 1 E+05 & 0.000 \\ \text { 2-Way Interactions } & 6 & 5145.5 & 5145.46 & 857.58 & 4 \mathrm{E}+04 & 0.000 \\ \text { 3-Way Interactions } & 4 & 754.6 & 754.64 & 188.66 & 9 \mathrm{E}+03 & 0.000 \\ \text { 4-Way Interactions } & 1 & 0.3 & 0.29 & 0.29 & 13.26 & 0.008 \\ \text { Curvature } & 1 & 0.0 & 0.02 & 0.02 & 0.73 & 0.421 \\ \text { Residual Error } & 7 & 0.2 & 0.15 & 0.02 & & \\ \text { Total } & 23 & 14999.3 & & & & \end{array}$

Unusual Observations for Strain

$\begin{array}{rrrrrr}\text { Obs } & \text { Strain } & \text { Fit } & \text { StDev Fit } & \text { Residual } & \text { St Resid } \\ 11 & 10.7028 & 10.5697 & 0.1370 & 0.1331 & 2.35 R \\ 12 & 12.8227 & 12.6896 & 0.1370 & 0.1331 & 2.35 R \\ 22 & 11.3085 & 11.5748 & 0.0957 & -0.2663 & -2.35 R\end{array}$

$R$ denotes an observation with a large standardized residual

Estimated Coefficients for Strain using data in uncoded units

\begin{tabular}{|c|c|}
\hline 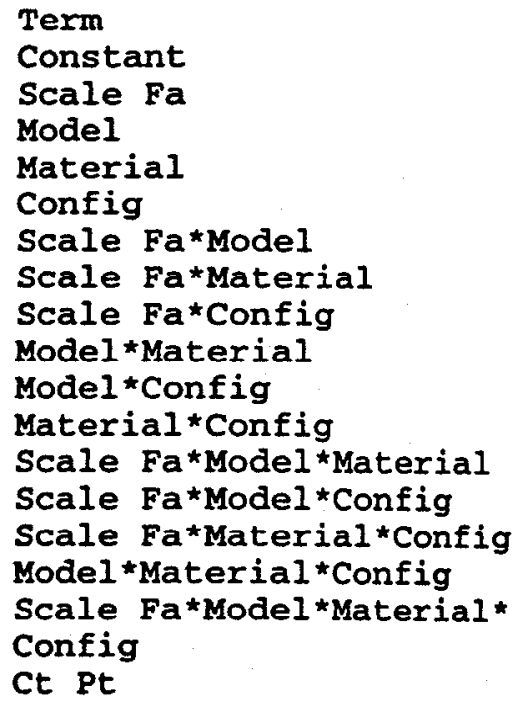 & $\begin{array}{r}\text { Coef } \\
15.355 \\
1.327 \\
7.135 \\
12.867 \\
11.795 \\
1.100 \\
-1.117 \\
1.367 \\
7.172 \\
6.240 \\
12.502 \\
-1.256 \\
1.506 \\
-1.577 \\
6.954 \\
-1.350 \\
-0.055\end{array}$ \\
\hline
\end{tabular}

\section{Alias Structure}

I

Scale

Model

Material

Config

Scale*Model

Scale Material

Scale*Config

Model Material

Model *Config

Material *Config

Scale*Model*Material

Scale*Model *Config 
Scale*Material*Config

Model *Material *Config

Scale ${ }^{\star M o d e l}{ }^{*}$ Material *Config

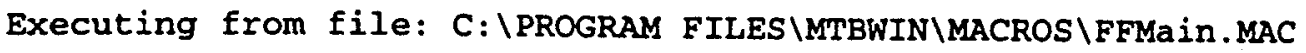

Macro is running ... please wait

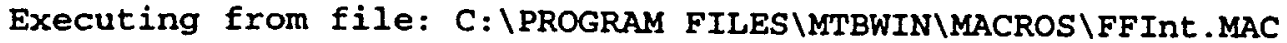

Macro is running .... please wait

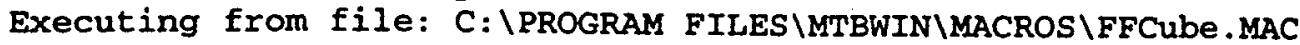

Macro is running ... please wait

- Centerpoint

- Factorial Point

Cube Plot (data means) for Strain
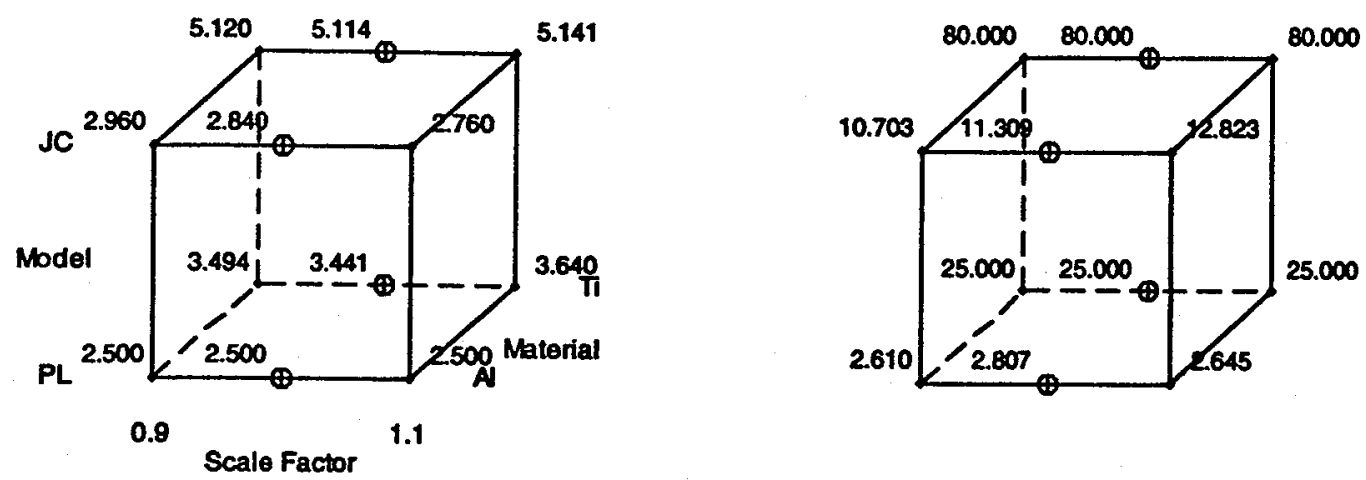

Thin

Config Thick 


\section{Pareto Chart of the Standardized Effects}

(response is Strain, Alpha $=.10$ )

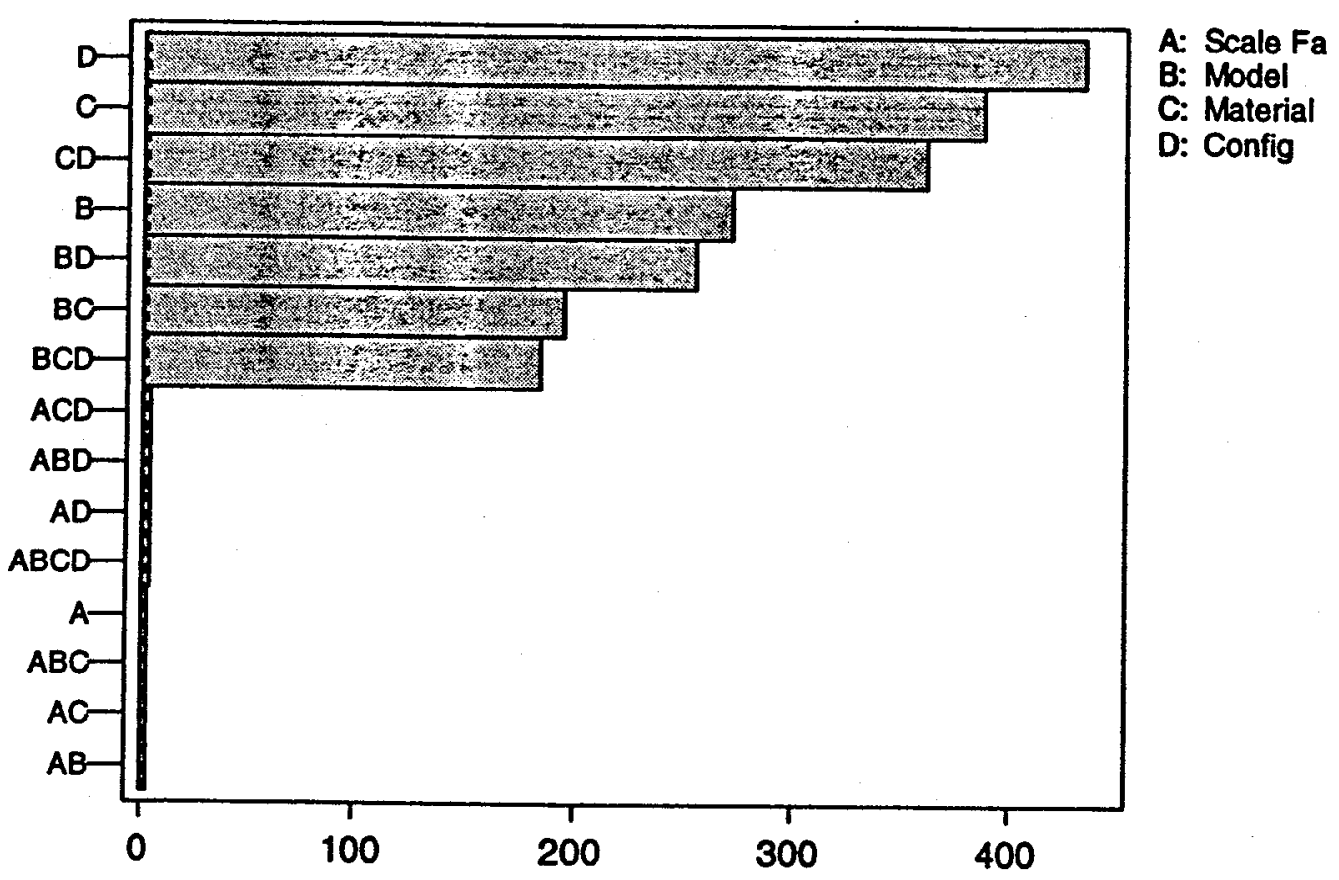

Normal Probability Plot of the Standardized Effects

(response is Strain, Alpha $=.10$ )

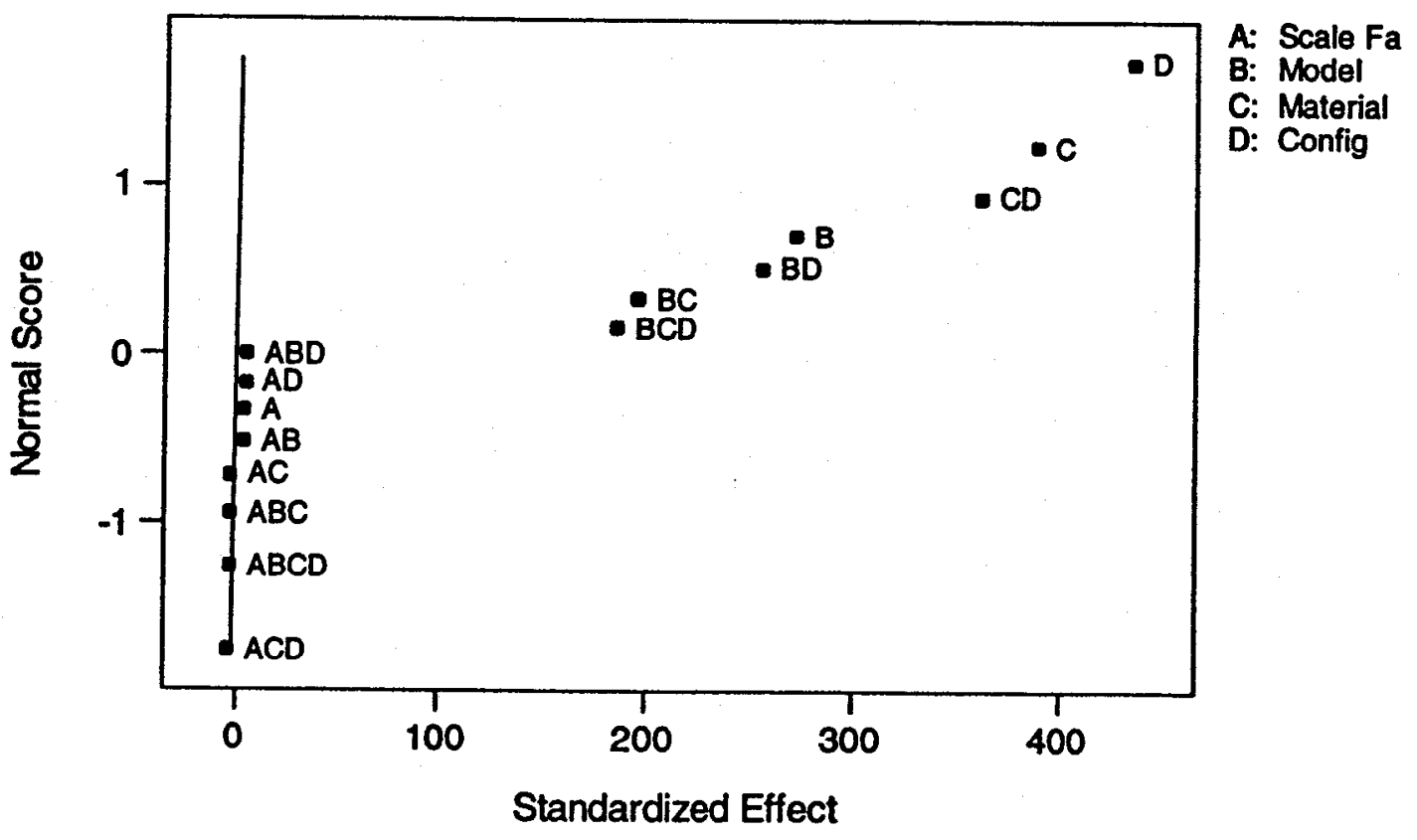




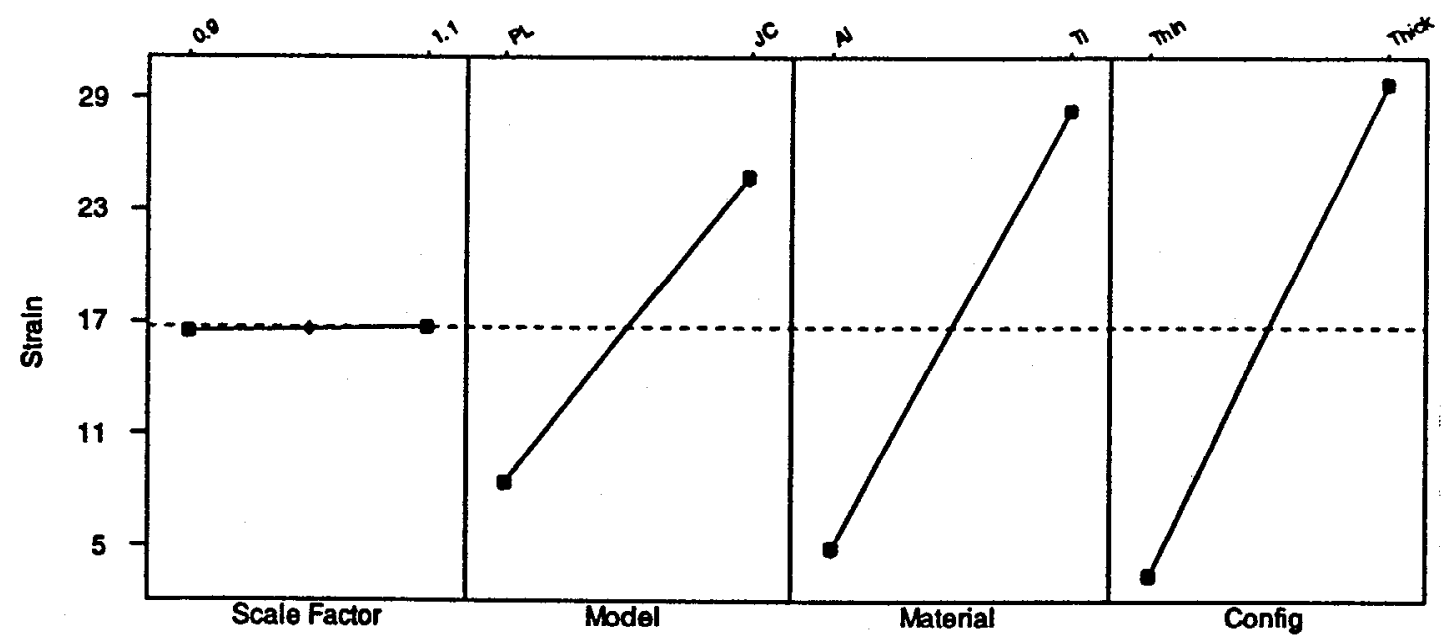

- Centerpoint

Interaction Plot (data means) for Strain

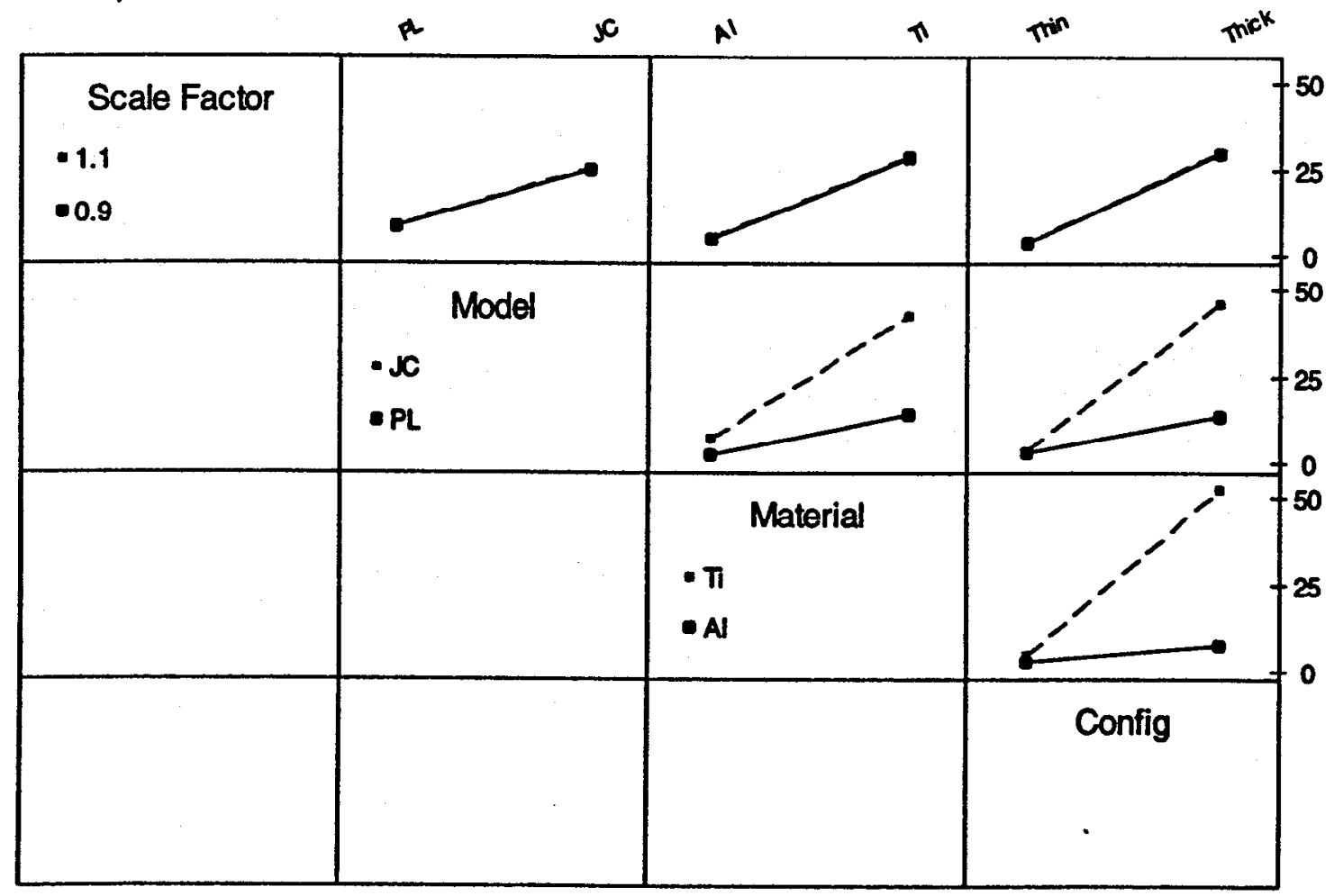


MINITAB 12 SESSION OUTPUT: DOE ANALYSIS FOR "DISPLACEMENT"

\section{Fractional Factorial Fit}

\begin{tabular}{|c|c|c|c|c|c|}
\hline $\begin{array}{l}\text { Term } \\
\text { Constant }\end{array}$ & Effect & $\begin{array}{r}\text { Coef } \\
1.09054\end{array}$ & $\begin{array}{r}\text { StDev Coef } \\
0.000991\end{array}$ & $1100, \frac{T}{2}$ & $\begin{array}{rl}P \\
0 & 0.0\end{array}$ \\
\hline Scale Fa & -0.00365 & -0.00182 & 0.000991 & -1.84 & 0.108 \\
\hline Model & 0.10464 & 0.05232 & 0.000809 & 64.64 & 0.000 \\
\hline Material & 0.07437 & 0.03718 & 0.000809 & 45.94 & 0.000 \\
\hline Config & -0.03701 & -0.01850 & 0.000809 & -22.86 & 0.000 \\
\hline Scale Fa*Model & 0.00358 & 0.00179 & 0.000991 & 1.80 & 0.114 \\
\hline Scale Fa*Material & -0.00499 & -0.00250 & 0.000991 & -2.52 & 0.040 \\
\hline Scale Fa*Config & 0.00121 & 0.00061 & 0.000991 & 0.61 & 0.561 \\
\hline $\begin{array}{l}\text { Model*Material } \\
\text { Model*Config }\end{array}$ & 0.06625 & 0.03312 & 0.000809 & 40.92 & 0.000 \\
\hline Model*Config & -0.01079 & -0.00540 & 0.000809 & -6.67 & 0.000 \\
\hline Material*Config & -0.06095 & -0.03047 & 0.000809 & -37.65 & 0.000 \\
\hline $\begin{array}{l}\text { Scale Fa*Model*Material } \\
\text { Scale Fa*Model*Config }\end{array}$ & $\begin{array}{r}0.00506 \\
-0\end{array}$ & 0.00253 & 0.000991 & 2.55 & 0.038 \\
\hline $\begin{array}{l}\text { Scale Fa*Model*Config } \\
\text { Scale Fa`Material*Config }\end{array}$ & $\begin{array}{r}-0.00128 \\
0.00806\end{array}$ & -0.00064 & 0.000991 & -0.65 & 0.538 \\
\hline $\begin{array}{l}\text { Scale Fa*Material*Config } \\
\text { Model *Material*Config }\end{array}$ & $\begin{array}{r}0.00806 \\
-0.02331\end{array}$ & 0.00403 & 0.000991 & 4.06 & 0.005 \\
\hline & -0.02 & -0 . & 0.000809 & -14.40 & 0.000 \\
\hline Config & -0.00799 & -0.00399 & 0.000991 & -4.03 & 0.005 \\
\hline Ct Pt & & -0.0 & 0.001717 & -1.04 & 0.333 \\
\hline
\end{tabular}

Analysis of Variance for Disp (coded units)

$\begin{array}{lrrrrrr}\text { Source } & \text { DF } & \text { Seq SS } & \text { Adj SS } & \text { Adj MS } & \text { F } & \text { P } \\ \text { Main Effects } & 4 & 0.107155 & 0.107155 & 0.0267887 & 2 E+03 & 0.000 \\ \text { 2-Way Interactions } & 6 & 0.049475 & 0.049475 & 0.0082458 & 524.46 & 0.000 \\ \text { 3-Way Interactions } & 4 & 0.003629 & 0.003629 & 0.0009072 & 57.70 & 0.000 \\ \text { 4-Way Interactions } & 1 & 0.000255 & 0.000255 & 0.0002551 & 16.22 & 0.005 \\ \text { Curvature } & 1 & 0.000017 & 0.000017 & 0.0000170 & 1.08 & 0.333 \\ \text { Residual Error } & 7 & 0.000110 & 0.000110 & 0.0000157 & & \\ \text { Total } & 23 & 0.160641 & & & & \end{array}$

Unusual Observations for Disp

$\begin{array}{rrrrrr}\text { Obs } & \text { Disp } & \text { Fit } & \text { StDev Fit } & \text { Residual } & \text { St Resid } \\ 13 & 1.01373 & 1.00973 & 0.00366 & 0.00400 & 2.64 \mathrm{R} \\ 14 & 1.01499 & 1.01098 & 0.00366 & 0.00400 & 2.64 \mathrm{R} \\ 23 & 1.00056 & 1.00857 & 0.00256 & -0.00801 & -2.64 \mathrm{R}\end{array}$

$R$ denotes an observation with a large standardized residual Estimated Coefficients for Disp using data in uncoded units

Term

Constant

Scale $\mathrm{Fa}$

Model

Material

Config

Scale Fa*Model

Scale Fa*Material

Scale Fa*Config

Model *Material

Model *Config

Material *Config

Scale Fa*Model Material

Scale Fa*Model*Config
Coef
1.10878
$-0.01824$
0.03444
0.06215
$-0.02456$
0.01788
$-0.02497$
0.00605
0.00780
0.00101
$-0.07076$
0.02532
$-0.00641$ 
Scale Fa*Material ${ }^{\star}$ Config Model *Material *Config Scale Fa*Model *Material * Config Ct Pt

0.04028

0.02827

$-0.03993$

$-0.00178$

Alias Structure

I

Scale

Model

Material

Config

Scale* Model

Scale*Material

Scale ${ }^{\star}$ Config

Model *Material

Model *Config

Material*Config

Scale*Model *Material

Scale*Model *Config

Scale*Material *Config

Model *Material *Config

Scale Model *Material *Config

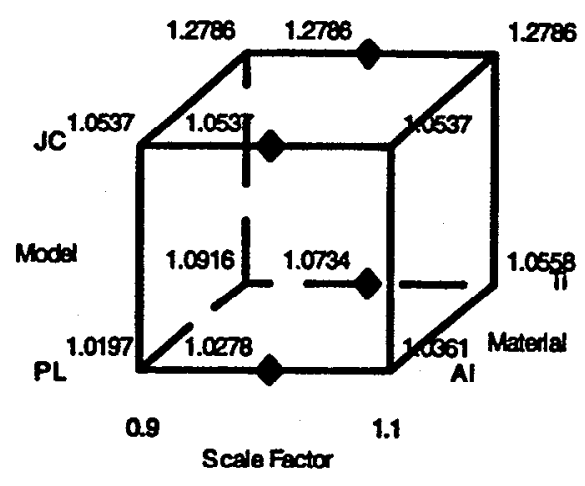

Thin

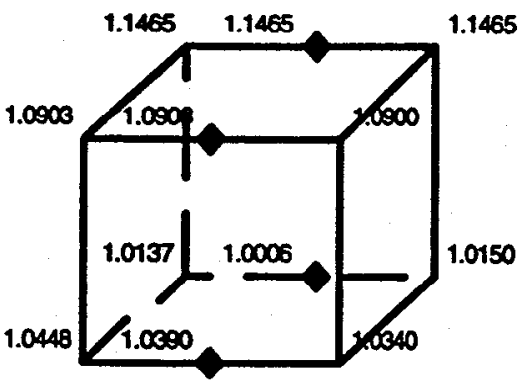

Contg Thick 


\section{Pareto Chart of the Standardized Effects}

(response is Disp, Apha $=.10$ )

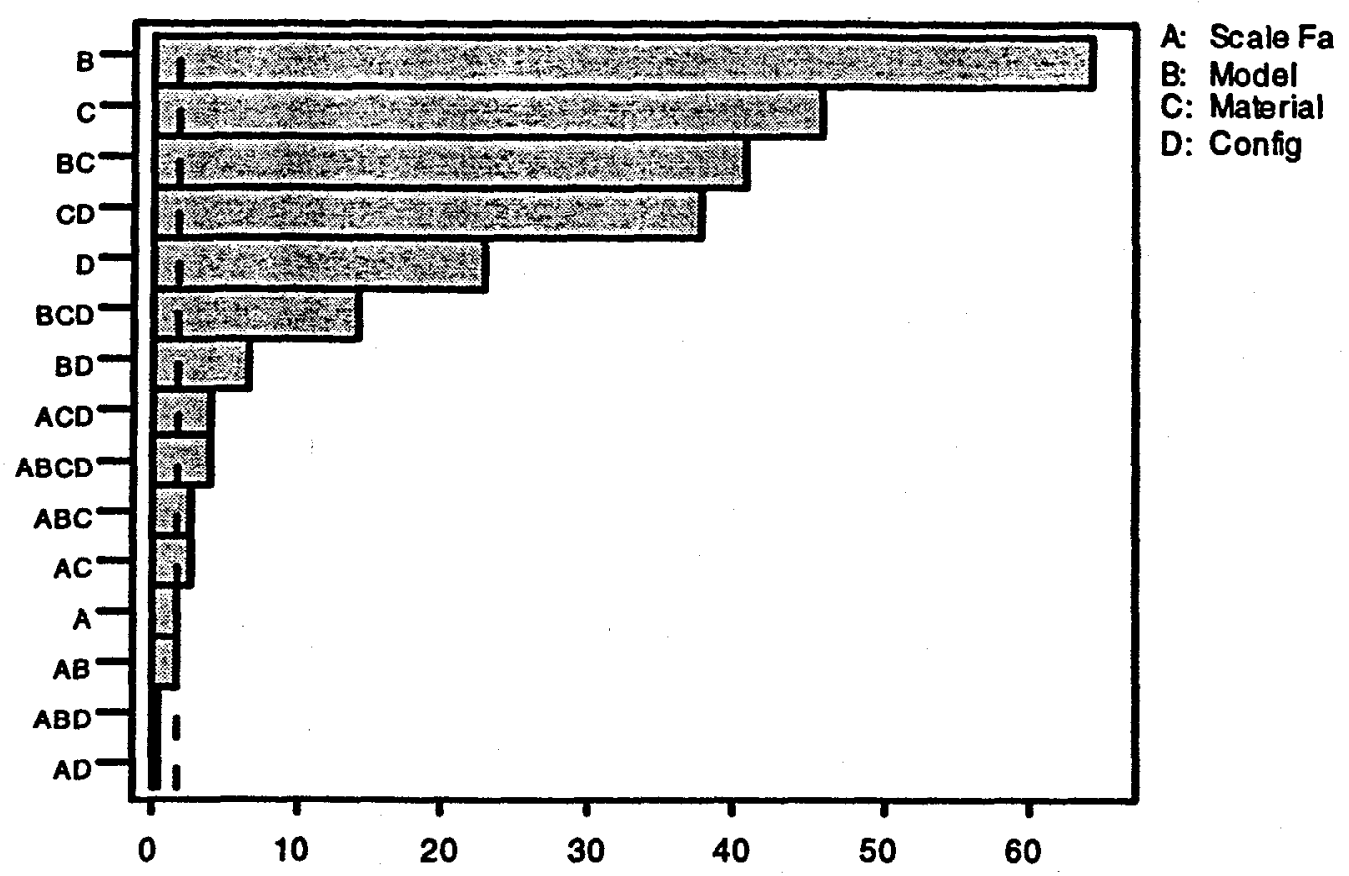

Normal Probability Plot of the Standardized Effects

(response is Disp, Alpha = .10)

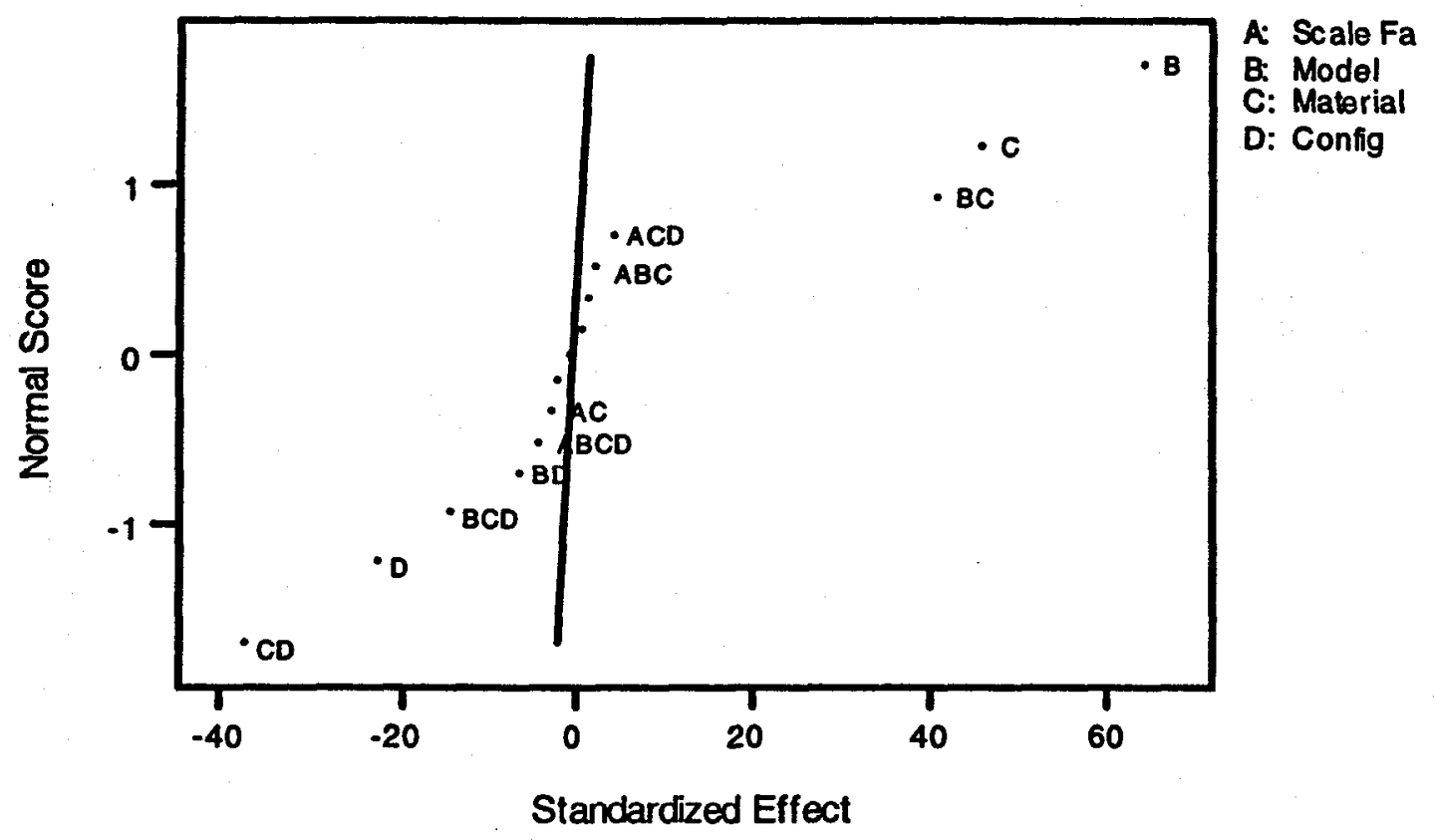



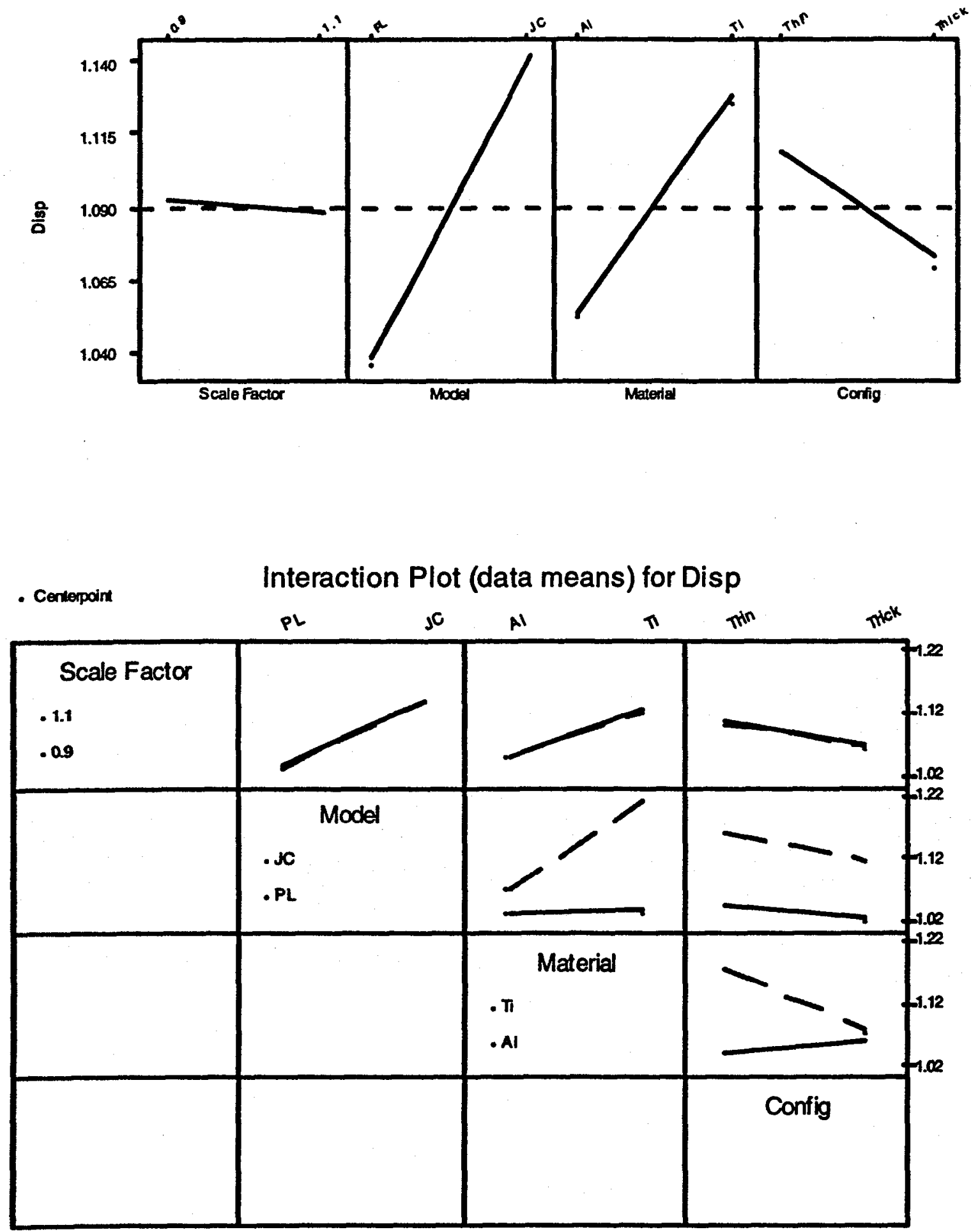